\title{
Groundwater-surface water interactions in the Jock River watershed, Ottawa, Ontario
}

\author{
By \\ Cassandra Michel \\ A thesis submitted to the Faculty of Graduate and Postdoctoral Affairs in partial \\ fulfillment of the requirements for the degree of \\ Master of Science \\ in \\ Geography \\ Carleton University \\ Ottawa, Ontario \\ (C) 2017 \\ Cassandra Michel
}




\begin{abstract}
Groundwater and surface water interactions in the Jock River watershed, Ottawa, Ontario were investigated during the 2015 growing season using end-member mixing analysis (EMMA). The Jock River sample sites were integrated into a spatially distributed single linear mixing model. Spatial and temporal variations amongst the dominant sources of baseflow were observed in the Jock River watershed. Baseflow generation across the Jock River watershed showed a dynamic relationship between the sources contributing to baseflow and antecedent moisture conditions. The wetland endmember was the dominant source of baseflow in the upper watershed and showed little temporal variation in end-member contributions throughout the growing season. Strong linear correlations $\left(\mathrm{R}^{2} 0.75-0.87\right)$ between the average proportion of the wetland endmember and natural features (forest, wetland and organic deposits) were observed. Results highlight the importance of different landscape components contributing to baseflow across the watershed, specifically the importance of wetlands at mitigating high and low flow conditions.
\end{abstract}




\section{ACKNOWLEDGMENTS}

I would like to extend my deepest gratitude to my supervisor Dr. Murray C. Richardson and my sponsor for this project Claire Milloy, without their belief, guidance and support this project would never have happened. I am sincerely grateful for the financial, academic and emotional support they have provided me with over the past 3 years.

I would also like to thank the Rideau Valley Conservation Authority (RVCA) and the Natural Sciences and Engineering Research Council of Canada (NSERC) for funding this research, providing me with the resources and support necessary to complete this project. I would like to thank the RVCA aquatics and GIS staff who helped collect hundreds of samples and provided me with high quality GIS datasets. I would also like to thank the RVCA for providing me with the best field assistant; Marisa Ramey's constant determination and positive attitude pushed me to keep going, and provided me with tonnes of laughs on extremely long field days.

This project involved a lot of field work and lab work, all of which would not have been possible without the help of my friends, family and volunteers who came out one day and sampled a stream, snowshoed a ditch and filtered some water. I am sincerely grateful to all of you. Thank you for listening to me talk about my thesis constantly, even when you didn't understand what I was saying.

I would like to dedicate this thesis to two amazing women, without whom this would have never been possible. To my grandmothers, Maureen Michel and Elizabeth McChesney, you showed me what it meant to be kind, wise and strong and always believed in me. I miss you, love you and thank you for everything you taught me. 


\section{TABLE OF CONTENTS}

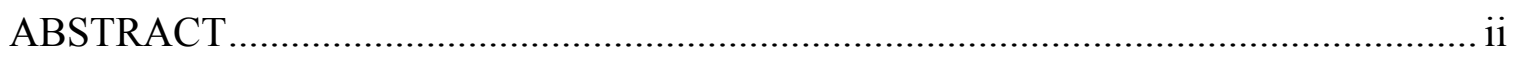

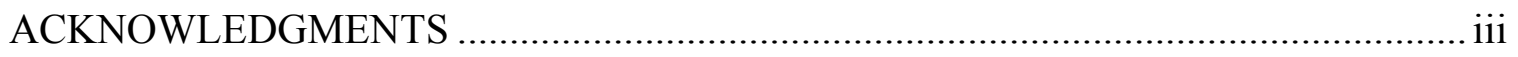

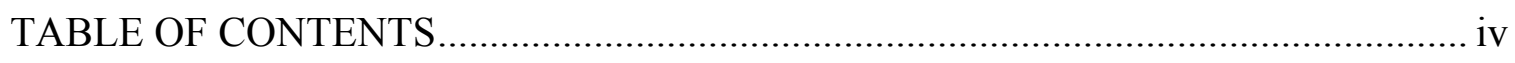

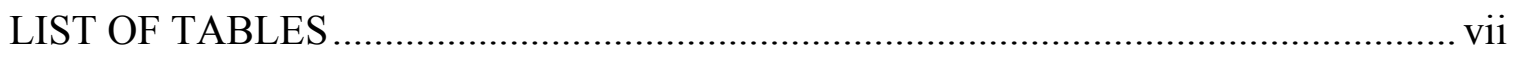

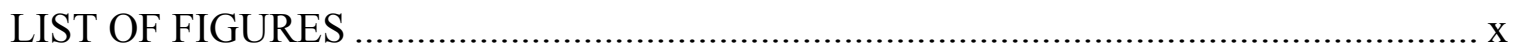

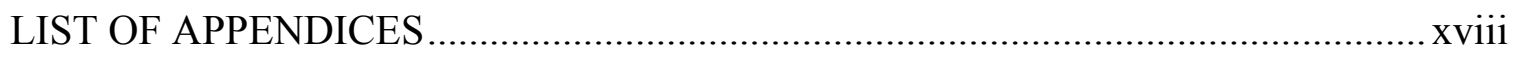

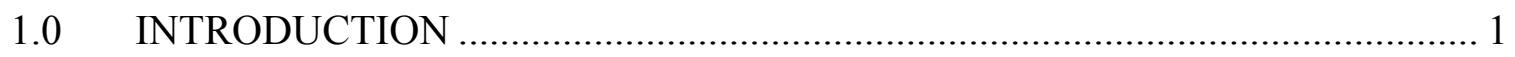

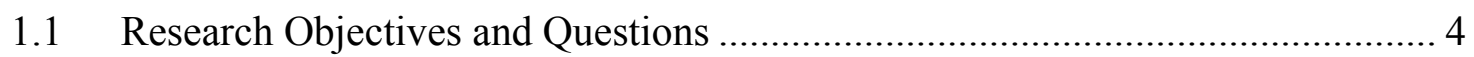

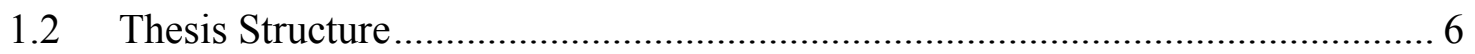

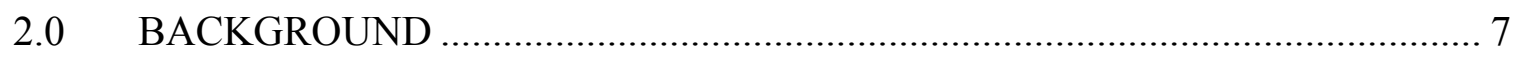

2.1 Groundwater Flow Systems and Surface Water Interactions............................ 7

2.1.1 Groundwater Flow Systems ................................................................... 7

2.1.2 Groundwater and Surface Water Interactions ............................................ 11

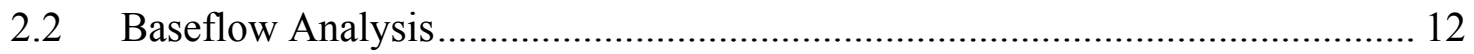

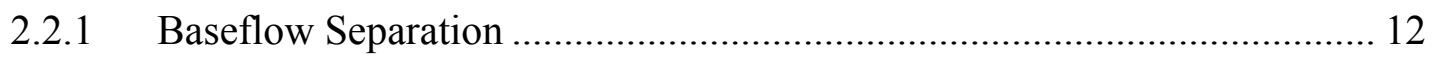

2.2.2 Baseflow Analysis and Groundwater Flow Systems ................................. 13

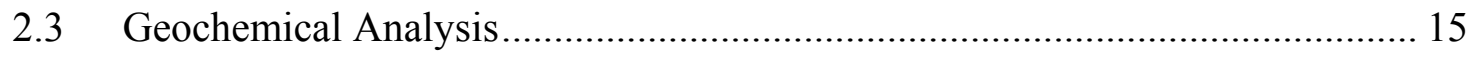

2.3.1 Three Component Mixing Model ........................................................... 15

2.3.2 Tracer and Component Uncertainty ...................................................... 15

2.3.3 End-member Mixing Analysis (EMMA) Mathematical Definition ............ 16

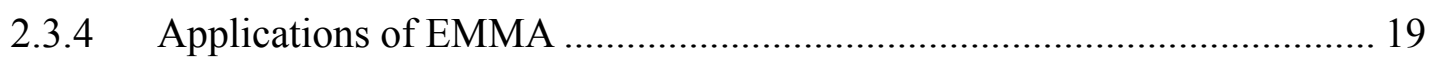

2.3.5 Determining the Number of End-members in EMMA ……….................... 20

2.3.6 Projecting Sites into a Reference Mixing Space.......................................... 24

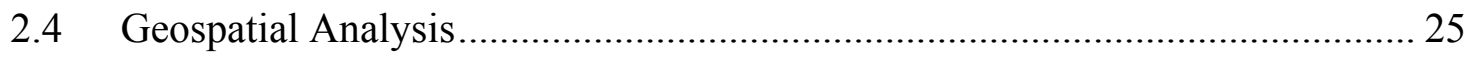

2.4.1 Watershed Characteristics and Tracer Studies.......................................... 25

2.4.2 Modelling Groundwater Fluxes Based on Watershed Characteristics ....... 26

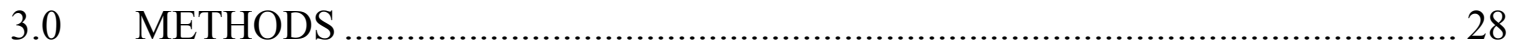

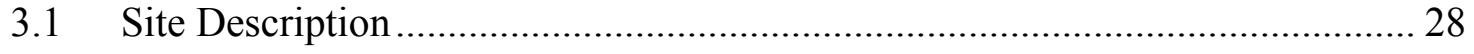

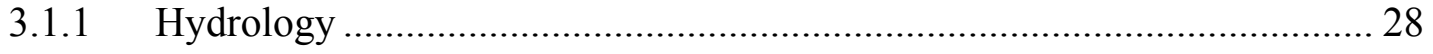

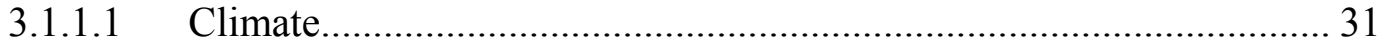

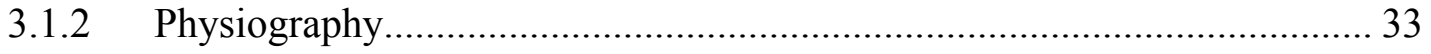

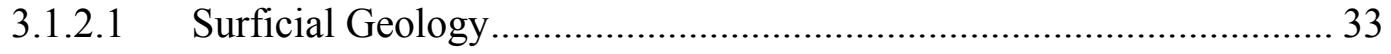

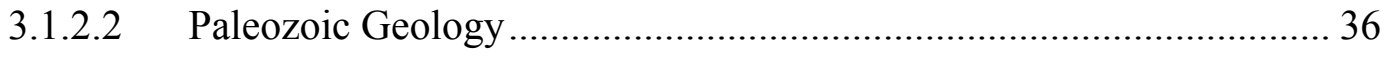




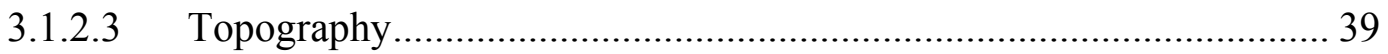

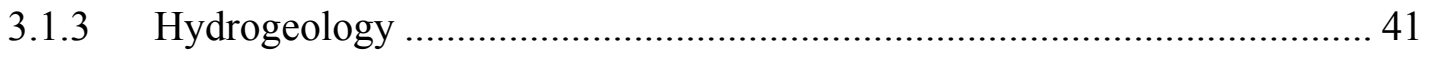

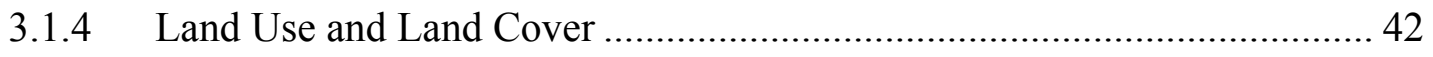

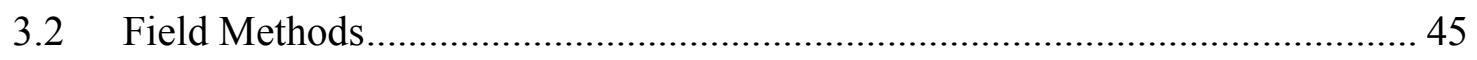

3.2.1 Precipitation Sample Collection …………………................................ 45

3.2.2 Surface Water Sample Collection.............................................................. 46

3.2.3 Groundwater Sample Collection........................................................... 50

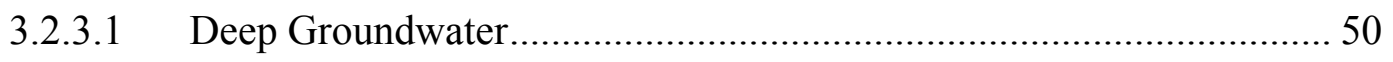

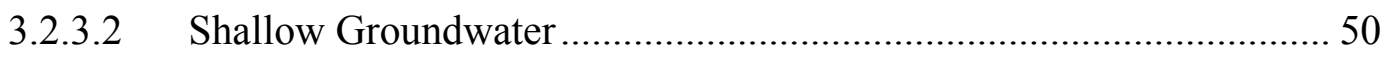

3.2.4 Hydrometric Measurements.................................................................. 52

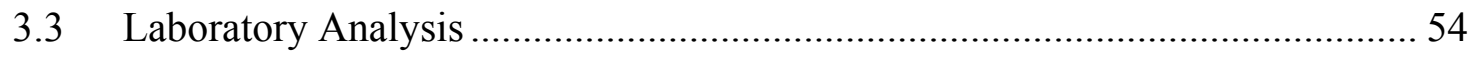

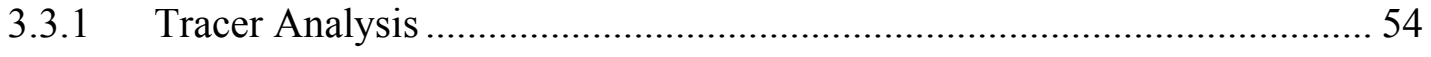

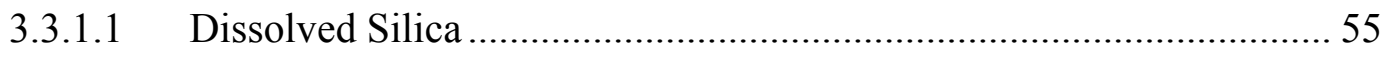

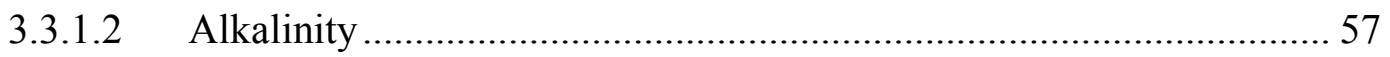

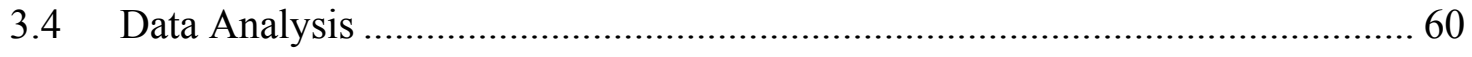

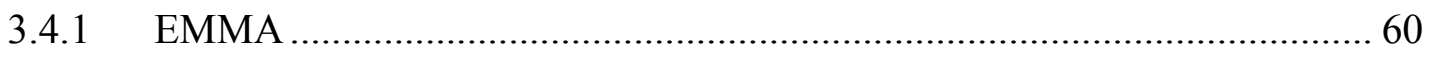

3.4.1.1 Assessment of Stream Water Variation and End-member Viability ... 63

3.4.1.2 Determining the Number of End-members ......................................... 63

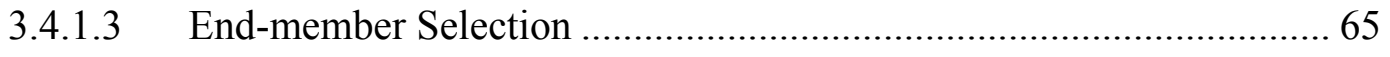

3.4.1.4 Calculation of End-member Proportions ............................................. 66

3.4.1.5 Projection of Tributaries and Headwaters into the Jock River Mixing Space 67

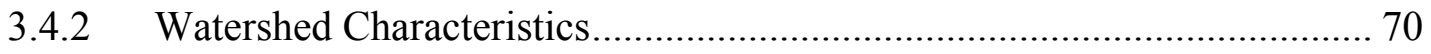
3.4.2.1 Watershed Delineations and Proportions of Watershed Characteristics 70

3.4.2.2 Recursive Partitioning and Regression Analysis................................. 71

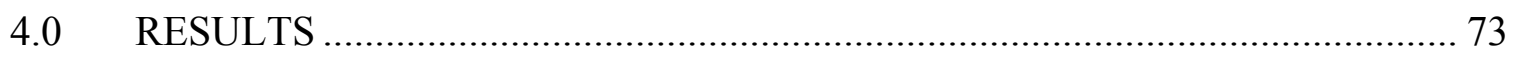

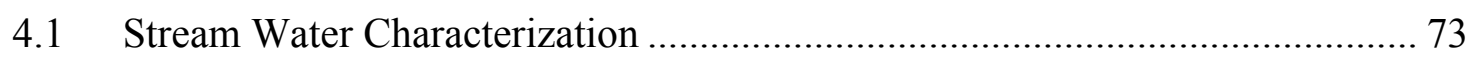

4.1.1 Hydrologic Conditions During Sample Collection...................................... 73

4.1.2 Stream Water Chemistry Variability ......................................................... 76

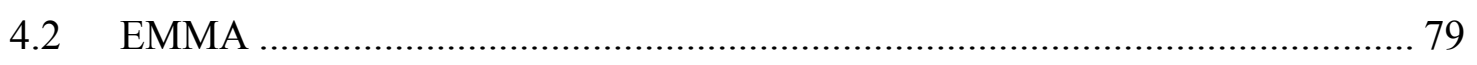

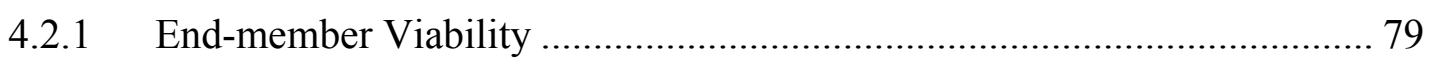

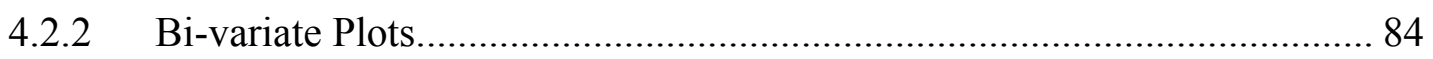

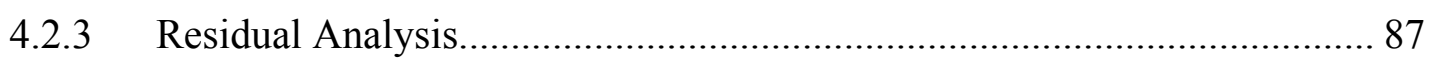

4.2.4 End-member Selection for the Jock River ................................................. 91 
4.2.5 Model Accuracy Evaluation for the Jock River....................................... 95

4.2.6 End-member Proportions for the Jock River ........................................... 98

4.2.7 Projecting Main Tributaries into the Jock River Mixing Space ............... 100

4.2.8 Projecting Headwaters into the Jock River Mixing Space........................ 111

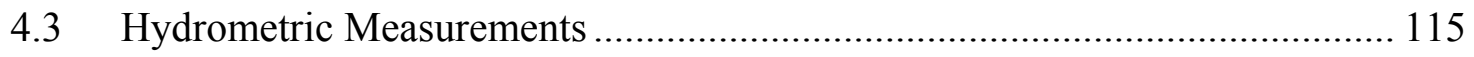

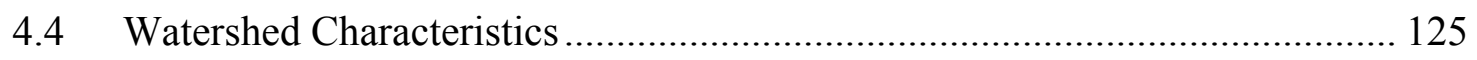

4.4.1 Recursive Partitioning (CART) ....................................................... 125

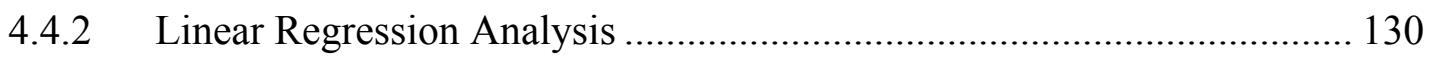

4.4.2.1 Simple Linear Regression Analysis.............................................. 130

4.4.2.2 Multiple Linear Regression (MLR)............................................. 133

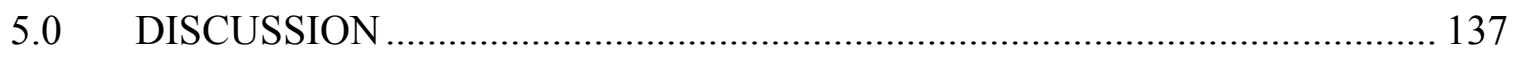

5.1 Conceptual Model of Baseflow Generation in the Jock River watershed........ 138

5.2 What do the End-Members Represent?.................................................... 142

5.2.1 GW_DW_1: Deep Groundwater from the Regional Limestone Aquifer. 143

5.2.2 W156-2: Basal Gravel or Esker? ............................................................ 144

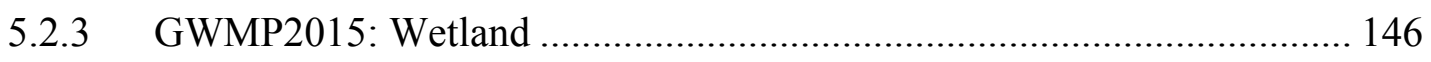

5.3 Methodological Outcomes: Applying EMMA with Limited Resources ......... 147

5.3.1 Integration of Spatial Variation into the Jock River Mixing Model ......... 149

5.3.2 The Influence of Spatial and Temporal Heterogeneity in End-members . 150

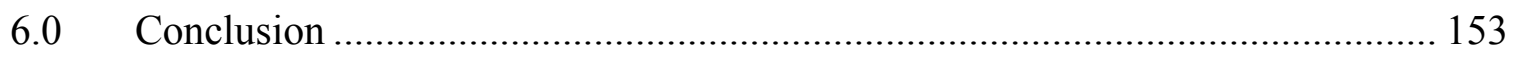

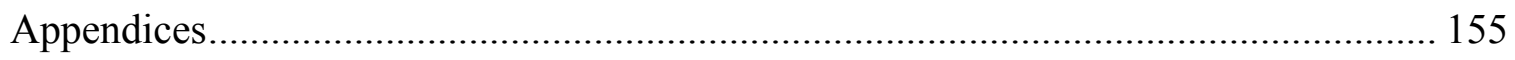

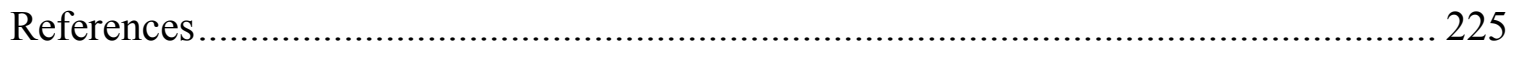




\section{LIST OF TABLES}

Table 4-1. Main tributary chemistry descriptive statistics: mean $(x)$, interquartile range (IQR) $\left(3^{\text {rd }}-1^{\text {st }}\right)$ and coefficient of variation $(\mathrm{CV})$.

Table 4-2. End-Member codes, long names and descriptions. 80

Table 4-3. End-member chemistry descriptive statistics: sample number (n) mean $(x)$, interquartile range (IQR) $\left(3^{\text {rd }}-1^{\text {st }}\right)$ and coefficient of variation $(\mathrm{CV}) .^{*}$ indicates that values, are not the median value but the value from a single sample in 2015, which was used as the end-member in subsequent EMMA.

Table 4-4. PGMN groundwater geochemistry descriptive statistics: sample number (n), mean $(x)$, interquartile range $(\mathrm{IQR})\left(3^{\text {rd }}-1^{\text {st }}\right)$ and coefficient of variation $(\mathrm{CV})$ from 20022015 PGMN groundwater geochemistry from 2015 sampling is provided below interannual descriptive statistics for each well.

Table 4-5. The number of end-members retained at each site using three criteria: (1) The number of end-members retained using the rule of one;(2) The number of end-members retained based on $\mathrm{PC}>15 \%$; and (3) The number of eigenvectors retained based on residual analysis (\# of end-members $=$ one $+\#$ of dimensions).

Table 4-6. Percent differences between the original median or 2015 value and its orthogonal projection into the Jock River sites 2 and 3 end-member mixing space for each end-member.

Table 4-7. Model quality parameters coefficient of determination $\left(\mathrm{R}^{2}\right)$ and relative root mean square error (RRMSE) for EMMA results of Jock River sites using 2 end-members and 3 end-members. 96

Table 4-8. Model quality parameters. Coefficient of determination $\left(\mathrm{R}^{2}\right)$, RRMSE and relative bias for main tributary sites projected into the Jock River (JR) mixing space and projected into their own two end-member ( $2 \mathrm{EM}$ ) and three end-member (3 EM) mixing spaces. Colour coded red to show increases, blue to show decreases and green to indicate no change relative to the JR. '-' indicates no suitable end-members could be identified. The columns PC1 and PC2 indicate if the PC's are representing all of the tracers or a subset of the tracers, tracers which load highest are in brackets. 
Table 4-9. Model quality parameters. Coefficient of determination $\left(\mathrm{R}^{2}\right)$, RRMSE and relative bias for headwater sites projected into the Jock River (JR) mixing space. Sites have been grouped based on the main tributary contributing areas in which they are located.

Table 4-10. Average proportions of end-members contributing to flow for each sample site/sub-catchment.

Table 4-11. Land use, land cover, surficial and Paleozoic geology proportions in each contributing area for the sample sites.

Table 4-12. Statistically significant watershed characteristics as determined through simple linear regression. Coefficient of determination $\left(\mathrm{R}^{2}\right)$ greater than 0.40 are included along with the $\mathrm{p}$-value and the direction of the trend.

Table 4-13. Selection of MLR model results for the prediction of the Wetland (GWMP2015) end-member. The (+) symbol indicates that multiple variables are combined and $(*)$ indicates the model is investigating the combination and interactions between multiple variables. 135

Table B-0-1.Geochemical/ isotopic sample collection days. 188

Table B-0-2. Results of multiple linear regression (MLR) models assessing the relationships between average end-member proportions and land use/cover proportions.

Table B-0-3. Hydrometric measurements collected during baseflow synoptic surveys and the calculated proportions, sites were normalized based on area, equations provided below.

Table B-0-4. Proportions of end-members on sample days and the conversion of those proportions of streamflow to $\mathrm{m}^{3} / \mathrm{s}$..

Table D-0-1. Stage and discharge measurements for the Jock River at Prince of Wales Road.

Table D-0-2. Stage and discharge measurements for the Jock River at Eagleson Road. 215 
Table D-0-3. Stage and discharge measurements for the Jock River at Franktown Road 216

Table D-0-4. Stage and discharge measurements for Flowing Creek. 217

Table D-0-5. Stage and discharge measurements for Hobbs Drain. 218

Table D-0-6. Stage and discharge measurements for Nichols Creek 219

Table D-0-7. Statistics for 2015 stream water geochemistry. 220

Table D-0-8. Statistics for 2015-2016 end-member geochemistry. 221

Table D-0-9. Percent Differences Between Observed and Predicted Solute Concentrations from EMMA for the Jock River Mixing Sites. 


\section{LIST OF FIGURES}

Figure 2-1. Local, intermediate, and regional groundwater flow systems (Tóth, 1963)... 8

Figure 2-2. Hydrologic sections showing groundwater flow in hypothetical settings: (a) groundwater flow from water table highs beneath uplands to hydrologic sinks in the lowlands (modified from Hubbert 1940); (b) local flow system in which the water table is recharged at topographic highs and discharged at topographic lows, overlying a regional flow system (modified from Winter 1976); (c) groundwater flow system in which the water table highs are not underneath topographic highs. Figure and description taken from Winter et al., (2003).

Figure 2-3. Numerical simulation of steady-state two-dimensional groundwater flow in a vertical cross section for two hypothetical settings. A) A continuous local flow-system boundary, as indicated by the stagnation point, preventing seepage from the lake. B) A discontinuous local flow-system boundary allows seepage from the lake (Taken directly from Winter, 1999).

Figure 3-1. The Jock River watershed and its main tributary subwatersheds. Watersheds were delineated using a Digital Elevation Model (DEM) produced from LiDAR and Drape imagery with a $2 \mathrm{~m}$ resolution. Streams which had been re-digitized and verified by Rideau Valley Conservation staff were used to burn streams into DEM for enhanced characterization of flow direction and contributing area. Main tributary sample sites were used as pour points to delineated main tributary subwatersheds. Waterbodies and wetlands of the surrounding Rideau Valley watershed are also shown here.

Figure 3-2. Hyeto-hydrograph for discharge $(\mathrm{m} 3 / \mathrm{s})$ at the Jock WSC gauge located at Moodie Road and precipitation $(\mathrm{mm})$ collected at the Ottawa International Airport (Ottawa INTL A) from 2012 to 2015.

Figure 3-3. Flow duration curve calculated based on discharge $\left(\mathrm{m}^{3} / \mathrm{s}\right)$ from the Jock WSC gauge located at Moodie Road. The inset is the long term (1969-2015) hydrograph at the site. The flow duration high flow threshold (Qhigh thr) is set to 5\% flow exceedance and equals $28.1 \mathrm{~m}^{3} / \mathrm{s}$. The low flow threshold (Qlow thr) is set to $95 \%$ flow exceedance and equals $0.08 \mathrm{~m}^{3} / \mathrm{s}$.

Figure 3-4. Graph illustrating the average monthly temperature in the Ottawa region from Climate Normal data (1981-2010) and 2015 climate data from the Ottawa Macdonald-

Cartier International airport. 32 
Figure 3-5. Graph illustrating the monthly precipitation $(\mathrm{mm})$ in the Ottawa region from Climate Normal data (1981-2010) and 2015 climate data from the Ottawa MacdonaldCartier International Airport.

Figure 3-6. Surficial geology and resource extraction in the Jock River watershed. 35

Figure 3-7. Paleozoic Geology of the Jock River subwatershed with inset showing the stratigraphy of Paleozoic rocks of Eastern Ontario (Derry et al., 1989) 38

Figure 3-8. Topography of the Jock watershed with inset map illustrating drift thickness.

Figure 3-9. Land use and land cover classification from 2010 for the Jock watershed. Land use land cover data source: Government of Canada; Agriculture and Agri-Food Canada. (2015). Land Use 1990, 2000 \& 2010 [GIS data set]. Retrieved from http://www.agr.gc.ca

Figure 3-10. Snow melt lysimeter installation at Heart's Desire March 12, 2015. Three halved PVC pipes are inserted at the base of the snow pack. Vinyl tubes drain snow meltwater into one collection jug downslope. Dug out sections were back filled after installation. Water samples were collected from the jug after/during potential melt days in April.

Figure 3-11. Field Sites in the Jock River watershed. Locations provided: end-members (groundwater, piezometer, precipitation and snowmelt); main tributary sample sites; headwater sites (sampled by RVCA aquatics staff in the spring and summer of 2015). Wetlands where a piezometer was installed have been colour coded light pink to illustrate the potential contributing area of the end-member.

Figure 3-12. Field sites in the Jock River watershed, locations of the main tributaries and sites along the Jock River where hydrometric and geochemical sampling occurred are indicated in teal, site code names are also provided. Piezometer, deep groundwater wells and snow melt collection sites and code names are also provided. Inset maps illustrate areas with multiple sample sites in greater detail

Figure 3-13. Shallow groundwater piezometers installed at Goodwood Marsh on July 17, 2015. Piezometer depth: $1.3 \mathrm{~m}$, protruding: $0.3 \mathrm{~m}$, this is the only piezometer that was not moved after initial installation. 
Figure 3-14. Example of temporary cross section installations using rebar at four sites in the Jock watershed: a) Hobbs Drain, b) Flowing Creek, c) Jock River at Prince of Wales Road (Jock Outlet) and d) Nichols Creek.

Figure 3-15. Stoichiometry of the hydrolysis of silicate minerals (albite and anorthite) to form kaolinite (Clarke, 2015).

Figure 3-16. Stoichiometry of the dissociation of carbonate species limestone $\left(\mathrm{CaCO}_{3}\right)$ and dolostone $\left(\mathrm{CaMg}\left(\mathrm{CO}_{3}\right)_{2}\right)$ by the weathering by carbonic acid $\left(\mathrm{H}_{2} \mathrm{CO}_{3}\right)$.

Figure 3-17. Three spatial resolutions of sites in the Jock River watershed. A) the Jock River sample sites at Prince of Wales (outlet), Eagleson Rd (middle) and Franktown Rd (headwaters), represents a coarse spatial and moderate temporal resolution. B) the main tributary sample sites and their catchments, represents a moderate spatial and temporal resolution. C) the summer headwater (HWDF) sites and their contributing areas, represents a fine spatial resolution and coarse temporal resolution.

Figure 4-1. Hyeto-hydrograph showing total daily precipitation $(\mathrm{mm})$ and average daily discharge $\left(\mathrm{m}^{3} / \mathrm{s}\right)$ along the Jock River (JKPW [outlet], JKER [middle], JKFT [headwaters]), Flowing Creek (FCGR), Hobbs Drain (HBFT) and Nichols Creek (NIKS) during the growing season of 2015. Sample days have been placed along the JKPW hydrograph to illustrate hydrologic conditions during sample collection. Not all sites were sampled on sample days, see table B-0-1 in Appendix B for sites collected on sample days. Precipitation data source: Government of Canada. (2017). eng-daily-0101201512312015 [Data file]. Retrieved from http://climate.weather.gc.ca

Figure 4-2. Box-whisker plots of stream chemistry and isotopic variability at main tributary sites throughout the 2015 growing season.

Figure 4-3. Box-whisker plots of end-member geochemistry and isotopic variability.... 81

Figure 4-4. Box-whisker plots of PGMN groundwater wells geochemical variability from 2002-2015, most samples were acquired in the autumn. 82

Figure 4-5. Bi-variate plots for each combination of solute pairs demonstrating the geochemical composition of Jock River sites (JKPW, JKER and JKFT) and its main tributaries (LMBR, MDOR, FCGR, HBFT, KC, NIKS) and end-members. Error bars indicate the standard error based on 2015 data and PGMN 2002-2015 data. The hatched circle/oval illustrates the spread of Jock River samples. 
Figure 4-6. Residual vs. fitted plots for 1, 2-dimensional mixing space for variables specific conductivity $(\mathrm{SpC}, \mu \mathrm{S} / \mathrm{cm})$, alkalinity $\left(\mathrm{mg} / 1\right.$ as $\left.\mathrm{CaCO}_{3}\right)$ and dissolved silica $\left(\mathrm{SiO}_{2}, \mathrm{mg} / \mathrm{l}\right)$ for the compiled Jock River sites.

Figure 4-7. Jock River sites projected in U-space for a two end-member mixing space (top) and a three end-member mixing space (bottom). Potential end-members are identified by both their ID's and the geologic/land cover type. The end-member mixing space is identified by the hatched lines.

Figure 4-8. Residuals vs. fitted concentrations $\mathrm{SpC}(\mu \mathrm{S} / \mathrm{cm}), \mathrm{SiO}_{2}(\mathrm{mg} / \mathrm{l})$ and Alkalinity (as $\mathrm{mg} / \mathrm{l} \mathrm{CaCO}_{3}$ ) for the Jock River sites in a 2 and 3 end-member mixing model.

Figure 4-9. End-member proportions for the Jock River sites; (a) Jock at Franktown Rd (JKFT)[headwaters]; (b) Jock at Eagleson Rd (JKER)[mid-point] and; (c) Jock at Prince of Wales (JKPW)[outlet]. End-members: GW_DW_1 [groundwater from deep limestone aquifer- regional groundwater], W156-2 [groundwater from basal gravel/esker aquifer], GWMP [groundwater from forested wetland- shallow groundwater flow system]. Colours were darkened to demonstrate the shift from upstream sites to downstream sites.

Figure 4-10. Main tributary sites: Leamy Creek (LMBR), Monahan Drain (MDOR), Flowing Creek (FCGR), Hobbs Drain (HBFT), Kings Creek (KC) and Nichols Creek (NIKS) projected into the Jock River 3 end-member U-space. End-members: GW_DW_1 [groundwater from deep limestone aquifer- regional groundwater ], W156-2 [groundwater from basal gravel/esker aquifer], GWMP [groundwater from forested wetland- shallow groundwater flow system]..... 101

Figure 4-11. End-member proportions for main tributary sites (MTS) from surface water values projected in the Jock River three end-member (JR 3 EM) mixing space and projected into their own two end-member mixing space (MTS 2 EM). 110

Figure 4-12. End-member proportions for Kings Creek and Nichols Creek projected into the Jock River two-dimensional mixing space and its own two-dimensional mixing space.

Figure 4-13. Headwater drainage features (HWDF) projected into the Jock River three end-member U-space. HWDF have been colour coded based on the main tributary contributing areas in which they are located..... 113

Figure 4-14. End-member proportions of headwater features, based on projection into the Jock River mixing space. 115 
Figure 4-15. Relative proportion of normalized net catchment discharge during the July $6^{\text {th }}, 2015$ baseflow synoptic survey. Moodie WSC gauge has been coloured yellow, to distinguish it from other Jock River hydrometric sites.

Figure 4-16. Relative proportion of normalized net catchment discharge during the August $8^{\text {th }}, 2015$ baseflow synoptic survey. Moodie WSC gauge has been coloured yellow, to distinguish it from other Jock River hydrometric sites.

Figure 4-17. Map illustrating the location of well W156-2/3 in relation to the WSC gauge at Moodie Drive. Surficial geology highlights the presence of the esker in relation to both sites. 121

Figure 4-18. Groundwater elevation at W156-2 and W156-3 and surface water level at upstream Water Survey of Canada (WSC) Moodie Drive gauge. Elevation of ground at well 92.88 masl and top of casing elevation 93.77 masl. Groundwater elevation data source: RVCA. (2017). W156-2_TwinElm2_Compiled_WL_2013-2016 [Data file]. Retrieved from RVCA staff. Water level data source: Government of Canada. (2017). Daily_Apr-5-2017_11_21_17PM [Data file]. Retrieved from https://wateroffice.ec.gc.ca/download/index_e.html?results_type=historical

Figure 4-19. Cross correlation functions performed between groundwater elevations for wells W156-2 and W156-3 at a daily time-step with upstream WSC Moodie Gauge surface water level and at an hourly time-step with downstream Jock River at Eagleson road surface water level.

Figure 4-20. Relative proportion of normalized net catchment discharge during the September $24^{\text {th }}, 2015$ baseflow synoptic survey. Moodie WSC gauge has been coloured yellow, to distinguish it from other Jock River hydrometric sites.

Figure 4-21. CART tree models identifying potential explanatory watershed characteristics for average end-member proportions a) wetland end-member (GWMP2015) b) basal gravel/esker end-member (W156-2) and c) bedrock end-member (GW_DW_1)

Figure 4-22. MLR diagnostic plots for the model Paleozoic Bedrock and Organic Deposits for the wetland (GWMP2015) end-member.

Figure 4-23. MLR diagnostic plots for the model March Formation and Forest for the wetland (GWMP2015) end-member 136 
Figure A-0-1. Local meteoric water lines (LMWLs) for the Ottawa area. Multiple lines have been plotted to show changes in the slopes and intercepts calculated from the long term (1972-2012) GNIP data for Ottawa, subsets of the Ottawa GNIP data from recent years (2000-2012 \& 2006-2012) and data collected from the Jock in 2015.

Figure A-0-2. LMWL' s plotted with a limited range for $\delta^{2} \mathrm{H}$ and $\delta^{18} \mathrm{O}$ to illustrate differences between LMWL's.

Figure A-0-3. Isotopic variation of end-member's: groundwater (GWMP2015, GWMP2016), and wetlands (HBP_2016 and HWY15P2_2016) along the LMWL. The mean isotopic ratios have been plotted for GW_DW_1 and GW_DW_2; the remaining PGMN wells are all single measuring points. All measuring points have been plotted for wetland sites to demonstrate their temporal variations, which were higher than observed variations groundwater isotopic ratios. Weighted mean annual precipitation (WMAP) for 2015 has been plotted as it typically represents the isotopic signature of groundwater. 172

Figure A-0-4. Calculated water level at Hobbs Drain outlet and Jock headwater swamp along Highway 15. The water level was calibrated based on manual water level measurements at these sites and corrected HOBO logger pressure transducer data....... 175

Figure A-0-5. The isotopic ratios from headwater sites across the Jock River watershed collected in the spring (HWDF Spring) and summer (HWDF Summer) of 2015. The GNIP long term LMWL, the Jock seasonal LMWL and groundwater/wetland endmembers have been plotted to demonstrate relative positions along the LMWL's 176

Figure A-0-6. Isotopic ratios of the Jock River outlet (JKPW), mid-point (JKER) and headwaters (JKFT) and its main tributaries: Leamy Creek (LMBR), Monahan Drain (MDOR), Flowing Creek (FCGR), Hobbs Drain (HBFT), Kings Creek (KC) and Nichols Creek (NIKS) plotted along the long term and seasonal LMWL's. Weighted mean annual precipitation (WMAP), groundwater and wetland (GWMP2015 GWMP2016, HBP_2016 and HWY15P2_2016) end-members have also been plotted. ........................................ 178

Figure A-0-7. Time series of $\delta^{18} \mathrm{O} \%$ content along the Jock River and main tributary sites during the 2015 growing season. 179

Figure A-0-8. Isoscape of $\delta^{18} \mathrm{O} \%$ from spring headwater samples during 2015. Sample collection dates have been identified. 182

Figure A-0-9. These two scenes demonstrate the spring headwater isoscape which has been projected onto the $5 \mathrm{~m}$ integer DEM surface in ArcScene 10.3.1 with a vertical 
exaggeration of 50. The direction of the green arrow indicates North (y), the direction of the red arrow indicates East (x) and the blue arrow indicates the vertical direction (z). 183

Figure A-0-10. Isoscape of $\delta^{18} \mathrm{O} \%$ from summer headwater samples during 2015. Sample collection dates have been identified.

Figure A-0-11. Surface water $\delta^{18} \mathrm{O} \%$ isoscape with surficial geology overlay. 186

Figure B-0-1. Bi-variate plots indicating linear relationships between measured concentrations and predicted concentrations of the main tributary sites projected into the Jock River mixing space.

Figure B-0-2. Residuals for main tributary sites projected into the Jock River mixing space.

Figure B-0-3. Bi-variate plots indicating linear relationships between measured concentrations and predicted concentrations of the headwater sites projected into the Jock River mixing space.

Figure B-0-4. Residuals for main tributary sites projected into the Jock River mixing space.

Figure B-0-5. Bi-variate plots indicating linear relationships between the average proportion of the wetland end-member and the proportion of land use and land cover classes.

Figure B-0-6. Bi-variate plots indicating linear relationships between the average proportion of the basal gravel/esker end-member and the proportion of land use and land cover classes.

Figure B-0-7. Bi-variate plots indicating linear relationships between the average proportion of the bedrock end-member and the proportion of land use and land cover classes.

Figure C-0-1. Bedrock groundwater discharge area delineated for the Jock River watershed from Velderman (1993). 
Figure C-0-2. Bedrock groundwater recharge area delineated for the Jock River watershed from Velderman (1993).

Figure C-0-3. Water well record for neighbouring well to GW_DW_2 2......................... 207

Well Figure C-0-4. Water well record for neighbouring well to GW_DW_1............... 208

Figure C-0-5. Well log for PGMN water well W084 ................................................. 209

Figure C-0-6. Well log for PGMN water well W175-2/3 ......................................... 210

Figure C-0-7. Well log for PGMN water well W156-2/3............................................ 211

Figure C-0-8. Well log for PGMN water well W085 ............................................. 212

Figure D-0-1. Stage discharge rating curve for the Jock River at Prince of Wales Road.

Figure D-0-2. Stage discharge rating curve for the Jock River at Eagleson Road. ........ 215

Figure D-0-3. Stage discharge rating curve for the Jock River at Franktown Road....... 216

Figure D-0-4. Stage discharge rating curve for Flowing Creek.................................... 217

Figure D-0-5. Stage discharge rating curve for Hobbs Drain........................................ 218

Figure D-0-6. Stage discharge rating curve for Nichols Creek. ................................... 219 


\section{LIST OF APPENDICES}

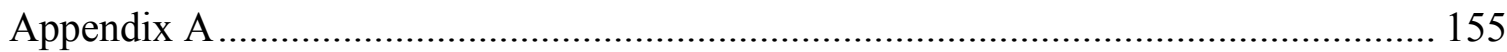

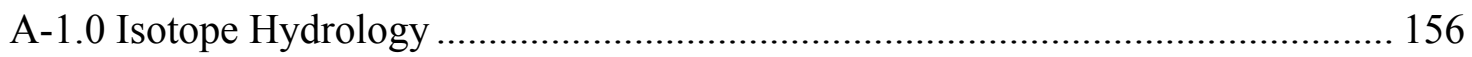

A-1.1 Stable Isotopes of Oxygen and Hydrogen .................................................. 156

A-1.2 Fractionation in the Hydrologic Cycle .................................................... 157

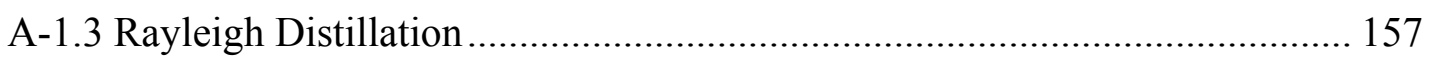

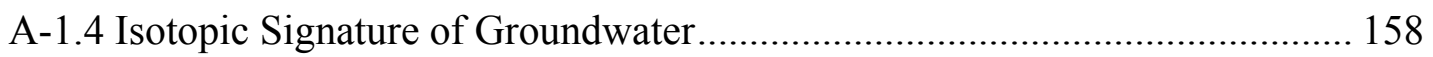

A-1.5 Isotope Hydrograph Separation ........................................................... 160

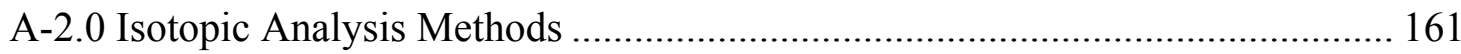

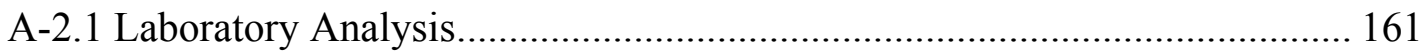

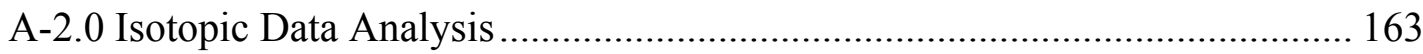

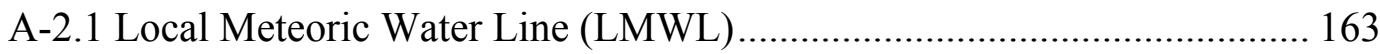

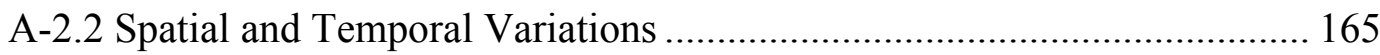

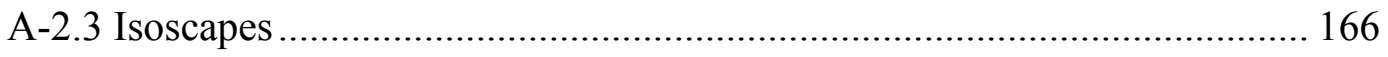

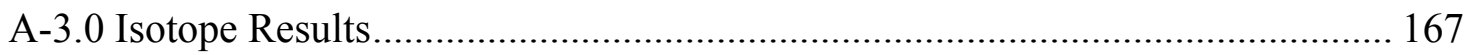

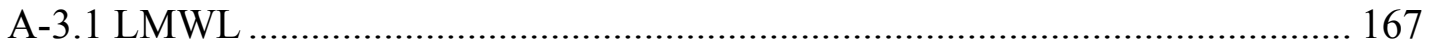

A-3.2 Spatial and Temporal Variation of Isotopic Ratios ...................................... 170

A-3.2.1 End-members: Groundwater and Wetlands........................................ 170

A-3.2.2 Stream Water: Headwaters, Jock River, Main Tributaries ..................... 175

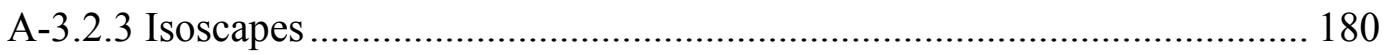

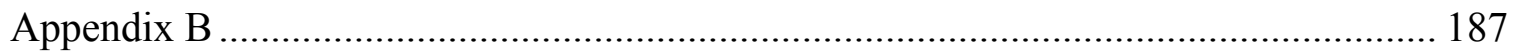

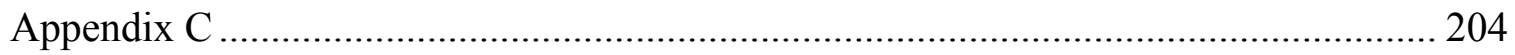

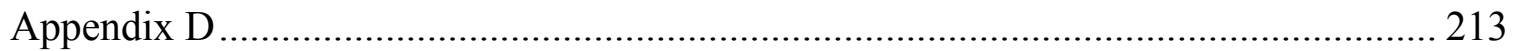




\subsection{INTRODUCTION}

Groundwater and surface water interactions are integral components of both groundwater and surface water flow systems. Groundwater interacts with surface water systems across a range of scales from small streams, lakes and wetlands to major river valleys and sea coasts (Winter, 1999). These interactions are complex and difficult to predict due to heterogeneity in geology, soil, topography, and variability in climate. Predictions of subsurface contributions to surface water bodies at scales useful to water resource management is a source of interest for both academics and water resource managers (Baker et al., 2003; Soulsby et al., 2004, 2006; Tetzlaff, Soulsby, et al., 2007; Tetzlaff, Waldron, et al., 2007; Capell et al., 2012). Groundwater contributions to surface water bodies is important to many facets of aquatic ecosystem health. The mineral rich cold groundwater slowly released to surface water bodies provides nutrients and refuge to aquatic plants, benthic invertebrates, amphibians and numerous other animal species. The slow and steady release of groundwater to surface water is known as baseflow. Baseflow maintains streamflow during low flow periods, when precipitation is scarce and flow is primarily derived from subsurface storage. Understanding the dynamic behaviour of baseflow, particularly during low flow conditions is an important step towards understanding the sensitivity of the system to changes in climate and land use.

Geochemical tracers and geographic information system (GIS) data layers have proven to be useful tools in upscaling process understanding of groundwater and surface water interactions to that of mesoscale systems (100-1000 km²) (Soulsby et al., 2004; Tetzlaff, Waldron, et al., 2007). Geochemical tracers have been used as an integrated measure of different geographic sources contributing to streamflow at varying spatial and 
temporal scales (Smart et al., 2001; Soulsby et al., 2004; Tetzlaff, Soulsby, et al., 2007). While the availability of numerous data layers allows for the investigation of how the spatial arrangement of watershed characteristics influences variability in flow paths, storage and residence time at the watershed scale (Soulsby et al., 2004; Tetzlaff, Soulsby, et al., 2007; Capell et al., 2012; Mountain et al., 2015). Combining these techniques with other hydrometric measurements provides a holistic methodology for the investigation of groundwater and surface water interactions at the mesoscale.

The Jock River watershed is a subwatershed of the Rideau River watershed located in Ottawa, Ontario, Canada. The watershed has a complex composition of geology, soils and land cover/land use. The headwaters of this system are mainly wetlands surrounded by outcrops and thin soils, such that the stream beds in the headwaters are incised bedrock. Soil thickness increases greatly in the middle of the watershed, due to the deposition of glaciofluvial materials from the Quaternary period. Sand deposits and thick clay plains in this area support a thriving agricultural industry. Anthropogenic influences in this region also include resource extraction (sand/gravel pits and quarries) and urban development. These numerous pressures and complexities make understanding groundwater and surface interactions, particularly baseflow generation and dynamics a source of interest in this watershed. Increased urban and agricultural development pressures, as are present in the Jock River watershed may alter areas that are important to baseflow generation.

This project seeks to understand baseflow generation and dynamics across the Jock River watershed. Spatial and temporal variation in baseflow generation was investigated through: continual geochemical sampling and hydrometric measurements 
along the Jock River and its main tributaries during the 2015 growing season; and two large scale synoptic geochemical surveys of headwater sites during the spring and summer of 2015. Numerous studies have used geochemical tracers, isotopes, hydrometric measurements and geospatial data layers to quantitatively assess groundwater-surface water interactions at large spatial scales (Rodgers et al., 2004; Soulsby et al., 2004, 2007; Tetzlaff and Soulsby, 2008b; Mountain et al., 2015). Based on a review of these studies a small subset of geochemical tracers were chosen which could be measured easily and cost-effectively. End-member mixing analysis (EMMA) was performed on the Jock River to identify potential end-members contributing to baseflow generation. EMMA was chosen as it assesses potential variability in the identity and number of groundwater endmembers contributing to stream flow. EMMA is typically applied to well sampled reference sites with a large suite of geochemical variables. This study is unique as it seeks to apply EMMA to a site with a limited number of samples using a small number of geochemical variables. Potential end-members; groundwater, wetlands and precipitation were independently sampled and screened to determine if they define the Jock River mixing space. The tributaries and headwater sites were then projected into the mixing space of the Jock River to determine if all sites were defined by the same end-members. Hydrometric measurements at the main tributaries were used to enhance our understanding of the flow dynamics and contributions across the watershed. Geospatial analysis of watershed characteristics was used to determine the influence of geology, soils and land use/land cover on baseflow generation and dynamics across the watershed. 


\subsection{Research Objectives and Questions}

The purpose of this study was to enhance our understanding of groundwater and surface water interactions in the Jock watershed using a combination of hydrometric and hydrochemical analysis techniques and GIS-based landscape modelling. More specifically, the overarching objective of was to quantify the proportional contributions of groundwater to surface water flows at different spatial and temporal scales to develop a conceptual model of baseflow generation and source areas within the watershed. The relationship between landscape composition and the variability in end-member proportions was also investigated to determine if watershed characteristics; geology, soil and land use/land cover enhanced our understanding of mechanisms controlling baseflow generation within the watershed. This project sought to answer the following questions:

1) How many end-members are required to explain baseflow generation in the Jock River during the growing season?

a) Does the number of end-members required vary between the Jock River and its main tributaries?

2) What end-members constrain the Jock River stream water mixing space?

a) Do the end-members identified for the Jock River constrain the stream water mixing space of its tributaries and headwater streams?

3) Do end-member contributions to baseflow generation vary temporally within the Jock River watershed?

4) Do end-member contributions to the stream network correlate to watershed characteristics such as land use/land cover, surficial geology and Paleozoic geology within the Jock watershed? 
a) Can watershed characteristics extracted from GIS layers be used to enhance and verify end-member contributions to baseflow generation within the Jock River watershed? 


\subsection{Thesis Structure}

This thesis contains six chapters. The first chapter (Introduction) is followed by the second chapter (Background), which provides a short review of groundwater flow systems, focusing on interactions between groundwater flow systems and surface water bodies. This chapter also provides an overview of methods of analysis of groundwater and surface water interactions using hydrometric and geochemical techniques. The third chapter (Methods) provides a detailed overview of the Jock River watershed's hydrology, physiography, hydrogeology and land use/land cover. The methods chapter also provides a synopsis of the field sampling/data collection techniques and laboratory analysis. The data analysis sub-chapter provides a detailed description of the application of the endmember mixing analysis technique and analysis of the relationships between end-member proportions and watershed characteristics. Chapter four (Results) provides an in-depth review of the results at all stages of the end-member mixing analysis. The results from the hydrometric analysis and geospatial analysis using watershed characteristics are also included in this section. The fifth chapter (Discussion) discusses the results as they pertain to our specific research questions and seeks to provide a synopsis of the most interesting and important findings. The final chapter (Conclusion) summarizes the key findings and provides suggestions for future research. 


\subsection{BACKGROUND}

\subsection{Groundwater Flow Systems and Surface Water Interactions}

\subsubsection{Groundwater Flow Systems}

Groundwater is defined as subsurface water beneath the water table in soils and geologic formations that are fully saturated (Freeze and Cherry, 1979; Fitts, 2002). Groundwater flow systems are controlled by the soil/geology of the region and the hydraulic gradient. The hydraulic conductivity of soils/geologic materials represents the ease with which fluid can flow through porous/fractured media. Geologic materials have a wide range of values for hydraulic conductivity, spanning 13 orders of magnitude (Freeze and Cherry, 1979). Hydraulic conductivity values vary throughout space in both the vertical and horizontal plane resulting in heterogeneity in the subsurface. This heterogeneity results in vastly different flow rates of water depending on the type of geologic material present. Heterogeneity in the subsurface also results in variability of the geochemical signature of groundwater, as the type of material present and the amount of contact time influence the concentration of solutes dissolved in the water. The longer the interaction between the rock and water the higher the mineralization content (Uhlenbrook and Hoeg, 2003; James and Roulet, 2006). Different regions and different features will then have unique hydrochemical signatures based on the material present and their residence time, making them useful tracers for groundwater and surface water interactions.

Topography is also a controlling factor on groundwater flow. It is generally assumed that the water table configuration in the subsurface is a subdued version of the topography of the land surface (Tóth, 1963; Sørensen and Seibert, 2007). It is also 
generally accepted that topographically high areas are groundwater recharge areas while, topographic lows are groundwater discharge areas (Freeze and Cherry, 1979; Winter, 1999). This is primarily true for regional groundwater flow systems, however the superposition of intermediate and local flow systems complicates the interactions between groundwater and surface water bodies (Winter, 1999). Tóth (1963) suggested that there are 3 groundwater flow systems: local, intermediate and regional. Local groundwater flow systems are thought to dominate the flow regime in areas with pronounced topographic relief, while regional groundwater flow systems are thought to dominate in areas with negligible local relief (Tóth, 1963; Freeze and Cherry, 1979; Sophocleous, 2002).

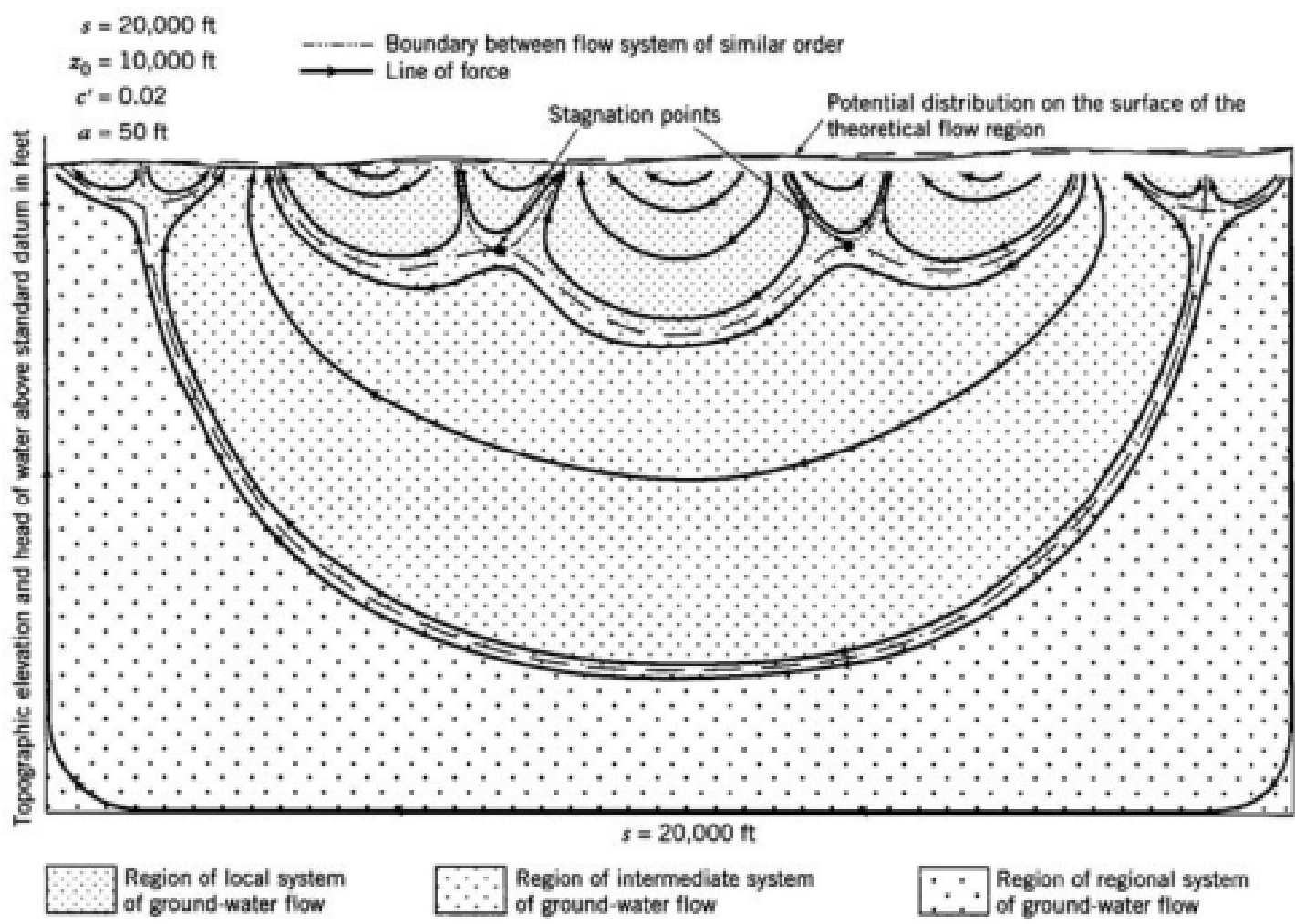

Figure 2-1. Local, intermediate, and regional groundwater flow systems (Tóth, 1963). 
Surface water flow systems are delineated as watersheds, subwatersheds or small basins. Watersheds are often the land unit used to manage water resources as typically they can be easily determined based on topographic demarcation. Groundwater flow systems also have watersheds at flow system divides (Winter et al., 2003). However, often the surface water and groundwater flow system divides do not coincide. Determining groundwater watersheds is difficult as they are not apparent from the land surface (Winter et al., 2003). Also as demonstrated by Tóth (1963) groundwater flow systems of different magnitudes can be superimposed upon one another, which makes it difficult to determine the extent of groundwater flow systems, as groundwater discharging to a surface water body may have originated from a more distant source, in which the groundwater has passed beneath other local flow systems before discharging to the surface water body (Winter, 1999; Winter et al., 2003). Furthermore, due to climatic variability groundwater divides may move in response to dynamic recharge and discharge conditions (Winter et al., 2003). The configuration of the water table also makes it difficult to determine the extent of groundwater watersheds. The assumption mentioned earlier that the water table is a subdued form of the land surface topography is not completely accurate as the configuration of the water table does not commonly reflect the configuration of the land surface (Winter et al., 2003). An example of this can be seen in figure $2-2 \mathrm{C}$, in which the surface water bodies are shown to be flow-through with respect to the shallow groundwater flow system, therefore highs in the water table do not correspond with topographic highs, thus making it difficult to determine which groundwater flow systems are contributing to surface water systems (Winter et al., 2003). This is particularly important when considering the boundaries of shallow groundwater 
flow, as the boundaries defined on the basis of surface topography may not be a true reflection of the shallow groundwater flow system (Winter et al., 2003).
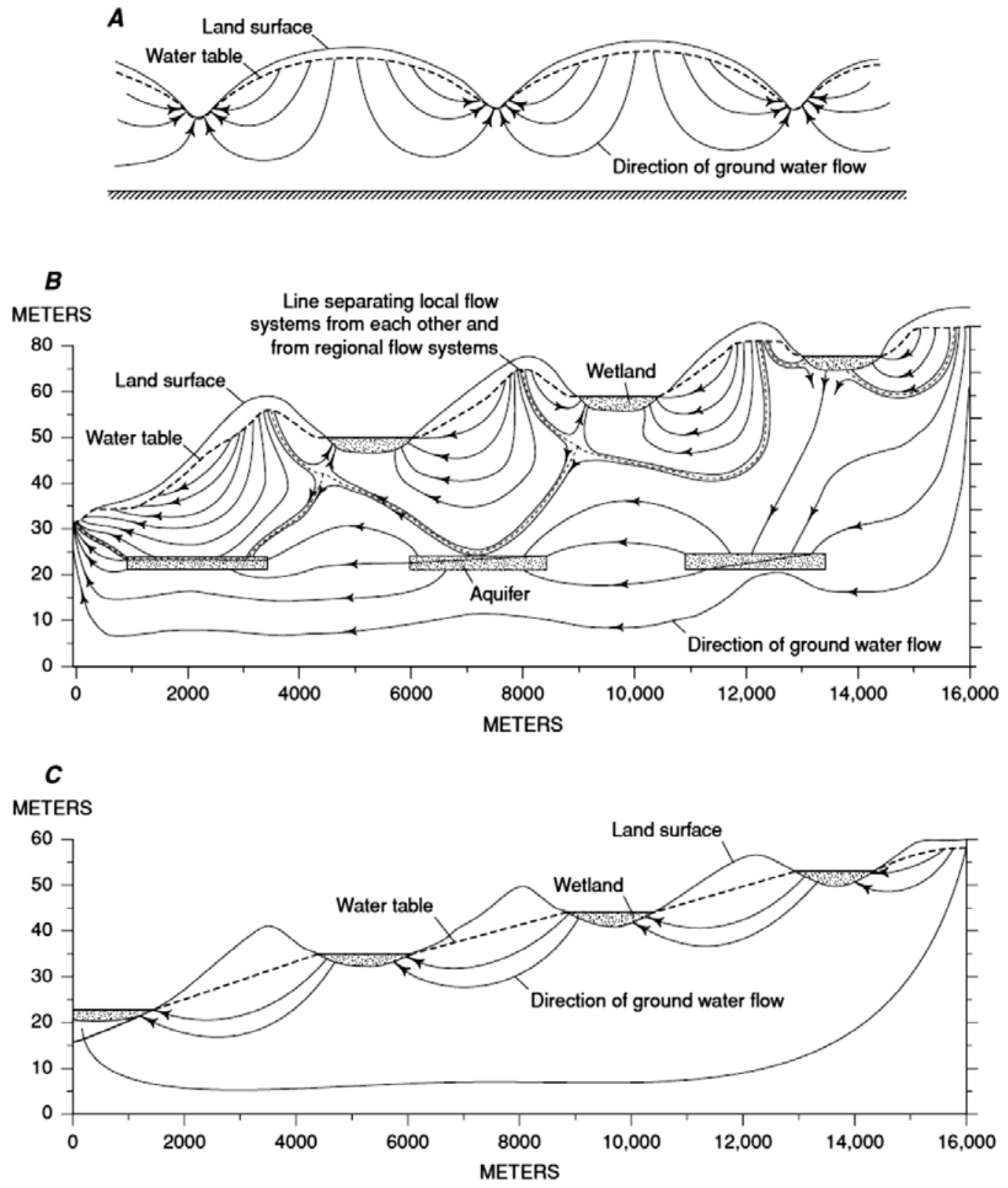

Figure 2-2. Hydrologic sections showing groundwater flow in hypothetical settings: (a) groundwater flow from water table highs beneath uplands to hydrologic sinks in the lowlands (modified from Hubbert 1940); (b) local flow system in which the water table is recharged at topographic highs and discharged at topographic lows, overlying a regional flow system (modified from Winter 1976); (c) groundwater flow system in which the water table highs are not underneath topographic highs. Figure and description taken from Winter et al., (2003). 


\subsubsection{Groundwater and Surface Water Interactions}

Interactions between groundwater flow systems and surface water bodies involves the exfiltration of groundwater to surface water and the infiltration of surface water into the groundwater flow system. Surface water bodies include headwater streams, rivers, lakes, wetlands and estuaries (Winter, 1995). These two flow systems are viewed as linked components of a hydrologic continuum (Sophocleous, 2002). The rate of flow is controlled by the soil/geologic hydraulic conductivity and the direction of flow either effluent or influent depends on the hydraulic head. As the hydraulic head is the fluid potential of a well point in the subsurface, following fluid mechanics, the direction of flow in space must be away from regions with higher fluid potential towards regions with lower fluid potential (Freeze and Cherry, 1979). For this reason, nested piezometers are often used in field studies to determine the horizontal and vertical flow gradients within the subsurface and between groundwater and surface water flow systems. Due to the cost and time required in installing and monitoring piezometers, studies which use nested piezometers often focus on groundwater and surface water interactions around a specific surface water body (Lee et al., 1980; Winter, 1984; Anderson and Cheng, 1993; Cey et al., 1998). To investigate groundwater and surface water interactions at the watershed scale, techniques which encompass spatial variability are necessary. Baseflow separation, isotopic analysis and geochemical analysis are methods which allow for an integrated investigation into groundwater and surface water interactions across a larger region. 


\subsection{Baseflow Analysis}

\subsubsection{Baseflow Separation}

Baseflow separation can be used as a method to determine groundwater discharge and recharge using streamflow data. This method is appealing as streamflow data is relatively easy to acquire and in many cases, long term hydrographic records exist at major river outlets. Wittenberg (1999) suggested that the main components of the groundwater balance can be identified from the streamflow data such as: discharge, evapotranspirative losses, storage and recharge. The most basic type of baseflow analysis is baseflow separation, in which streamflow data is partitioned into two components: direct runoff and baseflow (Eckhardt, 2008). The assumption is that baseflow, is the slow and constant release of groundwater into the stream, while peaks in the hydrograph represent runoff in response to rainfall events. Baseflow is often considered to be analogous to groundwater discharge, and is often used to represent the groundwater component in water balance modelling and hydrochemical analysis (Tallaksen, 1995).

Cey et al., (1998) investigated groundwater and surface water interactions in a small agricultural watershed by assessing the contributions of groundwater to surface water within a $450 \mathrm{~m}$ reach. Groundwater discharge estimates determined by baseflow analysis using the velocity-area method were found to be more accurate than those estimated using mini-piezometers and seepage meters. Based on the argument that the errors in measuring streamflow using the velocity-area method are smaller than those associated with point measurements of hydraulic gradient and conductivity from minipiezometers (Cey et al., 1998). The heterogeneity of the soil/geology results in differences in the calculated groundwater flux from mini-piezometers and seepage meters 
(Cey et al., 1998). Cey et al., (1998) states that to obtain an accurate picture of the hydraulic head and hydraulic conductivity distributions in the near stream zone an excessive number of mini-piezometers would need to be installed, while measurement of the stream discharge provides an integrated measure of total groundwater discharge at the point of measurement.

\subsubsection{Baseflow Analysis and Groundwater Flow Systems}

One of the main issues with baseflow analysis is highlighted by Winter's (1976) numerical simulation of groundwater and surface water interactions. In this simulation, the flow systems as shown in figure 2-3, have important implications for understanding baseflow contributions to streams (Winter, 1999). One common assumption is that baseflow contributions to stream flow represents discharge/recharge across the entire basin (Winter, 1999). However, if a stream were to occupy the lowest topographic position, as seen on the left side of the diagram in figure $2-3$, then it would receive discharge from two flow systems (Winter, 1999). It would receive contributions from both the local groundwater flow system and the regional groundwater flow system, which is recharged at the highest topographic point on the left side of the diagram (Winter, 1999). Streamflow in this model is then a mix of groundwater from multiple flow systems with various spatial contributions the extent of which is extremely difficult to determine. This challenges the assumption that baseflow contributions represent discharge/recharge across the entire basin, as the recharge area may be located outside of the catchment boundary and discharge may not be related to one singular groundwater flow system. Isotopes and geochemical tracers may be better tools to identify groundwater contributions to streamflow. Variations in isotopic and chemical signatures 
because of residence time and host rock composition provide a more reliable estimate of groundwater flow systems contributing to surface water bodies.

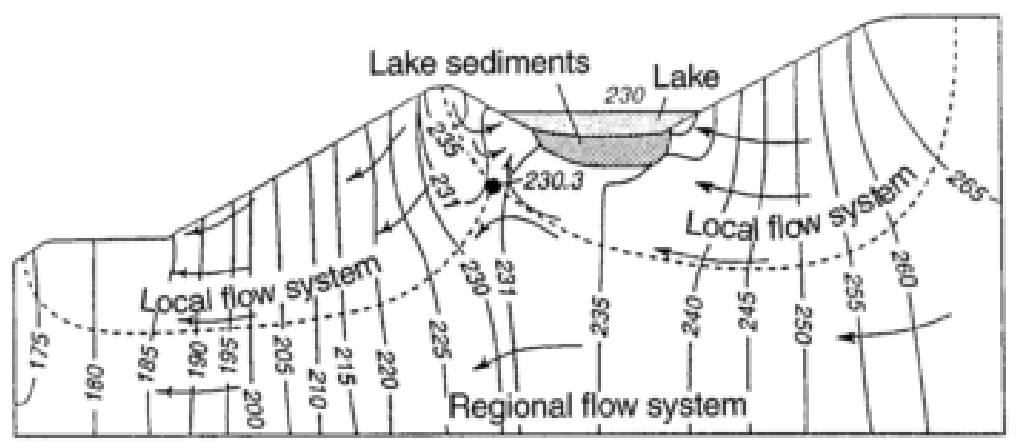

A

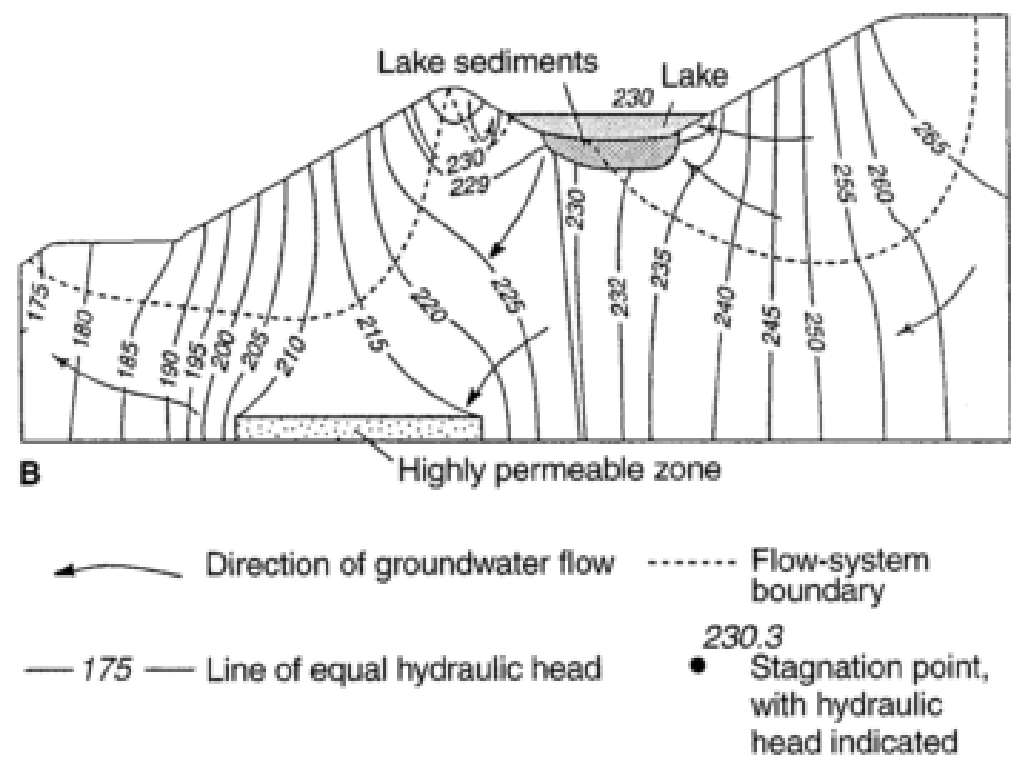

Figure 2-3. Numerical simulation of steady-state two-dimensional groundwater flow in a vertical cross section for two hypothetical settings. A) A continuous local flow-system boundary, as indicated by the stagnation point, preventing seepage from the lake. B) A discontinuous local flow-system boundary allows seepage from the lake (Taken directly from Winter, 1999). 


\subsection{Geochemical Analysis}

\subsubsection{Three Component Mixing Model}

Three component mixing models are used to relate information regarding the geographic sources of the components. As water moves through a landscape, the hydrochemical composition is altered due to interactions with organic and inorganic material in the unsaturated and saturated zone (Uhlenbrook and Hoeg, 2003). Differences in residence time and host rock, mean that different sources will have unique hydrochemical signatures allowing for the determination of the geographic sources and flow pathways. In a review of recently published papers which employed the use of hydrochemical tracers, Klaus and McDonnell (2013) found that the most popular hydrochemical tracer used in three component mixing model studies was silica followed closely by chloride and electrical conductivity. The total streamflow is then a combination of different source components, as shown in equation 1 , in which $f_{G,} f_{S}$ and $f_{P}$ represent the fraction of total streamflow $\left(f_{T}\right)$ that is attributed to groundwater, soil water and precipitation respectively. Solving the mass balance equation with more than two unknowns requires additional equations, using conservative tracers or isotopes or both.

$$
f_{T}=f_{G}+f_{S}+f_{P}
$$

Equation 1

\subsubsection{Tracer and Component Uncertainty}

Tracers must be chosen carefully as different tracers can describe different endmembers (Klaus and McDonnell, 2013). Rice and Hornberger (1998) used seven pairs of 
dual isotopic and chemical tracer combinations to determine if consistent results would be obtained through hydrograph separation analysis. Of the 70 hydrograph separations performed in this study less than $50 \%$ of the pair combinations returned the same results for each component for the same storm (Rice and Hornberger, 1998). These results demonstrate that the fractions of flow attributed to different components can be highly dependent on the tracers used. Uhlenbrook and Hoeg (2003) addressed issues in the uncertainty of the hydrochemical and isotopic hydrograph separation methods. In this study silica and $\delta^{18} \mathrm{O}$ were used to conduct two, three- and five-component hydrograph separations. In each method the error associated with spatial heterogeneity introduced the largest source of uncertainty to the final calculated fractions (Uhlenbrook and Hoeg, 2003). Substantial uncertainty was found in the calculated mixing fractions, errors of up to and more than $100 \%$ were found for a specific component (Uhlenbrook and Hoeg, 2003). The large uncertainty surrounding spatial heterogeneity illustrates that the results presented from isotopic and geochemical hydrograph separations should be viewed cautiously (Uhlenbrook and Hoeg, 2003).

\subsubsection{End-member Mixing Analysis (EMMA) Mathematical Definition}

EMMA is another method which can be used to evaluate the mixing of soil and groundwater end-members to explain/predict stream geochemistry variability. EMMA relies on the assumptions of linearity in the mixing process, the conservative behaviour of tracers, and the invariance of end-member compositions both spatially and temporally (Hooper, 2001). In a three-component mixing model described in the previous section the number of tracers required is two (number of tracers $=$ one - number of components), however EMMA uses numerous solutes to solve an over-determined system of equations, 
i.e., more tracers are used than are required (Hooper, 2001). The main underlying assumption is that solutes $(p)$, mix conservatively such that the stream water is a convex combination of its source solutions, i.e., end-members (Christophersen and Hooper, 1992). The observations of the stream water should then lie in the convex set whose vertices represent the end-members (Christophersen and Hooper, 1992). The mathematical definition outlined in Christophersen and Hooper, (1992) states that the observations for samples $(n)$ and the hypothesized linearly independent end-members $(k)$ are represented by the matrices $\mathbf{X}(n \times p)$ and $\mathbf{B}(k \times p)$ respectively. Any single observation in $\mathbf{X}$ is represented by $\boldsymbol{x}_{\boldsymbol{i}}$, which is a $l \times p$ vector. Each row of $\mathbf{B}, \boldsymbol{b}_{\boldsymbol{j}}$ (dimensions $l \times p$ ) is one end-member, therefore if each stream water sample is an exact and conservative mixture of these $k$ end-members, there exists a $l \times k$ row vector $\boldsymbol{l}_{\boldsymbol{i}}$ such that, each element of $\boldsymbol{l}_{\boldsymbol{i}}$ is greater than or equal to zero and the sum of all elements is equal to one (Christophersen and Hooper, 1992).

$$
x_{i}=l_{i} B
$$

Equation 2

EMMA solves equation 2 through a system of overdetermined linear equations by adopting a least squares objective function (Christophersen and Hooper, 1992). As the stream chemistry is known, the end-members need to be evaluated to determine if they fit the mixing sub-space, therefore the end-members are projected into the sub-space defined by the stream chemistry to evaluate the mixing model. This sub-space is defined through the eigenvectors resulting from principal component analysis (PCA). PCA is used to reduce the dimensionality of the tracer dataset to several eigenvectors. The number of eigenvectors retained relates to the number of end-members used to define the system, discussed in more detailed in section 2.4.5. The eigenvectors form a new mixing space, $\mathbf{U}$ 
space, in which the coordinates of the observations are an orthogonal projection of the original points which are uncorrelated from one another, as defined by equation 6 (Christophersen and Hooper, 1992). In equation $3 \mathbf{V}^{\mathbf{T}}$ is the transpose of the matrix of scaled eigenvectors $(m \times p)$ (Christophersen and Hooper, 1992). End-members are then projected into the $\mathbf{U}$ space and screened to see if they circumscribe the data (Christophersen and Hooper, 1992). If all stream water observations are bound by the end-members then a feasible set has been identified (Christophersen and Hooper, 1992). Analysis of the chemistry of the orthogonal projection of the end-members in $\mathbf{U}$ space and the original chemical concentrations should be done to assess the viability of the endmembers. Differences between the orthogonal projection and the original measurement may indicate spatial variability in end-member composition or reactions which violate the assumption of conservative mixing (Christophersen and Hooper, 1992). If a good mixing model is identified the proportions of each end-member are then calculated following simple mass-balance calculations, equations 3-6 (Burns et al., 2001). The predicted stream water chemistry is then calculated based on the proportions of the end-members, to evaluate the mixing models' fit. Poor predictions of the stream water chemistry suggest that additional site characterization may be required (Christophersen and Hooper, 1992).

$$
\begin{array}{cc}
\boldsymbol{U}=\boldsymbol{X} \boldsymbol{V}^{\mathbf{T}} & \text { Equation 3 } \\
Q_{T}=Q_{E M 1}+Q_{E M 2}+Q_{E M 3} & \text { Equation 4 } \\
U 1_{T} Q_{T}=U 1_{E M 1} Q_{E M 1}+U 1_{E M 2} Q_{E M 2}+U 1_{E M 3} Q_{E M 3} & \text { Equation 5 } \\
U 2_{T} Q_{T}=U 2_{E M 1} Q_{E M 1}+U 2_{E M 2} Q_{E M 2}+U 2_{E M 3} Q_{E M 3} & \text { Equation 6 }
\end{array}
$$




\subsubsection{Applications of EMMA}

The Panola Mountain Research Watershed (PMRW) is a long studied and well equipped, 41 ha basin in Atlanta, Georgia, USA. EMMA has been applied there in several studies to determine the geographic sources and flow paths defining the stream geochemistry (Christophersen et al., 1990; Hooper et al., 1990, 1998; Christophersen and Hooper, 1992; Burns et al., 2001; Hooper, 2001). As EMMA is based on the stream chemistry, it follows that only catchment processes that influence the stream chemistry are reflected in the model. The conceptual model of the watershed is then limited to the end-members that are identified from the stream chemistry. For the 41 ha catchment EMMA of five solutes (calcium, magnesium, sulfate, silica and alkalinity) identified three end-members which constrain and reliably predict the stream water chemistry: groundwater from the floodplain, groundwater from the riparian zone in the upper part of the catchment and groundwater from the vadose zone of the A-horizon in the soil (Hooper, 2001). The study conducted in Hooper (2001) sought to test the spatial extent of the end-members to evaluate what aspects of the catchment were being reflected in the conceptual model produced through EMMA. The results of this study indicated that the stream chemistry is mostly reflecting the contributions from different parts of the riparian zone (floodplain and upper groundwater). The hillslope samples which represent mobile water collected from a large trench and occupy the largest portion of the landscape were not reflected in the stream chemistry (Hooper, 2001). Burns et al., (2001) examined a 10 ha sub-catchment in the 41 ha PMRW for two storm events and found that much of contributions to streamflow during early rising of hydrograph and stream recession also resulted from the riparian groundwater. Burns et al., (2001) found that during peak stream 
flow runoff from the 3.6 ha outcrop contributed most significantly and hillslope contributions were minor. These findings indicate that the results of the EMMA do not reflect the workings of the catchment as a whole, as this landscape unit must contribute to streamflow (Hooper, 2001). Van Meerveld et al., (2015) examined the hillslope-riparian process hydrometrically using water level time series from 26 groundwater wells. A connected groundwater table was used to determine hydrologic connection between the hillslope and the stream (van Meerveld et al., 2015). Results indicated that the hillslope was disconnected from the stream most of the time except during large rainfall events when almost the entire hillslope became connected to the stream (van Meerveld et al., 2015). These results indicate that this landscape unit is contributing to storm flow but that this contribution is not expressed by the stream chemistry conceptual model. Hooper (2001) offers possible explanations to the lack expression of the hillslope end-member such as: chemical reactions, a delay in the translation of water from hillslope to riparian zone which is not expressed during a storm event and increased residence time in the alluvial aquifer altering this end-member. These studies illustrate that geochemical analysis is often heightened by hydrometric assessments which aid in identifying processes not captured by the stream water geochemistry.

\subsubsection{Determining the Number of End-members in EMMA}

Determining the number and identity of end-members contributing to stream flow in the catchment is an important aspect of EMMA as it forms the basis of the conceptual model of the watershed. In EMMA, the number of end-members used to define the stream water mixing space relates to the number of eigenvectors retained. Traditionally this number is decided based on the variance explained by the eigenvectors. Often, the 
"rule of one" is used in which, each eigenvector retained should explain 1/(number of solutes) variance (Hooper, 2003; James and Roulet, 2006). This method is problematic as it is a heuristic method, which offers little justification in the decision-making process (Hooper, 2003). Hooper (2003) presented a new approach to determine the number of end-members, which relies on the geometry of the stream water dataset rather than the variance explained by eigenvectors. This method examines the residuals of the projected stream water chemistry and the observed stream water chemistry. The identity of endmembers does not need to be known before hand, therefore potential end-members are screened to determine if they fit the stream water mixing space.

The mathematical method described in Hooper (2003) is similar to that in Christophersen and Hooper (1992) in which the stream water is represented by the matrix $\mathbf{X}$. The matrix $\mathbf{X}^{*}$ is the standardized values, stream data are standardized based on its mean and standard deviation so that each solute has equal weight (Hooper, 2003). Through use of PCA, the "best" $m$-dimensional subspace $(m<p)$ that fits $\mathbf{X}^{*}$ is the first $m$ eigenvectors of the solute correlation matrix (Hooper, 2003). $\mathbf{V}$ is the matrix formed by the first $m$ eigenvectors and is the basis of the new $m$-dimensional sub-space (Hooper, 2003).The matrix $\widehat{\mathbf{X}}^{*}$ is the orthogonal projection of $\mathbf{X}^{*}$, see equation 7 . The matrix $\widehat{\mathbf{X}}^{*}$ is then destandardized by multiplying by the standard deviation and adding the mean to yield the matrix $\widehat{\mathbf{X}}$. The residuals of the projected and the original data are determined by subtracting the destandardized projected values by the original stream chemical data, see equation 8 .

$$
\begin{array}{cr}
\widehat{X^{*}}=X^{*} V^{T}\left(V V^{T}\right)^{-1} V & \text { Equation } 7 \\
E=\hat{X}-X & \text { Equation } 8
\end{array}
$$


Diagnostic plots of the residuals $\left(\mathbf{e}_{\mathbf{i}}\right)$ versus the observed concentration $\left(\mathbf{x}_{\mathbf{i}}\right)$ for each solute $i$ are evaluated to determine the correct number of end-members to retain. The lowest dimensional mixing space in which the residual plots show no structure, is chosen. Similar, to regression analysis, a "good" mixing sub-space is indicated by a random pattern in the residuals (Hooper, 2003). Structure in the residuals indicates a deficiency in the mixing model, due to either the non-conservative behaviour of tracers or an inadequate number of end-members (Hooper, 2003). The dimensions of the subspace $(m)$ is the rank of $\mathbf{X}$ (Hooper, 2003). The rank is directly related to the number of endmembers required in a mixing model (Hooper, 2003). For a correlation matrix one more end-member than the rank is required (Hooper, 2003). A rank of one, indicates that one eigenvector should be retained, therefore the mixing space is a line which is defined by two end-members. In a two-dimensional mixing space this would be represented by a triangle.

Hooper (2003) tested the application of this method in the PMRW and found that most sites demonstrated an increase in the number of eigenvectors retained based on the analysis of residual plots, when compared to the commonly applied "rule of one". Hooper (2003) found that through retention of the third eigenvector, which only explained $2 \%$ of the variability, limited expression of the hillslope could be observed during high discharge at the lower gauge. Hooper (2003) argues that the residual plots provide more information for deciding the rank than the eigenvalues or scalar diagnostics alone, as they outline general patterns and outliers in the solute concentrations.

James and Roulet (2006) tested the applicability of Hooper's method in the Westcreek watershed $\left(1.47 \mathrm{~km}^{2}\right)$ located in Mont-Saint-Hillare, Quebec, Canada. The 
watershed was divided into eight variably nested catchments ranging in size from 0.07$1.47 \mathrm{~km}^{2}$. The largest catchment was the Lk catchment; all subsequent catchments were located upstream. Numerous solutes were analyzed and five were identified which showed conservativeness based on linearity amongst solute pairs. Residual analysis results were also compared to those derived using the "rule of one". The results for the Lk catchment were consistent amongst both methods and indicated a rank of one for this site (James and Roulet, 2006). Both methods of analysis were also applied to each nested catchment upstream to test the hypothesis that the number of end-members was the same for each catchment independent of scale (James and Roulet, 2006). Results from the "rule of one" indicated that five of the seven nested catchments had a rank of one, two of the smaller catchment Aw and Sb had a rank of two (James and Roulet, 2006). Residual analysis of these sites showed structure in the residuals for electrical conductivity for a one dimensional analysis, however this also occurred at the Lk site (James and Roulet, 2006). Structure in the residuals in alkalinity for a one-dimensional mixing space was identified at two sites ( $\mathrm{Yv}$ and $\mathrm{Yc}$ ) indicating that these sites may be defined by a twodimensional mixing space (James and Roulet, 2006). James and Roulet (2006) conclude that results from the residual analysis support the hypothesis of a similar rank across scale. Based on the residual analysis all sites have the same number of end-members (two or three). Alkalinity and electrical conductivity were determined to be the most compatible tracers in a single mixing model across all scales (James and Roulet, 2006). This study illustrates that residual analysis of solutes can be used to validate both the selection of tracers used in EMMA and the number of end-members retained. 


\subsubsection{Projecting Sites into a Reference Mixing Space}

As discussed in section 2.4.4 EMMA provides a conceptual model for catchment processes reflected in the stream geochemistry. Stream water collected at the outlet should in theory reflect catchment processes as whole. However, it has been shown that catchment processes across the entire watershed are not always reflected proportionally at the outlet. Hooper (2003) suggests that if the ratios of end-members contributing to streamflow remain constant across sites and end-member contribution is the result of physical mixing rather than equilibrium chemistry, then other sites can be projected into the mixing subspace of the reference site. The basis of this technique is similar to the use of trilinear "piper" diagrams which provide a simple classification of a solution through their ion ratios (Hooper, 2003). A site will fit into the mixing space of another site if the solutes are added to the solutions with the same initial chemistry in the same ratio (Hooper, 2003). Therefore, if a site has water which starts with a different chemistry, contacts a different material, exchanges solutes in a way which violates weathering stoichiometry or has a different set of controlling end-members it will not fit into the same mixing space (Hooper, 2003).

Hooper (2003) tested this theory by projecting upstream sites in the PMRW into the lower gauge reference site. Upstream sites projected into the lower gauge reference site had higher relative root mean square error (RRMSE) than when these sites were projected into their own mixing space. Some sites fit into the projected mixing space better than others, indicting either other controlling end-members or weathering processes influencing stream chemistry at these sites. James and Roulet (2006) also applied this approach in the Westcreek watershed. Upstream catchments were projected 
into the two-dimensional mixing subspace of the Lk catchment. Only the Ef catchment directly upstream of the Lk gauge showed a relatively good fit when projected into the Lk mixing subspace (James and Roulet, 2006).The RRMSE and the relative bias of predicted concentrations of major ions projected into the Lk mixing subspace indicated that $\mathrm{Na}^{+}$, $\mathrm{Mg}^{2+}$ and $\mathrm{Ca}^{2+}$ either do not adhere to the assumption of physical mixing or are not mixing in the same ratio as the Lk reference site (James and Roulet, 2006). Solutes alkalinity and electrical conductivity were found to have smaller and consistent RRMSE and relative bias indicating that these solutes are more appropriate in the application of a single linear mixing model across scale (James and Roulet, 2006). James and Roulet (2006) suggested that the spatial variation in the stream water chemistry may be due to variability in bedrock and soil composition influencing the groundwater end-member.

\subsection{Geospatial Analysis}

\subsubsection{Watershed Characteristics and Tracer Studies}

A few researchers have investigated the influence of landscape controls in rainfall-runoff models, flow path analysis and transit times (Soulsby et al., 2004; Laudon et al., 2007; Tetzlaff, Soulsby, et al., 2007; Capell et al., 2012). By combining GIS data layers for soil, geology, land use/ land cover and topography with the results from tracer analysis, a better understanding of how landscape characteristics influence flow generation can be gained. Tetzlaff, Soulsby, et al., (2007) used GIS analysis of topographic wetness index $(\ln (\mathrm{A} / \tan \mathrm{B}))$ and the UK Hydrology of Soil Type (HOST) classification to identify landscape controls on runoff dynamics in two small catchments within the Girnock catchment in Scotland. Environmental tracers, alkalinity and ${ }^{18} \mathrm{O}$ where used to assess streamflow generation processes at the catchment scale (Tetzlaff, 
Soulsby, et al., 2007). Although the catchments investigated had differences in their landscape characteristics, their mean residence times and groundwater contributions were very similar, highlighting how flow generation is dependent on the subtle interplay between different aspects of landscape organization (Tetzlaff, Soulsby, et al., 2007). In other studies multiple linear regression (MLR) has been used to gain a more quantitative description of how watershed characteristics influence flow generation (Soulsby et al., 2004; Laudon et al., 2007). Laudon et al., (2007) used MLR to determine controlling watershed characteristics for 15 nested boreal streams in northern Sweden. The percentage of soil groups' peat, till and silt as well as catchment area and median subcatchment area were used in MLR to determine which catchment characteristics best explained the rising limb, peak flood and falling limb of the hydrograph (Laudon et al., 2007). The correlation between the percentage of peat in the sub-catchment and the preevent water fraction had an $\mathrm{R}^{2}$ of 0.79 , indicating higher contributions of overland flow in these catchments, with over $50 \%$ of streamflow attributable to event water in wetland dominated catchments (Laudon et al., 2007). These studies illustrate how our understanding of catchment dynamics can be enhanced by combining results from environmental tracer surveys with information extracted from GIS data layers.

\subsubsection{Modelling Groundwater Fluxes Based on Watershed Characteristics}

Analysis of hydrologic processes at the catchment scale is influenced by heterogeneity in the soil/geology, variability in land use/land cover and variations in local and regional topography, necessitating the need for the analysis of how watershed characteristics influence the dynamics of flow generation. As mentioned in section 2.1, hydraulic conductivity and the hydraulic gradient are the main drivers of groundwater 
flow. Darcy's Law is the fundamental principal governing how most groundwater flow is conceptualized. On this basis, Baker et al. (2003) developed a model called MRIDARCY which uses a moving window "neighborhood analysis" to determine potential energy gradients from a smoothed DEM surface and hydraulic conductivity values estimated from surficial geology mapping to determine potential subsurface water flux. Results of the map-based predictions using MRI-DARCY accounted for $85 \%$ of the observed variation in base flow from 128 United States Geological Survey (USGS) gauges, $69 \%$ of the observed variation in discharge accrual from 48 river segments, and $29 \%$ of the residual variation in local groundwater flux from 33 locations as measured by hyporheic temperature profiles after factoring out the effects of climate (Baker et al., 2003). The model is limited in that it accounts for the potential of local subsurface flow paths, and not the actual water movement or the input from deep regional groundwater flows (Baker et al., 2003). The model does however illustrate the influence of these watershed characteristics on groundwater fluctuations. 


\subsection{METHODS}

\subsection{Site Description}

\subsubsection{Hydrology}

The Jock River watershed is a subwatershed of the Rideau River watershed located southwest of the Ottawa city center. The Jock River is approximately $75 \mathrm{~km}$ in length, its catchment encompasses an area of roughly $557 \mathrm{~km}^{2}$. The main tributaries to the Jock River include: Monahan Drain, Leamy Creek, Flowing Creek, Hobbs Drain, Kings Creek and Nichols Creek, see figure 3-1. Long term hydrographic records, from the Water Survey of Canada (WSC) gauge at Moodie Road, indicate that the Jock River experiences large seasonal variability, with extremely high flows during the spring melt period and extremely low flows during the summer. Figure 3-2 demonstrates that large peaks in the hyeto-hydrograph are associated with spring snow melt. Smaller intermittent peaks in figure 3-2 are in response to increases in the intensity or number of rainfall events. The Ottawa region experienced a significant drought in 2012, which can be seen in figure 3-2 as flow approaches $0 \mathrm{~m}^{3} / \mathrm{s}$ during this period. The flow duration curve seen in figure 3-3, indicates that $Q_{5}$ is $28.1 \mathrm{~m}^{3} / \mathrm{s}$ and $Q_{95}$ is $0.08 \mathrm{~m}^{3} / \mathrm{s}$, further illustrating the dynamic range in flow conditions between high flow conditions during the spring melt and low flow conditions in the summer months. 


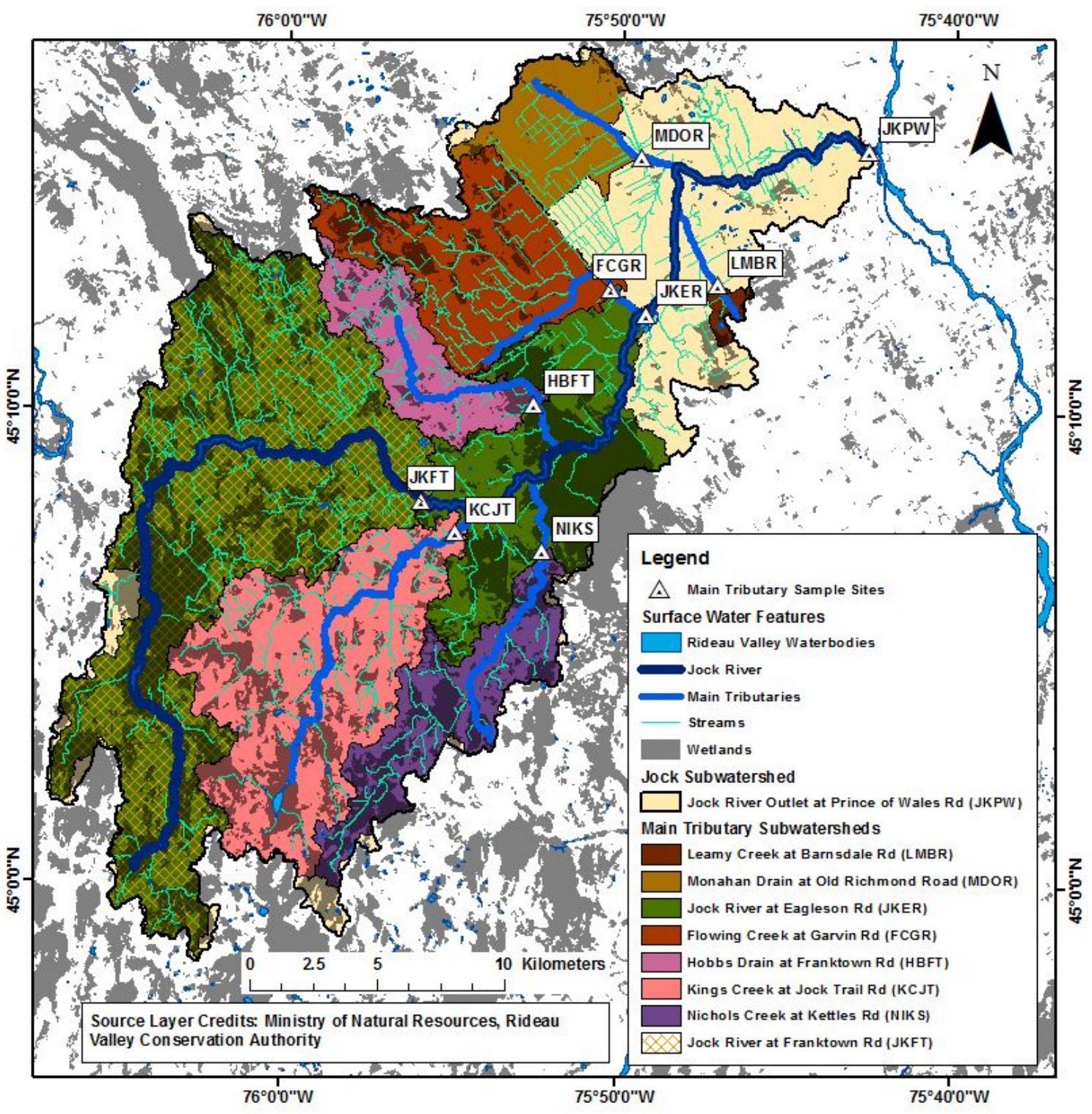

Figure 3-1. The Jock River watershed and its main tributary subwatersheds. Watersheds were delineated using a Digital Elevation Model (DEM) produced from LiDAR and Drape imagery with a $2 \mathrm{~m}$ resolution. Streams which had been re-digitized and verified by Rideau Valley Conservation staff were used to burn streams into DEM for enhanced characterization of flow direction and contributing area. Main tributary sample sites were used as pour points to delineated main tributary subwatersheds. Waterbodies and wetlands of the surrounding Rideau Valley watershed are also shown here.

Wetlands data source: Ontario Ministry of Natural Resources and Forestry. (2013). Wetland-Eco Regions $6 E$ and $7 E$ [GIS Data Set]. Retrieved

from https://www.javacoeapp.lrc.gov.on.ca/geonetwork/srv/en/main.home.

Rideau Valley waterbodies data source: Ontario Ministry of Natural Resources. (2011). Water Feature Area[GIS Data Set]. Retrieved from https://www.javacoeapp.lrc.gov.on.ca/geonetwork/srv/en/main.home. Streams data source: Rideau Valley Conservation Authority (2017). Jock River Watercourse [GIS Data Set]. Retrieved from Rideau Valley Conservation Authority. 


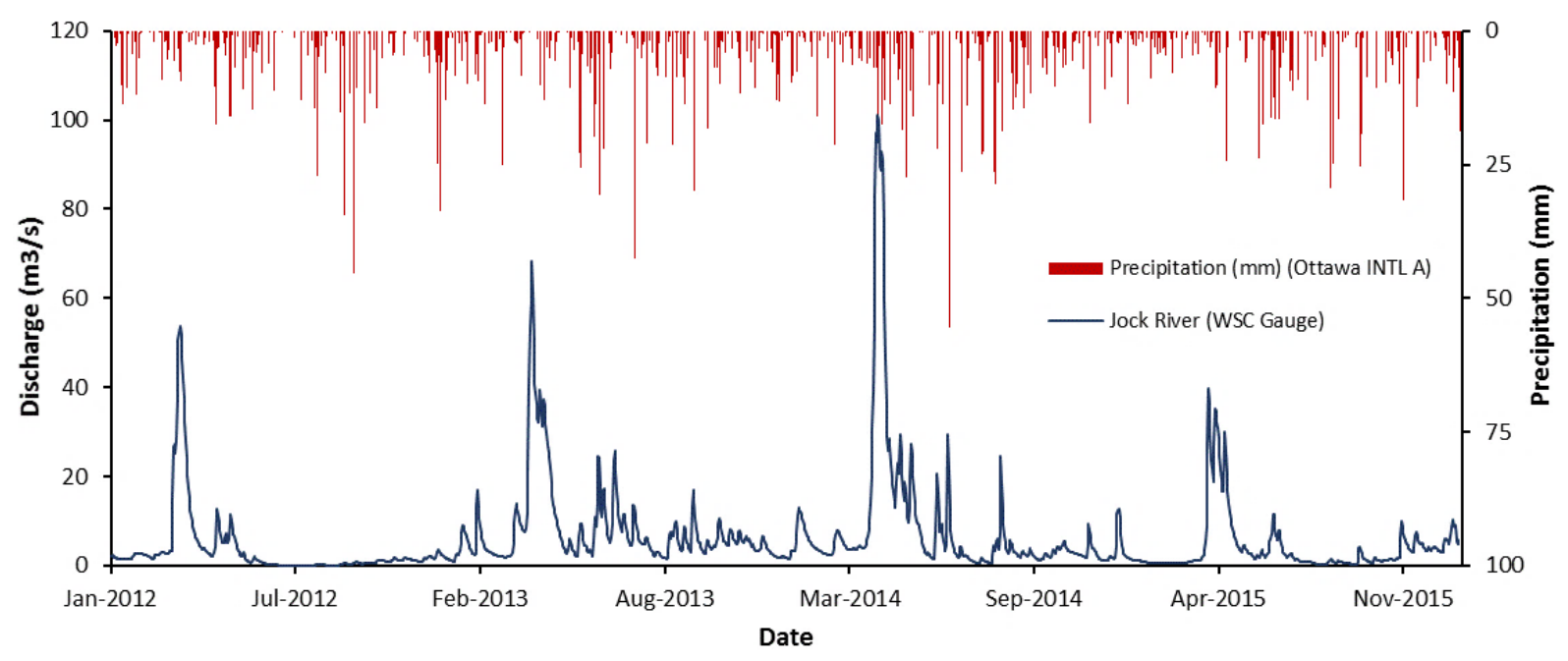

Figure 3-2. Hyeto-hydrograph for discharge ( $m 3 / s)$ at the Jock WSC gauge located at Moodie Road and precipitation $(\mathrm{mm})$ collected at the Ottawa International Airport (Ottawa INTL A) from 2012 to 2015.

Discharge data source: Government of Canada. (2017). Daily_Mar-15-2017_12_40_18AM [Data file]. Retrieved from https://wateroffice.ec.gc.ca Precipitation data source: Government of Canada. (2016). eng-hourly-03012012-03312012 (2013, 2014, 2015) [Data file]. Retrieved from http://climate.weather.gc.ca

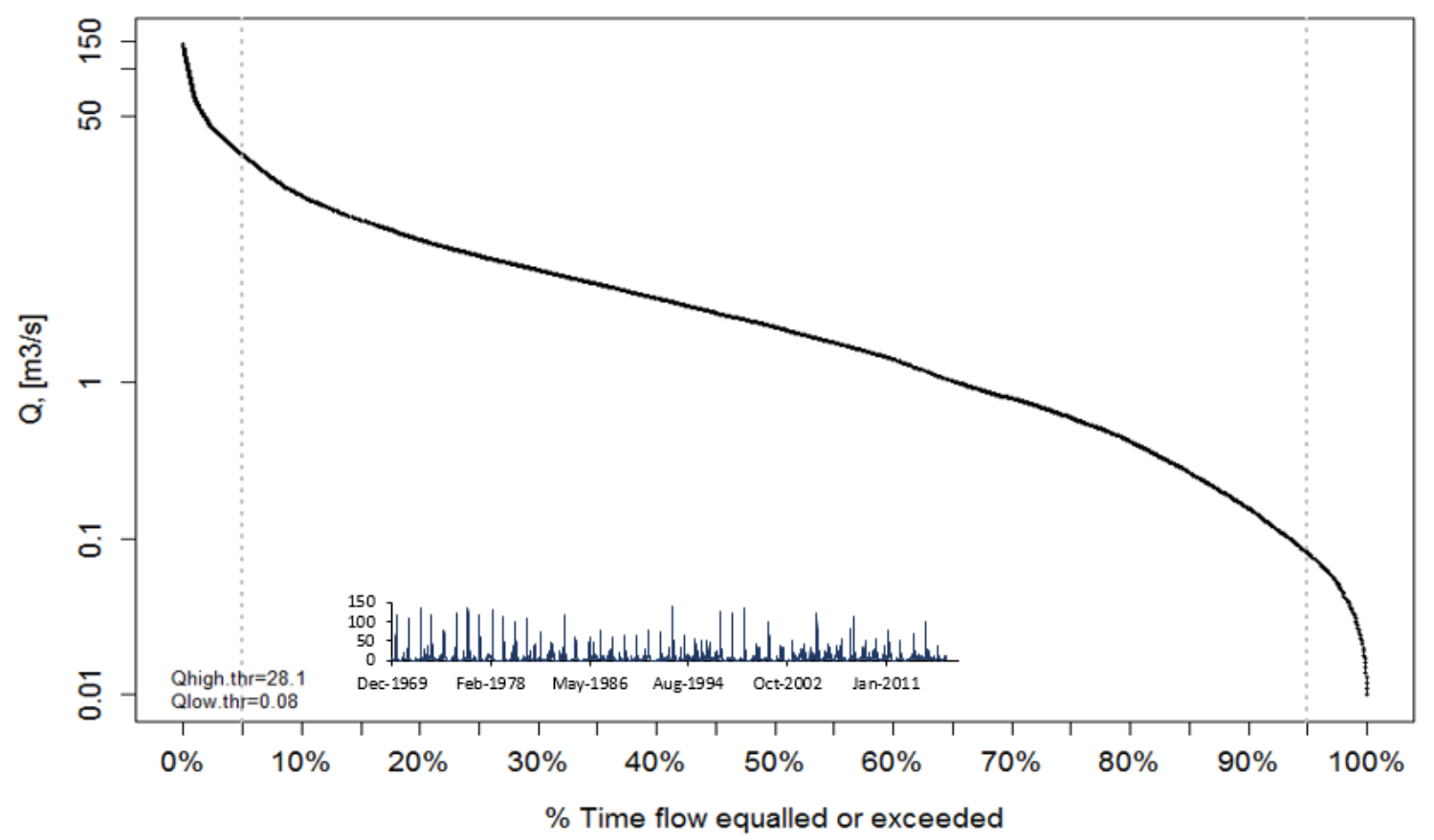

Figure 3-3. Flow duration curve calculated based on discharge $\left(\mathrm{m}^{3} / \mathrm{s}\right)$ from the Jock WSC gauge located at Moodie Road. The inset is the long term (1969-2015) hydrograph at the site. The flow duration high flow threshold (Qhigh thr) is set to 5\% flow exceedance and equals $28.1 \mathrm{~m}^{3} / \mathrm{s}$. The low flow threshold (Qlow thr) is set to $95 \%$ flow exceedance and equals $0.08 \mathrm{~m}^{3} / \mathrm{s}$. 


\subsubsection{Climate}

The Ottawa area is characterized as a humid continental climate with cold winters and warm humid summers. The growing season typically spans 159 days, starting around April $30^{\text {th }}$ and ending October $7^{\text {th }}$. Figure 3-4 compares the 2015 average monthly temperature with the climate normal data for average monthly temperatures $\left({ }^{\circ} \mathrm{C}\right)$, both are from the Ottawa Macdonald-Cartier International Airport, climate normal data spans from 1981 and 2010. This figure illustrates that January and February were slightly colder than the climate normal, but for the most part the remainder of the months were similar in temperature to the climate normal.

Climate data indicates that the total annual precipitation for this region is 943.4 $\mathrm{mm}, 20 \%$ of which is contributed by snowfall, the highest precipitation months are from June to October. The total precipitation in the year 2015 was $738.4 \mathrm{~mm}$, which is lower than the climate normal. June and August were slightly wetter than the climate normal with precipitation totalling $\sim 100 \mathrm{~mm}$ in both months. The months of February, March and July demonstrate considerably lower precipitation totals than the climate normal, as seen in figure 3-5. 


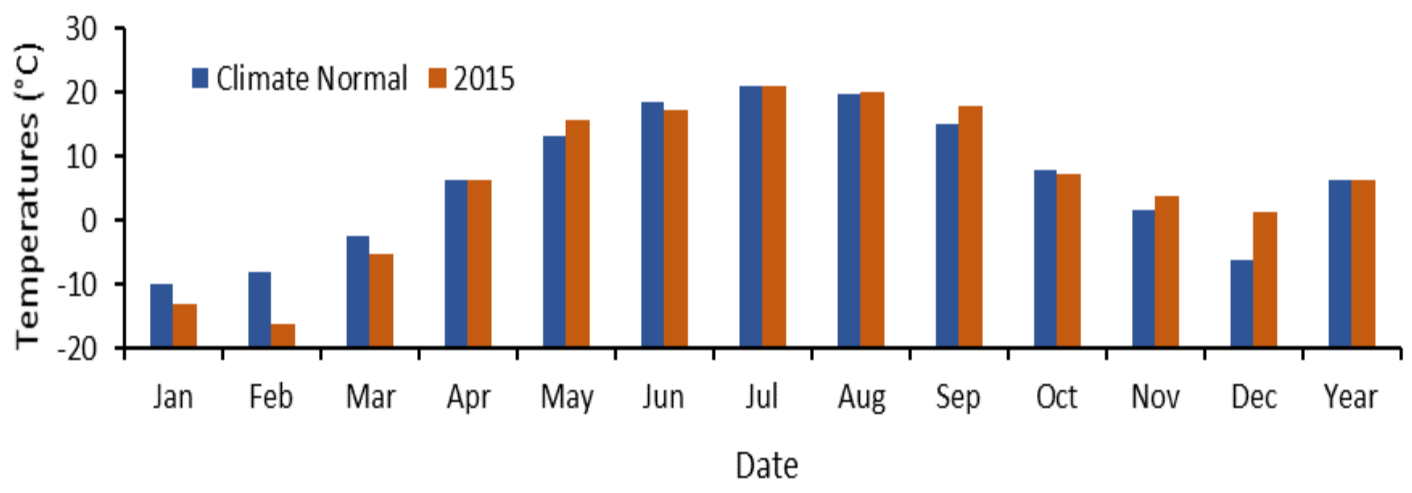

Figure 3-4. Graph illustrating the average monthly temperature in the Ottawa region from Climate Normal data (1981-2010) and 2015 climate data from the Ottawa Macdonald-Cartier International airport.

Climate Normal data source: Government of Canada (2017). normals-6106000-1981-2010 [Data file]. Retrieved from http://climate.weather.gc.ca

2015 climate data source: Government of Canada. (2017). eng-daily-01012015-12312015 [Data file]. Retrieved from http://climate.weather.gc.ca

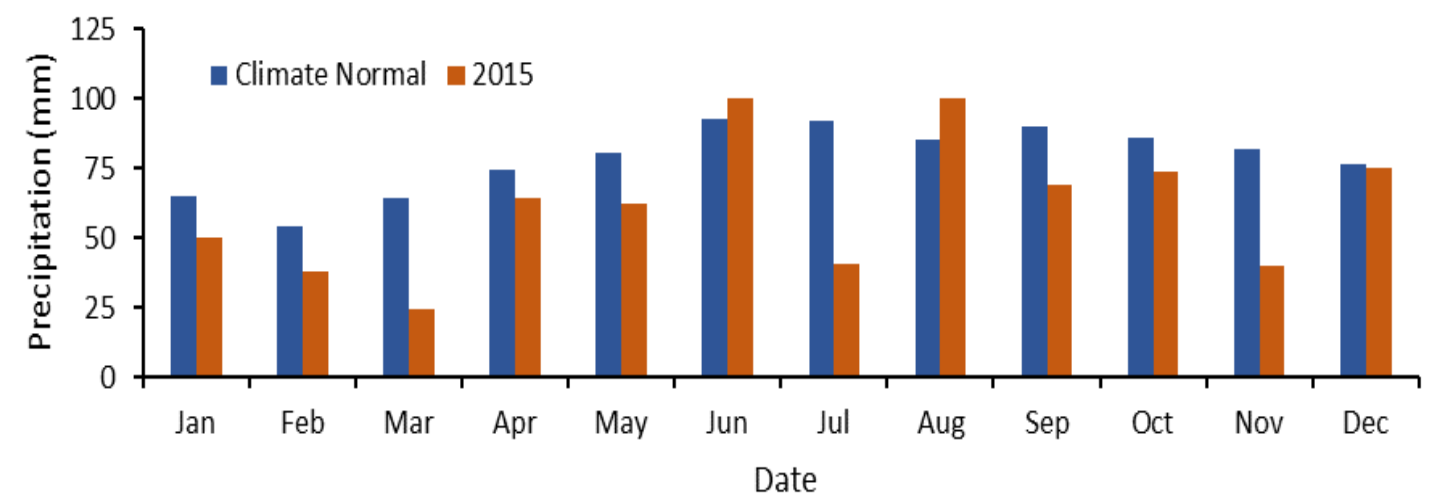

Figure 3-5. Graph illustrating the monthly precipitation ( $\mathrm{mm}$ ) in the Ottawa region from Climate Normal data (1981-2010) and 2015 climate data from the Ottawa MacdonaldCartier International Airport.

Climate Normal data source: Government of Canada (2017). normals-6106000-1981-2010 [Data file]. Retrieved from http://climate.weather.gc.ca 2015 climate data source: Government of Canada. (2017). eng-daily-01012015-12312015 [Data file]. Retrieved from http://climate.weather.gc.ca 


\subsubsection{Physiography}

\subsubsection{Surficial Geology}

The headwaters of the Jock watershed are characterized by thin overburden and organic material, as seen in figure 3-6. Paleozoic bedrock is predominantly limestone and dolostone in this area. Bedrock is covered by a thin veneer of soil, the inset map in figure 3-8 demonstrates that the drift thickness in areas identified as Paleozoic bedrock is $0-1 \mathrm{~m}$. Areas categorized as organic demonstrate an increase in drift thickness of 1-10 m. Organic materials in this region are mainly gyttja and peat in bogs, fens, swamps and poorly drained areas (Ontario Geologic Survey, 2010).

The middle of the Jock watershed is characterized by materials of glacio-fluvial origin. Coarse to medium grained sand and gravel deposits occur throughout this area. Beach formations are present mainly in this section and are often fossiliferous in nature. Sandy and silty compact diamicton is present in the center of the watershed. It is overlain by discontinuous gravel, sand and boulders (Ontario Geologic Survey, 2010). This deposit is commonly referred to as basal gravel, and may underlie all other overburden units in this area (Velderman, 1993).

Progressing towards the outlet, the surficial geologic material is from the Quaternary period and originated due to the presence and retreat of the Champlain Sea. The presence of sand deposits and the beaches described above are categorized as nearshore sediments from the Champlain Sea (Ontario Geologic Survey, 2010). The clay, silt deposit, described as clay, silty clay and silt, are categorized as offshore marine deposits (Ontario Geologic Survey, 2010). The clay, silt region is locally covered in thin sands and may contain lenses and pockets of sand at depth; the clay at depth is described 
as uniform blue-grey (Ontario Geologic Survey, 2010). There is also a large esker that cuts across the upper portion of the watershed. An increase in elevation can be seen in this region, see figure 3-8. Resource extraction is heaviest in this area as seen in figure 36; there is a large Quarry in the northern portion of the esker and numerous sand and gravel pits in the southern portion. 


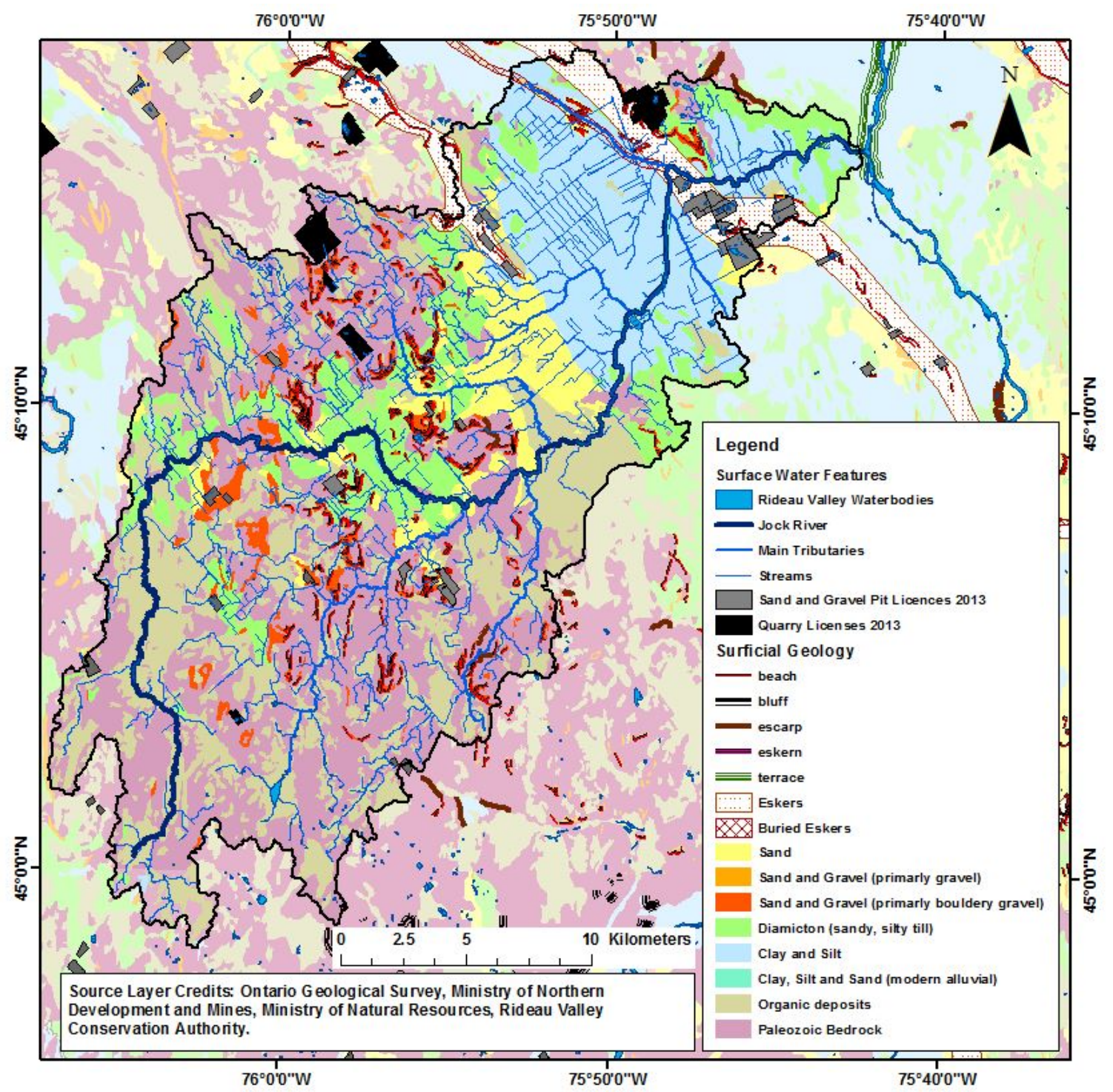

Figure 3-6. Surficial geology and resource extraction in the Jock River watershed. Surficial geology data source: Ontario Geological Survey. (2010). Surficial Geology of Southern Ontario [GIS data set]. Retrieved from http://www.geologyontario.mndm.gov.on.ca

Aggregate resources data source 1: Ontario Geological Survey. (2013). Aggregate resources inventory of the City of Ottawa, southern Ontario [GIS data set]. Retrieved from

http://www.geologyontario.mndm.gov.on.ca

Aggregate resources data source 2: Ontario Geological Survey. (2013). Aggregate resources inventory of the County of Lanark, southern Ontario [GIS data set]. Retrieved from

http://www.geologyontario.mndm.gov.on.ca

Rideau Valley waterbodies data source: Ontario Ministry of Natural Resources. (2011). Water Feature

Area [GIS Data Set]. Retrieved from https://www.javacoeapp.lrc.gov.on.ca/geonetwork/srv/en/main.home.

Streams data source: Rideau Valley Conservation Authority (2017). Jock River Watercourse [GIS Data

Set]. Retrieved from Rideau Valley Conservation Authority. 


\subsubsection{Paleozoic Geology}

The Paleozoic geology of the region is predominantly carbonate rocks. The main formations present in Jock watershed are: the Gull River Formation, the Rockcliffe Formation, the Oxford Formation and the March Formation, as can be seen in figure 3-7. The March and Oxford Formations are lower Ordovician strata, their distribution is limited to eastern Ontario, together they form the Beekmantown Group (Armstrong and Dodge, 2007). The March Formation is the first in this sequence. It consists of quartz sandstones, dolomitic sandstones and dolostones and disconformably overlies the Nepean Formation (Armstrong and Dodge, 2007). The Nepean Formation is Cambrian in age and is characterized by sandstones with minor conglomerates (Armstrong and Dodge, 2007). The chemical composition of drill core analysis from previous studies in the region report $41.1 \% \mathrm{SiO}_{2}, 0.73 \% \mathrm{Fe}_{2} \mathrm{O}_{3}, 2.77 \% \mathrm{Al}_{2} \mathrm{O}_{3}, 19.9 \% \mathrm{CaO}$ and $10.1 \% \mathrm{MgO}$ and $26 \%$ loss on ignition for the March Formation (Velderman, 1993).

The Oxford Formation overlies the March Formation, it consists mainly of browngrey to green- grey, thin- to thick-bedded, very fine- to medium-crystalline dolostone, with local thin shale beds, quartz sandstone and shaley dolostone interbedding near the base (Johnson et al. 1992). Chemical analysis of drill cores in this formation from previous studies report $9.34 \% \mathrm{SiO}_{2}, 1.00 \% \mathrm{Fe}_{2} \mathrm{O}_{3}, 4.94 \% \mathrm{Al}_{2} \mathrm{O}_{3}, 26.48 \% \mathrm{CaO}$ and 17.29\% $\mathrm{MgO}$ and 39.79\% loss on ignition (Velderman, 1993). Both formations have relatively high $\mathrm{CaO}$ and $\mathrm{MgO}$ concentrations but differ considerably in $\mathrm{SiO}_{2}$ presumably due to the increased presence of sandstone in the March Formation.

The Rockcliffe Formation is from the Middle Ordovician. This formation disconformably overlies the Oxford Formation (Velderman, 1993; Armstrong and Dodge, 
2007). The Rockcliffe Formation is also limited in its distribution to eastern Ontario (Armstrong and Dodge, 2007). It consists of interbedded quartz sandstones and shales (Velderman, 1993; Armstrong and Dodge, 2007). The Ottawa Group Formations overlie the Rockcliffe Formation, the Gull River is the most prevalent of this group in the Jock River watershed. Other formations such as the Bobcaygeon and the Verulam are present along the northern boundaries of the watershed. The Gull River Formation consists of light grey to brown limestones with silty dolostone beds more prevalent towards the base of the formation (Armstrong and Dodge, 2007). Minor shales and thin sandstone beds are also locally present (Armstrong and Dodge, 2007). Numerous faults can also be observed in figure 3-7, the faults in this area form part of the Ottawa-Bonnechere Graben. Figure 3-7, also demonstrates the abundance of outcrops in the headwaters of this region. 


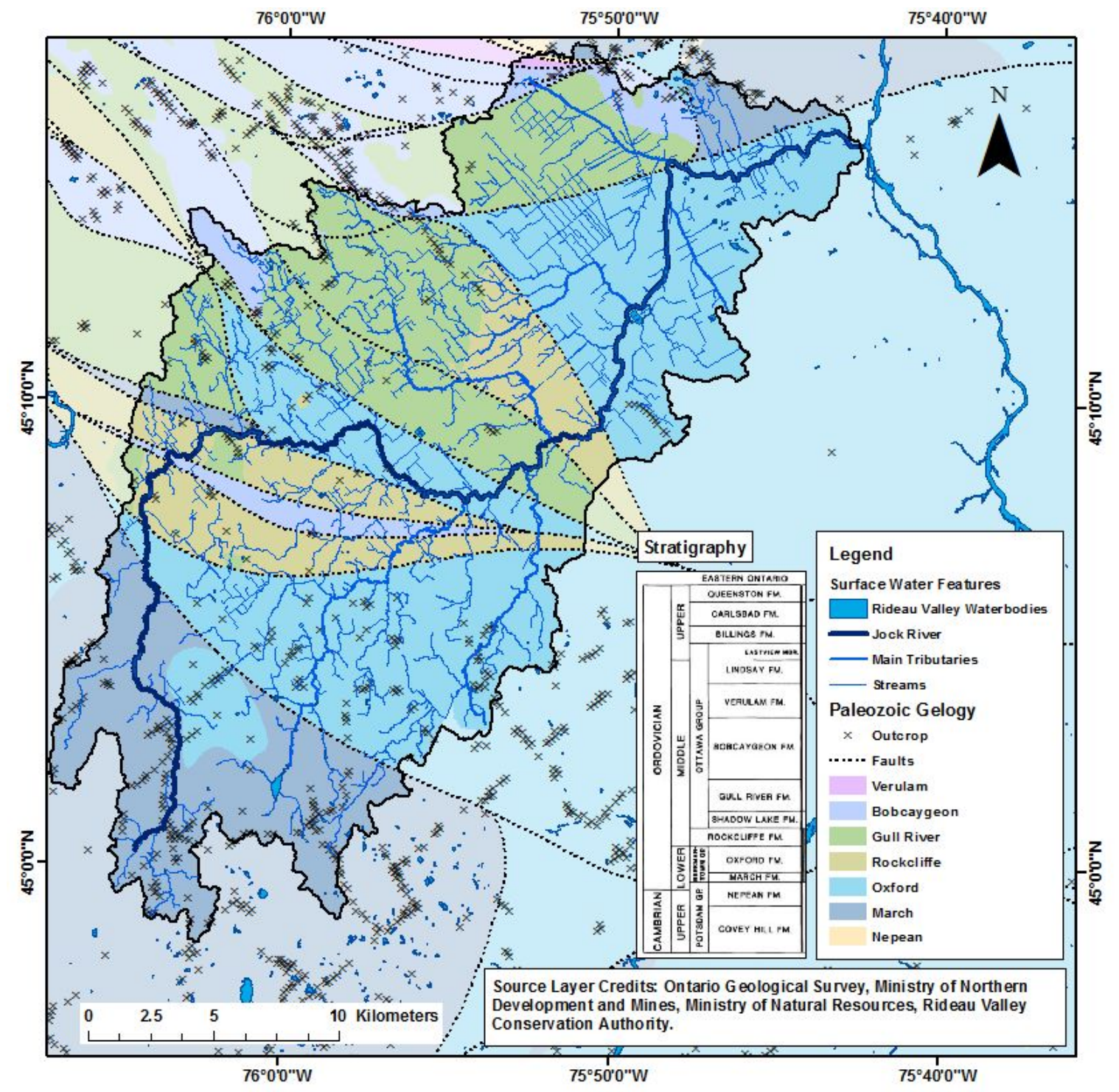

Figure 3-7. Paleozoic Geology of the Jock River subwatershed with inset showing the stratigraphy of Paleozoic rocks of Eastern Ontario (Derry et al., 1989).

Paleozoic geology data source: Ontario Geological Survey. (2010). Surficial Geology of Southern Ontario [GIS data set]. Retrieved from http://www.geologyontario.mndmf.gov.on.ca

Rideau Valley waterbodies data source: Ontario Ministry of Natural Resources. (2011). Water Feature Area [GIS Data Set]. Retrieved from https://www.javacoeapp.lrc.gov.on.ca/geonetwork/srv/en/main.home. Streams data source: Rideau Valley Conservation Authority (2017). Jock River Watercourse [GIS Data Set]. Retrieved from Rideau Valley Conservation Authority. 


\subsubsection{Topography}

The topography of this area is gently sloping. Topographic highs in the headwater region are 164 meters above sea level (masl) which declines to a low of 72 masl near the outlet. Figure 3-8 is a digital elevation model (DEM) at $5 \mathrm{~m}$ resolution. Data was acquired through the Rideau Valley Conservation Authority (RVCA), as the City of Ottawa's LiDAR DEM only extends to the City boundary. The DEM is a mosaic of a $1 \mathrm{~m}$ LiDAR DEM and a $2 \mathrm{~m}$ DEM produced from DRAPE imagery by RVCA staff. To increase processing time on watershed delineations the $2 \mathrm{~m}$ resolution DEM was then converted to a $5 \mathrm{~m}$ integer DEM, as seen in figure 3-8. Contour lines at $10 \mathrm{~m}$ intervals were then created to help illustrate topographic gradients. The inset map in figure 3-8 demonstrates the drift thickness in the region in meters. Figure 3-8 illustrates that the area with the greatest drift thickness which is predominantly clay, silt as discussed in section 3.1.2.1, is the topographically lowest and flattest portion of the watershed. The steepest topographic area is in the northern portion where the esker is located. The topography is most dynamic in the middle of the watershed which is dominated by medium to coarse grained glacial deposits and contains an abundance of faults, as seen in figures 3-6 and 3-7. 


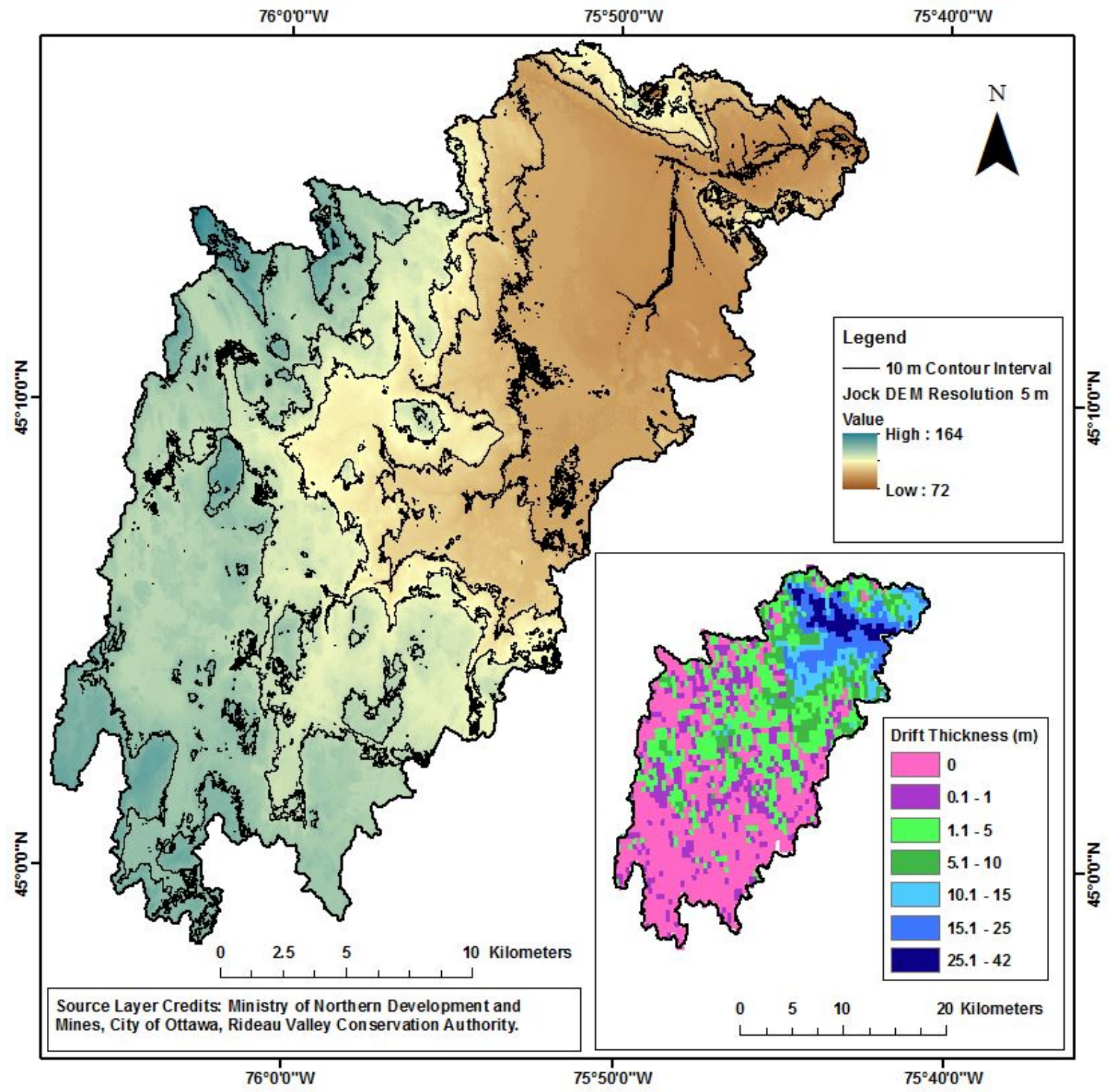

Figure 3-8. Topography of the Jock watershed with inset map illustrating drift thickness. DEM data source: Rideau Valley Conservation Authority. (2016). [GIS data set]. Unpublished data. Drift thickness data source: Ontario Geological Survey. (2010). Bedrock topography and overburden thickness mapping, southern Ontario [GIS data set]. Retrieved from http://www.mndm.gov.on.ca 


\subsubsection{Hydrogeology}

The main overburden aquifer in this area is the basal gravel aquifer (described in section 3.1.2.1). Flow in this aquifer is controlled by flow in a porous media (Velderman, 1993). The basal gravel aquifer is overlain by either compact till or massive marine clay and silt deposits. The clay/silt deposit in the eastern portion of the study area forms an aquitard which creates artesian confined conditions in this area (Velderman, 1993). Till outcrop areas occur mainly in the western portion of the watershed and are covered by marshes and wetlands (Velderman, 1993). The Provincial Groundwater Monitoring Network (PGMN) well W156-2 may access this aquifer as the well record (see Appendix $B$ ) indicates it is completed in a gravel and boulder layer 25 meters below ground surface (mbgs). The gravel and boulder layer is covered by a thick layer of bluish gray-gray clay and overlies the fractured dolostone of the Oxford Formation. An unconfined overburden aquifer exists near the outlet of the Jock River resulting from the esker complex and glaciofluvial till deposits in this region. W156-2 may access also access the esker as it is located close to the well. Due to similarities in the materials of these depositions, it is difficult to determine which aquifer is represented at W156-2 based solely on the well records. Conversely, PGMN well W085 is most likely representative of water in the unconfined overburden aquifer, as its close to the outlet and its well record indicates it is completed 15 mbgs in glacial till characterized by fine sand with cobbles and boulders.

The Oxford, March and Nepean formations are identified as the best producing bedrock aquifers for the Jock watershed (Williams, 1991). Flow in these formations is controlled by fracture flow, which is enhanced by the dissolution of the carbonate rocks (Velderman, 1993). Large parts of the aquifer flow under confined conditions and in 
some parts artesian conditions have been observed (Velderman, 1993). Artesian and flowing wells, are present in and around the village of Richmond. PGMN well W156-3 and domestic well GW_DW_2 are believed to represent water from the Oxford Formation. The well record for W156-3 specifies that the greyish dark dolostone here is part of the Oxford Formation, while a nearby well records for GW_DW_2 demonstrate similar stratigraphy to that of W156-3 (see Appendix B).

Other sequences in the Ottawa Group are considered to be poor to variable water producers, as these sections are characterized by massive limestone in which fractures are not extensive (Velderman, 1993). PGMN wells W175-2, W175-3 and W084 are described as dolostone, limestone, shale and sandstone and are characterized as belonging to the Gull River Formation (see Appendix B). The groundwater from domestic well GW_DW_1 is from grey limestone. The exact well record for this well could not be identified and does not go into as much detail as the PGMN well logs therefore it is unknown if this well is completed in the Gull River Formation or another formation.

\subsubsection{Land Use and Land Cover}

The land use and land cover of the region is shown in figure 3-9 and provided in more detail in table 4-11. Land use and land cover in this area can be distilled into two categories increased anthropogenic land use near the outlet and natural features in the headwaters. The area near the outlet is dominated by cropland and settlement area. Much of the region is primarily agricultural; cropland is a major land use type in all the main tributary watersheds except for Nichols Creek. The dominance of this land cover type is seen in figure 3-9 where we see that the middle of the watershed is mainly cropland, especially in the region where clay, silt is the dominant surficial geologic material. 
Natural areas such as forest and forest wetland typify the headwaters region. Forest is the second most dominant land cover type and is significantly present in all main tributary watersheds except for Monahan Drain. 


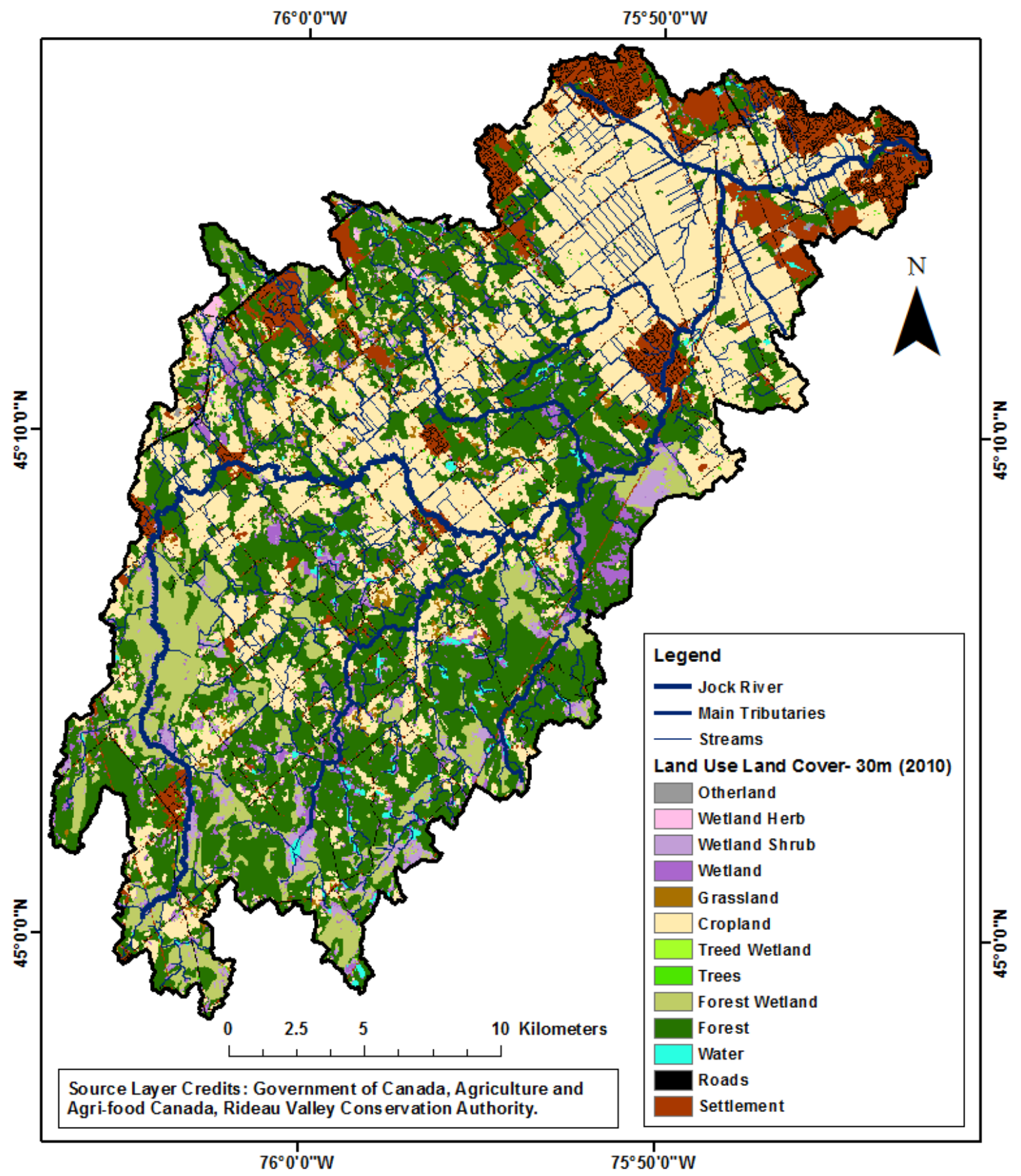

Figure 3-9. Land use and land cover classification from 2010 for the Jock watershed. Land use land cover data source: Government of Canada; Agriculture and Agri-Food Canada. (2015). Land Use 1990, 2000 \& 2010 [GIS data set]. Retrieved from http://www.agr.gc.ca Streams data source: Rideau Valley Conservation Authority (2017). Jock River Watercourse [GIS Data Set]. Retrieved from Rideau Valley Conservation Authority. 


\subsection{Field Methods}

\subsubsection{Precipitation Sample Collection}

Snow meltwater samples were collected using snow melt lysimeters constructed from PVC piping, vinyl tubing and a large collection container. Three PVC pipes were cut in half and inserted at the base of the snow pack. The PVC pipes then drained gravitationally through the vinyl tubing into one large collection container covered in white plastic to minimize radiative effects, see figure 3-11. Snow melt lysimeters were installed between March 5 to 12, 2015 at four sites located across the watershed, see figure 3-10. Samples were collected regularly during the snow melt period, following potential melt days.

Rainfall was collected from a rain gauge as soon as possible following large storm events. If events were small and infrequent precipitation was collected when the volume was sufficient to supply the isotopic and geochemical analysis. The precipitation gauge was located outside catchment boundaries in a central location to allow for more frequent sampling and minimize fractionation due to evaporation between rain events and sample collection, see figure 3-10. The precipitation gauge was also vented to reduce potential fractionation due to evaporation.

All precipitation (including snow melt) samples were collected for geochemical analysis in $250 \mathrm{ml}$ HDPE bottles and $20 \mathrm{ml}$ scintillation vials for isotopic analysis.

Precipitation sample $\mathrm{pH}$ and specific conductivity $(\mathrm{SpC})$ in Microsiemens per centimeter $(\mu \mathrm{S} / \mathrm{cm})$ were measured in the lab following collection on a $V W R \circledR$ Symphony benchtop meter. Snow meltwater samples were frozen until alkalinity, silica and isotopic analysis 
could be performed. ${ }^{1}$ Rain samples were refrigerated $\left(\sim 4^{\circ} \mathrm{C}\right)$ until alkalinity, silica and isotopic analysis could be performed.

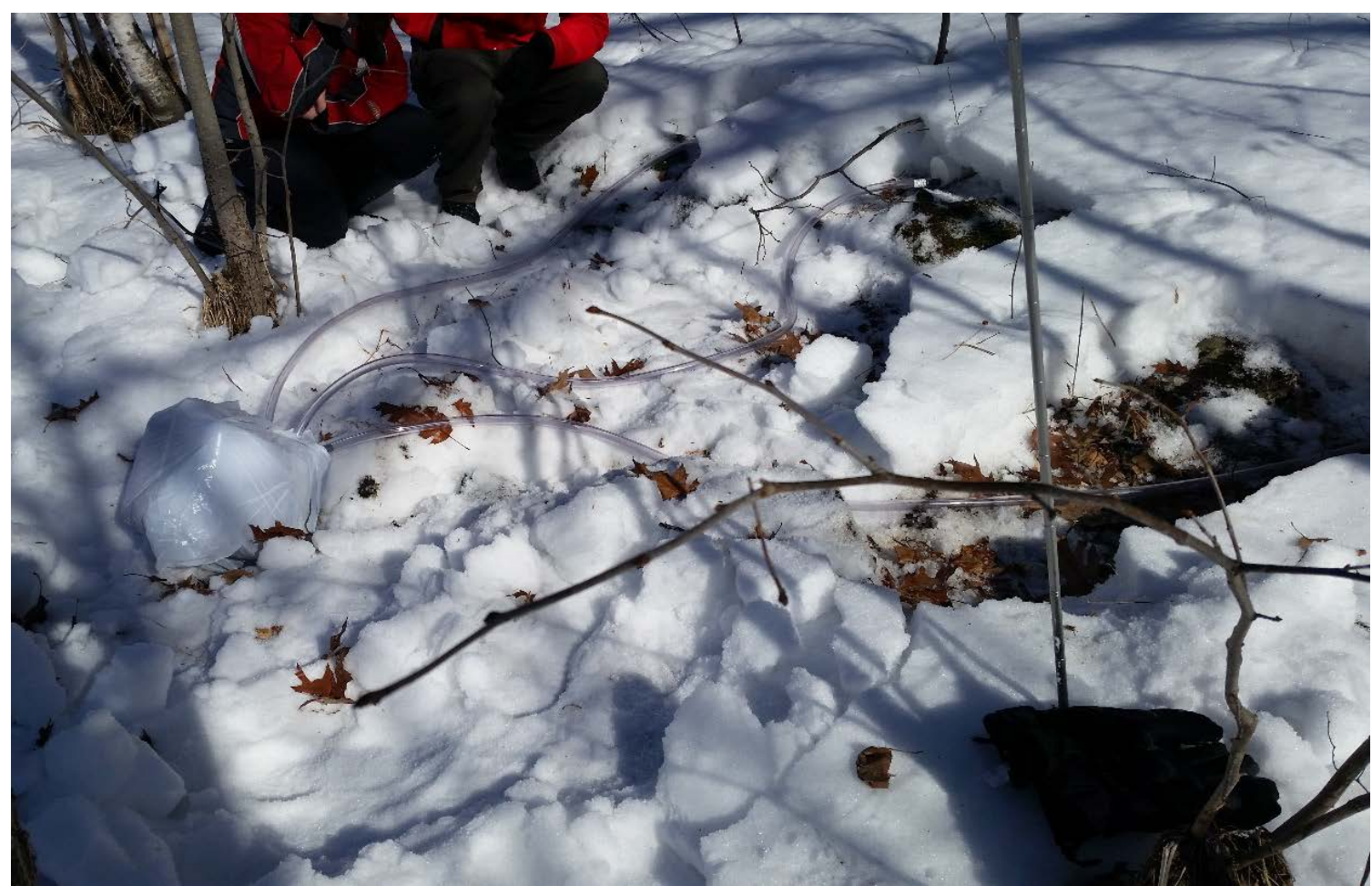

Figure 3-10. Snow melt lysimeter installation at Heart's Desire March 12, 2015. Three halved PVC pipes are inserted at the base of the snow pack. Vinyl tubes drain snow meltwater into one collection jug downslope. Dug out sections were back filled after installation. Water samples were collected from the jug after/during potential melt days in April.

\subsubsection{Surface Water Sample Collection}

Two parallel sampling efforts were conducted in this study, one to address temporal variability at a small number of locations along the mainstem and tributaries of the Jock River, and one to address spatial variability through a synoptic survey of headwater streams. Surface water samples were collected at regular intervals (weekly to bi-weekly) from 3 points along the Jock River and near the outlet of the main tributaries. Samples were collected from May to November 2015, with some supplemental sampling in the

\footnotetext{
${ }^{1}$ Snow melt samples were frozen due to mix up between lab fridge and freezer in the initial stages of sample collection.
} 
summer of 2016. A total of 104 samples were collected from the Jock River and its tributaries during the 2015 growing season, and an additional 60 were collected between June 17 and July 21 of 2016. Surface water samples from headwater streams were collected through two synoptic surveys (spring and summer 2015) by RVCA aquatics staff as part of their ecological analysis of headwater drainage features (HWDF) in the Jock watershed. During the spring survey (April 2 -12, 2015) 123 samples were collected. During the summer survey (July 15 - August 4,2015) 91 samples were collected, see figure 3-10 for locations.

All surface water samples collected were collected following the same methodology as precipitation sample collection. Geochemistry sample bottles were rinsed three times with deionized water in the lab prior to field sampling. Both geochemistry and isotopic samples were rinsed three times in the field with sample water prior to collection. Samples were then stored in a cooler with freezer packs until they could be transferred to fridge storage. Geochemical analysis of alkalinity and silica was conducted within 24 hours, if time permitted. Field variables temperature, $\mathrm{pH}, \mathrm{SpC}$ and dissolved oxygen (DO) were collected using a YSI® professional series sonde calibrated at the beginning of each field day. Samples were filtered with a $0.45 \mu \mathrm{m}$ PVDF syringe filter in the lab prior to all geochemical analysis. 


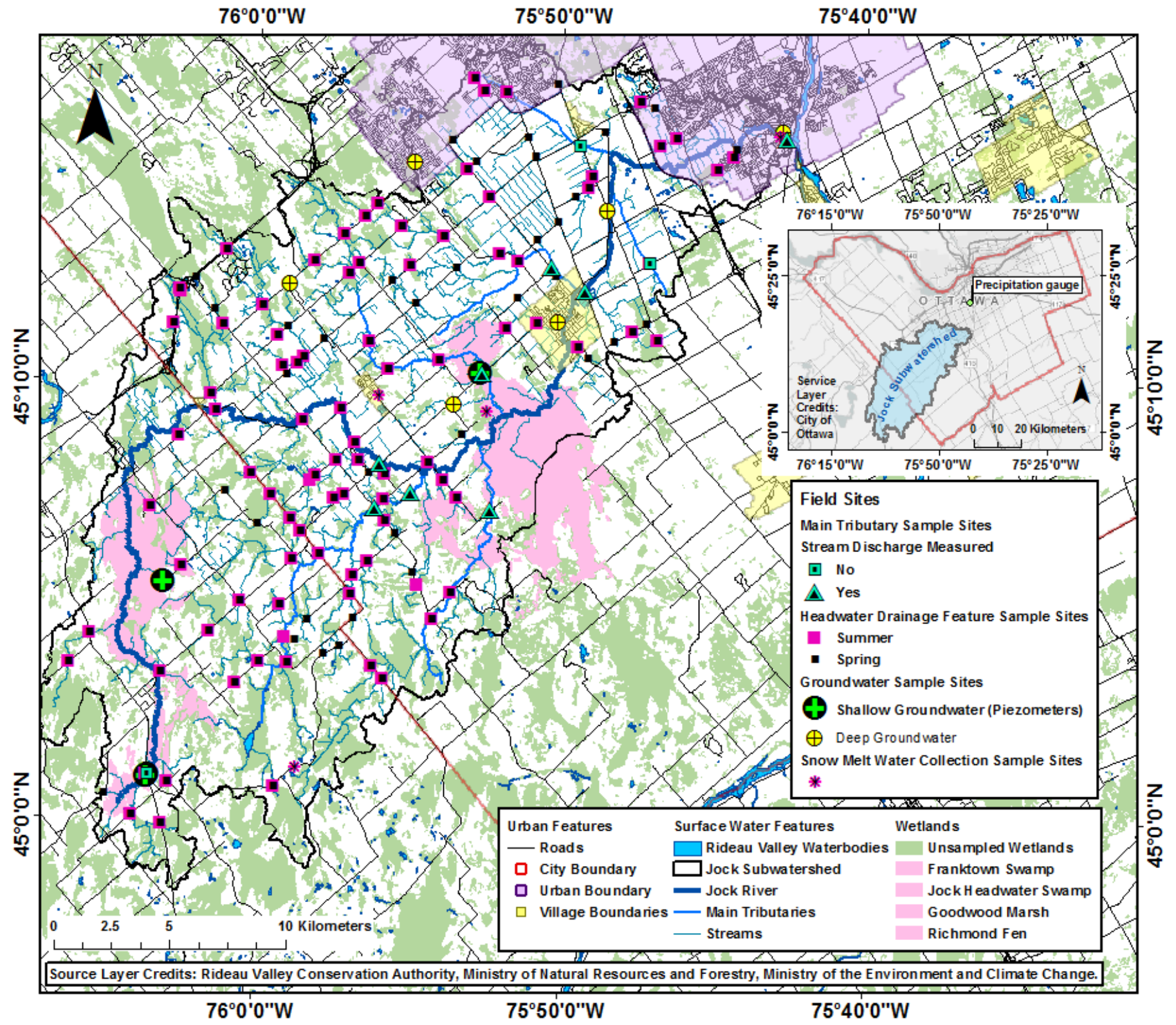

Figure 3-11.

Field Sites in

the Jock River

watershed.

Locations

provided: end-

members

(groundwater,

piezometer,

precipitation

and snowmelt);

main tributary

sample sites;

headwater sites

(sampled by

RVCA aquatics

staff in the

spring and

summer of

2015). Wetlands

where a

piezometer was

installed have

been colour

coded light pink

z to illustrate the

potential

s contributing

area of the end-

member. 


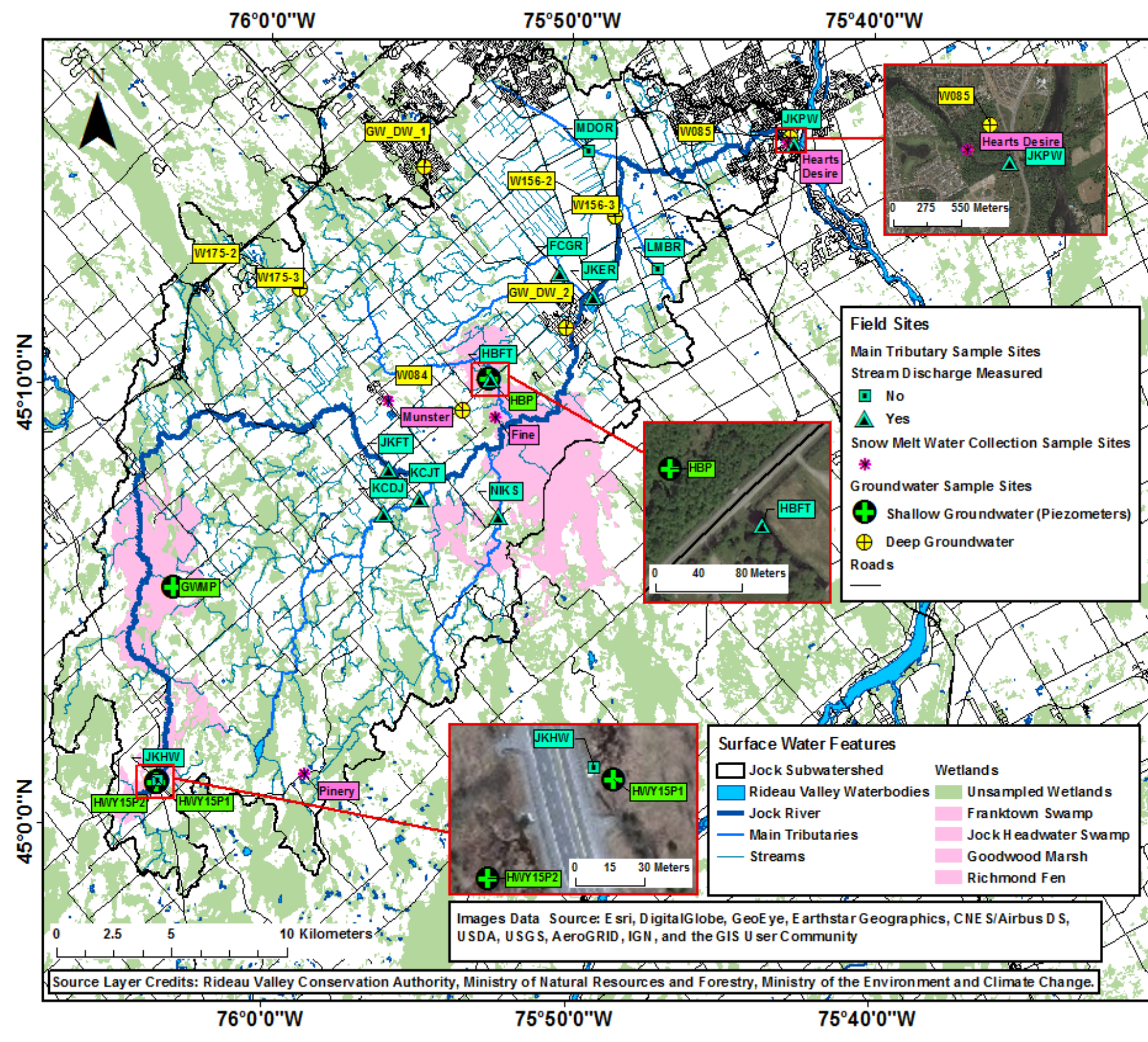

Figure 3-12.

Field sites in

the Jock River

watershed,

locations of the

main tributaries

and sites along

the Jock River

where

hydrometric

and

$\mathbf{z}$ geochemical

sampling

io occurred are

${ }^{\circ}$ indicated in

teal, site code

names are also

provided.

Piezometer,

deep

groundwater

wells and snow

melt collection

sites and code

names are also

provided. Inset

maps illustrate

areas with

भ multiple sample

sites in greater

detail 


\subsubsection{Groundwater Sample Collection}

\subsubsection{Deep Groundwater}

Groundwater sampling was conducted on two domestic wells that were not attached to softeners and on four PGMN wells. Domestic wells were sampled 2-3 times over the course of the 2015 growing season. PGMN wells were sampled once in the summer, due to cost and time required to routinely sample monitoring wells. PGMN wells were purged three well volumes, using manual foot valves. Groundwater field variables (temperature, $\mathrm{pH}, \mathrm{SpC}$ and $\mathrm{DO}$ ) were recorded at regular intervals and checked to ensure stabilization of field variables before sample collection. Water well records could not be found for the domestic wells. Since the exact well volume was unknown, water was purged until field variables stabilized. Samples were filtered in the field with a $0.45 \mu \mathrm{m}$ PVDF syringe filter and analyzed for alkalinity and silica content in the field. Additional filtered samples were collected for isotopic and supplemental geochemical analysis. Samples were stored in a cooler with freezer packs until transferred to fridge storage.

\subsubsection{Shallow Groundwater}

Four Solonist ${ }^{\circledR}$ shielded drive point piezometers were installed in wetlands in the upper portion of the watershed. Due to the thin soil cover in these regions it was difficult to install the piezometers deep in the soil. This combined with dry conditions meant that in many cases piezometers needed to be relocated to areas with deeper and wetter soil horizons to obtain the necessary sample volume for geochemical and isotopic analysis. The final location of the piezometers can be seen in figure 3-10. Samples were collected sporadically due to shipment issues, thin/dry soil conditions, relocation of piezometers 
and other technical issues. During the 2015 growing season, only 7 piezometer samples were collected. Due to issues described above and the small number of samples collected, supplemental samples were collected in the summer of 2016 from June $17^{\text {th }}$ to July $21^{\text {st }}$ to determine some variability in geochemical and isotopic values of samples collected in 2015. During the summer of 2016 a total of 21 piezometer samples were collected.

Samples were collected using a peristaltic pump, initial purging of sample well volume was conducted but long recovery times limited the ability to purge and collect samples in a timely fashion while conducting subsequent field work. Therefore, piezometers were not purged before sample collection. Samples were stored in a cooler with freezer packs until transferred to fridge storage. Piezometer samples $\mathrm{pH}$ and $\mathrm{SpC}$ $(\mu \mathrm{S} / \mathrm{cm})$ were measured in the lab following collection on a $V W R \circledR$ symphony benchtop meter. Samples were stored in the fridge until further geochemical and isotopic analysis could be conducted.

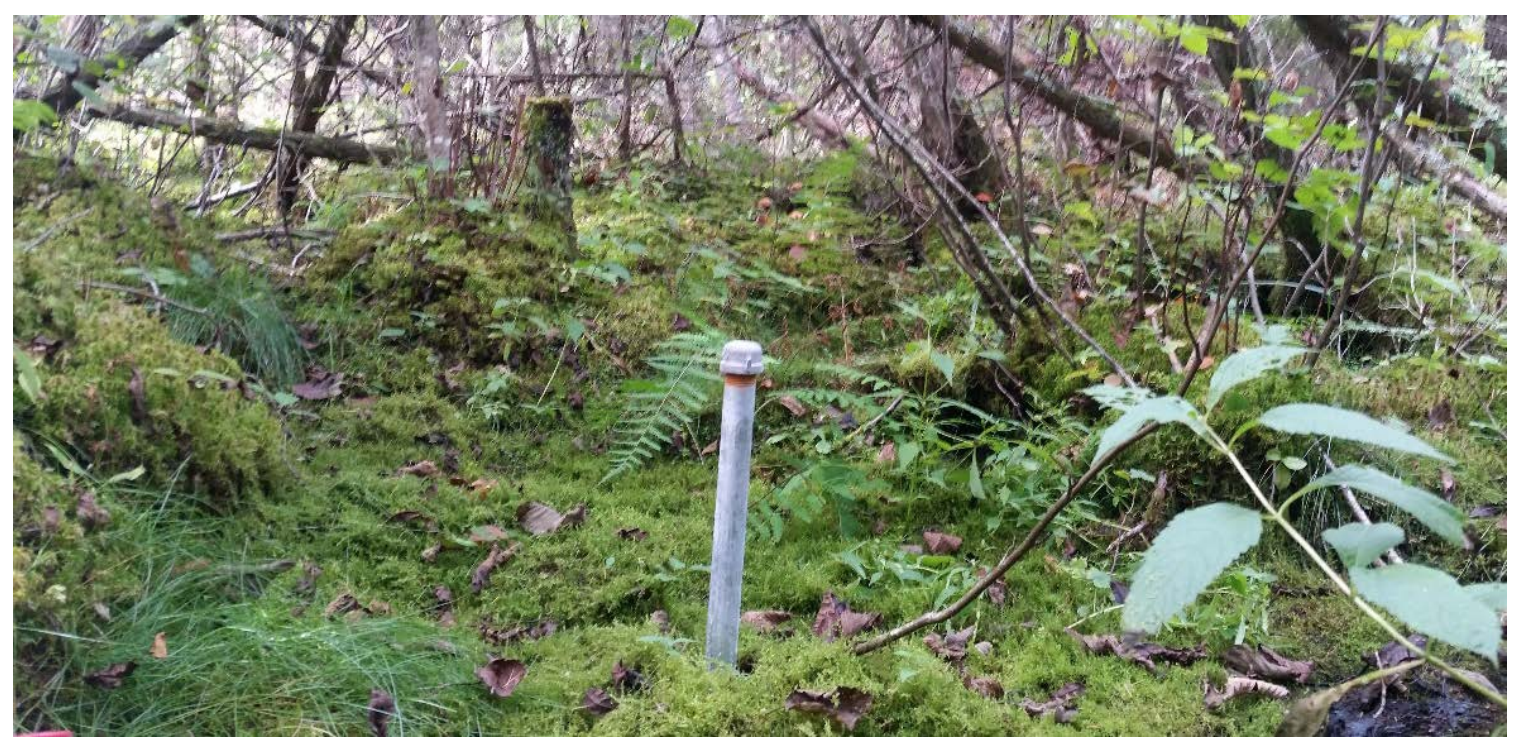

Figure 3-13. Shallow groundwater piezometers installed at Goodwood Marsh on July 17, 2015. Piezometer depth: $1.3 \mathrm{~m}$, protruding: $0.3 \mathrm{~m}$, this is the only piezometer that was not moved after initial installation. 


\subsubsection{Hydrometric Measurements}

Discharge was measured at several of the main tributaries at regular intervals (weekly to bi-weekly), see figure 3-10 for discharge sites. Stream flow was not measured at Monahan Drain and Leamy Creek as both sites were extremely clogged with algae and vegetation. It was determined that flow measurements using the SonTek ${ }^{\circledR}$ FlowTracker ${ }^{\circledR}$ Handheld $A D V \circledR$ (Acoustic Doppler Velocimeter) would not be optimal at these locations due to vegetation/algae interferences and deep clay beds. A stilling well equipped with an Onset ${ }^{\circledR} H O B O$ ware ${ }^{\circledR}$ data logger was installed at Monahan Drain to measure changes in stage during the study period.

Semi-permanent stream cross sections were installed at all other sites by insertion of rebar along the stream banks. The velocity area method was used to determine discharge across stream sections. Each cross section consisted of at least 20 or more stations at which individual discharge measurements were taken. The total discharge and uncertainty for the cross section was calculated by the FlowTracker ${ }^{\circledR}$ Handheld $A D V ®$. The uncertainty percentages were evaluated to ensure that uncertainty was lower than $10 \%$. Discharge files were downloaded from the FlowTracker ${ }^{\circledR}$ Handheld $A D V 囚$ at the end of each field day and saved for post processing. The final discharge values used in the development of seasonal rating curves are given in Appendix C. Three discharge measurements were omitted from the beginning of the season (May 28 to June 16, 2015) from several sites, due to technician error in the measurement process. As these measurements underestimated the total flow they were omitted from the development of the seasonal rating curve. Other data points at sites Nichols Creek and Kings Creek were omitted due to beaver dam construction, which caused significant backwater issues. 
Beaver dams were a significant issue at Kings Creek, the data logger and cross section was relocated further upstream late in the season. However, the cross section was moved too late and not enough data points were collected for an accurate rating curve to be developed for this tributary.

Several baseflow synoptic surveys were conducted following the method proposed by Hinton (2005) in which low-flow/baseflow measurements are conducted on main tributaries across the watershed in a one day synoptic survey. Low-flow synoptic surveys began July $6^{\text {th }}$ and continued until September $24^{\text {th }}$. During that period 6 out of 12 hydrometric measurements were completed over the course of one field day, beginning at the outlet and progressing towards the headwaters, see table A-0-1 in Appendix A, for dates. These synoptic surveys provide a series of snapshots of baseflow conditions across the watershed over time. They also provide quantitative measurements of geographic areas contributing to low-flow generation across the watershed over time. 


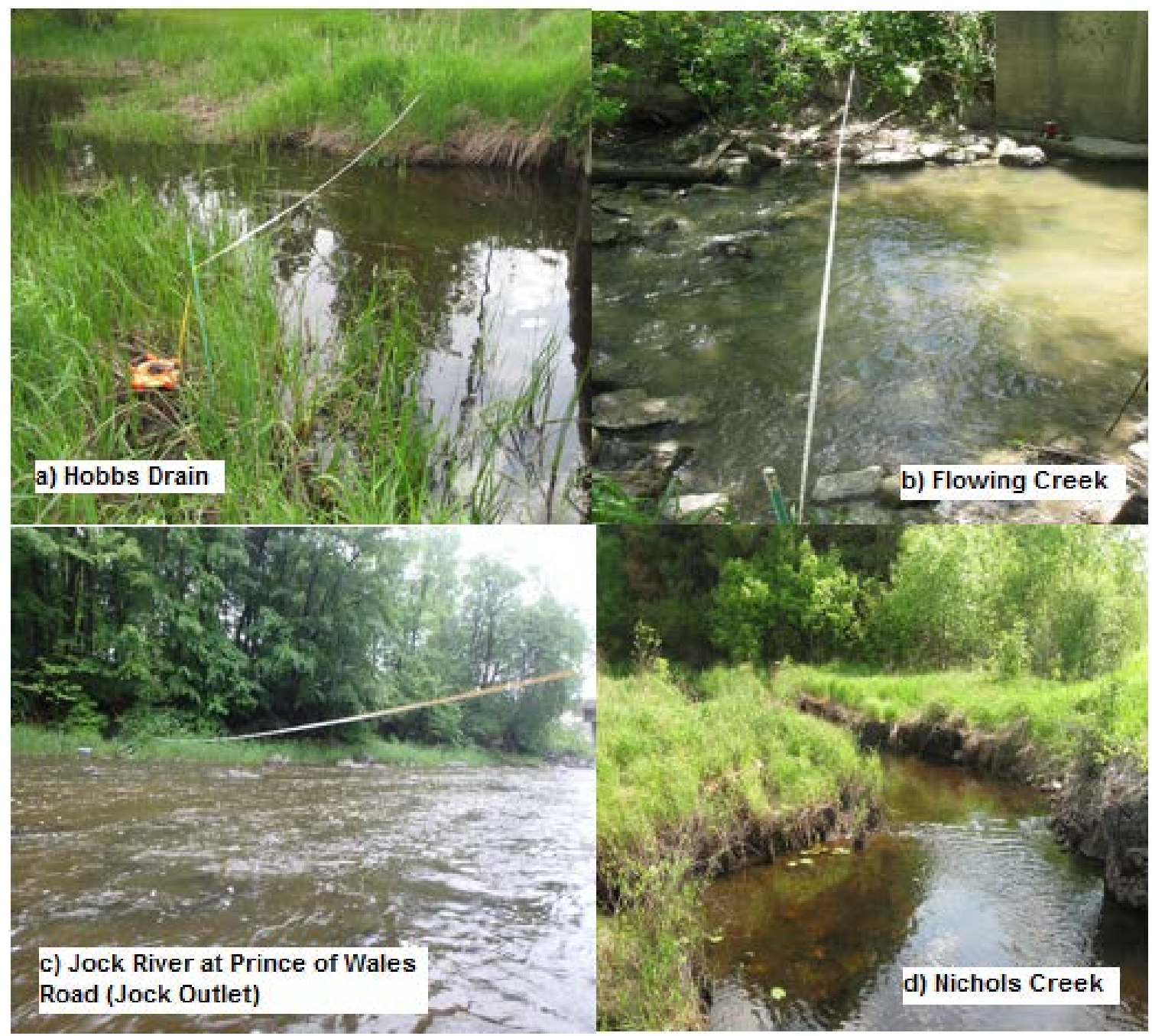

Figure 3-14. Example of temporary cross section installations using rebar at four sites in the Jock watershed: a) Hobbs Drain, b) Flowing Creek, c) Jock River at Prince of Wales Road (Jock Outlet) and d) Nichols Creek.

\subsection{Laboratory Analysis}

\subsubsection{Tracer Analysis}

Geochemical tracers alkalinity and silica were analysed in the field for groundwater samples and at the Water and Ice Research Laboratory (WIRL) at Carleton University for all other samples. Many studies have utilized alkalinity and/or silica as conservative tracers in groundwater and surface water interaction studies (Hooper and Shoemaker, 1986; Rice and Hornberger, 1998; Uhlenbrook and Hoeg, 2003; Rodgers et 
al., 2004; Soulsby et al., 2004; James and Roulet, 2006; McGrane et al., 2014). Other end-member mixing analysis studies (EMMA) have used alkalinity and/or silica in combination with other major ions (Hooper et al., 1998; Burns et al., 2001; James and Roulet, 2006). In this study, only a subset of the data was analyzed for major ions, due to the cost of analysis. Summer HWDF samples, a selection of surface water samples from the main tributaries, groundwater samples, piezometer samples and a selection of precipitation (both snowmelt and rain water) were sent for major ion analysis. Samples sent for analysis were filtered after collection using a $0.45 \mu \mathrm{m}$ PVDF syringe filter. The filtered samples were stored in $50 \mathrm{ml}$ falcon tubes in the fridge until they could be sent for major ions analysis by SGS Environmental. Samples were not preserved before storage therefore it is unknown whether biological activity may have impacted the results. Isotopic analysis was also conducted on all samples collected see Appendix $A$ for detailed isotopic analysis methodology.

\subsubsection{Dissolved Silica}

Dissolved silica $\left(\mathrm{SiO}_{2}\right)$ occurs due to the chemical weathering of siliceous minerals. Weathering of siliceous minerals, releases cations and silica to form an array of more stable aluminosilicate clay minerals (Clarke, 2015). The chemical weathering of silicate minerals occurs through hydrolysis, this process relies on the addition of acid from the soil and atmosphere as the product clays are hydrated with hydroxyl ions, see figure 3-14 for example dissociation (Uhlenbrook and Hoeg, 2003; Clarke, 2015). The dissolution of silica is therefore enhanced under higher temperature and lower $\mathrm{pH}$ conditions (Uhlenbrook and Hoeg, 2003). However, the weathering of siliceous minerals is much slower than that of carbonate minerals (Clarke, 2015). Thermodynamic 
equilibrium is rarely reached and the dissolution of silica will occur continuously in the soil (Uhlenbrook and Hoeg, 2003; Clarke, 2015). The residence time of water with siliceous minerals is then an important factor in the final concentration of dissolved silica (Uhlenbrook and Hoeg, 2003). It should also be noted that dissolved silica is a biologically active chemical used by diatoms, as such analysis must be undertaken to ensure that it behaves conservatively in order to be used in EMMA (Hooper and Shoemaker, 1986).

$$
\begin{aligned}
& \mathrm{NaAlSi}_{3} \mathrm{O}_{8} \text { albite }+4.5 \mathrm{H}_{2} \mathrm{O}+\mathrm{H}_{2} \mathrm{CO}_{3} \rightarrow \mathrm{Na}^{+}+ \mathrm{HCO}_{3}^{-}+1 / 2 \mathrm{Al}_{2} \mathrm{Si}_{2} \mathrm{O}_{5}(\mathrm{OH})_{4 \text { kaolinite }} \\
&+2 \mathrm{H}_{4} \mathrm{SiO}_{4}^{\circ} \\
& \mathrm{CaAl}_{2} \mathrm{Si}_{2} \mathrm{O}_{8 \text { anorthite }}+\mathrm{H}_{2} \mathrm{O}+2 \mathrm{H}_{2} \mathrm{CO}_{3} \rightarrow \mathrm{Ca}^{2+}+2 \mathrm{HCO}_{3}^{-}+\mathrm{Al}_{2} \mathrm{Si}_{2} \mathrm{O}_{5}(\mathrm{OH})_{4} \text { kaolinite }
\end{aligned}
$$

Figure 3-15. Stoichiometry of the hydrolysis of silicate minerals (albite and anorthite) to form kaolinite (Clarke, 2015).

The standard method of analysis of dissolved silica is the photometric determination of molybdate reactive silica in water (ASTM International, 2010). A Hach ${ }^{\circledR} \mathrm{DR} / 890$ Colorimeter was used to determine the dissolved silica content of all samples. Surface water, groundwater and shallow groundwater (piezometer) samples were analyzed using the high range $(1-75.0 \mathrm{mg} / \mathrm{L})$ silicomolybdate method. Precipitation samples (snow melt and rain water) were analyzed using the low range $(0-1.60 \mathrm{mg} / \mathrm{L})$ heteropoly blue method. Most samples were stored in the fridge until analysis, except for a selection of snow melt samples as discussed in section 3.2.1 and those measured in the field. Samples were brought to room temperature before analysis was conducted. Samples were filtered using a $0.45 \mu \mathrm{m}$ PVDF syringe filter. In the silicomolybdate method silica and phosphate in the sample reacts with the molybdate ion under acidic conditions to form yellow silicomolybdate and phosphomolybdate acid complexes (Hach Company, 2013a). The addition of citric acid eliminates the phosphate complexes and 
silica is then determined by measuring the remaining yellow colour (Hach Company, 2013a). The precision of this method of measurement on this device is $\pm 1.0 \mathrm{mg} / \mathrm{L}$, with a detection limit of $1.00 \mathrm{mg} / \mathrm{L} \mathrm{SiO}_{2}$. Sequential replicate samples were collected from surface water on the main tributaries during the summer of 2016. The absolute differences of 18 samples had an average of $0.6 \mathrm{mg} / \mathrm{L}$, a standard deviation of $0.8 \mathrm{mg} / \mathrm{L}$ and a range of 0 to $3.6 \mathrm{mg} / \mathrm{L}$.

The heteropoly blue method used for precipitation samples is similar to the previous method as silica and phosphate react with the molybdate ion under acidic conditions to form yellow silicomolybdic and phosphomolydic acid complexes (Hach Company, 2013b). The acid then reduces the yellow silicomolybdic acid to an intense blue colour proportional to its silica concentration (Hach Company, 2013b). The precision of this method of measurement on this device is $\pm 0.025 \mathrm{mg} / \mathrm{L}$, with a detection limit of $0.020 \mathrm{mg} / \mathrm{L}$. For more detailed step by step procedural methodology please refer to the $H a c h \circledR$ technical documentation. The test procedure and reagents were validated using the standard additions method outlined in the $H a c h \circledR$ technical documentation.

\subsubsection{Alkalinity}

Alkalinity is the acid neutralizing capacity of solutes in a water sample, and consists of the sum of titratable carbonates and non-carbonates in a filtered water sample (U.S. Geological Survey, 2012). Alkalinity is usually expressed as the difference between two components the acid buffers (bicarbonate, carbonate and hydroxide ions) and the hydrogen ion concentration (Neal, 2001). Organic anions such as humates and fulvates can also act as buffers under acidic conditions (Neal, 2001). In circumneutral to alkaline systems (pH 6-10), alkalinity is considered to be mostly bicarbonate (Neal, 2001). It is 
therefore acceptable in these systems to undertake acidimetric titration to a single end point, which for bicarbonate species is approximately pH 4.5 (Neal, 2001). In bicarbonate bearing waters in which the alkalinity $>200 \mu \mathrm{Eql}^{-1}$ and the $\mathrm{pH}<10$, the hydrogen ion and hydroxyl ion concentration is insignificant compared to the bicarbonate (Neal, 2001).

Carbonate rocks such as limestone and dolostone compose only $0.1 \%$ of the lithosphere, yet due to their high rate of weathering they can have a dominant effect in watershed geochemistry (Clarke, 2015). Figure 3-15, shows the dissociation of limestone and dolostone into $\mathrm{Ca}^{2+}, \mathrm{Mg}^{2+}$ and bicarbonate $\left(\mathrm{HCO}_{3}^{-}\right)$by carbonic acid $\left(\mathrm{H}_{2} \mathrm{CO}_{3}\right)$. The extent of the dissolution is a function of the $\mathrm{CO}_{2}$ in the soil and atmosphere as this creates the weak carbonic acid (Clarke, 2015). Under open system conditions dissolution of carbonate minerals will proceed until calcite saturation as the partial pressure of $\mathrm{CO}_{2}$ in the soil is continually replenished by the atmosphere (Clarke, 2015). Thermodynamic equilibrium is not reached under closed system conditions, due to limited $\mathrm{CO}_{2}(\mathrm{Clarke}$, 2015). Under open system conditions the amount of carbonate dissolved is controlled by the partial pressure of the soil $\mathrm{CO}_{2}$, so the concentration of $\mathrm{Ca}^{2+}$, dissolved inorganic carbon species and $\mathrm{pH}$ can be determined (Clarke, 2015).

$$
\begin{aligned}
& \mathrm{CaCO}_{3}+\mathrm{H}_{2} \mathrm{CO}_{3} \rightarrow \mathrm{Ca}^{2+}+2 \mathrm{HCO}_{3}^{-} \\
& \mathrm{CaMg}\left(\mathrm{CO}_{3}\right)_{2}+2 \mathrm{H}_{2} \mathrm{CO}_{3} \rightarrow \mathrm{Ca}^{2+}+\mathrm{Mg}^{2+}+4 \mathrm{HCO}_{3}^{-}
\end{aligned}
$$

Figure 3-16. Stoichiometry of the dissociation of carbonate species limestone ( $\mathrm{CaCO}_{3}$ ) and dolostone $\left(\mathrm{CaMg}\left(\mathrm{CO}_{3}\right)_{2}\right)$ by the weathering by carbonic acid $\left(\mathrm{H}_{2} \mathrm{CO}_{3}\right)$.

Alkalinity was determined through acidimetric titration using the $\operatorname{Hach}{ }^{\circledR}$ Digital Titrator. Samples were stored in the fridge until analysis could be completed, and the freezer for a selection of snow melt samples as discussed in section 3.2.1. Analysis was completed within 24 hours of sample collection, unless otherwise stated. Samples were 
brought to room temperature before analysis was conducted. Samples were filtered using a $0.45 \mu \mathrm{m}$ PVDF syringe filter. For groundwater, surface water and piezometric samples a sulfuric acid with a normality of $1.6 \mathrm{~N} \pm 0.5 \%$ was used in the titration. A sample volume of $100 \mathrm{ml}$ was used, when possible, as per the recommendation in the $\mathrm{Hach}{ }^{\circledR}$ technical procedure for samples with an alkalinity concentration between $100-400 \mathrm{mg} / \mathrm{L}$ as $\mathrm{CaCO}_{3}$. Smaller sample volumes were used for piezometric samples as less sample was collected in the field due to dry conditions or shallow soil depth. Phenolphthalein indicator powder was added to samples with a $\mathrm{pH}>8.3$, if colour changed to pink then the sample was titrated with the digital titrator to an end point of $\mathrm{pH} 8.3$ (Hach Company, 2015). If sample $\mathrm{pH}$ was $<8.3$, bromcresol green-methyl red indicator was added and was titrated until the sample colour changed to pink and a pH end point of $4.3-4.9$ was reached (Hach Company, 2015). The $\mathrm{pH}$ was checked with a $V W R \circledR$ symphony benchtop meter. The Hach ${ }^{\circledR}$ Digital Titrator has a precision of \pm 1 digit, which equates to \pm 1 $\mathrm{mg} / \mathrm{L} \mathrm{CaCO}_{3}$. Sequential replicate samples were collected from surface water on the main tributaries during the summer of 2016. The absolute differences of 18 replicate samples had an average of $5.37 \mathrm{mg} / \mathrm{L} \mathrm{CaCO}_{3}$, a standard deviation of $3.68 \mathrm{mg} / \mathrm{L} \mathrm{CaCO}_{3}$ and a range of 0-14 mg/ $\mathrm{L} \mathrm{CaCO}_{3}$. Precipitation samples (snow melt and rain water) were titrated using sulfuric acid with a normality of $0.16 \mathrm{~N} \pm 0.5 \%$ and a sample volume of $100 \mathrm{ml}$. The same procedure outlined above was used in the titration of precipitation samples; however, samples were rarely analyzed within 24 hours due to time constraints. For more detailed step by step procedural methodology please refer to the $\operatorname{Hach}{ }^{\circledR}$ technical documentation. The test procedure and reagents were validated using the standard additions method outlined in the Hach ${ }^{\circledR}$ technical documentation. 


\subsection{Data Analysis}

\subsubsection{EMMA}

EMMA was used to identify the sources contributing to stream flow in the Jock River. The applicability of EMMA using a limited set of tracers and a small sample size was investigated. EMMA was chosen over geochemical hydrograph separation to determine the number of end-members and their identity as it allows for less subjectivity in end-member selection and more rigorous methods of evaluating the legitimacy of the end-members selected. This method of analysis addresses our main research objectives which seek to identify the number and identity of end-members contributing to stream flow in the Jock River.

Following the methods proposed in Hooper (2003) the main tributary and headwater sites where projected into the Jock River mixing space, to determine if endmembers remained invariant across scale. The Jock River sites were pooled together to increase the sample size number for principal component analysis (PCA). Pooling the sites together was deemed appropriate as it was determined that the sites along the Jock River were not statistically significantly different from each other (discussed in more detail in section 4.1.2). The mixing space of the Jock River, represents a conceptual model of the end-members contributing to stream chemistry across the watershed at a coarse spatial resolution (three sites: JKFT, JKER, JKPW) and a moderate temporal resolution (sampled 10-11 times over 2015 growing season).

To determine the influence of landscape spatial heterogeneity on streamflow generation, projection of stream water sample sites into the Jock River mixing space was conducted at two different spatial resolutions. The main tributaries of the Jock River 
represent a moderate spatial (6 sites) and moderate temporal resolution (sampled 10-12 times). The headwater sites sampled during the spring and summer represent a low temporal resolution but a fine spatial resolution (91-123 sites). Headwater samples from the summer survey (91 sites) were also projected into the Jock River mixing space. If the end-members identified the Jock River mixing model don't constrain the stream water chemistry of these sites, this indicates that chemical reactions may be occurring which results in non-conservative tracer behaviour or that other end-members are generating streamflow at these sites. The differences in the spatial resolutions of sample sites can be seen in figure 3-16 which demonstrates the spatial divisions of sample sites in the Jock watershed. 


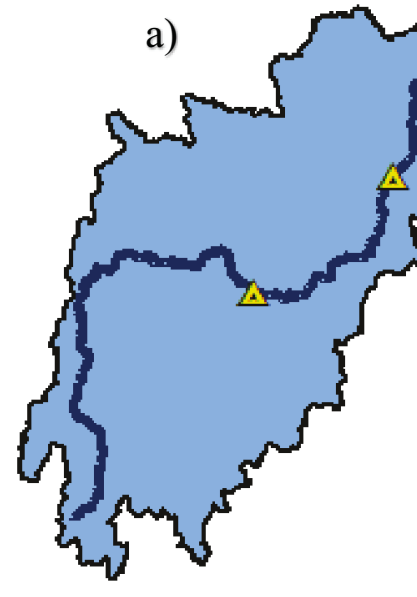

$\triangle$ Jock River Sample sites

- Jock River

$\square$ Jock River Subwatershed

Source Layer Credits: Ontario Ministry of

Natural Resources and

Forestry, Rideau Valley

Conservation Authority. b)

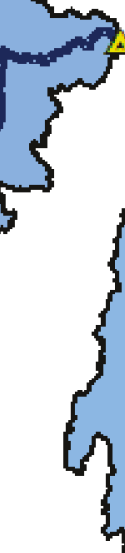

c)

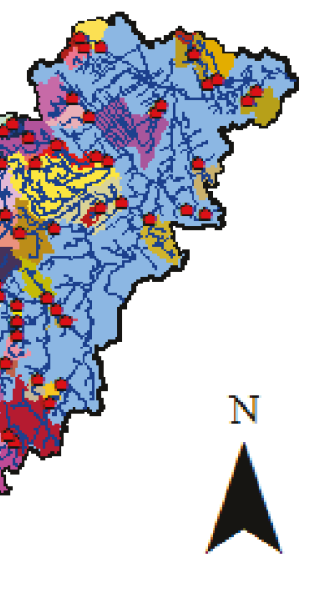

$\mathrm{N}$

Figure 3-17. Three spatial resolutions of sites in the Jock River watershed. A) the Jock River sample sites at Prince of Wales (outlet), Eagleson Rd (middle) and Franktown Rd (headwaters), represents a coarse spatial and moderate temporal resolution. B) the main tributary sample sites and their catchments, represents a moderate spatial and temporal resolution. $C)$ the summer headwater (HWDF) sites and their contributing areas, represents a fine spatial resolution and coarse temporal resolution. OHN watercourse data source: Ontario Ministry of Natural Resources and Forestry (2011). OHN Watercourse [GIS Data Set]. Retrieved from https://www.javacoeapp.lrc.gov.on.cal Streams data source: Rideau Valley Conservation Authority (2017). Jock River Watercourse [GIS Data Set]. Retrieved from Rideau Valley Conservation Authority. 


\subsubsection{Assessment of Stream Water Variation and End-member Viability}

Prior to conducting EMMA, it was imperative to first ensure that the samples collected for the Jock River and its main tributaries were representative of stream water chemistry under a variety of hydrologic conditions. As a small number of samples were collected during the 2015 growing season, it is vital that these samples reflect a range of hydrologic conditions and that multiple samples capture similar hydrologic conditions, to guarantee that the signal of end-members and not environmental noise is analyzed in the EMMA. It is also important to verify that the stream water variability is greater than the end-member variability. Hooper (2001) suggests 3 criteria for evaluating viable endmembers. End-members are considered viable if the concentrations are more extreme than that of the stream water chemistry, such that the end-members bound the mixing space of the stream water chemistry, the variability in the end-member chemistry is low

relative to that of the stream water chemistry and the end-members are distinctly different from one another. Box-whisker plots and basic descriptive statistics are used to assess variation in the geochemical composition of streamflow and potential end-members.

\subsubsection{Determining the Number of End-members}

EMMA uses PCA to reduce the dimensionality of the stream water chemistry mixing space, resulting in a new mixing space called $U$-space. For temporal analysis of stream geochemistry three tracers were used: $\mathrm{SpC}(\mu \mathrm{S} / \mathrm{cm})$, alkalinity (as $\mathrm{mg} / \mathrm{L} \mathrm{CaCO}_{3}$ ) and dissolved silica $\left(\mathrm{SiO}_{2} \mathrm{mg} / \mathrm{L}\right)$. These tracers were chosen as they are low cost, easy to measure variables that can be determined with basic laboratory equipment. The lowest dimensional mixing space possible with this number of tracers is 2 dimensions ( 3 end- 
members). Based on Hooper (2003) residual analysis was used to determine the number of end-members to retain in the subsequent EMMA. This method examines the residuals of the observed stream water chemistry and the predicted stream water chemistry. Residual plots are generated for each dimensional mixing space, for each solute at each sample point. The lowest dimensional mixing space in which the residual plots show no structure, is considered to represent the correct number of end-members contributing to stream flow. This method does not require that the end-members be identified before hand.

A script was developed in $\mathrm{R}$ version 3.2.3 using the packages MASS, compositions, broom and HydroGOF to automate the process described above for the Jock River sites combined and the main tributary sample sites. The output of the script is a compilation of residual plots for a 1 and 2-dimensional mixing space. The residual plots were then evaluated for structure. Structure in the residual plots indicates either nonconservative behaviour of tracers or an inappropriate number of end-members. Due to the small sample size, structure in the residuals was difficult to interpret. Therefore, the number of eigenvectors retained following the rule of one, was also evaluated. As found in the studies by Hooper (2003) and James and Roulet (2006) this produced results which conflicted with those from the residual analysis. The final EMMA was performed for both a one and two-dimensional system (i.e., two and three end-members). The final decision on the number of end-members contributing to each system, was determined using the rule of one and validated by examining the RRMSE, the relative bias, coefficients of determination for solutes and the mixing plots of the final models. 


\subsubsection{End-member Selection}

To capture spatial heterogeneity in groundwater flow numerous potential endmembers were sampled across the watershed as can be seen in figure 3-10. Deep groundwater wells which access different aquifers were sampled to determine if differences in deep regional, intermediate and shallow groundwater flow systems could be identified. All potential end-members were screened for their ability to fit into the Jock River mixing space. End-members deemed viable were then projected into the Jock River mixing space. The percent difference between the observed end-member concentration and the destandardized orthogonally projected end-member concentration was calculated (see equation 9). James and Roulet (2006) suggest that a criterion for an acceptable fit is a $15 \%$ difference between the median end-member values and their orthogonal projection. Barthold et al., (2011) used this criterion and two additional criteria in their automated EMMA procedure for the Xilin River sub-catchment. Barthold et al., (2011) employed numerous iterations of different tracer combinations to determine EMMA sensitivity to the number and types of tracers used in EMMA. The procedure used by Barthold et al., (2011) produced numerous output results, therefore end-members were evaluated based on quantitative measures such as the percent difference; the amount of deviation in plausible end-member contributions between 0-100\%; and the Euclidean distance between the median end-member and the median of the projected stream water. End-members contributing to the Jock River were evaluated based on the criteria described by James and Roulet, (2006) and Barthold et al., (2011). The Euclidean distance was not a reliable measure as it often selected end-members in the center of the mixing space. This is because the Euclidean distance does not take into consideration the 
end-members' position in the mixing space. End-members used in the final mixing model were selected based on a combination of the following criteria: end-members bound the stream water chemistry, have a low percent difference, produced plausible results $(0$ $100 \%$ ) and fit with a conceptual understanding of the watershed.

$$
\% \text { Difference }=\frac{\mid \text { Observed EM-Destandardized } E M \mid}{\left(\frac{\text { Observed } E M-\text { Destandardized } E M}{2}\right)} \cdot 100 \% \quad \text { Equation } 9
$$

\subsubsection{Calculation of End-member Proportions}

End-member proportions were calculated by simultaneously solving equations 36 (section 2.4.3). Equation 3 represents the unknown proportions of the end-members, which sum to 1. Equations 5-6 define the concentration of a single sample in U-space in which $U 1$ and $U 2$ represent its coordinates in $U$-space. The variables $U 1_{n}$ and $U 2{ }_{n}$ represent the concentration of the $n^{\text {th }}$ end-member in U-space. Matrix $\mathbf{A}$ is generated to solve this series of equations easily through matrix multiplication. Matrix A represents the coefficients of the unknowns, i.e., the projected end-members in U-space. The proportions of each end-member are solved through matrix multiplication of the projected surface water values in U-Space for $U 1, U 2$ and a column of ones and the inverse of matrix $\mathbf{A}$, see equation 10.

\footnotetext{
$\left[\begin{array}{ccc}1 & 1 & 1 \\ E M 1 U 1 & E M 2 U 1 & E M 3 U 1 \\ E M 1 U 2 & E M 2 U 2 & E M 3 U 2\end{array}\right]^{-1} \cdot\left[\begin{array}{ccc}1 & S W U 1 & S W U 2 \\ \vdots & \vdots & \vdots \\ \vdots & \vdots & \vdots\end{array}\right] \quad$ Equation 10

* $E M=$ end-member, $S W=$ surface water
} 
End-member proportions were then validated by converting the proportions into predicted concentrations of the original solutes. The predicted concentrations were calculated through matrix multiplication of the constrained end-member proportions and the destandardized orthogonally projected end-members, see equation 11. Relative root mean square error (RRMSE, $r$ ) is a scalar measure of fit, as it is scaled by the mean concentration of each solute to make them unitless (Hooper, 2003). RRMSE was calculated to evaluate model accuracy, see equation 12. Coefficients of determination and residuals were also evaluated to assess model accuracy and to inform model selection.

$$
\begin{aligned}
& {\left[\begin{array}{ccc}
P S W E M 1 & P S W E M 2 & P S W E M 3 \\
\vdots & \vdots & \vdots \\
\vdots & \vdots & \vdots
\end{array}\right] \cdot\left[\begin{array}{cccc}
D E M 1 S p C & D E M 1 \text { Alkalinity } & D E M 1 \mathrm{SiO}_{2} \\
D E M 2 S p C & D E M 2 \text { Alkalinity } & D E M 2 \mathrm{SiO}_{2} \\
D E M 3 S p C & D E M 3 \text { Alkalinity } & D E M 3 \mathrm{SiO}_{2}
\end{array}\right] \quad \text { Equation } 11} \\
& \text { * } P=\text { projected, } D=\text { destandardized } \\
& r_{j}=\frac{\sqrt{\sum_{i=1}^{n}\left(\hat{x}_{i j}-x_{i j}\right)^{2}}}{n \cdot \bar{x}_{j}}
\end{aligned}
$$

\subsubsection{Projection of Tributaries and Headwaters into the Jock River Mixing Space}

To determine if a single linear mixing model explains baseflow sources across different spatial scales, the main tributaries and headwater sites were projected in the Jock River mixing space. The main tributary and headwater sites were standardized $\left(Y^{*}\right)$ based on the mean and standard deviation of the Jock River. The standardized values were then orthogonally projected into the mixing subspace by substituting $Y^{*}$ for $X^{*}$ in equation 7 (section 2.4.5). The sites were evaluated to determine how well they fit into 
the Jock River mixing space. Most sites had points which were not constrained within the mixing triangle. Points outside the mixing triangle were constrained through projection onto the mixing triangle. This method has been applied by Dr. Hooper, and the equations are based on an Excel spreadsheet provided by Dr. Hooper at the Aberdeen Catchment Science Summer School attended in August of 2015. First the unconstrained proportions determined through matrix multiplication as described above, see equation 13 are calculated. These values are then screened to determine if they are negative; negative values are coded as true and positive values are coded as false. A coding system developed by Dr. Hooper sums these columns to determine a unique code between 0-7 for every possible end-member combination (for a 3 end-member mixing space). The points are projected onto the mixing triangle by minimizing the distance from point $\left(x^{*}\right.$, $\left.y^{*}\right)$ to the line $y=m x+b$, see equation 13 for each end-member. The example in equation 14 shows the calculation for the projection of surface water $(\mathrm{SW})$ points onto the mixing triangle for end-member 1 , in which $\left(m_{E M \frac{3}{2}}\right)$ represents the slope $(m)$ of end-members 3 and $2\left(E M \frac{3}{2}\right)$ in U-space, $\left(S W_{x} \& S W_{y}\right)$ represents the projected surface water $(S W)$ coordinates $(x, y)$ in $\mathrm{U}$-space and $\left(b_{E M \frac{3}{2}}\right)$ represents the y-intercept $(b)$ of end-members 3 and $2\left(E M \frac{3}{2}\right)$ in U-space. The constrained end-member proportions are then determined based on a series of if, else statements based on the code generated from the unconstrained proportions. If proportions have a code which indicates a negative unconstrained proportion, the constrained proportion is calculated based on the projected coordinates of the negative end-members. For example, if the code for the unconstrained proportion of end-member 1 is equal to 2 this indicates that end-member 2 is negative 
and the proportion is split between end-members 1 and 3, the constrained end-member is then calculated following equation 14. In equation 14 (EM3 U1) represents the U1 (principal component 1) value of end-member 3, (EM1 U1) is the value of end-member 1 and Projected SW EM 2 is the value of the surface water point projected onto the mixing triangle for end-member 2.

Projected SW onto mixing triangle $=\frac{m_{E M_{\frac{3}{2}}} * S W_{x}+S W_{y}-m_{E M \frac{3}{2}} * b_{E M \frac{3}{2}}}{1+m_{E M \frac{3}{2}}{ }^{2}} \quad$ Equation 13 $S W$ constrained proportion $E M 1=\frac{E M 3 U 1-\text { Projected } S W E M 2}{E M 3 U 1-E M 1 U 1}$

Equation 14

The model accuracy of the predicted concentrations of the main tributaries and headwater features were evaluated by calculating the RRMSE and relative bias $\left(b_{j}\right)$, see equation 15. Relative bias for a site projected based on its own eigenvectors is always zero, therefore the higher the relative bias for sites projected into the Jock River subspace the poorer the fit. The RRMSE of the projected site and the reference are compared to evaluate model fit. Models were also evaluated based on the coefficients of determination and analysis of residuals. The main tributaries were also projected into their own mixing space to determine if the number and identity of the end-members matched with those identified for the Jock River mixing space.

$$
b_{j}=\frac{\sum_{i=1}^{n}\left(\hat{x}_{i j}-x_{i j}\right)}{\bar{x}_{j}}
$$

Equation 15 


\subsubsection{Watershed Characteristics}

The purpose of this analysis is to determine if the spatial heterogeneity captured in GIS data layer's surficial geology, Paleozoic geology and land use/land cover enhances and verifies the results of our EMMA. Variations in the proportions of endmembers contributing to streamflow along the Jock River and at the main tributaries represents potential differences in processes generating baseflow. Presumably these differences are related to the landscape composition of each sites upstream contributing area. Analysis of watershed characteristics seeks to determine if there is any linear correlation between end-member proportions at a site and its upstream contributing area landscape composition.

\subsubsection{Watershed Delineations and Proportions of Watershed}

\section{Characteristics}

The upstream contributing area for each sample point was delineated to determine the relative proportions of watershed characteristics. The DEM described in section 3.1.2.3 was used to delineate catchments for each sample point. Catchment delineation and preprocessing was performed in ArcMap version 10.3.1 (ESRI, 2015). Preprocessing of this DEM included stream burning; a recently digitized/corrected stream layer provided by RVCA staff was burned into the resampled $5 \mathrm{~m}$ grid size integer DEM. The flow accumulation raster did not always align with known/observed stream locations along the eastern edge of the watershed. To force the flow accumulation to match with known stream locations the DEM was clipped to the extent of the Jock watershed previously delineated by RVCA staff. To further enforce known drainage patterns, the streams were burned to a deep depth $(20 \mathrm{~m})$. The sample sites were used as pour points, 
and were relocated to match with flow accumulation grid cells if necessary. Pour points included the sample sites along the Jock River (Prince of Wales Rd, Eagleson Rd and Franktown Rd) and the sample sites at the main tributaries: Flowing Creek, Hobbs Drain, Monahan Drain, Leamy Creek, Nichols Creek and Kings Creek.

The proportions of watershed characteristics for each catchment was determined in ArcMap version 10.3.1 (ESRI, 2015). The $30 \mathrm{~m}$ Landsat land use land cover classification raster obtained from Agriculture Canada was used to determine the proportions of land use types: agriculture (cropland, grassland), urban (settlement, roads) and landcover types: forest (trees, forest), wetland (forest wetland, treed wetland, wetland undifferentiated, wetland shrub and wetland herb). Paleozoic bedrock geology and surficial geology GIS layers obtained from the Ministry of Northern Development and Mining were used to determine the proportions of different bedrock types and surficial geologic material in each sub-catchment. The surficial and Paleozoic bedrock GIS datasets were primarily generated from maps at a scale of 1:50 000. The surficial geologic materials and Paleozoic bedrock formations assessed included: Paleozoic bedrock, clay/silt, organic deposits, diamicton, sand, the Oxford Formation, the March Formation, the Bobcaygeon Formation, the Gull River Formation and the Rockcliffe Formation. Watershed characteristics with proportions smaller than 0.03 were excluded from analysis.

\subsubsection{Recursive Partitioning and Regression Analysis}

Recursive partitioning using classification and regression tree models (CART) was performed to undertake an initial analysis of potential relationships between the proportions of watershed characteristics in each sub-catchment and the average 
proportions of end-members contributing to flow at each sub-catchment. Recursive partitioning examines the data space and partitions it by fitting a simple prediction model within each partition (Loh, 2011). The partitions are represented graphically as decision trees which can either be used for classification or regression analysis (Loh, 2011).

CART was applied to explore potential structure in the relationships between all watershed characteristics and the variations in end-member contributions across the Jock watershed.

Simple linear regression was performed on all watershed characteristic proportions and the average end-member proportions for each main tributary sample site. Watershed characteristics which demonstrated strong linear relationships with the endmember proportions were then combined in multiple linear regression (MLR) models. Forward step-wise MLR was applied using watershed characteristics which demonstrated a strong linear relationship with end-member proportions. The coefficient of determination $\left(\mathrm{R}^{2}\right)$ and $\mathrm{p}$-values were used to determine if the MLR model gained more explanatory power with the inclusion of the new variable(s). Watershed characteristics were retained in the MLR model if they remained significant ( $p$-value $<0.05$ ). Numerous different permutations were performed and recorded for each end-member proportion at each site. 


\subsection{RESULTS}

\subsection{Stream Water Characterization}

\subsubsection{Hydrologic Conditions During Sample Collection}

The hyeto-hydrograph (figure 4-1) demonstrates the hydrologic conditions in the watershed over the 2015 growing season, the average daily discharge $\left(\mathrm{m}^{3} / \mathrm{s}\right)$ at the outlet and at several of the main tributaries as well as the total daily precipitation $(\mathrm{mm})$ are shown. Surface water sample collection of the Jock River and its main tributaries began at the end of May under wet antecedent moisture conditions. Wet antecedent moisture conditions continued into June, which had higher than average precipitation. In May and June, the average daily flow at the outlet ranges from $1.79-3.39 \mathrm{~m}^{3} / \mathrm{s}$. Samples collected between May $26^{\text {th }}-28^{\text {th }}$ and June $3^{\text {rd }}-6^{\text {th }}$ reflect the hydrologic conditions of a falling limb of a peak in response to large rainfall events on May $25^{\text {th }}(30.3 \mathrm{~mm})$ and May $30^{\text {th }}$ $(13.8 \mathrm{~mm})$ respectively. The highest daily average discharge at the outlet was $9.49 \mathrm{~m}^{3} / \mathrm{s}$ on June $14^{\text {th }}$. This peak flow in the hydrograph is in response to a large precipitation $(15.9 \mathrm{~mm})$ event under wet antecedent moisture conditions. Samples collected before June $17^{\text {th }}$ most likely represent wet antecedent moisture hydrologic conditions in the watershed.

Following the June $14^{\text {th }}$ peak the flow at the outlet demonstrates a steady recession, in 2015 July experienced drier than normal conditions, total precipitation during this month was $40.8 \mathrm{~mm}$, which is half of that expected based on the climate normal for this month. Early August brought an increase in precipitation $(10.8 \mathrm{~mm}$ over three days), but this had little influence on flow conditions at the outlet due to dry antecedent moisture conditions in the watershed. The lowest daily average at the outlet 
was $0.35 \mathrm{~m}^{3} / \mathrm{s}$ on August $8^{\text {th }}$ (figure $4-1$ ). The low flow reflects that flow during this time is primarily derived from subsurface storage. Samples collected between July $6^{\text {th }}-$ August $10^{\text {th }}$ most likely reflect low flow dry antecedent moisture hydrologic conditions in the watershed.

Late August saw above average precipitation contributions, totalling $89.2 \mathrm{~mm}$. Samples collected on August $27^{\text {th }}-28^{\text {th }}$ reflect a return to baseflow conditions as the last major precipitation event before sample collection was 7-8 days prior (figure 4-1). Flow during these collection days is on average $1.07 \mathrm{~m}^{3} / \mathrm{s}$ which is comparable to flow during the mid July collection days $\left(1.13 \mathrm{~m}^{3} / \mathrm{s}\right)$. Samples collected in the beginning of September $3^{\text {rd }}-4^{\text {th }}$ also reflect similar conditions to those described, as average daily flow is $0.77 \mathrm{~m}^{3} / \mathrm{s}$ and the last major precipitation event was $15-16$ days prior. These samples also reflect low flow baseflow under dry antecedent moisture hydrologic conditions in the watershed.

The sample days September $17^{\text {th }}, 24^{\text {th }}$ and October $29^{\text {th }}-30^{\text {th }}$ demonstrate a return to increased antecedent moisture conditions. Flow rates during this sample period are increasing, due to the end of the growing season and an increase in autumnal precipitation. Samples collected on September $17^{\text {th }}$ reflect the falling limb of a large precipitation event, $46.2 \mathrm{~mm}$ over 3 days. Samples collected at the end of October were taken during a large precipitation event $(33 \mathrm{~mm})$. Flow during this time was responsive to this precipitation due to wet antecedent moisture conditions in the watershed. 


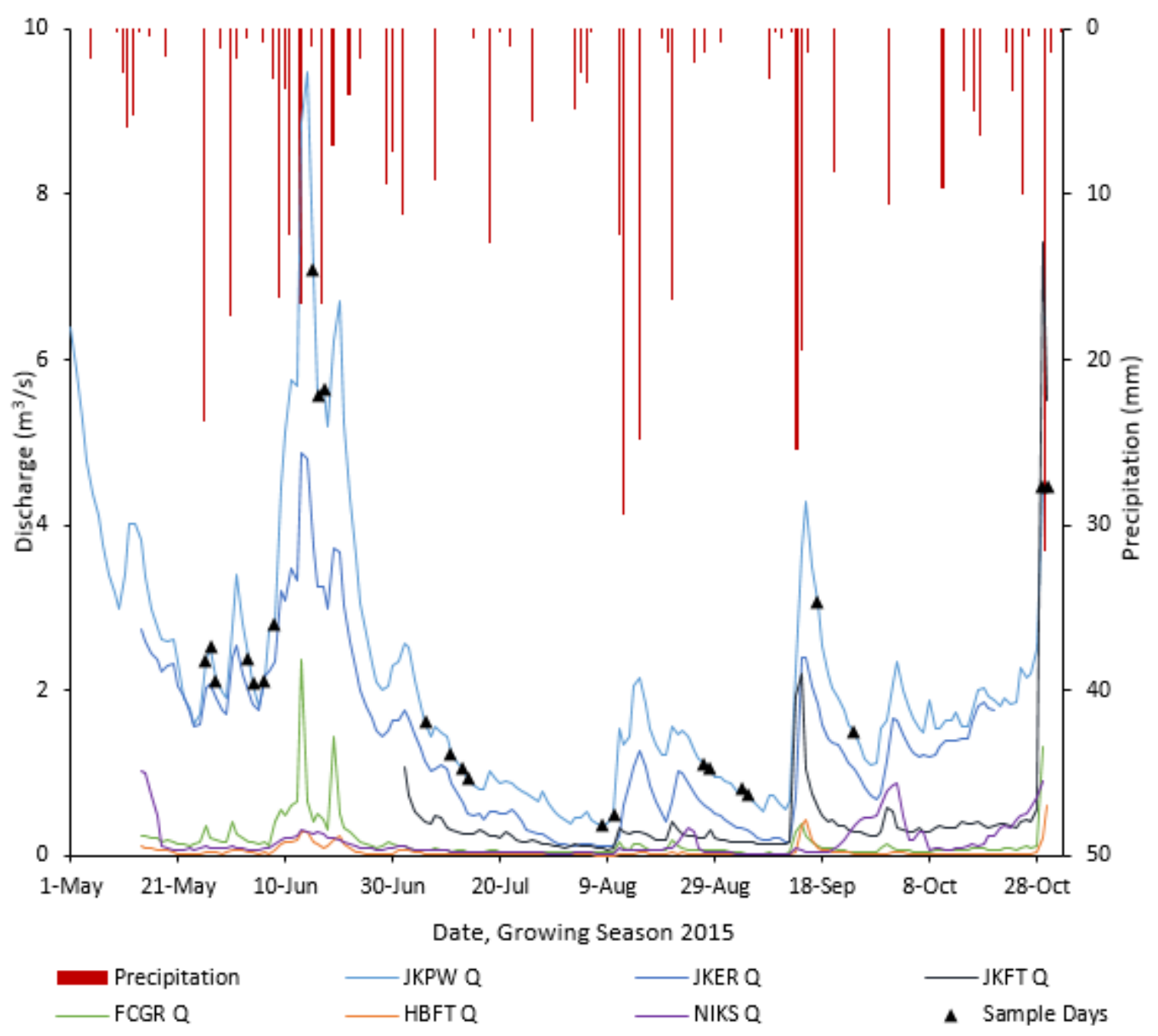

Figure 4-1. Hyeto-hydrograph showing total daily precipitation ( $\mathrm{mm}$ ) and average daily discharge $\left(\mathrm{m}^{3} / \mathrm{s}\right)$ along the Jock River (JKPW [outlet], JKER [middle], JKFT [headwaters]), Flowing Creek (FCGR), Hobbs Drain (HBFT) and Nichols Creek (NIKS) during the growing season of 2015. Sample days have been placed along the JKPW hydrograph to illustrate hydrologic conditions during sample collection. Not all sites were sampled on sample days, see table B-0-1 in Appendix B for sites collected on sample days. Precipitation data source: Government of Canada. (2017). eng-daily-01012015-12312015 [Data file]. Retrieved from http://climate.weather.gc.ca 


\subsubsection{Stream Water Chemistry Variability}

The box-whisker plots (figure 4-2) demonstrate the stream chemistry variability amongst sample sites during the 2015 growing season. The boxes represent the $1^{\text {st }}$ and $3^{\text {rd }}$ quartiles and the whiskers represent the highest and lowest values within 1.5 times the interquartile range. The median concentration and outliers in the stream chemistry are also indicated. In figure 4-2 Leamy Creek (LMBR) and Kings Creek (KC) show significant outliers in $\mathrm{SpC}$. Stream chemistry concentrations appear to be significantly different amongst the sites sampled. Analysis of variance (ANOVA) was performed, to determine if these differences were significant. ANOVA was performed on all sites, including each Jock River site (JKPW, JKER and JKFT) as a unique site for each variable ( $\mathrm{SpC}$, alkalinity and $\left.\mathrm{SiO}_{2}\right)$. Results showed significant differences $(\mathrm{p}<0.0001)$ between all sites. ANOVA was also performed on two subsets of the data: the Jock River sites and the main tributaries without the Jock River sites. The differences amongst the Jock River sites did not remain significant for each variable: $\mathrm{SpC} p=0.0015$, alkalinity $\mathrm{p}=$ $0.65, \mathrm{SiO}_{2} \mathrm{p}=0.04$. When the Jock River sites were removed from the data set the differences amongst the main tributary sites remained significant $(\mathrm{p}<0.0001)$ for all variables. It can therefore be concluded that the stream geochemistry signal does not vary significantly along the Jock River, but does vary significantly amongst the Jock River tributaries. 

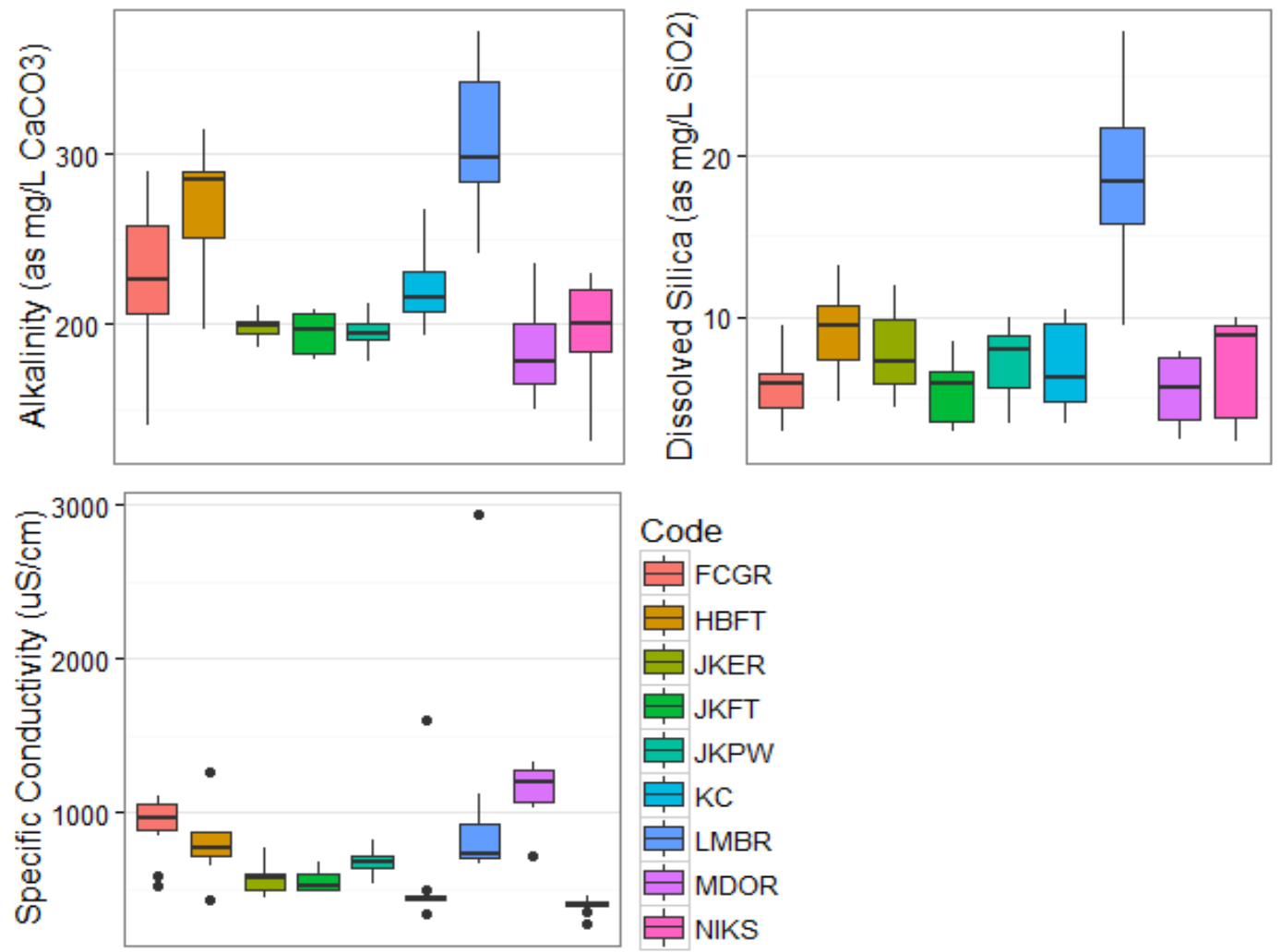

Figure 4-2. Box-whisker plots of stream chemistry variability at main tributary sites throughout the 2015 growing season.

Table 4-1. Main tributary chemistry descriptive statistics: mean $(\bar{x})$, interquartile range (IQR) $\left(3^{r d}-1^{s t}\right)$ and coefficient of variation $(\mathrm{CV})$.

\begin{tabular}{|c|c|c|c|c|c|c|c|c|c|c|}
\hline \multirow{2}{*}{$\begin{array}{c}\text { Main Tributary Sample } \\
\text { Site }\end{array}$} & \multirow[b]{2}{*}{$\mathrm{N}$} & \multicolumn{3}{|c|}{$\begin{array}{c}\mathrm{SpC} \\
(\mu \mathrm{S} / \mathrm{cm})\end{array}$} & \multicolumn{3}{|c|}{$\begin{array}{l}\text { Alkalinity (as } \mathrm{mg} / \mathrm{L} \\
\left.\qquad \mathrm{CaCO}_{3}\right)\end{array}$} & \multicolumn{3}{|c|}{$\begin{array}{c}\mathrm{SiO}_{2} \\
(\mathrm{mg} / \mathrm{L})\end{array}$} \\
\hline & & $\bar{x}$ & $I Q R$ & $\begin{array}{l}\mathrm{CV} \\
(\%) \\
\end{array}$ & $\bar{x}$ & $I Q R$ & $\begin{array}{l}\mathrm{CV} \\
(\%) \\
\end{array}$ & $\bar{x}$ & $I Q R$ & $\begin{array}{l}\mathrm{CV} \\
(\%) \\
\end{array}$ \\
\hline $\begin{array}{l}\text { Jock River at Prince of } \\
\text { Wales Road (JKPW) }\end{array}$ & 10 & 682.3 & 73.5 & 12.3 & 195.4 & 10 & 5.2 & 7.3 & 3.2 & 29.5 \\
\hline $\begin{array}{l}\text { Jock River at Eagleson } \\
\text { Road (JKER) }\end{array}$ & 11 & 562.3 & 107.7 & 16.7 & 198.5 & 7.5 & 3.5 & 7.8 & 3.9 & 34.4 \\
\hline $\begin{array}{l}\text { Jock River at } \\
\text { Franktown Road } \\
\text { (JKFT) }\end{array}$ & 11 & 551.9 & 97.4 & 11.4 & 194.8 & 23 & 5.9 & 5.4 & 3.2 & 36.3 \\
\hline Leamy Creek (LMBR) & 10 & 1005.0 & 127 & 69.3 & 305.5 & 59 & 15.0 & 18.9 & 6.1 & 28.5 \\
\hline $\begin{array}{l}\text { Monahan Drain } \\
\text { (MDOR) }\end{array}$ & 10 & 1148.9 & 203.3 & 16.1 & 183.3 & 35 & 14.4 & 5.5 & 4.0 & 38.8 \\
\hline $\begin{array}{l}\text { Flowing Creek } \\
\text { (FCGR) }\end{array}$ & 12 & 921.8 & 173.8 & 20.7 & 227.4 & 52 & 17.5 & 5.9 & 2.1 & 37.4 \\
\hline Hobbs Drain (HBFT) & 12 & 821.6 & 150.6 & 28.9 & 267.5 & 39 & 13.9 & 9.1 & 3.4 & 27.9 \\
\hline Kings Creek (KC) & 11 & 542.5 & 15.1 & 65.2 & 219.6 & 24.3 & 9.2 & 6.9 & 4.9 & 37.5 \\
\hline Nichols Creek (NIKS) & 11 & 397.8 & 24.3 & 12.2 & 197.4 & 36 & 14.2 & 6.7 & 5.6 & 47.9 \\
\hline
\end{tabular}


In Table 4-1 Leamy Creek appears to be the most variable of the streams as it has the greatest IQR in all variables. It also has the highest average values for alkalinity and $\mathrm{SiO}_{2}$ and the second highest average $\mathrm{SpC} . \mathrm{SpC}$ IQR are the largest amongst all variables, and $\mathrm{CV}$ are in the range of $11.4 \%$ and $69.3 \%$ as $\mathrm{SpC}$ is extremely variable. Alkalinity and $\mathrm{SiO}_{2}$ are primarily weathering products as such, higher concentrations may be related to increased weathering in their source waters. Monahan Drain has low mean alkalinity $(183.3 \mathrm{mg} / \mathrm{l})$ and $\mathrm{SiO}_{2}(5.5 \mathrm{mg} / \mathrm{l})$, low values may indicate that source waters for this site have undergone little chemical weathering. Alternatively, Leamy Creek and Hobbs Drain have the highest mean alkalinity, $305.5 \mathrm{mg} / 1$ and $267.5 \mathrm{mg} / \mathrm{l}$ respectively, and the highest mean $\mathrm{SiO}_{2}$ concentrations, $18.9 \mathrm{mg} / 1$ and $9.1 \mathrm{mg} / 1$ respectively. Higher concentrations at these sites may indicate increased chemical weathering in their source waters. Alkalinity for sites along the Jock River have the lowest CV, $3.5-5.9 \%$, demonstrating that concentrations remain relatively stable throughout the season. The remaining sites have CV between 9.2-17.5\%, this increase in variability amongst the tributaries could indicate the importance of spatial heterogeneity in end-member mixing. The $\mathrm{CV}$ for $\mathrm{SiO}_{2}$ are relatively high for all sites ranging from $28.5-47.9 \%$. Higher variability in the CV for $\mathrm{SiO}_{2}$ is beneficial in EMMA as it indicates that environmental forcing's may play an important role in the concentration of $\mathrm{SiO}_{2}$ in stream water. 


\subsection{EMMA}

\subsubsection{End-member Viability}

End-members are considered viable if the end-members are distinctly different from one another. The box-whisker plots in figure 4-3 illustrate the variability in the endmember geochemistry. The end-members in figure 4-3 appear to be distinct from one another in all plots. Precipitation end-members are tightly constrained and appear similar. The Goodwood Marsh piezometer (GWMP) shows significant differences between samples collected in 2015 and those collected in 2016. These differences could be attributed to seasonal variation and dilution of the hydrochemical signature as the samples in 2015 were collected in autumn (October- November) during wet antecedent moisture conditions while the samples in 2016 were collected in the summer (June- July) during dry antecedent moisture conditions. The piezometers at Hobbs Drain (HBP) and in the headwater wetland at Highway 15 (HWY15P2) have the largest variation in alkalinity amongst all end-members. End-members are significantly distinct, and are therefore considered to be viable end-members. 
Table 4-2. End-Member codes, long names and descriptions.

\begin{tabular}{|c|c|c|}
\hline $\begin{array}{l}\text { End-Member } \\
\text { Code }\end{array}$ & $\begin{array}{l}\text { End-Member } \\
\text { Long Name }\end{array}$ & End-Member Description \\
\hline \multirow[b]{2}{*}{ GWMP 2015} & \multirow[b]{2}{*}{$\begin{array}{l}\text { Goodwood Marsh } \\
\text { piezometer } 2015\end{array}$} & Collected: autumn of 2015 \\
\hline & & $\begin{array}{l}\text { Represents: wet-antecedent moisture conditions for a } \\
\text { forest wetland. }\end{array}$ \\
\hline \multirow[b]{2}{*}{ GWMP 2016} & \multirow{2}{*}{$\begin{array}{l}\text { Goodwood Marsh } \\
\text { piezometer } 2016\end{array}$} & Collected: summer of 2016 \\
\hline & & $\begin{array}{l}\text { Represents: dry-antecedent moisture conditions for a } \\
\text { forest wetland. }\end{array}$ \\
\hline \multirow[b]{2}{*}{ HBP 2016} & \multirow[b]{2}{*}{$\begin{array}{l}\text { Hobbs Drain } \\
\text { piezometer } 2016\end{array}$} & Collected: summer of 2016 \\
\hline & & $\begin{array}{l}\text { Represents: dry-antecedent moisture conditions for a } \\
\text { forest wetland. }\end{array}$ \\
\hline \multirow[b]{2}{*}{ HWY15SW } & \multirow{2}{*}{$\begin{array}{c}\text { Highway } 15 \\
\text { surface water } \\
2015-2016\end{array}$} & Collected: summer of $2015 \& 2016$ \\
\hline & & $\begin{array}{l}\text { Represents: surface water outflow from the headwater } \\
\text { swamp for the Jock River }\end{array}$ \\
\hline \multirow[b]{2}{*}{ GW_DW_1 } & \multirow[b]{2}{*}{$\begin{array}{l}\text { groundwater } \\
\text { domestic well } 1\end{array}$} & Collected: summer 2015 \\
\hline & & $\begin{array}{l}\text { Represents: groundwater from a deep well in limestone } \\
\text { bedrock. }\end{array}$ \\
\hline \multirow[b]{2}{*}{ GW_DW_2 } & \multirow{2}{*}{$\begin{array}{l}\text { groundwater } \\
\text { domestic well } 2\end{array}$} & Collected: summer 2015 \\
\hline & & $\begin{array}{l}\text { Represents: groundwater from a deep well in limestone } \\
\text { bedrock which is part of the Oxford Formation. }\end{array}$ \\
\hline \multirow[b]{2}{*}{ W084 } & \multirow{2}{*}{$\begin{array}{l}\text { PGMN Well ID } \\
\text { W0000084-1 }\end{array}$} & Collected: summer 2015 \\
\hline & & $\begin{array}{l}\text { Represents: groundwater from a deep well in the Gull } \\
\text { River Formation (dolostone/limestone/shale/sandstone) }\end{array}$ \\
\hline \multirow[b]{2}{*}{ W085 } & \multirow[b]{2}{*}{$\begin{array}{l}\text { PGMN Well ID } \\
\text { W0000085-1 }\end{array}$} & Collected: summer 2015 \\
\hline & & $\begin{array}{l}\text { Represents: groundwater from a deep well in an } \\
\text { unconfined glacial till aquifer. }\end{array}$ \\
\hline \multirow[b]{2}{*}{ W156-2 } & \multirow{2}{*}{$\begin{array}{l}\text { PGMN Well ID } \\
\text { W0000156-2 }\end{array}$} & Collected: summer 2015 \\
\hline & & $\begin{array}{l}\text { Represents: groundwater from a deep well from gravel, } \\
\text { boulder Oxford Formation interface. }\end{array}$ \\
\hline \multirow[b]{2}{*}{ W156-3 } & \multirow{2}{*}{$\begin{array}{l}\text { PGMN Well ID } \\
\text { W0000156-3 }\end{array}$} & Collected: summer 2015 \\
\hline & & $\begin{array}{l}\text { Represents: groundwater from a deep well in the } \\
\text { Oxford Formation (fractured dolostone) }\end{array}$ \\
\hline \multirow[b]{2}{*}{ W175-2 } & \multirow{2}{*}{$\begin{array}{l}\text { PGMN Well ID } \\
\text { W0000175-2 }\end{array}$} & Collected: summer 2015 \\
\hline & & $\begin{array}{l}\text { Represents: groundwater from a deep well in the Gull } \\
\text { River Formation (dolostone/limestone/shale/sandstone) }\end{array}$ \\
\hline \multirow[b]{2}{*}{ W175-3 } & \multirow{2}{*}{$\begin{array}{l}\text { PGMN Well ID } \\
\text { W0000175-3 }\end{array}$} & Collected: summer 2015 \\
\hline & & $\begin{array}{l}\text { Represents: groundwater from a deep well in the Gull } \\
\text { River Formation (dolostone/limestone/shale/sandstone) }\end{array}$ \\
\hline
\end{tabular}



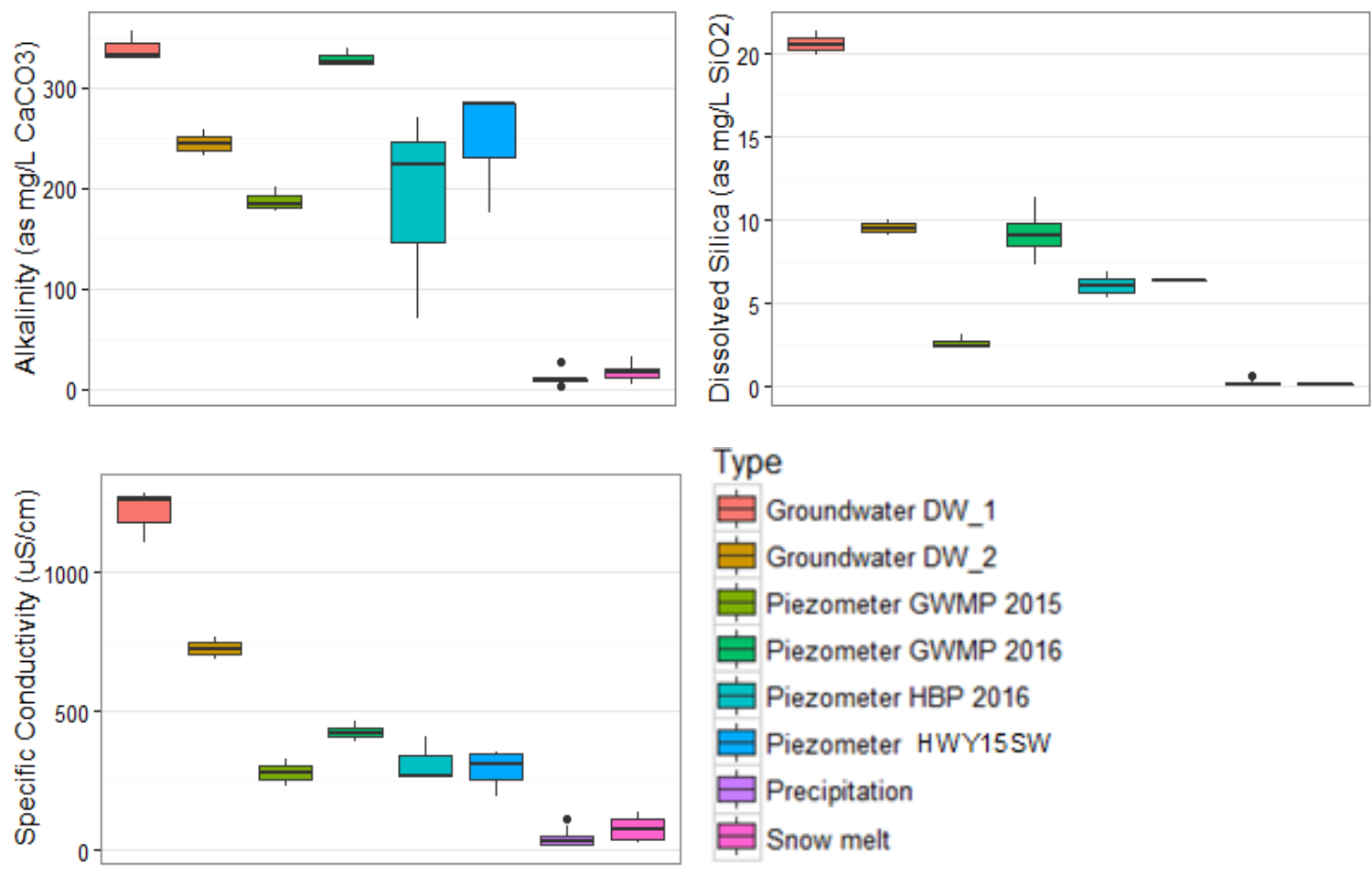

Figure 4-3. Box-whisker plots of end-member geochemistry and variability.

As PGMN wells were only sampled once during the 2015 growing season their variability was assessed based on samples collected from outside the 2015 growing season. Geochemical data for PGMN wells from 2002 to 2015, collected by RVCA staff and analyzed by the Ministry of the Environment and Climate Change (MOECC), was used to assess inter-annual variability of groundwater geochemistry. Figure 4-4 shows the box-whisker plots for conductivity, alkalinity and silica. Groundwater end-members in figure 4-4 appear to have distinct conductivity and alkalinity concentrations. Groundwater at well W156-2 and W156-3 have lower conductivity and alkalinity concentrations, and appear to be distinctly different from other wells. Silica concentrations at all the sites appear to fall within a similar range of values. Wells W1752, W175-3 and W084 are all part of the Gull River Formation but demonstrate significant differences in their concentrations in all variables, further illustrating the influence of spatial heterogeneity in geological materials in groundwater concentrations. Each well 
can then be considered its own end-member although some wells are completed in the same formation.
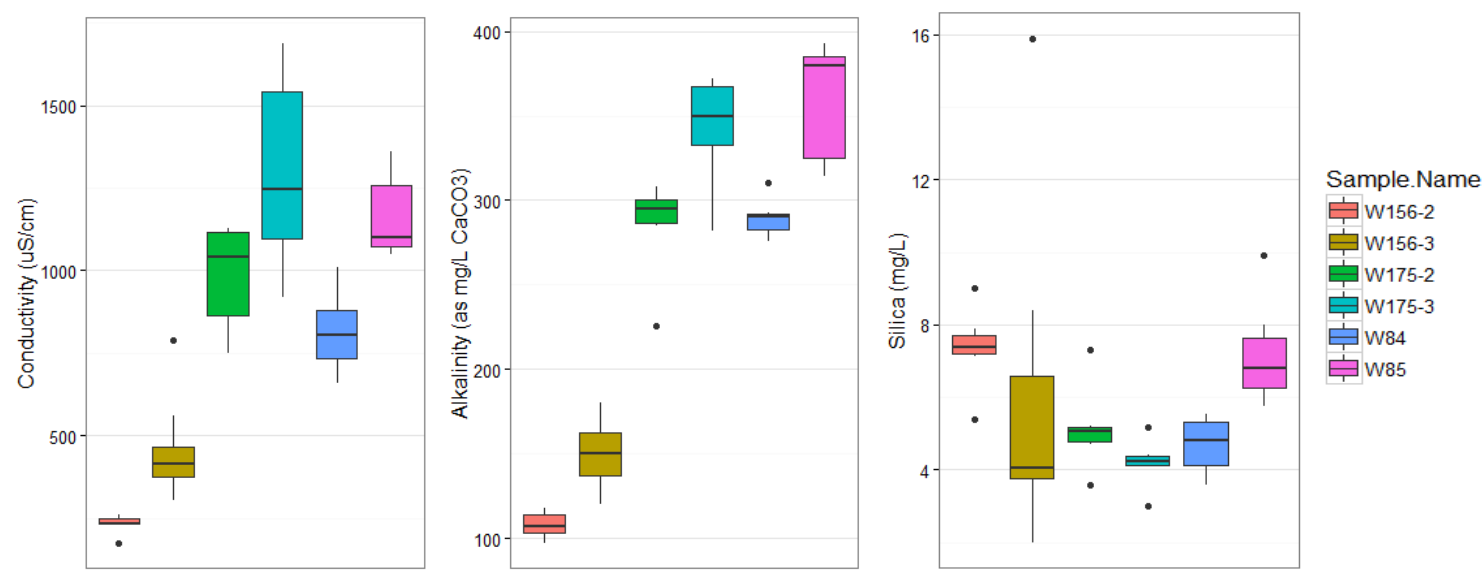

Figure 4-4. Box-whisker plots of PGMN groundwater wells geochemical variability from 2002-2015, most samples were acquired in the autumn.

One of the main assumptions in end-member mixing analysis is that the endmembers remain constant in their geochemical signature throughout time. This is important as the median value of the end-member is used to define the mixing space. For end-members to be considered viable the variability in the end-member chemistry should be low relative to that of the stream water chemistry. Evaluating the CV's in table 4-3 in comparison with those from table 4-1, most end-members sampled appear to be less variable than the stream water chemistry. Precipitation (rain and snowmelt) show the greatest amount of variation of all end-members and have CV higher than stream water in all variables. Piezometer SpC CV are within the same range of variability, $7-27 \%$ as stream water $11.4-28.9 \%$ (excluding stream water outliers). Piezometer alkalinity and $\mathrm{SiO}_{2} \mathrm{CV}$ 's are lower than stream water, except for HBP which has a high CV in alkalinity 55.7\%. Groundwater CV's for the domestic wells sampled (GW_DW_1 and GW_DW_2) have substantially lower CV's for all variables, but only reflect summer 
samples. All end-members, except for precipitation have lower variability than the stream water and can be considered viable end-members.

Table 4-3. End-member chemistry descriptive statistics: sample number $(n)$ mean $(\bar{x})$, interquartile range (IQR) $\left(3^{\text {rd }}-1^{\text {st }}\right)$ and coefficient of variation $(C V) . *$ indicates that values, are not the median value but the value from a single sample in 2015, which was used as the end-member in subsequent EMMA.

\begin{tabular}{|c|c|c|c|c|c|c|c|c|c|c|}
\hline \multirow{3}{*}{ End-Members } & \multirow{3}{*}{$n$} & \multicolumn{3}{|c|}{$\begin{array}{c}\mathrm{SpC} \\
(\mu \mathrm{S} / \mathrm{cm})\end{array}$} & \multicolumn{3}{|c|}{$\begin{array}{c}\text { Alkalinity (as mg/L } \\
\left.\mathrm{CaCO}_{3}\right)\end{array}$} & \multicolumn{3}{|c|}{$\begin{array}{c}\mathrm{SiO}_{2} \\
(\mathrm{mg} / \mathrm{L})\end{array}$} \\
\hline & & $\bar{x}$ & $I Q R$ & $\begin{array}{l}C V \\
(\%)\end{array}$ & $\bar{x}$ & $I Q R$ & $\begin{array}{l}C V \\
(\%)\end{array}$ & $\bar{x}$ & $I Q R$ & $\begin{array}{l}C V \\
(\%)\end{array}$ \\
\hline & & \multicolumn{3}{|c|}{ Median } & \multicolumn{3}{|c|}{ Median } & \multicolumn{3}{|c|}{ Median } \\
\hline \multirow{2}{*}{ Snowmelt } & \multirow{2}{*}{$14-6$} & 78.1 & 77.5 & 58.2 & 17.8 & 9.4 & 51.8 & 0.1 & 0.1 & 46.1 \\
\hline & & \multicolumn{3}{|c|}{30.9} & \multicolumn{3}{|c|}{9.7} & \multicolumn{3}{|c|}{0.2} \\
\hline \multirow{2}{*}{ Rain } & \multirow{2}{*}{$14-9$} & 44.2 & 27.6 & 77.7 & 10.7 & 2.6 & 58.6 & 0.2 & 0.1 & 88.8 \\
\hline & & \multicolumn{3}{|c|}{60.5} & \multicolumn{3}{|c|}{14.8} & \multicolumn{3}{|c|}{0.2} \\
\hline \multicolumn{11}{|c|}{ Piezometers (2015 - 2016) } \\
\hline \multirow{2}{*}{ GWMP 2015} & \multirow{2}{*}{$2-3$} & 279.5 & 47.5 & 24.0 & 187.7 & 12.5 & 6.9 & 2.6 & 0.4 & 15.3 \\
\hline & & \multicolumn{3}{|c|}{279.5} & \multicolumn{3}{|c|}{184.0} & \multicolumn{3}{|c|}{2.4} \\
\hline \multirow{2}{*}{ GWMP 2016} & \multirow{2}{*}{$4-5$} & 424.3 & 30.6 & 7.4 & 328.8 & 8.8 & 2.4 & 9.2 & 1.4 & 18.4 \\
\hline & & \multicolumn{3}{|c|}{421.0} & \multicolumn{3}{|c|}{326.0} & \multicolumn{3}{|c|}{9.1} \\
\hline \multirow{2}{*}{ HBP 2016} & \multirow{2}{*}{$2-4$} & 312.7 & 74.5 & 27.0 & 188.0 & 100.0 & 55.7 & 6.1 & 0.8 & 18.5 \\
\hline & & \multicolumn{3}{|c|}{267.0} & & 224.0 & & & 6.1 & \\
\hline HWY15P2 & $4-1$ & 290.0 & 153.0 & 25.8 & 248.0 & 54.0 & 25.1 & 6.4 & - & - \\
\hline 2016 & & & 271.0 & & & 284.0 & & & 6.4 & \\
\hline & & & & undwa & $r(2015$ & & & & & \\
\hline GW DW 1 & 3 & 1217.7 & 91.5 & 8.1 & 339.3 & 14.0 & 4.5 & 20.6 & 0.8 & 3.7 \\
\hline & 3 & & 1260.0 & & & 332.0 & & & 20.5 & \\
\hline GW DW 2 & 2 & 726.5 & 39.5 & 7.7 & 245.0 & 13.0 & 7.5 & 9.6 & 0.5 & 6.7 \\
\hline & 2 & & 726.5 & & & 258.0 & & & 10.0 & \\
\hline & & & $\mathrm{He}$ & ater $S$ & $\operatorname{lmp}(20$ & & & & & \\
\hline HWY15SW & 3 & 365.9 & 15.1 & 0.04 & 148.3 & 1.5 & 0.01 & 5.1 & 0.9 & 0.2 \\
\hline HWY YJSW & 3 & & $319.0 *$ & & & 138.0 * & & & $6.0 *$ & \\
\hline
\end{tabular}

Most PGMN groundwater samples from 2002-2015 were collected in autumn, therefore seasonal variation could result in some differences between samples collected in 2015 and those collected in the past. Table 4-4 provides descriptive statistics on the PGMN wells geochemistry from 2002-2015 as well as the values for the samples collected in 2015. Alkalinity and silica concentrations from 2015 for W156-2 is the 
closest to the mean concentration. The $\mathrm{CV}$ for conductivity are similar in range to that of stream water, $11.4-28.4 \%$. The CV are generally lower for alkalinity and silica, 4.1$12.5 \%$ and $13.5-23.3 \%$ (excluding $66.4 \%$ for $\mathrm{W} 156-3$ ) respectively. The variability in PGMN groundwater geochemistry is sufficiently low in comparison to the stream water variability, as such these end-members are considered to be viable.

Table 4-4. PGMN groundwater geochemistry descriptive statistics: sample number (n), mean $(\bar{x})$, interquartile range (IQR) $\left(3^{\text {rd }}-1^{\text {st }}\right)$ and coefficient of variation $(C V)$ from 20022015 PGMN groundwater geochemistry from 2015 sampling is provided below interannual descriptive statistics for each well.

\begin{tabular}{|c|c|c|c|c|c|c|c|c|c|c|}
\hline \multirow{3}{*}{ Groundwater Well } & \multirow{3}{*}{$\mathrm{n}$} & \multicolumn{3}{|c|}{ Conductivity (uS/cm) } & \multicolumn{3}{|c|}{ Alkalinity (mg/l) } & \multicolumn{3}{|c|}{ Si (mg/l) } \\
\hline & & $\bar{x}$ & $I Q R$ & CV $(\%)$ & $\bar{x}$ & $I Q R$ & CV $(\%)$ & $\bar{x}$ & $I Q R$ & $\mathrm{CV}(\%)$ \\
\hline & & \multicolumn{3}{|c|}{2015} & \multicolumn{3}{|c|}{2015} & \multicolumn{3}{|c|}{2015} \\
\hline \multirow{2}{*}{ W084 } & \multirow{2}{*}{6} & 816 & 142.8 & 15.5 & 289.8 & 9.8 & 4.1 & 4.7 & 1.2 & 16.9 \\
\hline & & \multicolumn{3}{|c|}{714.0} & \multicolumn{3}{|c|}{290.0} & \multicolumn{3}{|c|}{5.6} \\
\hline \multirow{2}{*}{ W085 } & \multirow{2}{*}{7} & 1167.9 & 187.5 & 11.4 & 358.1 & 60.0 & 9.8 & 7.2 & 1.4 & 20 \\
\hline & & \multicolumn{3}{|c|}{1075.0} & \multicolumn{3}{|c|}{393.0} & \multicolumn{3}{|c|}{7.3} \\
\hline \multirow{2}{*}{ W156-2 } & \multirow{2}{*}{7} & 233 & 18.5 & 12.5 & 108.0 & 11.0 & 7 & 7.4 & 0.5 & 13.5 \\
\hline & & \multicolumn{3}{|c|}{174.0} & \multicolumn{3}{|c|}{107.0} & \multicolumn{3}{|c|}{7.5} \\
\hline \multirow{2}{*}{ W156-3 } & \multirow{2}{*}{12} & 447.6 & 91.5 & 28.4 & 149.0 & 25.3 & 12.5 & 5.6 & 2.8 & 66.4 \\
\hline & & \multicolumn{3}{|c|}{304.9} & \multicolumn{3}{|c|}{164.0} & \multicolumn{3}{|c|}{4.1} \\
\hline \multirow{2}{*}{ W175-2 } & \multirow{2}{*}{6} & 984.9 & 252.5 & 16.6 & 284.8 & 13.8 & 10.5 & 5.2 & 0.4 & 23.3 \\
\hline & & \multicolumn{3}{|c|}{749.1} & \multicolumn{3}{|c|}{308.0} & \multicolumn{3}{|c|}{5.1} \\
\hline \multirow{2}{*}{ W175-3 } & \multirow{2}{*}{6} & 1298.3 & 445.0 & 23.5 & 342.2 & 34.8 & 9.9 & 4.2 & 0.2 & 16.6 \\
\hline & & \multicolumn{3}{|c|}{920.0} & & 372. & & & 5. & \\
\hline
\end{tabular}

\subsubsection{Bi-variate Plots}

The bi-variate plots (figure 4-5) were generated to illustrate the variability in compositions and groupings between different combinations of solute pairs. In the top panel (alkalinity vs. $\mathrm{SiO}_{2}$ ) end-members appear to constrain the data well. In the panels containing SpC ( $\mu \mathrm{S} / \mathrm{cm})$, Monahan Drain (MDOR) and Flowing Creek (FCGR) appear to be missing a high $\mathrm{SpC}$ and low alkalinity/$/ \mathrm{SiO}_{2}$ end-member to constrain them. All the Jock River samples are constrained by the end-members for each solute pair. The hatched 
circle/oval around the Jock River sites is used to illustrate that these sites occupy the same mixing space. In the top panel the tributaries Nichols Creek (NIKS), Kings Creek (KC), Monahan Drain and Flowing Creek have some samples which overlap with the Jock. In the middle panel the Jock samples are more tightly constrained and only a few sites have one or two samples within their range. In the bottom panel Hobbs Drain (HBFT) shows the most overlap with the Jock River sites. The middle and bottom panels appear almost as mirror images of one another and illustrate differences between the main tributaries. In both panels, sites Kings Creek and Nichols Creek are diametrically opposed to Flowing Creek and Monahan Drain. Headwater sites plot more closely to wetland end-members in the middle and bottom panels. In the top panel the main tributary sites demonstrate more overlap and appear less distinct from one another. In this panel, most of the main tributaries plot between the wetland end-members and groundwater end-members sampled from the Oxford Formation. In all panels, Leamy Creek (LMBR) appears to be most distinct from other end-members, shows the most variability, and is not constrained by potential end-members in 2 of the 3 solute pairs. 

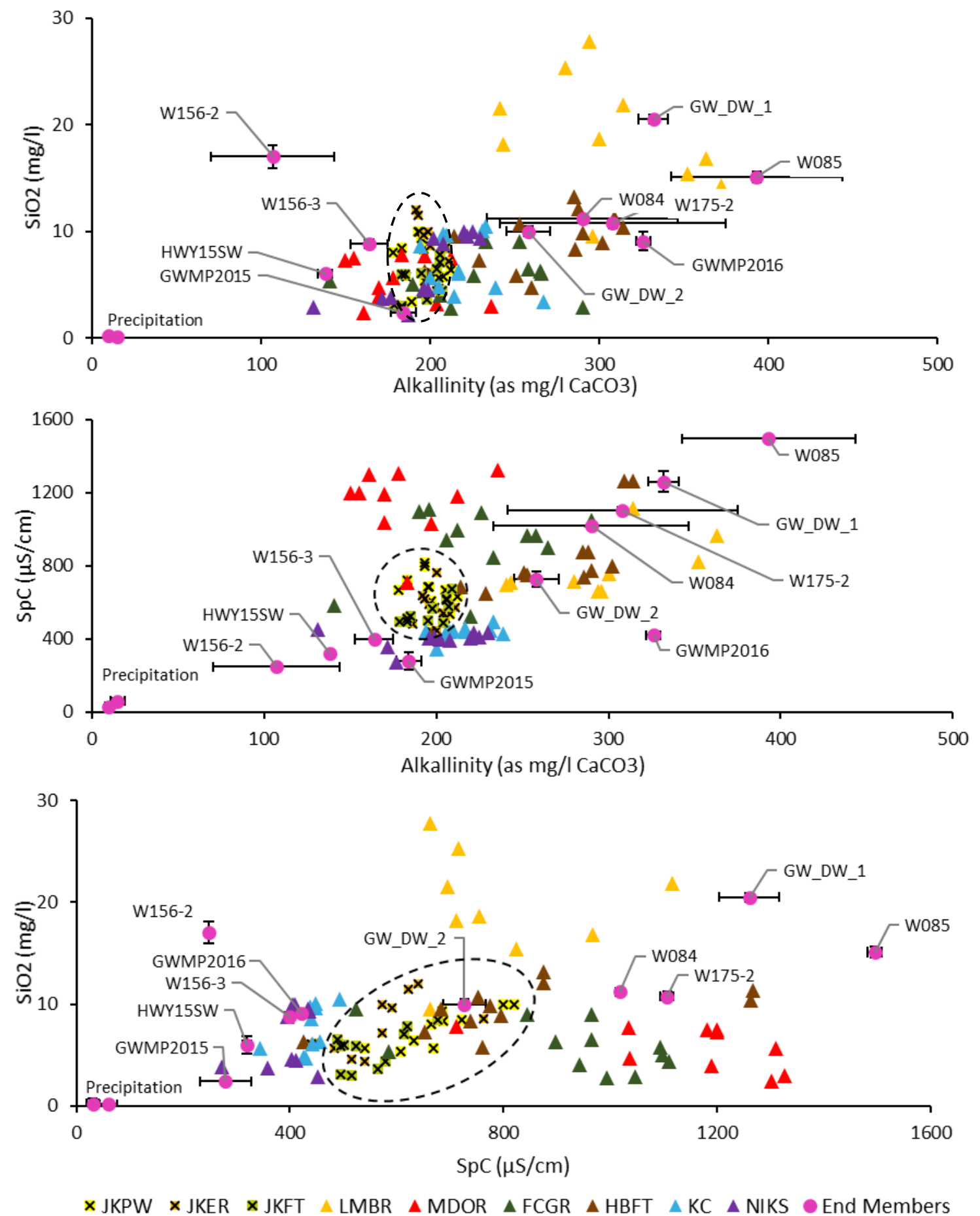

Figure 4-5. Bi-variate plots for each combination of solute pairs demonstrating the geochemical composition of Jock River sites (JKPW, JKER and JKFT) and its main tributaries (LMBR, MDOR, FCGR, HBFT, KC, NIKS) and end-members. Error bars indicate the standard error based on 2015 data and PGMN 2002-2015 data. The hatched circle/oval illustrates the spread of Jock River samples. 
Through examination of the different combinations of solute pairs, the optimal solute pair combination from figure 4-5 would be alkalinity and dissolved silica, as this appears to constrain most of the data. Examining all of the plots in figure 4-5, there appears to be some similarities in potential end-members amongst the stream sites. In panels 2 and 3 Kings Creek and Nichols Creek are characterized by having high wetland contributions, while Flowing Creek and Monahan Drain appear to be more groundwater dominated. In the top panel these distinct groupings aren't as apparent, illustrating that the inclusion of specific conductivity reveals patterns amongst sites not captured by the alkalinity and dissolved silica alone. If one solute pair were selected and the proportions were calculated using a mass balance approach, the proportions calculated from each combination would yield a different result. In these figures the selection of the endmember is entirely based on visual assessment and user interpretation, therefore different end-members could be selected based on those which best constrain the data. EMMA provides a method which allows for integration of variation amongst all the tracers and provides more quantitative methods of end-member selection. Furthermore, the EMMA model and the proportions calculated from it, can be evaluated using more rigorous statistical metrics, providing for more confidence and less subjectivity in the results.

\subsubsection{Residual Analysis}

Residual analysis was used to assess the number of end-members to retain for the subsequent EMMA. Residual plots for a 1 and 2-dimensional mixing space for each variable at each site were produced. As mentioned earlier, PCA performed on small sample sizes can produce misleading results, as the variance is maximized individual points may have a greater effect in the results of the PCA. To mitigate this, the Jock 
River sites were combined to increase the number of samples included in the PCA. The Jock River sites were not found to be statistically significantly different from each other, and demonstrated the smallest variability in all solutes. The similarity and consistency in solute concentration indicates that, although the sample sites differ in location, they are from the same population. By pooling the sites together to perform PCA, the spatial and temporal heterogeneity of the Jock River was captured. Figure 4-6 provides the residual plots for the combined Jock River sites. Residuals were analyzed for structure; no structure in the residuals indicates a good mixing space and conservative tracer behaviour. The residuals demonstrate no structure in both the 1 and 2-dimensional mixing space. Therefore, the lowest dimensional mixing space should be used in the subsequent EMMA for the Jock River. 

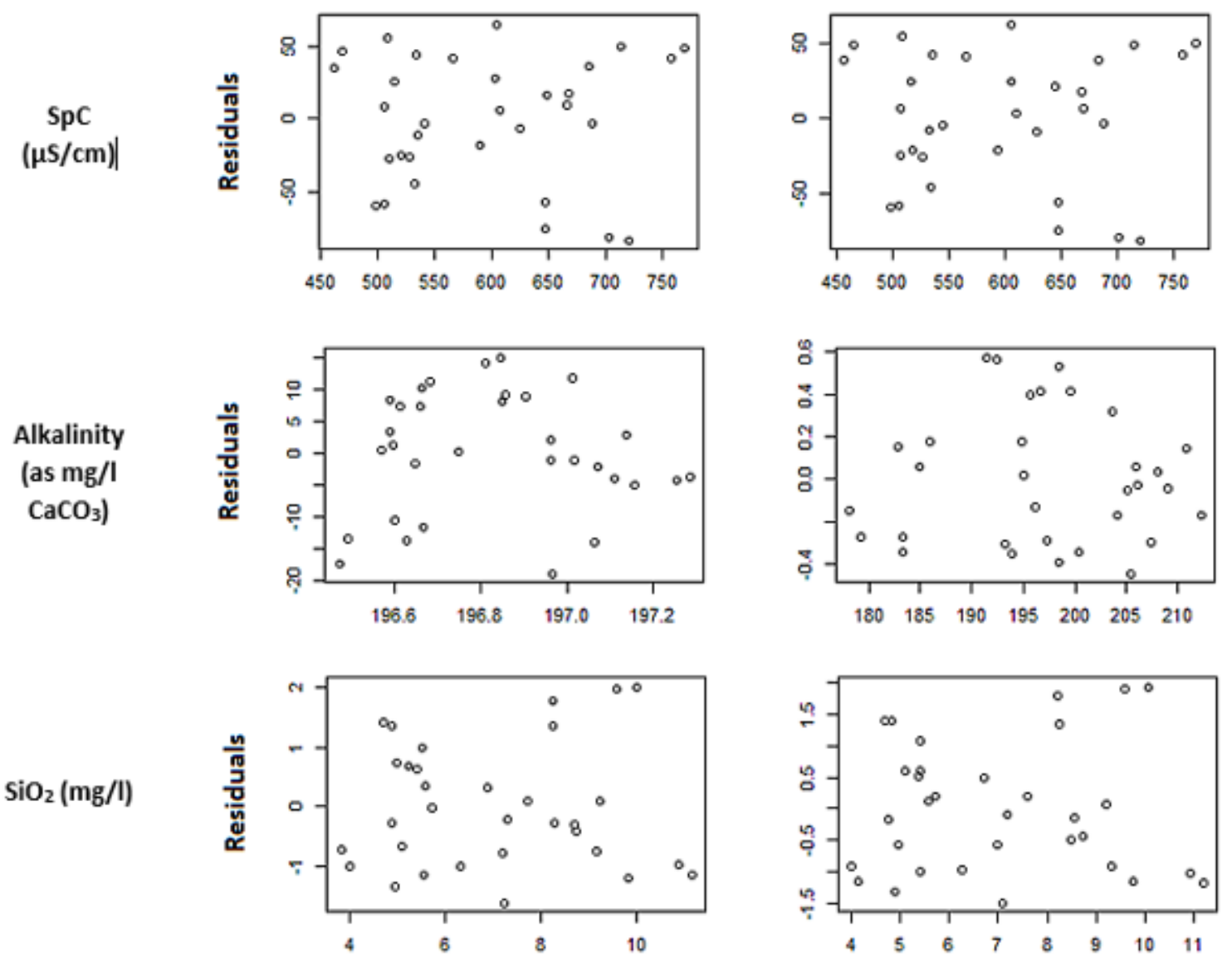

Fitted Concentrations (units vary by solute)

Figure 4-6. Residual vs. fitted plots for 1, 2-dimensional mixing space for variables specific conductivity $(\mathrm{SpC}, \mu \mathrm{S} / \mathrm{cm})$, alkalinity $\left(\mathrm{mg} / \mathrm{l}\right.$ as $\left.\mathrm{CaCO}_{3}\right)$ and dissolved silica $\left(\mathrm{SiO}_{2}\right.$, mg/l) for the compiled Jock River sites.

Due to the small sample size and the pooling together of the Jock River sites the number of end-members retained using the rule of one was also examined. The rule of one is a heuristic rule, stating that an eigenvector must explain one/ \# tracer's variance for it to be retained. In this study, only three tracers were measured repeatedly at each site therefore, each eigenvector must explain $33 \%$ of the variance in the dataset in order to be retained. This is a relatively large percentage so the number of eigenvectors that explained $15 \%$ of variance were also counted to see if the number of end members 
retained increased. Table 4-5 illustrates the differences in the total number of end-

members retained using these different criteria.

Table 4-5. The number of end-members retained at each site using three criteria: (1) The number of end-members retained using the rule of one;(2) The number of end-members retained based on $P C>15 \%$; and (3) The number of eigenvectors retained based on residual analysis (\# of end-members $=$ one + \# of dimensions).

\begin{tabular}{cccc}
\hline Tributary & $\begin{array}{c}\text { Using Rule of One: } \\
\text { (one/\# tracers) } \\
\text { (\% Cumulative } \\
\text { Variance) }\end{array}$ & $\begin{array}{c}\text { PC }>\mathbf{1 5 \%} \\
\text { (\% Cumulative } \\
\text { Variance) }\end{array}$ & $\begin{array}{c}\text { Residual } \\
\text { Analysis }\end{array}$ \\
\hline Jock River (combined sites) & $\mathbf{3}(87 \%)$ & $\mathbf{3}(87 \%)$ & $\mathbf{2}$ \\
Leamy Creek & $\mathbf{3}(62 \%)$ & $\mathbf{3}(87 \%)$ & $\mathbf{2}$ \\
Monahan Drain & $\mathbf{3}(85 \%)$ & $\mathbf{3}(85 \%)$ & $\mathbf{2}$ \\
Flowing Creek & $\mathbf{3}(87 \%)$ & $\mathbf{3}(87 \%)$ & $\mathbf{2}$ \\
Hobbs Drain & $\mathbf{2}(80 \%)$ & $\mathbf{3}(93 \%)$ & $\mathbf{2}$ \\
Kings Creek & $\mathbf{2}(59 \%)$ & $\mathbf{3}(89 \%)$ & $\mathbf{2}$ \\
Nichols Creek & $\mathbf{2}(66 \%)$ & $\mathbf{3}(96 \%)$ & $\mathbf{2}$ \\
\hline
\end{tabular}

Using the rule of one, most of the systems are characterized by three endmembers, that explain $62-87 \%$ of the variance. Hobbs Drain, Kings Creek and Nichols Creek are defined by two end-members that explain 59-66\% of the variance. If principal components that explained $15 \%$ variance or greater were retained, all sites were then increased to three end-member systems, and explained $85-96 \%$ of the total variance. Based on the residual analysis all sites are two end-member systems. Because of the small sample size, EMMA was performed on the pooled Jock River sites using both a two and three end-member mixing model. The final number of end-members retained was decided based on the model fit. EMMA was also performed on the main tributary sites using both a two and three end-member mixing model to see if the end-members 
selected for the compiled Jock River sites matched those selected at each main tributary site.

\subsubsection{End-member Selection for the Jock River}

Individual end-members were screened to determine which best defined the mixing space of the Jock River sites. The percent differences for end-members projected into the Jock River data for a two and three end-member mixing space are provided in table 4-6. The projected end-members and surface water values are shown in U-space for a one and two-dimensional mixing space in figure 4-7. The final end-members retained needed to meet two criteria: they must bound the stream samples and they must have a low percent difference in one or more of the solutes. End-members with lower percent differences are chosen over other end-members which also constrain the stream water chemistry. For both the two and three end-member mixing model of the Jock River GWMP2015 (Goodwood Marsh piezometer 2015) and GW_DW_1 (Groundwater domestic well 1) were chosen as end-members. The third end-member added to the three end-member mixing model was W156-2, which is potentially representative of the basal gravel aquifer or the esker complex in the north-eastern portion of the watershed.

For the two end-member mixing model GW_DW_1 has a lower percent difference in $\mathrm{SpC}$ and $\mathrm{SiO}_{2}$ than other constraining groundwater end-members. For a three end-member mixing model Table 4-6 shows that GW_DW_1 has the lowest percent difference in all 3 solutes and is the most extreme point for most groundwater endmembers, as seen in figure 4-7. GW_DW_2 also has lower percent differences in a two end-member mixing model and low percent differences amongst all solute pairs in a three 
end-member mixing, however it was not chosen as an end-member because it does not completely bound the stream water chemistry in either mixing space.

GWMP2015 was chosen as the second end-member as it has the lowest percent difference for alkalinity and $\mathrm{SpC}$ in both two and three end-member mixing models. Percent differences for $\mathrm{SiO}_{2}$ is relatively high amongst all wetland end-members in both mixing models. GWMP2015 is also the most extreme of all the wetland end-members, as seen in figure 4-7. The wetland end-members in both models demonstrate a progression from the more dilute GWMP2015 to the more concentrated GWMP2016 which is positioned closer to groundwater end-members. Precipitation end-members are the most extreme points in both models but are not considered to be a viable end-members for two reasons: the percent differences are large and it does not fit the conceptual model of baseflow generation. Since surface water samples were collected after snowmelt had dissipated and overland flow does not contribute to baseflow generation, precipitation is not a viable end-member in this conceptual model of baseflow generation. If surface water samples had been collected during precipitation events, precipitation could be a viable end-member in a rainfall-runoff model. However, surface water samples were collected primarily during baseflow periods when direct overland flow would not be contributing to surface water and all contributions to streams would originate from delay sources, such as groundwater and wetlands. Precipitation has been included in the mixing space to illustrate the position of extremely low solute concentration variables in the endmember mixing space. The position of GWMP2015 and GWMP2016 in U space relative to precipitation and groundwater end-members is used to reinforce the idea that GWMP2015 represents a dilute wetland end-member under wet antecedent moisture 
conditions. W156-2 was selected as the third end member in the three end-member

mixing model as it bounds the lower portion of the mixing space entirely and has a lower percent difference than W156-3 in all solutes.

Table 4-6. Percent differences between the original median or 2015 value and its orthogonal projection into the Jock River sites 2 and 3 end-member mixing space for each end-member.

\begin{tabular}{|c|c|c|c|c|c|c|c|c|c|}
\hline \multirow{3}{*}{$\begin{array}{c}\text { Potential } \\
\text { End-Member }\end{array}$} & \multicolumn{3}{|c|}{$\begin{array}{c}\mathrm{SpC} \\
(\mu \mathrm{S} / \mathrm{cm})\end{array}$} & \multicolumn{3}{|c|}{$\begin{array}{c}\text { Alkalinity } \\
\text { (as mg/L CaCO3) }\end{array}$} & \multicolumn{3}{|c|}{$\begin{array}{c}\mathrm{SiO}_{2} \\
(\mathrm{mg} / \mathrm{L})\end{array}$} \\
\hline & \multirow[t]{2}{*}{ Original } & $\begin{array}{r}2 \text { EM } \\
\text { Orth } \\
\text { Proj }\end{array}$ & $\begin{array}{l}\mathbf{3} \text { EM } \\
\text { sonal } \\
\text { ction }\end{array}$ & \multirow[t]{2}{*}{ Original } & \multicolumn{2}{|c|}{$\begin{array}{c}2 \text { EM } 3 \text { EM } \\
\text { Orthogonal } \\
\text { Projection }\end{array}$} & \multirow[t]{2}{*}{ Original } & $\begin{array}{r}2 \text { EM } \\
\text { Orth } \\
\text { Proj }\end{array}$ & $\begin{array}{l}\mathbf{3} \text { EM } \\
\text { onal } \\
\text { ction }\end{array}$ \\
\hline & & \multicolumn{2}{|c|}{$\begin{array}{c}\text { Percent } \\
\text { Difference }\end{array}$} & & \multicolumn{2}{|c|}{$\begin{array}{c}\text { Percent } \\
\text { Difference }\end{array}$} & & \multicolumn{2}{|c|}{$\begin{array}{c}\text { Percent } \\
\text { Difference }\end{array}$} \\
\hline \multirow{2}{*}{ GW_DW_1 } & \multirow{2}{*}{1260} & 1230.6 & 1262.1 & \multirow{2}{*}{332} & 198.5 & 332 & \multirow{2}{*}{20.5} & 22.1 & 20.4 \\
\hline & & 2.4 & 0.2 & & 50.3 & 0 & & 7.5 & 0.2 \\
\hline \multirow{2}{*}{ GW_DW_2 } & \multirow{2}{*}{726.5} & 732.7 & 747 & \multirow{2}{*}{258} & 197.2 & 257.9 & \multirow{2}{*}{10} & 10.3 & 9.5 \\
\hline & & 0.8 & 2.8 & & 26.7 & 0.1 & & 2.5 & 5 \\
\hline \multirow{2}{*}{ W156-3 } & \multirow{2}{*}{398.6} & 530.3 & 522.3 & \multirow{2}{*}{164} & 196.7 & 163.1 & \multirow{2}{*}{8.8} & 5.4 & 5.9 \\
\hline & & 28.3 & 26.9 & & 18.1 & 0.5 & & 47.1 & 40.1 \\
\hline \multirow{2}{*}{ W156-2 } & \multirow{2}{*}{248} & 619.3 & 597.5 & \multirow{2}{*}{107} & 196.9 & 104.5 & \multirow{2}{*}{17} & 7.6 & 8.7 \\
\hline & & 85.6 & 82.7 & & 59.2 & 2.3 & & 76.8 & 64.6 \\
\hline W084 & 1017 & 907.7 & 929.7 & 290 & 197.6 & 290.6 & 112 & 14.4 & 13.3 \\
\hline 10004 & 1017 & 11.4 & 9 & 270 & 37.9 & 0.2 & 11.2 & 25.1 & 17 \\
\hline W085 & 1495 & 1243.3 & 1289.5 & 393 & 198.5 & 394.5 & 151 & 22.4 & 20 \\
\hline 6000 & 1470 & 18.4 & 14.8 & 393 & 65.8 & 0.4 & 15.1 & 38.9 & 27.8 \\
\hline W175-2 & 1106 & 945.1 & 971.4 & 308 & 197.7 & 309 & 107 & 15.3 & 13.9 \\
\hline & & 15.7 & 13 & & 43.6 & 0.3 & & 35.1 & 25.9 \\
\hline W175-3 & 1293 & 1049.7 & 1091.1 & 372 & 198.0 & 373.4 & 108 & 17.8 & 15.6 \\
\hline W & 1270 & 20.8 & 16.9 & Ji2 & 61.0 & 0.4 & 10.0 & 48.6 & 36.2 \\
\hline GWMP2015 & 2795 & 339.0 & 336 & 184 & 196.2 & 183.6 & 24 & 0.9 & 1.1 \\
\hline 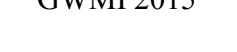 & 279.0 & 19.2 & 18.4 & 104 & 6.4 & 0.2 & 2.4 & 90.6 & 77.7 \\
\hline GWMP2016 & 421 & 569.4 & 599.6 & 326 & 196.8 & 324.7 & 91 & 6.4 & 4.8 \\
\hline UWVIVIT 2010 & 421 & 30.0 & 35 & 520 & 49.4 & 0.4 & 9.1 & 34.6 & 61.3 \\
\hline HRP2016 & 267 & 416.1 & 422.3 & 224 & 196.4 & 222.9 & 61 & 2.7 & 2.4 \\
\hline 1010010 & 201 & 43.6 & 45.1 & 227 & 13.2 & 0.5 & 0.1 & 76.2 & 86.8 \\
\hline HWY15P2 2016 & 308 & 451.3 & 471.7 & 284 & 196.4 & 282.8 & 64 & 3.6 & 2.5 \\
\hline & & 37.7 & 42 & & 36.4 & 0.4 & & 56.7 & 87.3 \\
\hline HWY15SW & 319 & 427.9 & 414 & 138 & 196.4 & 137.3 & 6 & 3.0 & 3.7 \\
\hline & 319 & 29.2 & 25.9 & 150 & 34.9 & 0.5 & & 66.2 & 46.3 \\
\hline Rain & 309 & 143.2 & 99.2 & 97 & 195.6 & 9.2 & 02 & -3.7 & -1.5 \\
\hline & & 129.1 & 105.1 & & 181.2 & 5.1 & & -218.4 & -251 \\
\hline Snow melt & 605 & 158.2 & 115.4 & 148 & 195.7 & 14.4 & 01 & -3.4 & -1.2 \\
\hline SHow ment & 00.3 & 89.4 & 62.4 & 14.0 & 171.9 & 2.7 & 0.1 & -217.2 & -254.6 \\
\hline $\begin{array}{r}\text { Average } \mathbf{P} \\
\text { Differer }\end{array}$ & cent & 37.44 & 33.35 & & 57.07 & 0.93 & & 11.35 & 4.71 \\
\hline
\end{tabular}



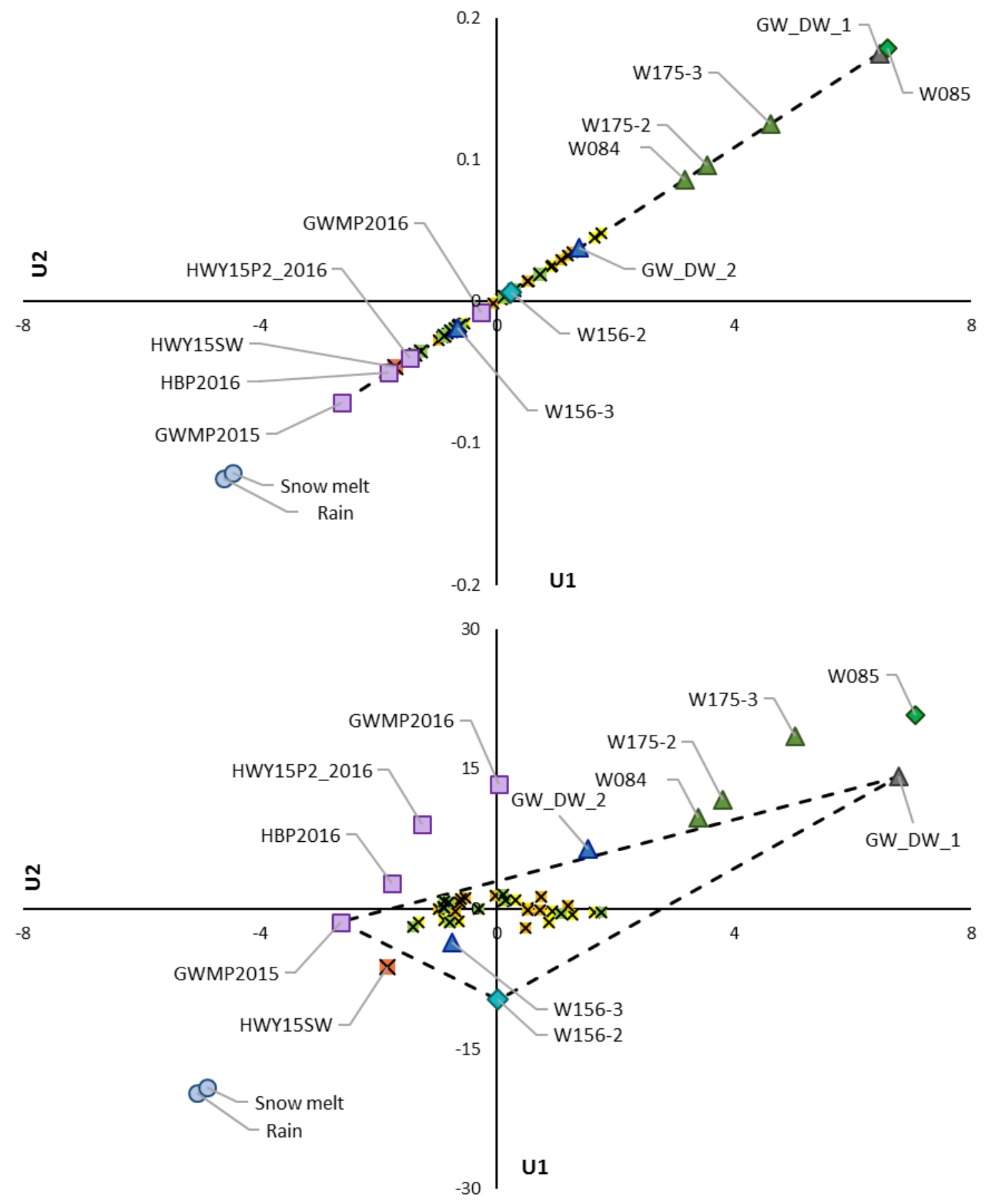

\begin{tabular}{|c|c|c|}
\hline JKER & JKER & JKFT \\
\hline HWY15SW & Wetlands & Oxford \\
\hline Gull River & Limestone & Basal Gravel/Oxford Interface \\
\hline Unconfined Till & Precipitation & - - - End Members \\
\hline
\end{tabular}

Figure 4-7. Jock River sites projected in U-space for a two end-member mixing space (top) and a three end-member mixing space (bottom). Potential end-members are identified by both their ID's and the geologic/land cover type. The end-member mixing space is identified by the hatched lines. 


\subsubsection{Model Accuracy Evaluation for the Jock River}

Table 4-7 and Figure 4-8 illustrates the Jock River mixing models accuracy for a two and three end-member mixing model. These parameters reflect the ability of the models to predict the stream water chemistry based on the matrix multiplication of the end-member proportions and the destandardized orthogonal projection of the endmembers into the mixing space. Recall, that the mixing space is defined based on the number of eigenvectors $(m)$ retained through matrix multiplication of the matrix formed by these eigenvectors $(\mathbf{V})$. Therefore, a two end-member model reflects the first eigenvector and a three end-member model reflects the first and second eigenvectors. For the Jock River data set the first eigenvector loads strongly (0.71) for both $\mathrm{SpC}$ and $\mathrm{SiO}_{2}$ but loads weakly for alkalinity (0.02). The lack of representation of alkalinity in the first principal component is reflected in the two end-member model as a zero correlation between the observed and predicted concentrations for alkalinity. The second eigenvector loads high for alkalinity (-1) and low for $\mathrm{SpC}$ and $\mathrm{SiO}_{2}$ (-0.02 and 0.05 , respectively), increasing the correlation between observed and predicted alkalinity to an $\mathrm{R}^{2}$ of 1 . The addition of this second eigenvector doesn't alter the $\mathrm{R}^{2}$ or RRMSE of $\mathrm{SpC}$ and $\mathrm{SiO}_{2}$ as these solutes are not expressed in this eigenvector. The perfect correlation is a mathematic phenomenon as the matrix multiplication of the eigenvectors is used to express the solutes in U-space in terms of their original coordinates. The use of PCA here reduces the dimensionality of the three tracers, so that the first component explains variance in two tracers and the second explains variance in the third. The calculated proportions are the result of the surface water coordinates relative to the coordinates of the end-members projected into the stream water mixing space. The random pattern in the 
residuals in figure 4-8 and the small RRMSE in table 4-7 indicate good model fit for both the 2 and 3 end-member mixing models. The RRMSE observed by James and Roulet (2006) for sites projected into their own mixing space was similarly low (2-15\%). The slightly higher RRMSE reported by James and Roulet (2006) may have resulted from EMMA being performed on a greater number of variables $\left(\mathrm{Na}^{+}, \mathrm{Ca}^{2+}, \mathrm{Mg}^{2+}\right.$, alkalinity and conductivity). The inclusion of more variables introduces more variability into the dataset increasing the RRMSE. Hooper (2003) also included more variables in the EMMA (alkalinity, $\mathrm{Na}^{+}, \mathrm{Ca}^{2+}, \mathrm{Mg}^{2+}, \mathrm{SO}_{4}{ }^{2-}$ and $\mathrm{Si}$ ), thus the RRMSE of sites projected into their own mixing space is similar to those found by James and Roulet (2006). The RRMSEs presented in table 4-7 are much smaller than those observed by Hooper (2003) and James and Roulet (2006) due to the reduction in variables included in the EMMA. The distribution of the surface water values in figure 4-7 appears to have enough variation in the $y$-axis that the retention of a third end-member for this system is appropriate. The final proportions for the three end-member model are provided in the subsequent sections.

Table 4-7. Model quality parameters coefficient of determination $\left(R^{2}\right)$ and relative root mean square error (RRMSE) for EMMA results of Jock River sites using 2 end-members and 3 end-members.

\begin{tabular}{|c|c|c|c|c|c|}
\hline \multicolumn{3}{|c|}{2 End-Members } & \multicolumn{3}{|c|}{3 End-Members } \\
\hline $\begin{array}{c}\mathrm{SpC} \\
(\mu \mathrm{S} / \mathrm{cm})\end{array}$ & $\begin{array}{c}\text { Alkalinity } \\
\text { (as mg/L } \\
\text { CaCO3) }\end{array}$ & $\underset{(\mathrm{mg} / \mathrm{L})}{\mathrm{SiO2}}$ & $\underset{(\mu \mathrm{Sp} / \mathrm{cm})}{\mathrm{SpC}}$ & $\begin{array}{c}\text { Alkalinity } \\
\text { (as mg/L } \\
\text { CaCO3) }\end{array}$ & $\begin{array}{c}\mathrm{SiO2} \\
(\mathrm{mg} / \mathrm{L})\end{array}$ \\
\hline \multicolumn{6}{|c|}{$R^{2}$} \\
\hline 0.81 & 0.00 & 0.81 & 0.81 & 1.00 & 0.81 \\
\hline \multicolumn{6}{|c|}{ RRMSE } \\
\hline 0.01 & 0.01 & 0.03 & 0.01 & $2.70 \times 10^{-4}$ & 0.03 \\
\hline
\end{tabular}




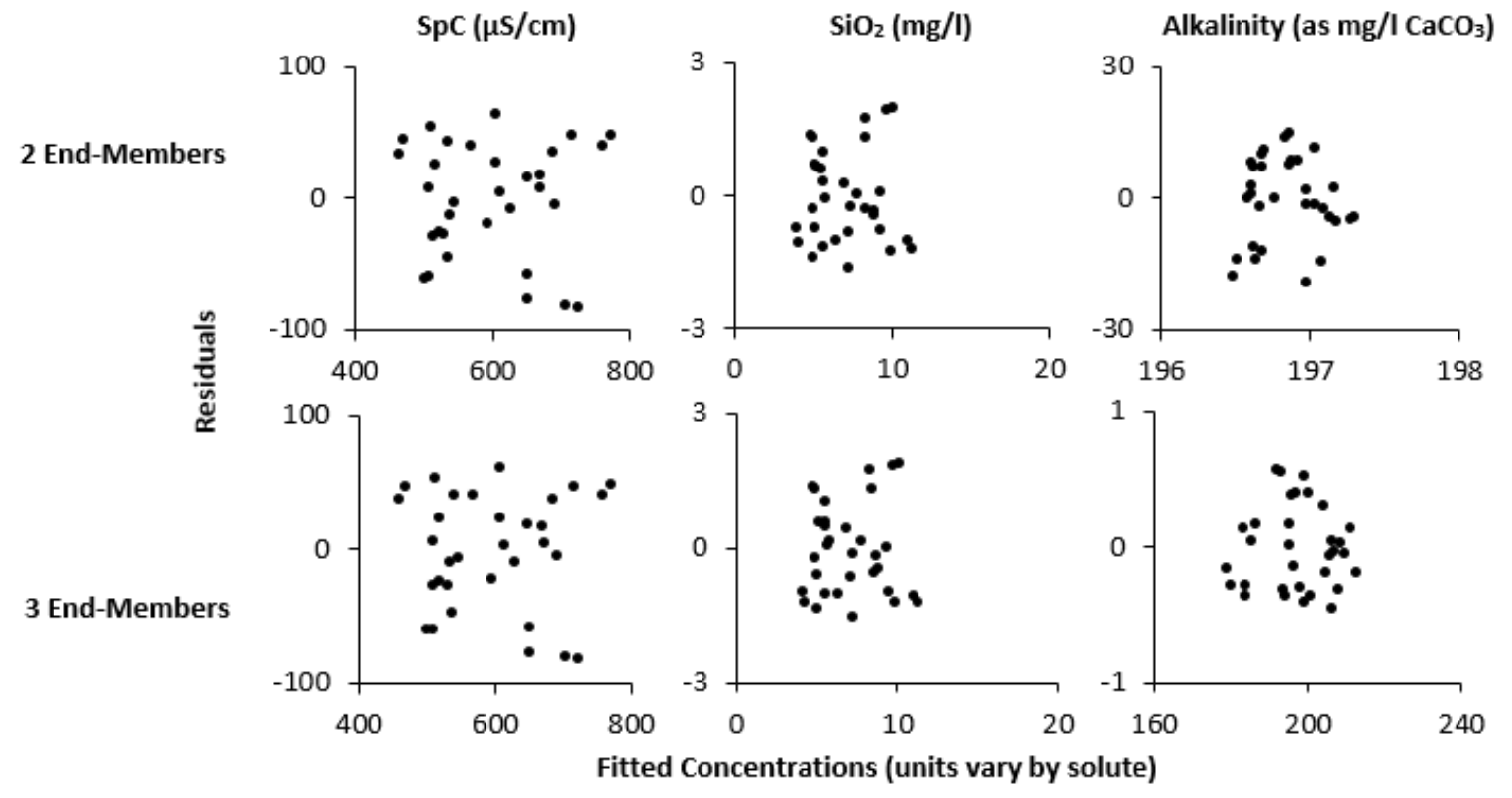

Figure 4-8. Residuals vs. fitted concentrations $\mathrm{SpC}(\mu \mathrm{S} / \mathrm{cm}), \mathrm{SiO}_{2}(\mathrm{mg} / \mathrm{l})$ and Alkalinity (as $\mathrm{mg} / \mathrm{l} \mathrm{CaCO}_{3}$ ) for the Jock River sites in a 2 and 3 end-member mixing model.

The model uncertainty calculated following Burns et al., (2001) is approximately $26.3 \%$, see equation 16 , in which $W_{u i}$ is the uncertainty value for the principal component I, $V_{i a} V_{i b}$ are the eigenvectors for constituent's $a$ and $b$ on principal component $i$, and $W_{a}$ and $W_{b}$ are the analytical uncertainties in the values of constituent's $a$ and $b$. The greatest uncertainty was calculated for principal component 1 in which large uncertainty in specific conductivity concentrations results in large uncertainty in model estimates $(\sim 21.3 \%)$. The uncertainty in the second principal component is much lower $(\sim 5 \%)$. Model uncertainty in Burns et al., (2001) was $11.7 \%$ which is considerably lower than seen here, as analytical uncertainties are usually much lower for cation and anions than for specific conductivity.

$$
W_{u i}=\left(\left(V_{i a} W_{a}\right)^{2}+\left(V_{i b} W_{b}\right)^{2}\right)^{0.5}
$$




\subsubsection{End-member Proportions for the Jock River}

Figure 4-9 demonstrates the final end-member proportions calculated for the Jock River sites. The Jock River at Franktown Rd (JKFT) is representative of the Jock River headwaters as this is the point before other main tributaries contribute flow to the Jock River. In figure 4-9 this site shows that the majority (>50\%) is from wetlands. Velderman (1993) notes that there is a connection between the basal gravel aquifer and the wetlands in the southern portion of the watershed. The representation of end-member W156-2 at the JKFT site may be a reflection of this relationship. Contributions from this endmember fluctuate between 7 to $25 \%$ of stream flow, increasing during low flow conditions. The groundwater end-member GW_DW_1 contributes 8-29\% of total streamflow at this site. Increases in contributions from this end member occur under wet antecedent moisture conditions in the beginning of the summer and autumn.

The Jock River at Eagleson Rd (JKER) shows that wetlands are an important source of flow under wet antecedent conditions with contributions of $64-78 \%$ during early June and late Autumn. During August, the sources generating flow shift markedly to groundwater end-members. August $8^{\text {th }}, 10^{\text {th }}$ and September $3^{\text {rd }}$ samples show that W156-2 is contributing to $41 \%, 44 \%$ and $36 \%$ of the flow respectively. GW_DW_1 and GWMP are both contributing approximately $30 \%$ of flow during this time.

Flow at the outlet (JKPW) follows the same trend described for the Jock River at Eagleson. The wetland end-member is still expressed at the outlet and is the greatest contributing end-member under wet antecedent conditions $(\sim 60 \%)$, indicating that contributions from wetlands upstream greatly impact total flow in the Jock River under wet antecedent moisture conditions. The end-member W156-2 contributes the most to 
flow at the outlet during drier antecedent moisture conditions, contributing between $49 \%$ and $34 \%$ of flow between August $8^{\text {th }}$ and September $24^{\text {th }}$, respectively. Groundwater endmember GW_DW_1 contributions remain fairly consistent throughout the growing season, the proportion of flow generated from this end-member is between 19-33\%.

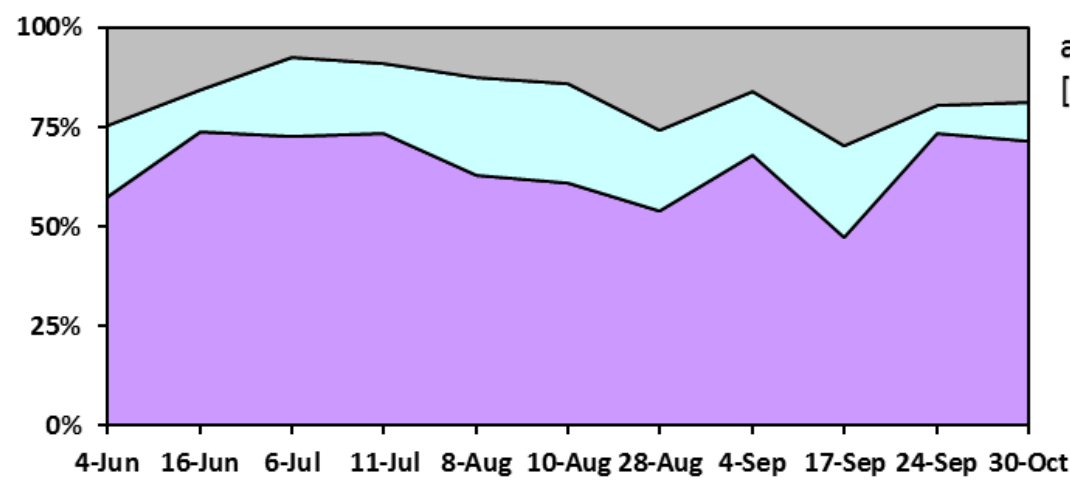

a) Jock River [headwaters] 口JKFT GW_DW_1

口JKFT W156-2

口JKFT GWMP

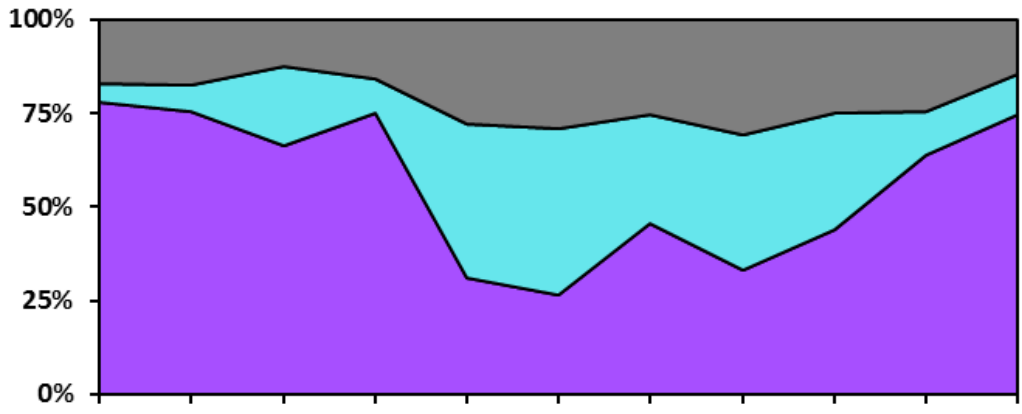

b) Jock River [mid-point]

口JKER GW_DW_1

口JKER W156-2

口JKER GWMP

17-Jun 6-Jul 11-Jul 13-Jul 8-Aug 10-Aug 28-Aug 3-Sep 17-Sep 24-Sep 29-Oct

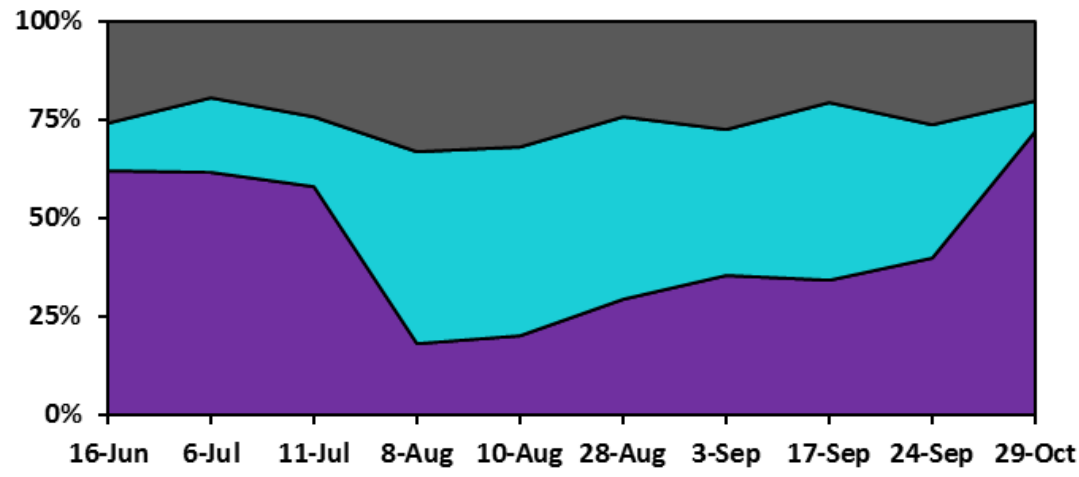

c) Jock River [outlet]

口JKPW GW_DW_1

口JKPW W156-2

口JKPW GWMP

Figure 4-9. End-member proportions for the Jock River sites; (a) Jock at Franktown Rd (JKFT) [headwaters]; (b) Jock at Eagleson Rd (JKER) [mid-point] and; (c) Jock at Prince of Wales (JKPW) [outlet]. End-members: GW_DW_1 [groundwater from deep limestone aquifer-regional groundwater], W156-2 [groundwater from basal gravel/esker aquifer], GWMP [groundwater from forested wetland-shallow groundwater flow system]. Colours were darkened to demonstrate the shift from upstream sites to downstream sites. 


\subsubsection{Projecting Main Tributaries into the Jock River Mixing Space}

The main tributary sites were projected into the Jock River mixing space to determine if a single linear mixing model could be used to explain flow generation in the Jock River watershed. Figure 4-10 illustrates that none of the main tributary sites are completely constrained by the end-members selected over the entire study period. King's Creek, Nichols Creek and Flowing Creek are the most well constrained, with only a few points outside of the mixing triangle, most of which are located close to the mixing line. King's Creek and Nichols Creek points are located closest to the wetland end-member and mostly lay along the mixing line between the wetland end-member and the groundwater end-member. Flowing Creek demonstrates a large variability in its distribution in the mixing space, with points scattered across the mixing triangle. Monahan Drain is half constrained by the mixing triangle. Most of its points are located along the mixing line between W156-2 and GW_DW_1. Hobbs Drain and Leamy Creek are the least constrained tributaries. Both sites have points which lay closer to the GW_DW_1 end-member. Hobbs Drain has several points which occupy the space in the middle of the mixing line between GWMP2015 and GW_DW_1. 


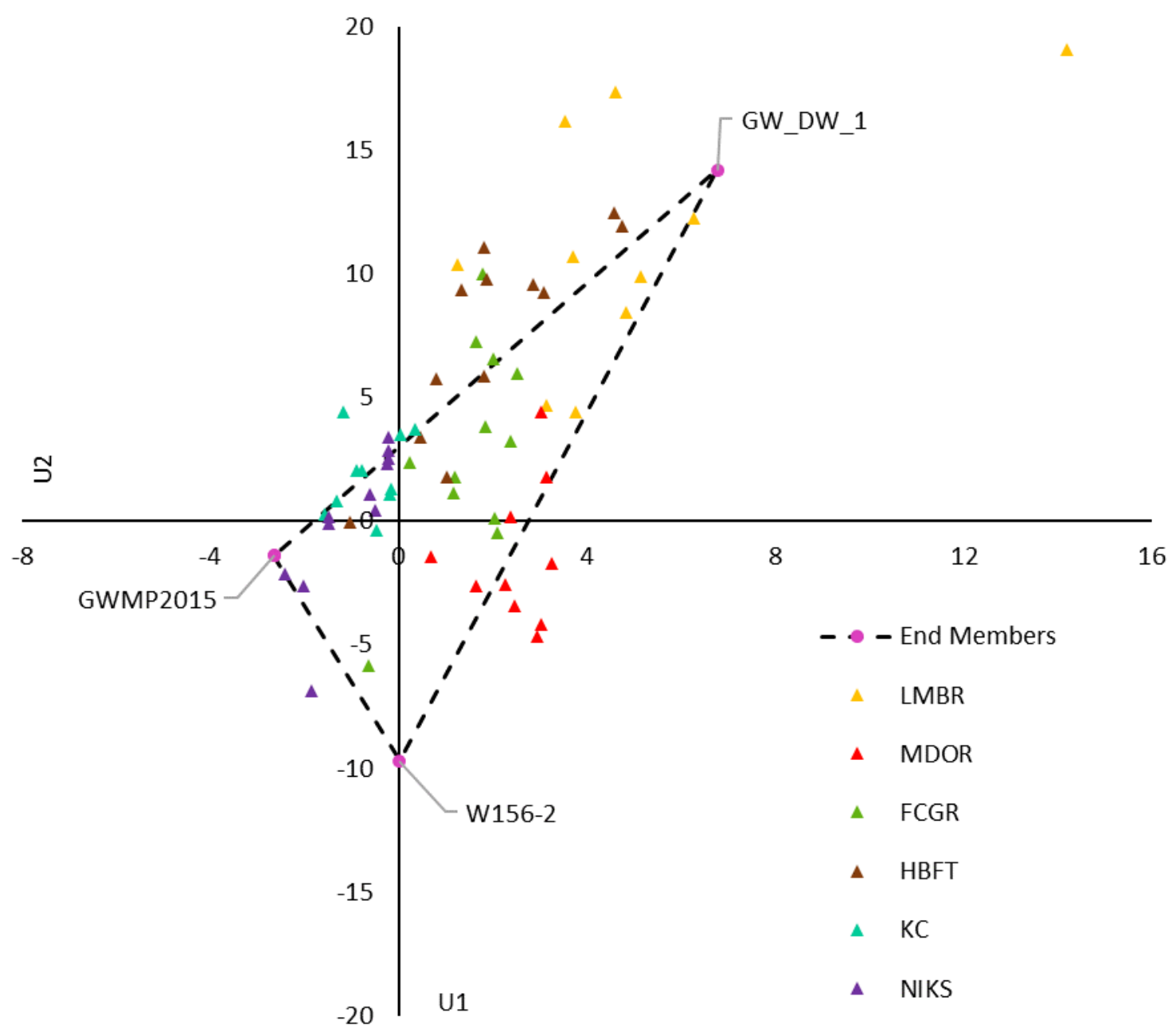

Figure 4-10. Main tributary sites: Leamy Creek (LMBR), Monahan Drain (MDOR), Flowing Creek (FCGR), Hobbs Drain (HBFT), Kings Creek (KC) and Nichols Creek (NIKS) projected into the Jock River 3 end-member U-space. End-members: GW_DW_1 [groundwater from deep limestone aquifer-regional groundwater ], W156-2 [groundwater from basal gravel/esker aquifer], GWMP [groundwater from forested wetland-shallow groundwater flow system].

All sites were constrained to the mixing triangle by minimizing the distance between the points and the mixing lines as outlined in section 3.4.1.5. Table 4-8 provides the values of the coefficient of determination $\left(\mathrm{R}^{2}\right)$, the RRMSE and the relative bias for the main tributary sites projected into the Jock River (JR) mixing space. The results from the Jock River are also provided in table 4-8 and are used as a benchmark to evaluate model fit for the projected main tributary sites. The tracers $\mathrm{SpC}$ and $\mathrm{SiO}_{2}$ show the 
largest decreases in $\mathrm{R}^{2}$, the largest increases in RRMSE when compared to the Jock River model. The $\mathrm{SiO}_{2}$ fit is the poorest amongst all solutes, the correlation between observed and predicted concentrations are extremely low $\left(\mathrm{R}^{2}=0.01-0.25\right)$ with only Hobbs Drain demonstrating a moderate correlation $\left(\mathrm{R}^{2}=0.44\right)$. RRMSE increases significantly at most sites $(0.11-0.37)$ compared to the Jock River model $($ RRMSE $=0.03)$. The relative bias for $\mathrm{SiO}_{2}$ is the greatest amongst all solutes $(\mathrm{RB}=-0.59-10.90)$, indicating overprediction. Plots of observed solute concentration versus the predicted solute concentration provided in Appendix B, figure B-0-1, show that in most cases when measured $\mathrm{SiO}_{2}$ concentrations were low, predicted values were overpredicted and when measured $\mathrm{SiO}_{2}$ concentrations were higher predicted concentrations were underpredicted. Examining the residual plots in Appendix B, figure B-0-2, there does not appear to be any structure in the residuals amongst the sample sites indicating that this tracer most likely is behaving conservatively.

Alkalinity appears to perform the best as a tracer, maintaining relatively high correlations between observed and predicted concentration $\left(\mathrm{R}^{2}=0.88-1.00\right)$, with the exception of Flowing Creek which has an $\mathrm{R}^{2}$ of 0.27 . RRMSE of the projected sites are very low (0.01-0.05) indicating good predictive ability. The relative bias is also the lowest for alkalinity amongst all solutes (-0.18-0.19). Most sites exhibit low negative relative bias indicating slight underprediction in alkalinity concentrations. Examining figure B-0-1 in Appendix B for the alkalinity of Flowing Creek, it becomes apparent that two sample points are influencing the model fit, with one point greatly overpredicted and one greatly underpredicted. These points are presumably why this site has a relative bias of zero. A limitation of this study is the small number of sample points collected for each 
individual site, this issue becomes most apparent under these circumstances, when a few sample points can significantly affect model quality parameters. The residual plots in Appendix $B$, figure $B-0-2$ demonstrate that most samples fall along a line at the 0 mark, Monahan Drain, Leamy Creek and Hobbs Drain demonstrated the most deviation in the residuals. The residuals at Flowing Creek, King's Creek and Nichols Creek are mostly equal to zero, with a few data points demonstrating under and overprediction. The influence of the under and overpredicted points on the overall correlation is greatest for Flowing Creek as the residuals are much larger than at other sites (-91.8 and 85.58) while most others range between (-23.29 and 21.99) with an average of -1.28 . Hobbs Drain demonstrates some potential curvature in its residuals. However, in order for patterns in the residuals to become more visually apparent, increased sample sizes are required.

Predictions for $\mathrm{SpC}$ have a moderately good correlation with observed measurements $\left(\mathrm{R}^{2}=0.41-0.78\right)$. The RRMSE was significantly greater $(0.04-0.18)$ than the Jock River RRMSE (0.01), but overall remained relatively low. The relative bias of the $\mathrm{SpC}$ amongst all sites ranges from -3.07 to 3.04, with most sites overpredicting SpC. Monahan Drain and Flowing Creek are the only sites which under predict SpC. The residual plots in Appendix A, figure A-0-2, suggests that one measurement at Leamy Creek was greatly underpredicted; this measurement is an outlier in the original measured dataset. Most residuals don't appear to have any structure. Kings Creek and Nichols Creek may have some curvature in their residuals for $\mathrm{SpC}$, however due to the small sample size this is difficult to interpret. Increased sample sizes may reveal more structure in the dataset and provide more reliable quantitative measures. 
Table 4-8. Model quality parameters. Coefficient of determination $\left(R^{2}\right), R R M S E$ and relative bias for main tributary sites projected into the Jock River (JR) mixing space and projected into their own two end-member (2 EM) and three end-member (3 EM) mixing spaces. Colour coded red to show increases, blue to show decreases and green to indicate no change relative to the JR. '-' indicates no suitable end-members could be identified. The columns $P C 1$ and $P C 2$ indicate if the $P C$ 's are representing all of the tracers or a subset of the tracers, tracers which load highest are in brackets.

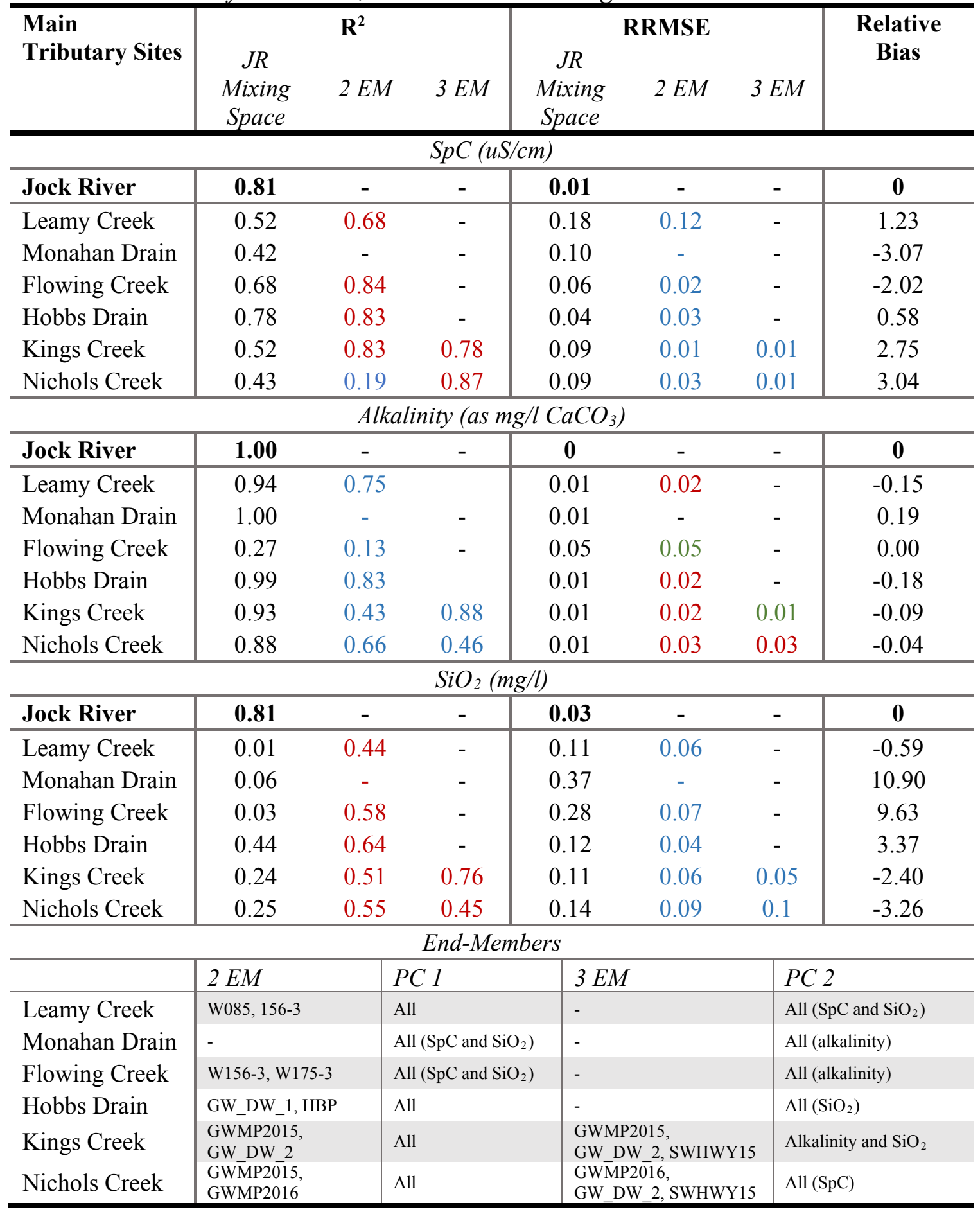


Hooper (2003) suggests that evaluation of the RRMSE of sites projected into a reference site use the RRMSE of sites projected into their own mixing space as a bench mark to evaluate model fit. The main tributary sites of the Jock River watershed were projected into their own one and two-dimensional mixing space to evaluate the RRMSE and to determine if the end-members remained consistent. In most cases, two endmembers could be identified in a one-dimensional mixing space for the main tributary sites. Monahan Drain is the only site in which suitable end-members could not be identified in a one-dimensional mixing space. Conversely in most cases a suitable endmember could not be identified for a two-dimensional mixing space. Only headwater sites Kings Creek and Nichols Creek had suitable end-members. The new end-members selected reflected temporal or small scale spatial variability in the wetland end-member. Table 4-8 has been colour coded to indicate changes in the predictive ability of the sites projected into their own mixing space versus the Jock River mixing space.

Overall the predictive ability in tracers $\mathrm{SpC}$ and $\mathrm{SiO}_{2}$ is improved through projection into their own mixing space. Prediction of alkalinity concentrations significantly worsened when sites were projected into their own 1-dimensional mixing space. Kings Creek and Nichols Creek were the only sites projected into a 2-dimensional mixing space and show alternating results for their model predictions between a 2 and 3 end-member mixing space. The end-members identified were slightly different from those identified in the Jock River mixing space. Leamy Creek proportions (figure 4-11) projected and constrained onto the mixing diagram did not always yield values between $0-100 \%$, presumably because the points were so far away from the mixing triangle. When projected into its own mixing space the end-members identified are W085 (unconfined 
overburden, sand and gravel) and W156-3 (limestone/dolostone, part of the Oxford Formation). The proportions here show seasonal trends with the first half of the growing season dominated by W156-3 and the latter half dominated by W085. This site is most likely dominated by three end members, as Leamy Creek cuts through a series of farm fields, it is likely that soil water from these fields is an important end member in this system.

Suitable end-members could not be identified for Monahan Drain. Figure 4-11 shows that when projected into the Jock River mixing space, this site is dominated by the W156-2 end-member, which could potentially represent the esker or the basal gravel aquifer. As this tributary is situated on top of the esker, the expression of this endmember as the major contributor to baseflow is appropriate. However, since it could not be constrained when these end-members were projected into its own mixing space, this indicates that there is potentially another end-member that is controlling the stream chemistry at this site or that the end-member W156-2 is in fact, not an expression of the esker water. The esker was not sampled directly therefore it is difficult to conclude if spatial heterogeneity of the esker groundwater signature may also be influencing the stream water chemistry at this site.

The projection of Flowing Creek into the Jock River mixing space fits moderately well to poorly. When projected into its own one-dimensional mixing space, model fit is improved for $\mathrm{SpC}$ and $\mathrm{SiO}_{2}$. End-members were chosen based on the same criteria outlined for the Jock river. For this site the end-members are both deep groundwater wells W156-3 and W175-3 (Gull River Formation). It is most likely that this site is defined by three end-members, however none of the end-members sampled constrain the 
two-dimensional mixing space. This indicates that an end-member which was not sampled may contribute significantly to flow at Flowing Creek. As Flowing Creek is also located in a predominantly agricultural area, it is also likely that soil water from overburden in adjacent fields is most likely an important end-member to this system.

Hobbs Drain, Kings Creek and Nichols Creek fit the Jock River mixing model the best. The proportion of the W156-2 end-member for these sites projected into the Jock River mixing space shows little contribution to stream flow in comparison to other sites. Hobbs Drain is dominated by the groundwater (GW_DW_1) end-member, whereas Kings Creek and Nichols Creek are dominated by the wetland end-member (GWMP2015). When these sites are projected into their own mixing space, the endmembers do not change significantly. The wetland end-member at Hobbs Drain is best defined by its own wetland end-member (HBP). Using this wetland end-member, wetland contributions at Hobbs Drain increase. The groundwater end-member for Hobbs Drain remains the same and generally shows the same trend over the growing season with groundwater contributions increasing during the drier months. The wetland end-member at Kings Creek remains consistent with the Jock River mixing model but the groundwater end-member appears to be best defined by GW_DW_2 (Oxford Formation). Both GW_DW_1 and GW_DW_2 are limestone/dolostone bedrock groundwater wells, but differences in the composition of the bedrock and the overlying surficial geology result in the spatial variation in these end-members. The shift in the groundwater end-member results in greater groundwater contributions at this site. There is little seasonal fluctuation in the groundwater end-member at this site. Nichols Creek shows the greatest change when projected into its own mixing space. When projected into its own mixing space the 
groundwater end-member is completely absent from flow at Nichols Creek. Nichols Creek is instead dominated by seasonal variability in the wetland end-member. The points lay along the line between the GWMP2015 (wet antecedent moisture conditions) and the GWMP2016 (drier antecedent moisture conditions). The results indicate that this site is completely dominated by the wetland end-member. The proportions of each wetland end-member indicate drier and wetter conditions therefore not surprisingly GWMP2016 contributes the most during the later/drier summer months.

In a two-dimensional mixing space (figure 4-12) Kings Creek demonstrates the greatest difference between the projection into the Jock River and its own mixing subspace. The change in the groundwater end-member selected at this site has a significant influence on the proportion of groundwater contributions to total streamflow. Nichols Creek demonstrates little variation between the end-member proportions from the Jock River model and its own projection. Wetland end-members at both sites have been subdivided into one representing contributions from the headwater swamp (HWY15SW) and the forested wetland Goodwood Marsh (GWMP2015-2016). In both instances these sites are most likely characterized by two end-members: a wetland endmember and a groundwater end-member.

The main tributaries of the Jock River can be projected into a single linear mixing model defined by the main stem of the Jock River, as indicated by the moderately good predictive ability of the model. Although the model fails in predicting $\mathrm{SiO}_{2}$ concentration with great accuracy the RRMSE is still relatively low. The projection of the sites into their own mixing space reveals that spatial and temporal heterogeneity in the endmembers exists and may lead significant changes in the proportions based on the end- 
members defined. Sites upstream demonstrate the best fit and the most consistency between the Jock River model and their own projections. Sites downstream demonstrate missing end-members or different end-members from the Jock River model. Increased site specific sampling of potential end-members may aid in better defining the main tributaries mixing spaces. Overall the general trends in end-member proportions remain consistent amongst the main tributaries projected into their own mixing space and into the Jock River. 
JR 3 EM
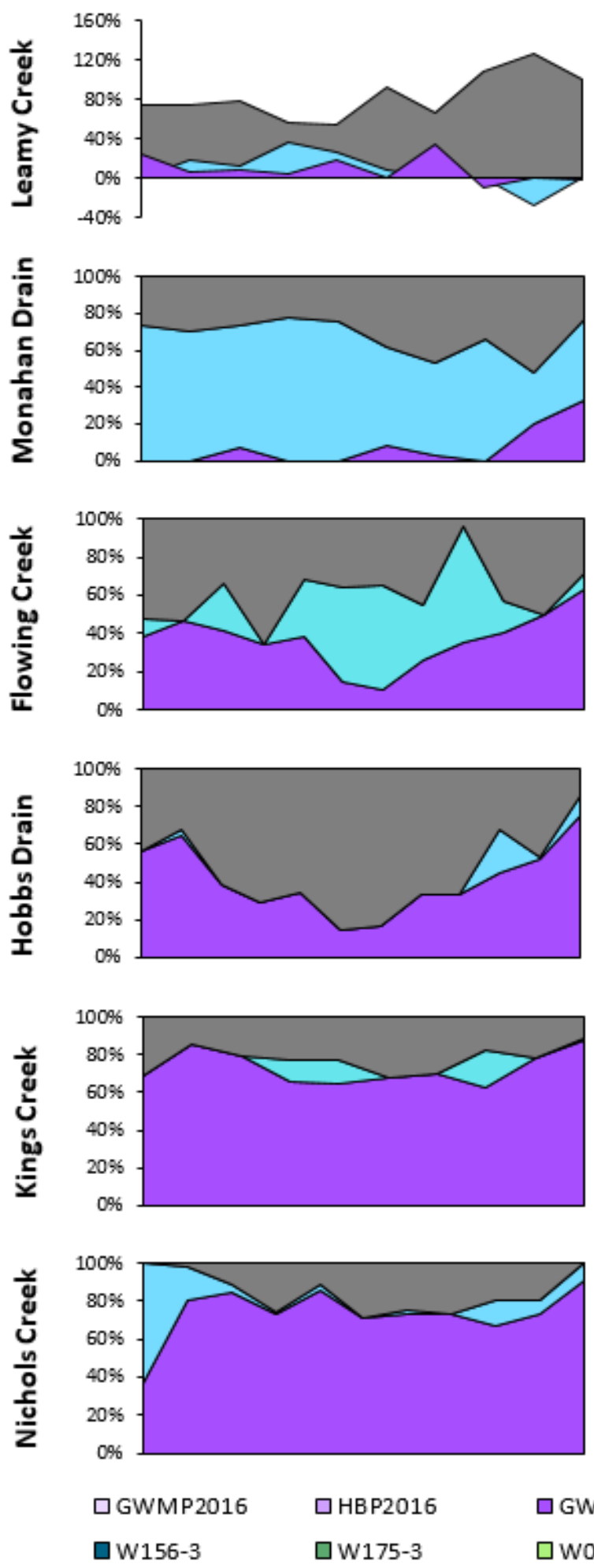
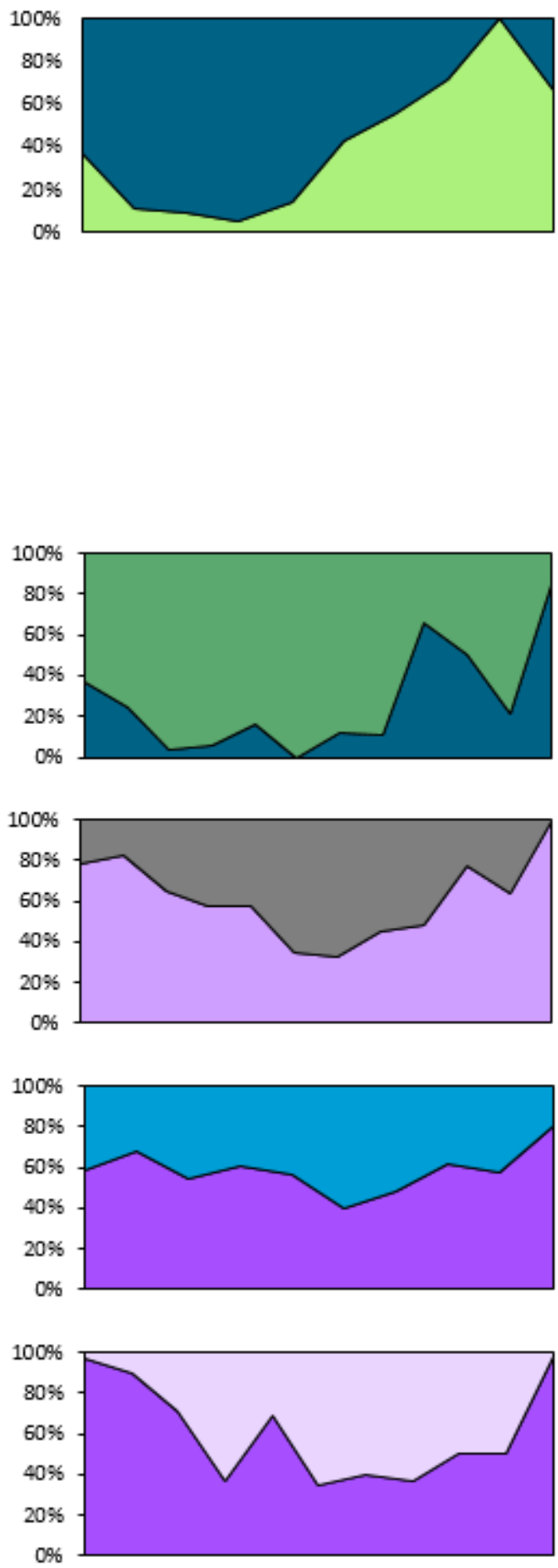

$\square$ GWMP2015

口W085

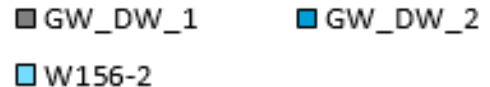

Figure 4-11. End-member proportions for main tributary sites (MTS) from surface water values projected in the Jock River three end-member (JR 3 EM) mixing space and projected into their own two end-member mixing space (MTS 2 EM). 


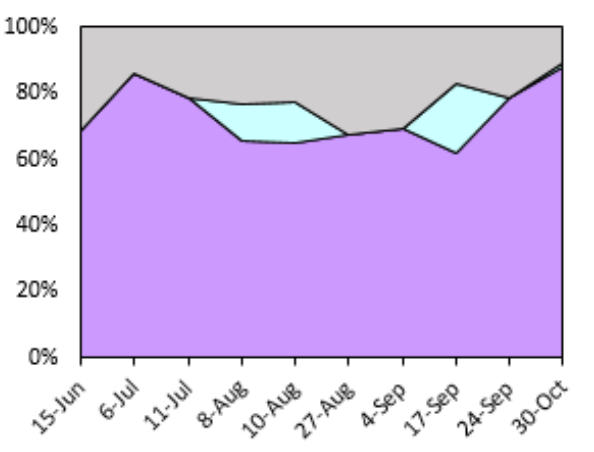

a) Kings Creek projected into Jock River 2-dimensional mixing space

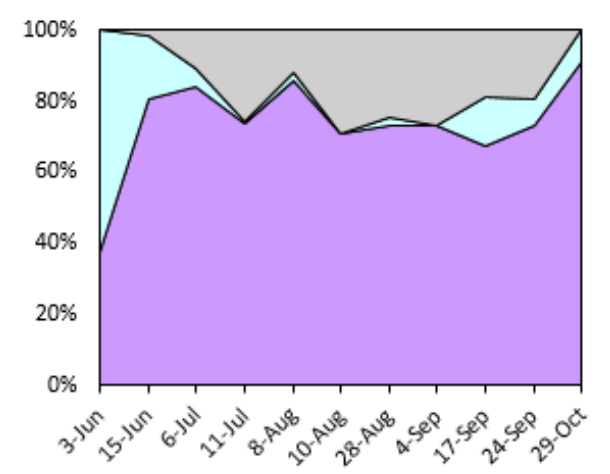

c) Nichols Creek projected into Jock River 2-dimensional mixing space

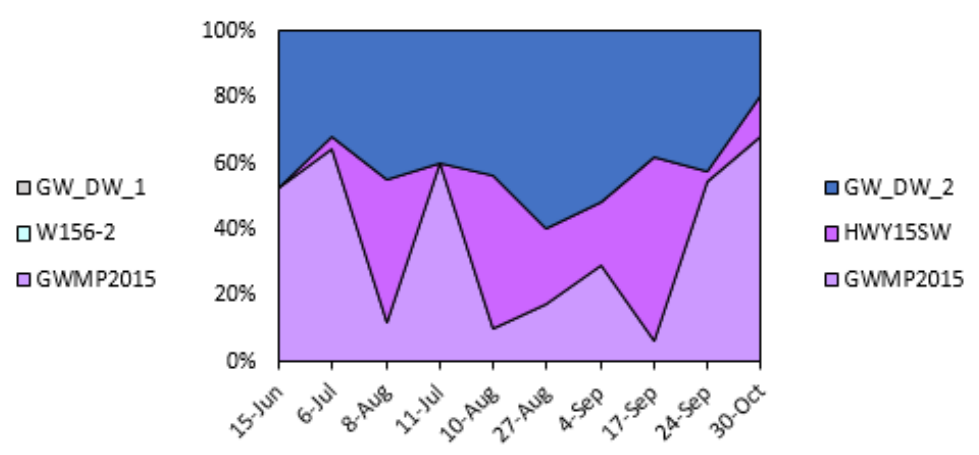

b) Kings Creek projected into its own 2-dimensional mixing space

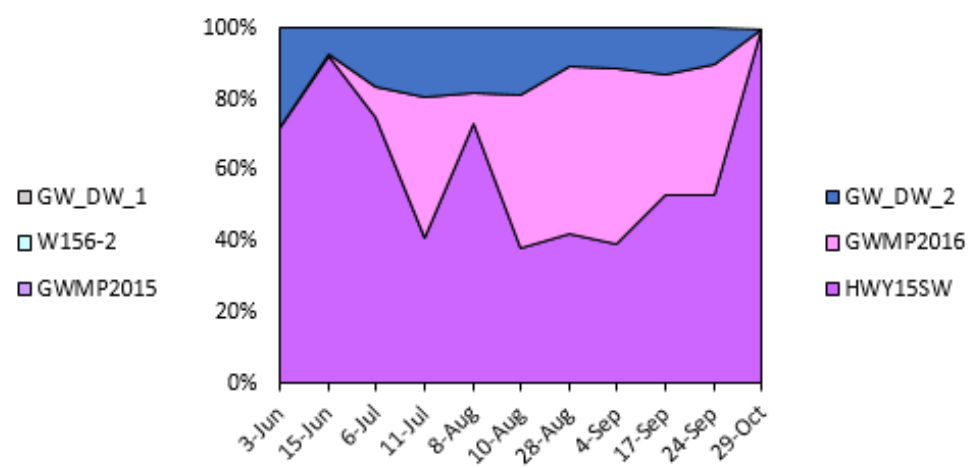

d) Nichols Creek projected into its own 2-dimensional mixing space

Figure 4-12. End-member proportions for Kings Creek and Nichols Creek projected into the Jock River two-dimensional mixing space and its own two-dimensional mixing space.

\subsubsection{Projecting Headwaters into the Jock River Mixing Space}

The spatial variability amongst surface water sites at greater spatial resolutions is further demonstrated by examining the projection of the headwater sites into the Jock River mixing space. Figure 4-13 shows the projection of the headwater sites into the Jock River mixing space, the sites have been symbolized based on their locations in the main tributary sub-catchments, see figure 3-1. Figure 4-13 shows that most of the headwater sites are not constrained by the Jock River mixing triangle and that the most variation can be seen for those located in the upper Jock catchment itself. Headwater projections were constrained to the mixing triangle by minimizing the distance between the points and the mixing lines as outlined in section 3.4.2.5. The model fit of the projected headwater sites 
is evaluated in table 4-9. Overall the headwaters demonstrate relatively low RRMSE, moderate to strong linear correlations and variable relative bias. Examining the residuals in Appendix B, figure B-0-4, structure in the residuals is apparent for solutes alkalinity and $\mathrm{SiO}_{2}$ in all the headwater sites grouped together. Examining the residuals based on their upstream contributing areas, sites within the Jock catchment and Kings Creek catchment demonstrate the greatest amount of structure in the residuals. Both demonstrate positive linear trends, which corresponds with their observed high relative bias. Therefore, when headwater sites are projected into the Jock River mixing model it systematically overpredicts alkalinity and $\mathrm{SiO}_{2}$ concentrations. Kings Creek was the only site which has demonstrated significant bias in the $\mathrm{SpC}$ concentrations predicted. Other sites had fewer headwater sites located in their catchments, therefore structure in the residuals is more difficult to interpret. Structure in the residuals may indicate that mixing ratios amongst the headwater sites differ from the Jock River or that the solutes are not mixing conservatively. Figure 4-14 illustrates the end-member proportions for headwater features projected into the Jock River mixing model. Most headwater features in figure 414 appear to be dominated by the wetland end-member, even in areas with no mapped wetlands. Headwater features in the uppermost portion of the watershed appear to be dominated by the W156-2 basal gravel/esker end-member, where there is very little overburden and it is primarily classified as wetland land cover. These results further indicate that the Jock River mixing space poorly defines the mixing space of the headwater features. Spatial and temporal heterogeneity in the end-members of smaller order streams may be too great to allow for accurate predictions of end-member contributions using the Jock River mixing model. Headwater sites projected into the 
mixing space of their upstream contributing area stream water chemistry may yield better results, but would require further sampling at these points.

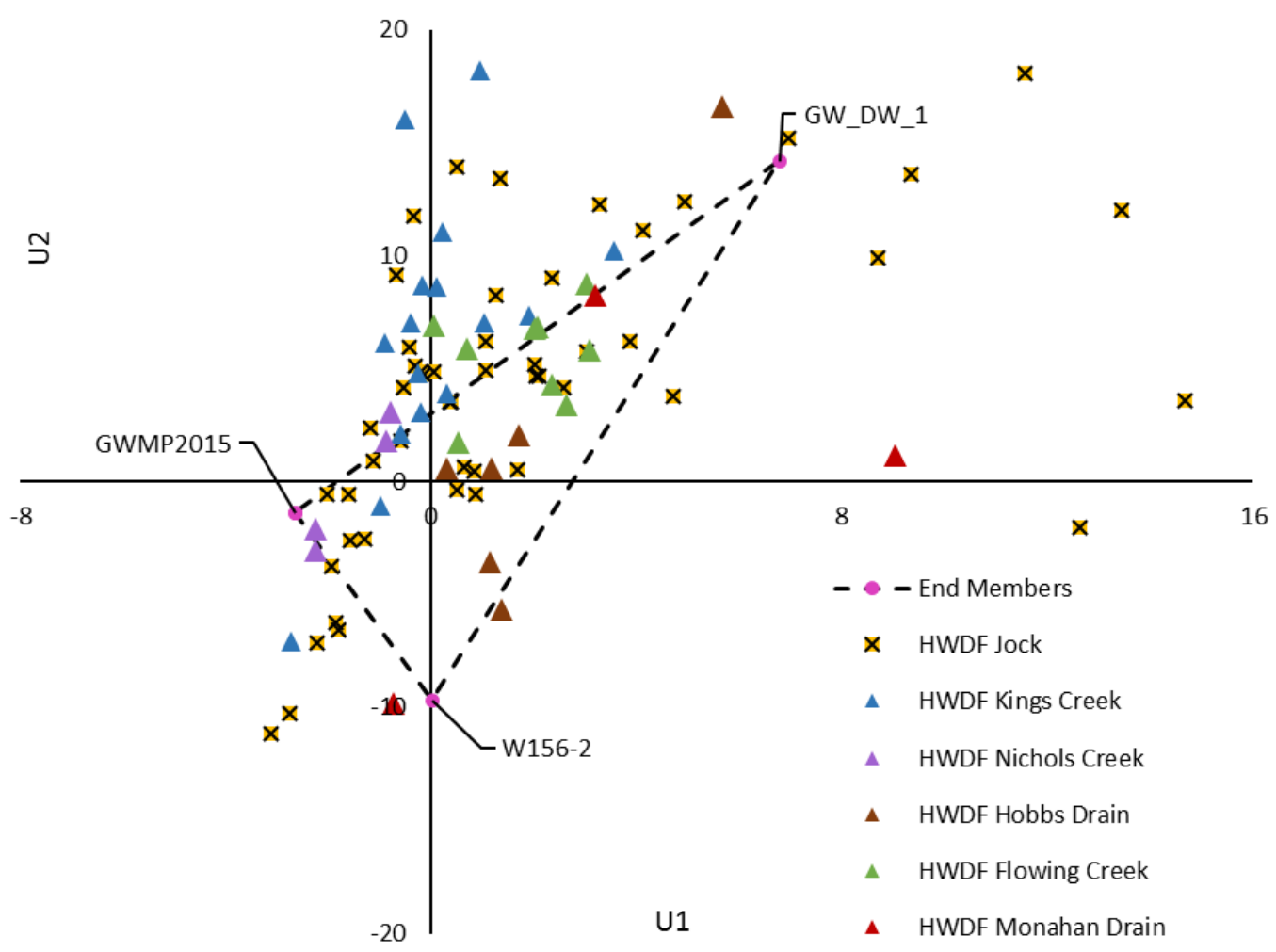

Figure 4-13. Headwater drainage features (HWDF) projected into the Jock River three end-member U-space. HWDF have been colour coded based on the main tributary contributing areas in which they are located. 
Table 4-9. Model quality parameters. Coefficient of determination $\left(R^{2}\right), R R M S E$ and relative bias for headwater sites projected into the Jock River (JR) mixing space. Sites have been grouped based on the main tributary contributing areas in which they are located.

\begin{tabular}{|c|c|c|c|}
\hline Headwater Sites & $\mathbf{R}^{2}$ & RRMSE & Relative Bias \\
\hline \multicolumn{4}{|c|}{$S p C(u S / c m)$} \\
\hline Jock River & 0.81 & 0.01 & $\mathbf{0}$ \\
\hline HWDF All & 0.32 & 0.07 & 10.10 \\
\hline HWDF Jock & 0.45 & 0.09 & 0.57 \\
\hline HWDF Kings Creek & 0.66 & 0.24 & 13.77 \\
\hline HWDF Nichols Creek & 0.96 & 0.27 & 1.76 \\
\hline HWDF Hobbs Drain & 0.77 & 0.09 & -0.22 \\
\hline HWDF Flowing Creek & 0.22 & 0.11 & 1.67 \\
\hline HWDF Monahan Drain & 0.23 & 0.34 & -1.10 \\
\hline \multicolumn{4}{|c|}{ Alkalinity (as mg/l $\mathrm{CaCO}_{3}$ ) } \\
\hline Jock River & 1.00 & $\mathbf{0}$ & $\mathbf{0}$ \\
\hline HWDF All & 0.70 & 0.04 & 22.19 \\
\hline HWDF Jock & 0.65 & 0.05 & 9.77 \\
\hline HWDF Kings Creek & 0.97 & 0.08 & 4.52 \\
\hline HWDF Nichols Creek & 0.99 & 0.06 & 0.39 \\
\hline HWDF Hobbs Drain & 0.95 & 0.20 & 2.72 \\
\hline HWDF Flowing Creek & 0.66 & 0.12 & 3.16 \\
\hline HWDF Monahan Drain & 0.92 & 0.34 & 1.70 \\
\hline \multicolumn{4}{|c|}{$\mathrm{SiO}_{2}(\mathrm{mg} / \mathrm{l})$} \\
\hline Jock River & 0.81 & 0.03 & $\mathbf{0}$ \\
\hline HWDF All & 0.29 & 0.06 & 19.53 \\
\hline HWDF Jock & 0.43 & 0.07 & 9.51 \\
\hline HWDF Kings Creek & 0.00 & 0.22 & 6.41 \\
\hline HWDF Nichols Creek & 0.94 & 0.14 & -1.10 \\
\hline HWDF Hobbs Drain & 0.28 & 0.29 & 1.11 \\
\hline HWDF Flowing Creek & 0.03 & 0.16 & 2.32 \\
\hline HWDF Monahan Drain & 0.93 & 0.21 & 0.77 \\
\hline
\end{tabular}




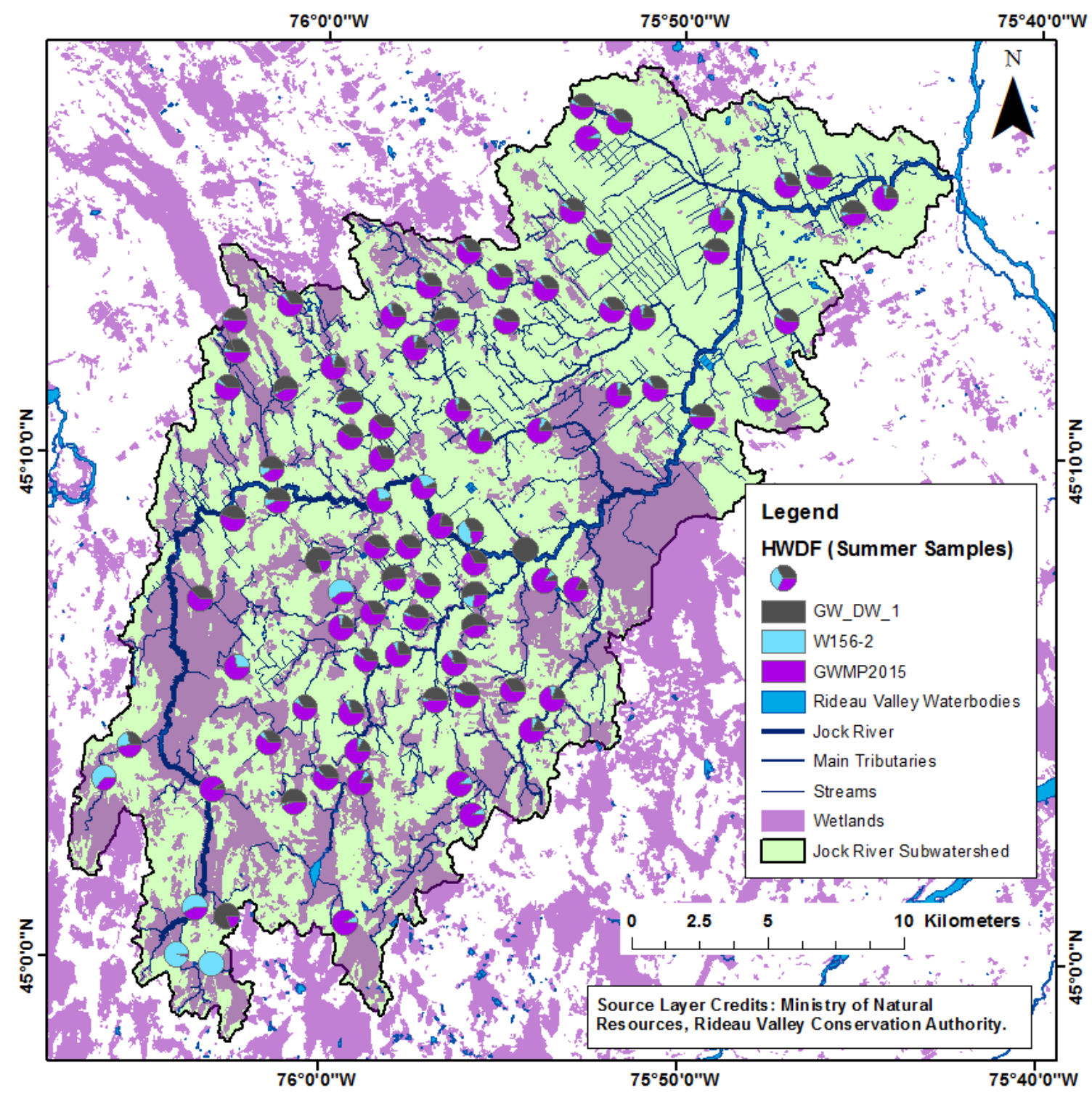

Figure 4-14. End-member proportions of headwater features, based on projection into the Jock River mixing space.

\subsection{Hydrometric Measurements}

Synoptic baseflow surveys were conducted on several baseflow days to determine the relative contributions of different sub-catchments to the total proportion of streamflow at the Jock watershed outlet. Results from hydrometric measurements are used to enhance and verify results from EMMA. Figure 4-15 illustrates the relative proportion of normalized net catchment discharge during the July $6^{\text {th }}, 2015$ baseflow 
synoptic survey. The Jock River mid-reach represents flow normalized for the Moodie Water Survey of Canada (WSC) flow gauge. The Jock River at Eagleson Road was removed as hydrometric measurements at this site produced negative results. Negative results could indicate that this reach is losing in this section. However, odd field conditions were observed at this site. Discharge measurements were difficult to collect as water was often moving in the opposite direction it should be or stagnant. Permit to take water records indicate that groundwater and surface water extractions were occurring in this area potentially altering local flow dynamics. These measurements were omitted from the figures but are included in the tables B-0-3 and B-0-4 in Appendix B.

The wetland end-member (GWMP) has been shown (figure 4-9 and 4-11) to dominate streamflow in the Jock River during wet antecedent moisture conditions and at several of its main tributaries (HBFT, KC, NIKS). Hydrometric measurements (figure 4$15)$ on July $6^{\text {th }}, 2015$ reflect moderately wet antecedent moisture in the watershed and capture baseflow before the low-flow period. Wetland dominated sub-catchments (JKFT, HBFT, KC and NIKS), contributed to $41 \%$ of flow in the catchment at this time. The Jock River mid-reach, which also contains a provincially significant wetland (Richmond Fen) contributed to $21 \%$ of flow in the catchment. Wetland proportions determined through EMMA was high during this period along the Jock River with proportions of $73 \%, 76 \%$ and $61 \%$ at JKFT, JKER and JKPW respectively. The proportions of flow attributed to the wetland end-member at wetland dominated tributaries during this time was $86 \%, 84 \%$ and $38 \%$ for KC, NIKS and HBFT respectively. Hydrometric measurements help validate EMMA results, as they illustrate that when the proportion of the wetland end-member was the dominant source of stream flow in the Jock River, the 
majority of streamflow in the catchment was originating from wetland dominated subcatchments.

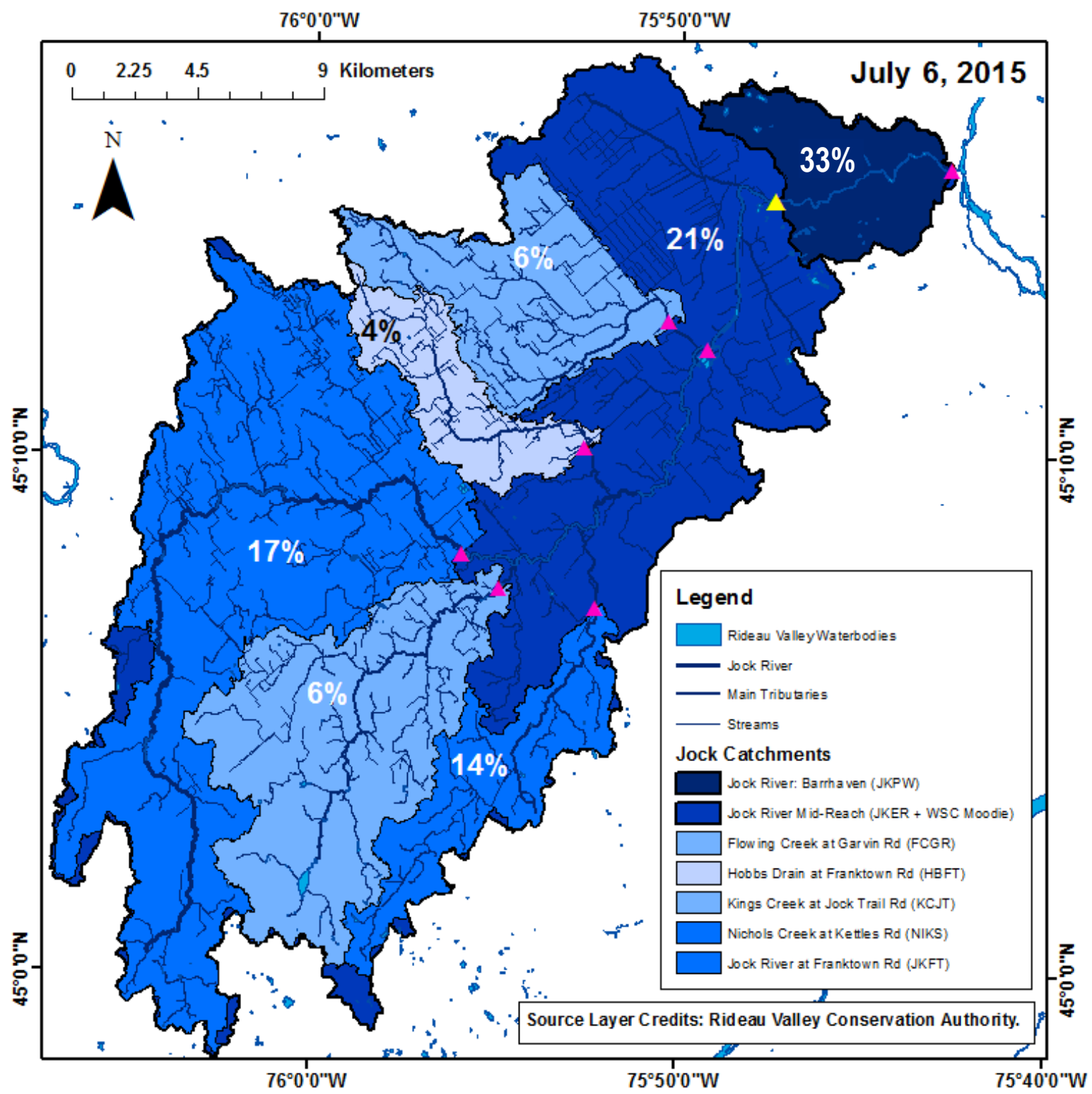

Figure 4-15. Relative proportion of normalized net catchment discharge during the July $6^{\text {th }}, 2015$ baseflow synoptic survey. Moodie WSC gauge has been coloured yellow, to distinguish it from other Jock River hydrometric sites.

During the low flow period contributions from the Jock River headwaters are drastically reduced (figure 4-16). The wetland dominated Nichols Creek and Hobbs Drain also demonstrate significant reductions in flow during this time, with contributions of $8 \%$ 
and $0.4 \%$ respectively. Totalling together the relative proportions of wetland dominated catchments (JKFT, HBFT, KC and NIKS), these areas are contributing approximately $18.4 \%$ of flow at the outlet, a $22.6 \%$ reduction when compared to July $6^{\text {th }}, 2015$. Contributions from the Jock River mid-reach were also significantly reduced (9\%) during this time, going from $21 \%$ to $12 \%$. EMMA results for the Jock River at JKER and JKPW indicate that $31 \%$ and $18 \%$ of flow was originating from wetlands. Wetland contributions at wetland dominated sub-catchments are still relatively high totalling $65 \%, 86 \%$ and $63 \%$ at KC, NIKS and JKFT. Therefore, the reduction in the proportion of the wetland end-member downstream is due to the reduction in the proportion of total flow contributions from these sub-catchments during the low flow period.

The lower portion of the Jock watershed contributes the most to total flow during the low flow period. EMMA results indicate that $41 \%$ and $49 \%$ of flow along the Jock River at JKER and JKPW is originating from the W156-2 basal gravel/esker endmember. The well W156-2 is completed in the basal gravel aquifer ( $25 \mathrm{mbgs})$ and is located close to the Jock River. To investigate the connections between W156-2 and the Jock River the water level from the WSC gauge at Moodie Road was examined. This gauge was chosen as it measures flow at the point where the Jock River intersects the esker (figure 4-17). Groundwater levels at both W156-2 and W156-3 appear to fluctuate similarly to the Jock River (figure 4-18). A cross-correlation analysis was performed between the wells W156-2 and W156-3 at a daily time-step with the daily surface water level from the WSC Moodie Gauge and at an hourly time-step with the hourly surface water level from the JKER gauge. The daily time-step analysis was based on data collected between 2013 and 2015. The hourly time-step analysis was based on data 
collected during the 2015 study period. Figure 4-19 illustrates the results of the crosscorrelation analysis, and demonstrates that at the daily time-step the greatest correlation is seen with a lag of 0 or 1 . Indicating direct connection between the groundwater and surface water level at this site. Results from the hourly time step further illustrate that there is little lag between the groundwater and surface water level.

Velderman (1993) states that where the basal till bedrock is confined surface water flow is sustained by deeper artesian groundwater in the fractured carbonate aquifer which discharges through the upper permeable zone. Velderman (1993) also indicates that most wells completed in this area are artesian indicating groundwater discharge conditions. Velderman's results seem to support findings of increased proportions of this end-member in streamflow at the JKER and the JKPW. The expression of the W156-2 end-member at the MDOR site projected into the Jock River mixing space also seems to indicate that this end-member is most likely representative of the basal gravel/esker aquifer. This end-member dominates streamflow at MDOR, this site is south-west of the esker and based on surficial geologic mapping overlies a buried esker. Direct sampling of the esker end-member and more dense sampling of wells completed at the basal gravel aquifer within the confined area could help to distinguish between the two sources. 


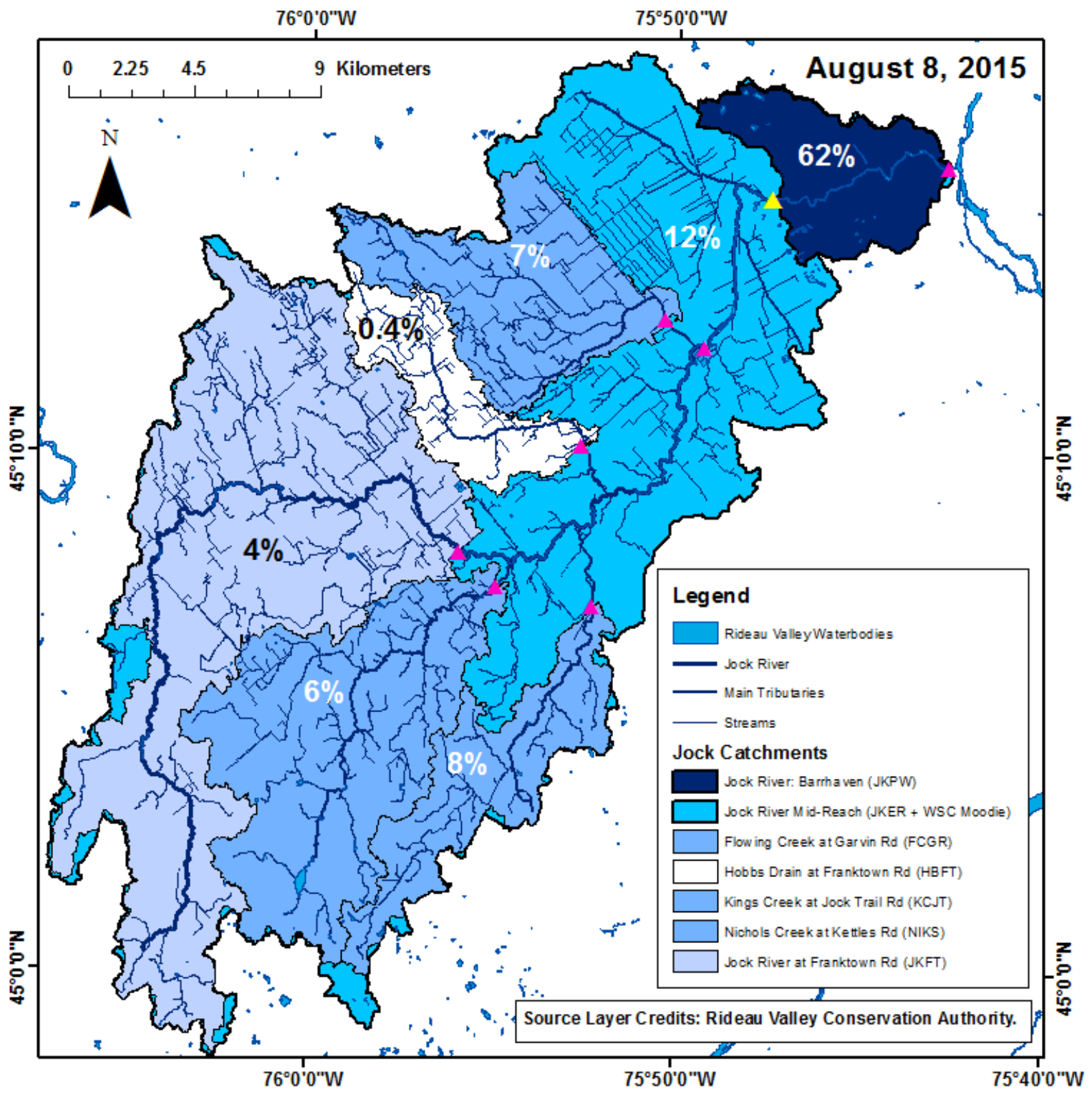

Figure 4-16. Relative proportion of normalized net catchment discharge during the August $8^{\text {th }}, 2015$ baseflow synoptic survey. Moodie WSC gauge has been coloured yellow, to distinguish it from other Jock River hydrometric sites. 


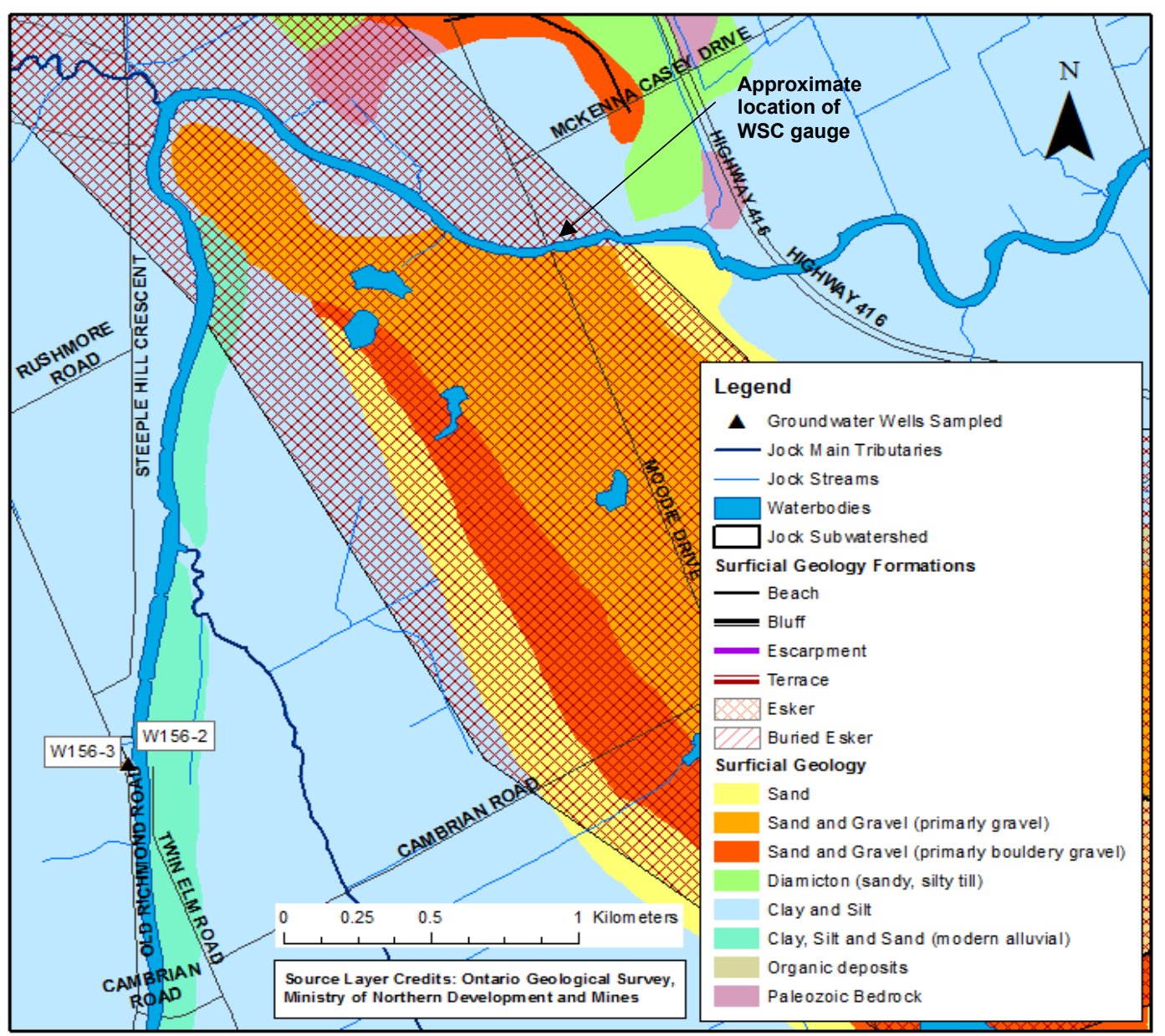

Figure 4-17. Map illustrating the location of well W156-2/3 in relation to the WSC gauge at Moodie Drive. Surficial geology highlights the presence of the esker in relation to both sites. 


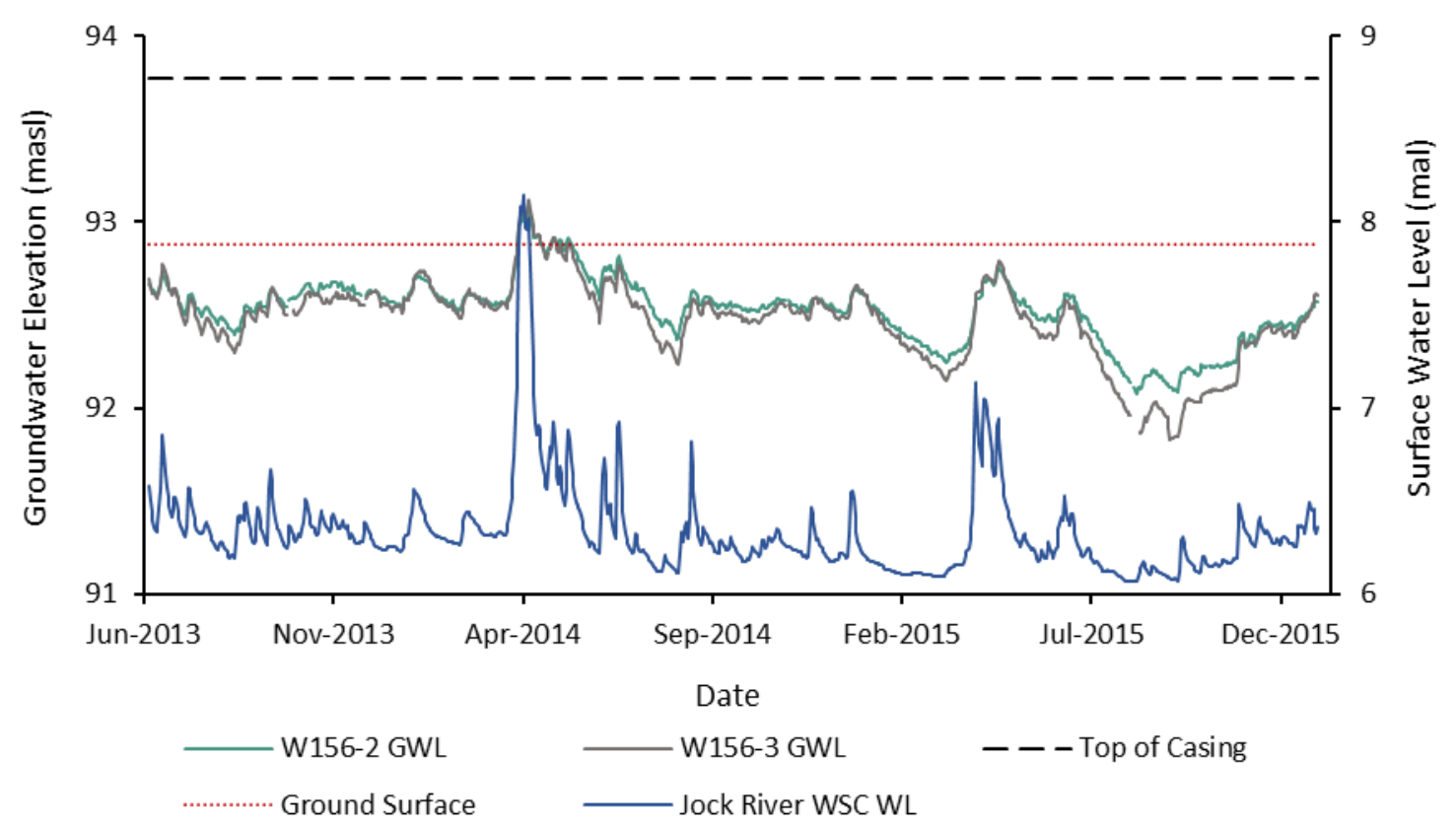

Figure 4-18. Groundwater elevation at W156-2 and W156-3 and surface water level at upstream Water Survey of Canada (WSC) Moodie Drive gauge. Elevation of ground at well 92.88 masl and top of casing elevation 93.77 masl. Groundwater elevation data source: RVCA. (2017).W156-2_TwinElm2_Compiled_WL_2013-2016 [Data file]. Retrieved from RVCA staff. Water level data source: Government of Canada. (2017). Daily_Apr-5-2017_11_21_17PM [Data file]. Retrieved

from https://wateroffice.ec.gc.caldownload/index e.html?results type=historical. 
W156-2 vs. Moodie Gauge

Daily Timestep (2013-2016)

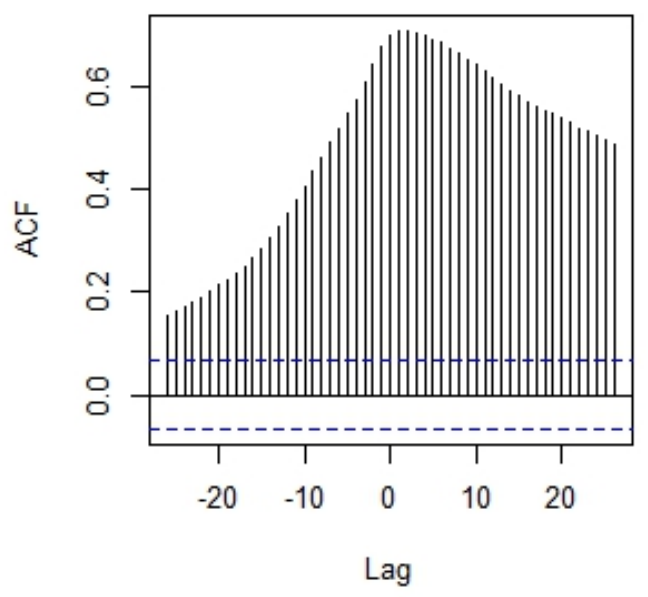

W156-2 vs. Jock at Eagleson Gauge Hourly Timestep (May-Nov 2015)

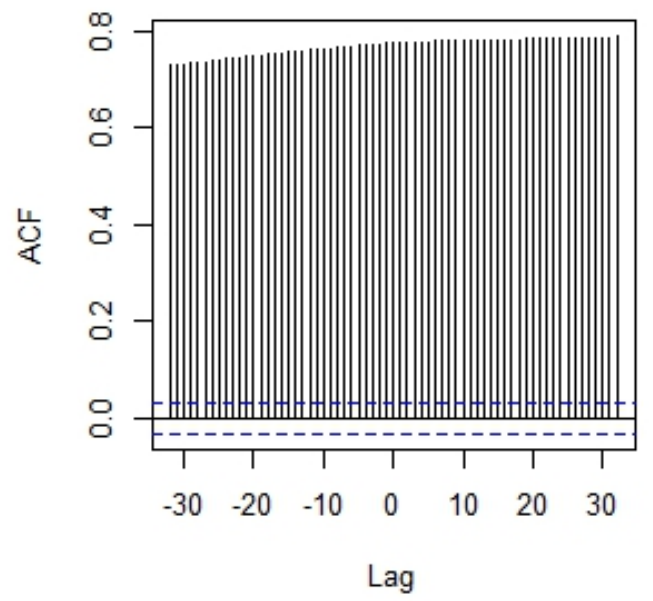

W156-3 vs. Moodie Gauge

Daily Timestep (2013-2016)

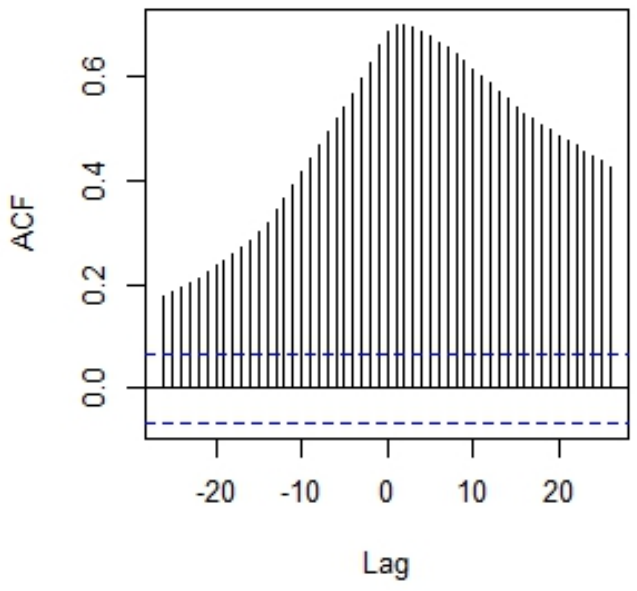

W156-3 vs. Jock at Eagleson Gauge Hourly Timestep (May-Nov 2015)

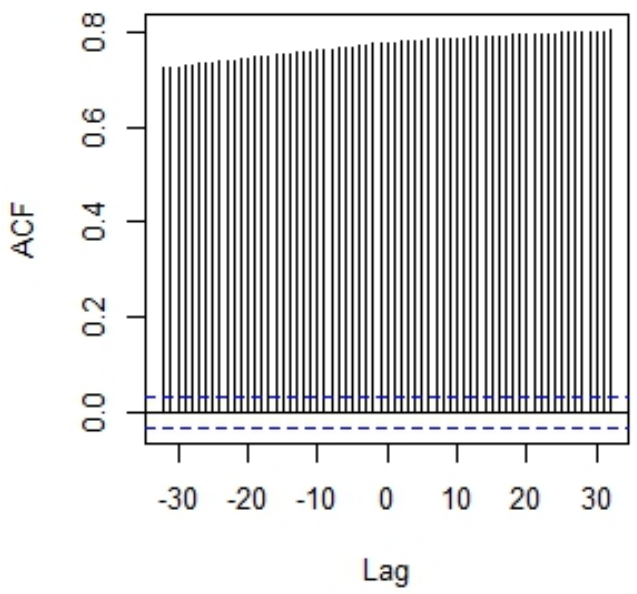

Figure 4-19. Cross correlation functions performed between groundwater elevations for wells W156-2 and W156-3 at a daily time-step with upstream WSC Moodie Gauge surface water level and at an hourly time-step with downstream Jock River at Eagleson road surface water level.

Water level data source: Government of Canada. (2017). Daily_Apr-5-2017_11_21_17PM [Data file]. Retrieved

from https://wateroffice.ec.gc.caldownload/index e.html?results type=historical 


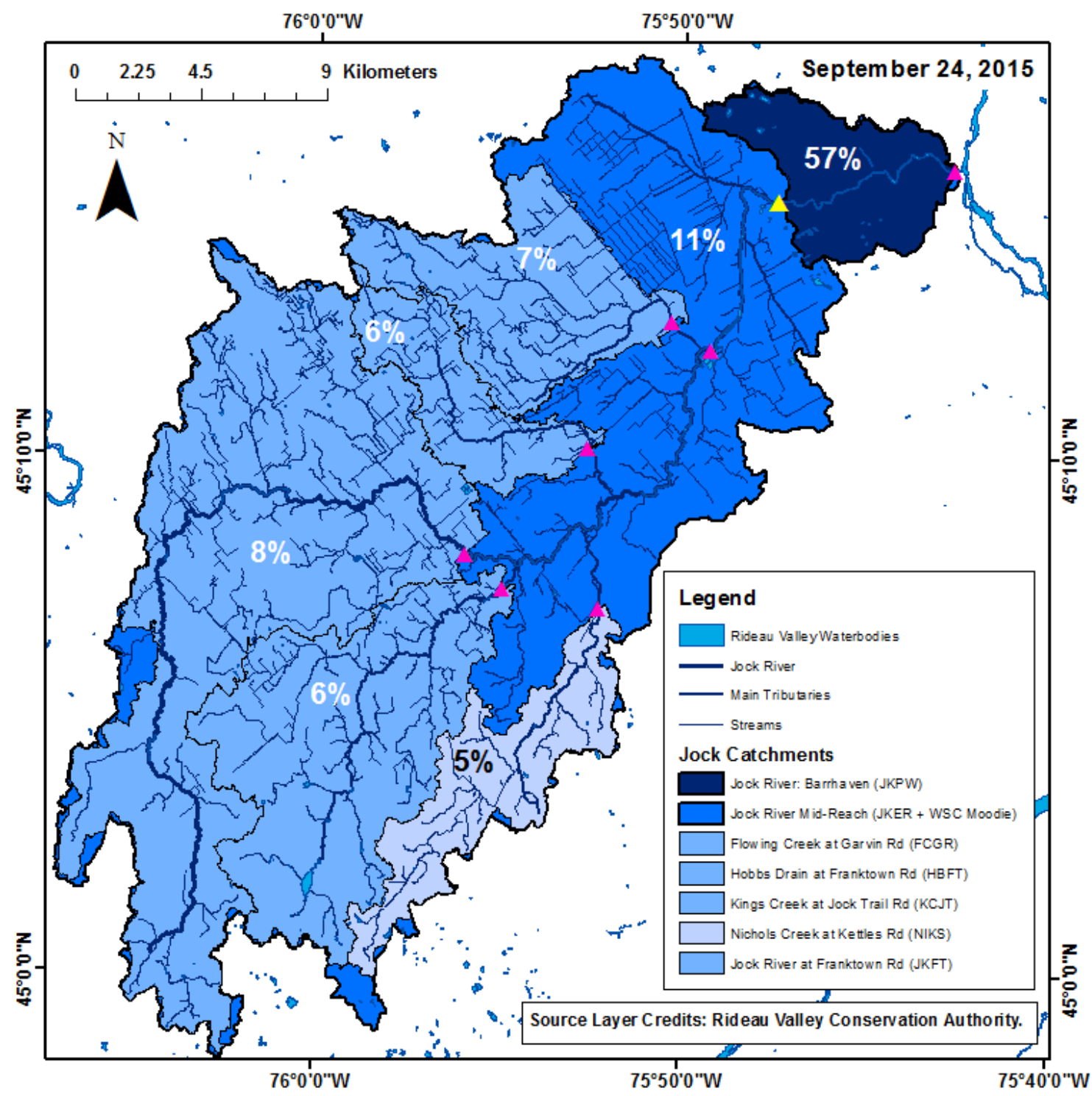

Figure 4-20. Relative proportion of normalized net catchment discharge during the September 24 $4^{\text {th }} 2015$ baseflow synoptic survey. Moodie WSC gauge has been coloured yellow, to distinguish it from other Jock River hydrometric sites.

During the autumn wet-up period flow contributions increase across the watershed, but remain lower than during the early summer period. The reduction in total flow contributions observed across the watershed between the early summer and autumn baseflow survey may be related to groundwater recharge. The Jock River headwaters and wetland dominated catchments were all contributing between 5 and $8 \%$ of total streamflow in the watershed totalling to $25 \%$ of total flow. EMMA results on September 
$24^{\text {th }}, 2015$ indicate increased proportions of the wetland end-member along the Jock River with $73 \%, 64 \%$ and $40 \%$ of flow at JKFT, JKER and JKPW respectively. Conversely, the Jock mid-reach didn't show increased contributions when compared to the low-flow period. EMMA results indicate lower contributions from the W156-2 endmember during this period with only $12 \%$ of flow originating from this end-member at JKER and 34\% at JKPW. The W156-2 end-member therefore appears to be an important end-member under drier antecedent moisture conditions.

\subsection{Watershed Characteristics}

\subsubsection{Recursive Partitioning (CART)}

Initial analysis of the relationships between watershed characteristics and the average end-member proportions was conducted through recursive partitioning using CART, refer to tables 4-10 and 4-11 for proportions. Figure 4-21 demonstrates the top variables selected from all watershed characteristics for each average end-member proportion. The variation in the average proportion of the wetland end-member (GWMP2015) across the Jock watershed appears to be best explained by the surficial geology within the sub-catchments. The tree model (figure 4-21), demonstrates that, unsurprisingly, organic deposits have the greatest explanatory power over the average proportion of wetland in each sub-catchment. Areas with greater organic deposits (>28.5\%) are also influenced by the proportion of Paleozoic bedrock. Sub-catchments with the greatest proportions of Paleozoic bedrock and organic deposits are in the headwaters (Jock at Franktown, Kings Creek and Nichols Creek) and have the highest average proportions of wetland contributions to streamflow. The tree model b) Basal Gravel/Esker (figure 4-21) reveals that the average proportion of the contributions from 
the basal gravel/esker (W156-2) end-member is best explained by the watershed characteristic settlement and diamicton. The Monahan Drain sub-catchment has the highest average proportion of the basal gravel/esker end-member, but also has the highest proportion of land categorized as settlement. Other sub-catchments with increased contributions from this end-member also have an increased proportion of land categorized as settlement. The relationship between settlement and the basal gravel/esker end-member is most likely coincidental rather than causal. Surficial geologic materials should have greater explanatory power, but the influence of diamicton appears to be tertiary in the tree model. In the final panel of figure 4-21 the variables with the greatest explanatory power for the contributions of the bedrock groundwater end-member across the Jock sub-catchments appears to be the proportions of clay/silt, the March Formation and organic deposits. The highest average proportion of the bedrock groundwater endmember is observed at Leamy Creek whose sub-catchment is dominated by the clay/silt watershed characteristic. Bedrock in tree model (figure 4-21 c) indicates that if the proportion of clay/silt is less than $76 \%$ in the sub-catchment, the interaction between clay/silt and the proportion of the March Formation is the next greatest explanatory variable for variation in the bedrock groundwater contributions to streamflow. In instances where the March Formation occupies more than 10\% of the sub-catchment the interaction between the March Formation and the proportion of area categorized as organic deposits has the greatest explanatory power for sub-catchments with lower average bedrock groundwater contributions. 
Table 4-10. Average proportions of end-members contributing to flow for each sample site/sub-catchment.

\begin{tabular}{lccc}
\hline Sub-catchment & $\begin{array}{c}\text { Wetland } \\
(G W M P 2015)\end{array}$ & $\begin{array}{c}\text { Basal } \\
\text { Gravel/Esker } \\
(W 156-2)\end{array}$ & $\begin{array}{c}\text { Bedrock } \\
\left(G W_{-} D W_{-} 1\right)\end{array}$ \\
\hline Jock River at Prince of Wales & 0.43 & 0.32 & 0.25 \\
Rd & 0.56 & 0.22 & 0.22 \\
Jock River at Eagleson Rd & 0.65 & 0.17 & 0.18 \\
Jock River at Franktown Rd & 0.07 & 0.60 & 0.33 \\
Monahan Drain & 0.10 & 0.11 & 0.80 \\
Leamy Creek & 0.37 & 0.24 & 0.40 \\
Flowing Creek & 0.41 & 0.03 & 0.35 \\
Hobbs Drain & 0.73 & 0.05 & 0.23 \\
Kings Creek & 0.74 & 0.11 & 0.15 \\
Nichols Creek & & & \\
\hline
\end{tabular}


Table 4-11. Land use, land cover, surficial and Paleozoic geology proportions in each contributing area for the sample sites.

\begin{tabular}{|c|c|c|c|c|c|c|c|c|c|}
\hline Watershed & $\begin{array}{c}\text { Jock at } \\
\text { Prince of } \\
\text { Wales }\end{array}$ & $\begin{array}{l}\text { Monahan } \\
\text { Drain }\end{array}$ & $\begin{array}{l}\text { Leamy } \\
\text { Creek }\end{array}$ & $\begin{array}{c}\text { Jock River } \\
\text { at Eagleson } \\
\text { Road }\end{array}$ & $\begin{array}{l}\text { Flowing } \\
\text { Creek }\end{array}$ & $\begin{array}{l}\text { Hobbs } \\
\text { Drain }\end{array}$ & $\begin{array}{c}\text { Jock River at } \\
\text { Franktown } \\
\text { Road }\end{array}$ & $\begin{array}{l}\text { Kings } \\
\text { Creek }\end{array}$ & $\begin{array}{c}\text { Nichols } \\
\text { Creek }\end{array}$ \\
\hline $\operatorname{Area}\left(\mathrm{km}^{2}\right)$ & 557 & 24 & 2 & 233 & 49 & 27 & 167 & 85 & 36 \\
\hline \multicolumn{10}{|c|}{ Surficial Geology \% } \\
\hline Paleozoic Bedrock & 32 & 8 & 0 & 33 & 19 & 35 & 37 & 56 & 57 \\
\hline Clay/Silt & 15 & 64 & 88 & 3 & 24 & 0 & 0 & 0 & 0 \\
\hline Organic Deposits & 27 & 5 & 10 & 37 & 13 & 14 & 38 & 30 & 38 \\
\hline Sand/Gravel & 7 & 2 & 0 & 6 & 8 & 17 & 7 & 7 & 5 \\
\hline Diamicton & 13 & 17 & 2 & 14 & 18 & 15 & 17 & 4 & 0 \\
\hline Sand & 6 & 5 & 1 & 7 & 18 & 19 & 2 & 3 & 0 \\
\hline \multicolumn{10}{|c|}{ Paleozoic Geology \% } \\
\hline Oxford Formation & 42 & 0 & 100 & 31 & 31 & 0 & 23 & 60 & 79 \\
\hline March Formation & 18 & 2 & 0 & 21 & 0 & 0 & 29 & 27 & 20 \\
\hline Bobcaygeon Formation & 5 & 14 & 0 & 5 & 3 & 0 & 7 & 3 & 0 \\
\hline Gull River Formation & 23 & 79 & 0 & 20 & 55 & 88 & 20 & 0 & 0 \\
\hline Rockcliffe Formation & 13 & 0 & 0 & 23 & 12 & 12 & 21 & 10 & 1 \\
\hline \multicolumn{10}{|c|}{ Land Use Landcover Classes \% } \\
\hline Settlement & 13 & 31 & 2 & 10 & 11 & 9 & 10 & 4 & 3 \\
\hline Forest (Forest, Trees) & 38 & 7 & 18 & 39 & 38 & 51 & 37 & 54 & 58 \\
\hline $\begin{array}{l}\text { Cropland (Cropland, } \\
\text { Unmanaged Grassland) }\end{array}$ & 33 & 61 & 77 & 29 & 46 & 32 & 30 & 22 & 6 \\
\hline $\begin{array}{c}\text { Wetland (Wetland Herb, } \\
\text { Wetland Shrub, Wetland } \\
\text { Undifferentiated, Treed } \\
\text { Wetland, Forest } \\
\text { Wetland) }\end{array}$ & 14 & 0 & 0 & 20 & 5 & 7 & 22 & 19 & 30 \\
\hline
\end{tabular}


a) Wetland End-member (GWMP2015)

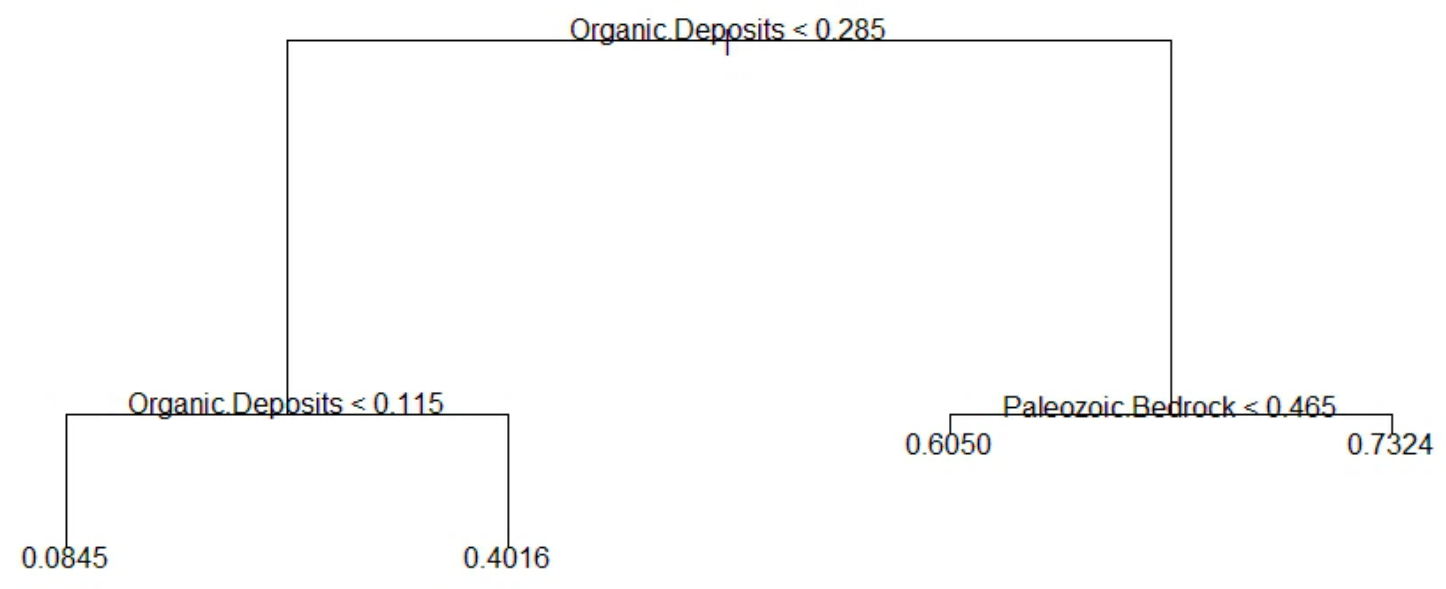

b) Basal Gravel/Esker End-member (W156-2)
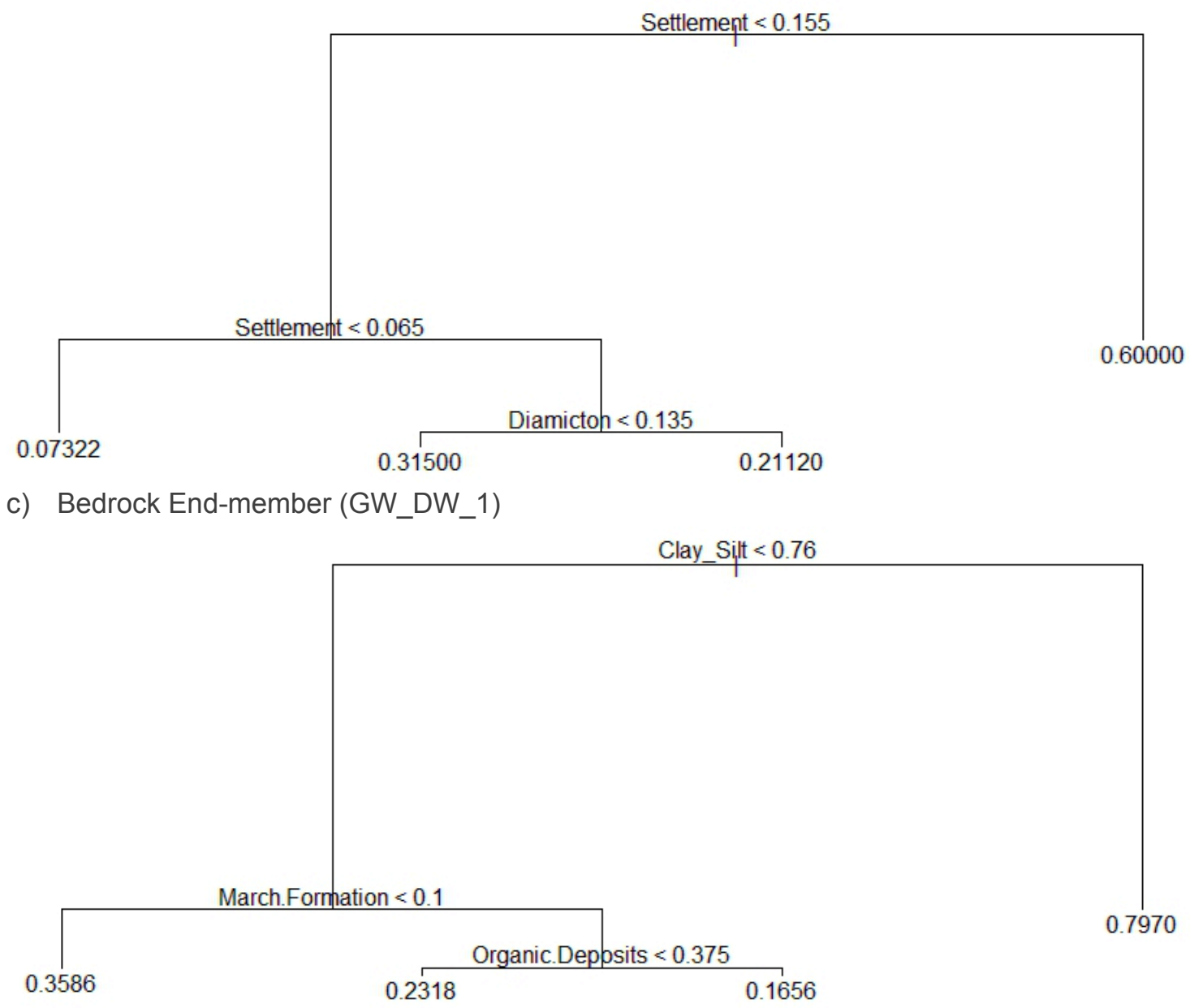

Figure 4-21. CART tree models identifying potential explanatory watershed characteristics for average end-member proportions a) wetland end-member (GWMP2015) b) basal gravel/esker end-member (W156-2) and c) bedrock end-member (GW_DW_1). 


\subsubsection{Linear Regression Analysis}

\subsubsection{Simple Linear Regression Analysis}

Simple linear regression analysis was performed using the average proportions of end-member contributions versus the proportions of watershed characteristics for each sub-catchment. Figures B-0-5 to B-0-7 in Appendix $A$ demonstrate the results of the single linear regression analysis for each watershed characteristic. Table 4-12 provides a synopsis of watershed characteristics which were determined to be statistically significant. The watershed characteristics identified for the wetland end-member are the most statistically significant of all the end-members. Paleozoic bedrock has the strongest relationship with an $\mathrm{R}^{2}$ of 0.90 and a $\mathrm{p}$-value $<0.0001$. The relationship between the proportion of Paleozoic bedrock and the wetland end-member is positive indicating that as the proportion of Paleozoic bedrock increases in the watershed the proportion of flow from the wetland end-member also increases. There is most likely a correlation between the proportion of Paleozoic bedrock and organic deposits as discussed in section 4.4.1 and seen in figure 4-21. The surficial geology of the headwaters is dominated by these two materials, therefore the observed relationship between these two land use classes and the proportion of the wetland end-member in streamflow is not surprising. There are significant negative relationships between the proportion of the wetland end-member and the proportion of area categorized as clay/silt and cropland. The proportion of area characterized as clay/silt and cropland share some commonalities as this type of surficial material is good arable land. There are fewer wetlands present in these areas and therefore less expression of this end-member in total streamflow. Similarly, the strong 
positive relationship between land cover types forest and wetland with the wetland endmember is expected, as areas with increased forest cover and wetland are primarily located in the headwaters where the wetland end-member is the most significant contributor to total streamflow.

The basal gravel/esker end-member has fewer statistically significant relationships with watershed characteristics. The two most significant watershed characteristics identified are the proportion of the Bobcaygeon Formation and the proportion of settlement in the watershed. The proportion of the Bobcaygeon Formation is small in all sub-catchments but is greatest in the Monahan Drain sub-catchment which also has the greatest proportion of basal gravel/esker contributions to total streamflow. The proportion of settlement in the Monahan Drain sub-catchment is also greater than for any other catchment. The contributions from this end-member to total streamflow are complicated, presumably the topographic gradient, the clay aquitard and the esker are influencing the contributions from this end-member to total streamflow. The complexity of theses processes is difficult to capture in simple linear analysis.

The watershed characteristics identified as statistically significant for the bedrock groundwater contributions to total streamflow are the same as those identified for the wetland end-member, but with opposing trend directions. Streamflow at sites in the lower portion of the watershed have increased contributions from the bedrock groundwater endmember, these areas also have increased proportions of cropland and clay/silt deposits which have the most statistically significant relationships, $R^{2}=0.73$, $p$-value $=0.003$ and $\mathrm{R}^{2}=0.70$, p-value $=0.005$ respectively. The most significant watershed characteristics are the most dominant land use/land cover types and surficial geology. The Paleozoic 
geology doesn't appear to have a significant influence on the contributions to total streamflow.

The proportion of area occupied by the March Formation has smaller correlations with the proportion of wetland end-member and the proportion of the bedrock groundwater end-member. The Oxford Formation and Gull River Formation are the most prevalent Paleozoic bedrock formations in the lower portion of the watershed, therefore the negative relationship between the March Formation and the contributions from the bedrock groundwater end-member indicate that contributions are predominately from either the Oxford or Gull River Formation in the lower watershed. The presence of the March Formation increases in the upper portion of the watershed where the two main Paleozoic bedrock types are the March Formation and the Oxford Formation. As the proportion of the Oxford Formation remains relatively consistent across the watershed, the positive relationship between the March Formation and the wetland end-member is most likely due to the increased proportion of this formation in the upper watershed. It should not be concluded that the March Formation contributes more significantly than the Oxford Formation to the wetland end-member. The results of the simple linear regression analysis highlights how the composition of the watershed can be used to supplement and confirm the results of the EMMA. The results also highlight the limitations in the interpretations of these simplistic variables influence on groundwater flow dynamics across the Jock River watershed. 
Table 4-12. Statistically significant watershed characteristics as determined through simple linear regression. Coefficient of determination $\left(R^{2}\right)$ greater than 0.40 are included along with the p-value and the direction of the trend.

\begin{tabular}{|c|c|c|c|c|c|c|c|c|c|}
\hline \multirow{2}{*}{$\begin{array}{c}\text { Watershed } \\
\text { Characteristics }\end{array}$} & \multicolumn{3}{|c|}{$\begin{array}{c}\text { Wetland } \\
(G W M P 2015)\end{array}$} & \multicolumn{3}{|c|}{$\begin{array}{c}\text { Basal Gravel/Esker } \\
(W 156-2)\end{array}$} & \multicolumn{3}{|c|}{$\begin{array}{c}\text { Bedrock } \\
\left(G W_{-} D W_{-} l\right)\end{array}$} \\
\hline & $\mathrm{R}^{2}$ & p-value & Trend & $\mathrm{R}^{2}$ & $\mathrm{p}$-value & Trend & $\mathrm{R}^{2}$ & $\mathrm{p}$-value & Trend \\
\hline $\begin{array}{l}\text { Paleozoic } \\
\text { Bedrock }\end{array}$ & 0.90 & $<0.0001$ & positive & - & - & - & 0.61 & 0.01 & negative \\
\hline Clay/Silt & 0.80 & 0.001 & negative & - & - & - & 0.70 & 0.005 & positive \\
\hline $\begin{array}{l}\text { Organic } \\
\text { Deposits }\end{array}$ & 0.80 & 0.001 & positive & - & - & - & 0.49 & 0.04 & negative \\
\hline $\begin{array}{l}\text { March } \\
\text { Formation }\end{array}$ & 0.69 & 0.005 & positive & - & - & - & 0.50 & 0.03 & negative \\
\hline Cropland & 0.86 & 0.0002 & negative & - & - & - & 0.73 & 0.003 & positive \\
\hline Forest & 0.75 & 0.002 & positive & 0.53 & 0.03 & negative & - & - & - \\
\hline Wetland & 0.87 & 0.0002 & positive & - & - & - & 0.58 & 0.02 & negative \\
\hline $\begin{array}{l}\text { Bobcaygeon } \\
\text { Formation }\end{array}$ & - & - & - & 0.79 & 0.001 & Positive & - & - & - \\
\hline Settlement & - & - & - & 0.87 & 0.0002 & positive & - & - & - \\
\hline
\end{tabular}

\subsubsection{Multiple Linear Regression (MLR)}

Stepwise multiple linear regression analysis was performed to assess if the relationships between the proportions of end-member contributions and watershed characteristics was improved through the inclusion of multiple predictor variables. Watershed characteristics identified as having strong linear relationships were added one at a time. Watershed characteristics were retained in the MLR model if they remained significant ( $p$-value $<0.05$ ). Different pairings were tested and recorded to identify the best model (see Appendix B, table B-0-2). MLR models were only significant for the average wetland (GWMP2015) end-member proportions. Table 4-13 highlights the best MLR models identified for the wetland (GWMP2015) end-member. Two MLR models demonstrated the greatest improvement: the Paleozoic bedrock and organic deposits model and the March Formation and Forest model. Both models had increased predictive 
ability with $\mathrm{R}^{2}$ of 0.96 and 0.97 respectively and with $\mathrm{p}$-values $<0.0001$. Figure $4-23$ shows the model diagnostics and indicates good model predictive ability. The models both indicate that the proportion of the wetland end-member in the total streamflow is related to both the distribution of natural features/organic deposits and the increased presence of Paleozoic bedrock, in particular the March Formation. As mentioned in section 4.4.2.1 the increased proportion of the March Formation in the upper portion of the watershed is likely the cause of the strong linear relationship. A large portion of this area of the watershed and the sub-catchments is also occupied by the Oxford Formation, however as it is present throughout most of the watersheds a significant linear relationship between this formation and the proportions observed does not occur. The relationship between forest/organic deposits and the wetland end-member further demonstrates the validity in the end-member proportions calculated using EMMA for headwater sites.

MLR models generated for the average proportions of the basal gravel/esker (W156-2) end-member and the bedrock groundwater (GW_DW_1) end-member did not demonstrate significant improvement over the simple linear relationships previously identified. In all models only one of the additional watershed characteristics remained significant. The proportions of these end-members relate to complex subsurface interactions, while simple linear relationships between the watershed characteristics did occur, other more complex processes occurring within the landscape presumably also influence the variance in the proportions contributing to total streamflow. The midsection of the watershed is a confined aquifer with artesian conditions, therefore 
contributions from deeper groundwater resources are also influenced by pressure gradients not easily captured and modelled at the subwatershed scale.

Table 4-13. Selection of MLR model results for the prediction of the Wetland (GWMP2015) end-member. The (+) symbol indicates that multiple variables are combined and (*) indicates the model is investigating the combination and interactions between multiple variables.

\begin{tabular}{|c|c|c|c|}
\hline \multicolumn{4}{|c|}{ Wetland (GMWMP2015) } \\
\hline MLR Models & $\mathrm{R}^{2}$ & p-value & Significant Variables \\
\hline Paleozoic.Bedrock+Organic.Deposits & 0.96 & $<0.00001$ & $\begin{array}{c}\text { Paleozoic Bedrock }=0.002, \\
\text { Organic Deposits }=0.02\end{array}$ \\
\hline Paleozoic.Bedrock*Organic.Deposits & 0.97 & 0.0004 & $\begin{array}{c}\text { Paleozoic Bedrock }=0.03, \\
\text { Organic Deposits }=0.07\end{array}$ \\
\hline Forest + Wetland & 0.95 & 0.0001 & $\begin{array}{c}\text { Forest }=0.03, \\
\text { Wetland }=0.004\end{array}$ \\
\hline Forest*Wetland & 0.96 & 0.0008 & $\begin{array}{l}\text { Forest }=0.03, \\
\text { Wetland }=0.03\end{array}$ \\
\hline March.Formation+Cropland & 0.94 & 0.0003 & $\begin{array}{l}\text { March Formation }=0.04 \\
\quad \text { Cropland }=0.003\end{array}$ \\
\hline March.Formation+Forest & 0.97 & $<0.00001$ & $\begin{array}{c}\text { March Formation }=0.0004, \\
\text { Forest }=0.0002\end{array}$ \\
\hline March.Formation*Forest & 0.97 & 0.0002 & Forest $=0.002$ \\
\hline Paleozoic.Bedrock+Wetland & 0.94 & 0.0001 & $\begin{array}{c}\text { Paleozoic Bedrock }=0.03, \\
\text { Wetland }=0.07\end{array}$ \\
\hline Organic.Deposits+Cropland & 0.93 & 0.0003 & $\begin{array}{l}\text { Organic Deposits }=0.05, \\
\text { Cropland }=0.02\end{array}$ \\
\hline Organic.Deposits+Forest & 0.95 & 0.0001 & $\begin{array}{c}\text { Organic Deposits }=0.003, \\
\text { Forest }=0.006\end{array}$ \\
\hline Organic.Deposits+Clay_Silt & 0.92 & 0.0006 & $\begin{array}{l}\text { Organic Deposits }=0.03, \\
\text { Clay } / \text { Silt }=0.03\end{array}$ \\
\hline Clay_Silt+Wetland & 0.94 & 0.0002 & $\begin{array}{l}\text { Clay } / \text { Silt }=0.03 \text {, } \\
\text { Wetland }=0.008\end{array}$ \\
\hline Clay_Silt+March.Formation & 0.91 & 0.0008 & $\begin{array}{l}\text { Clay } / \text { Silt }=0.01, \text { March } \\
\text { Formation }=0.04\end{array}$ \\
\hline
\end{tabular}




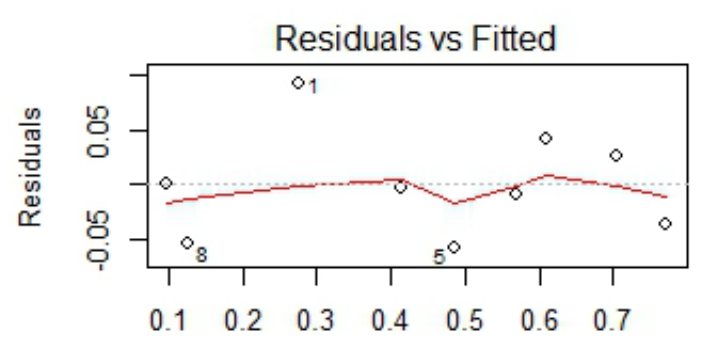

Fitted values

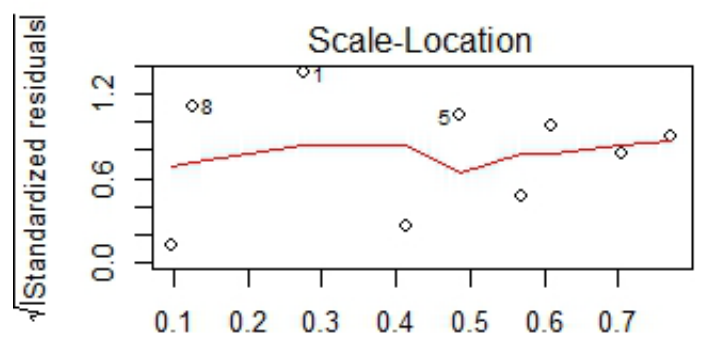

Fitted values

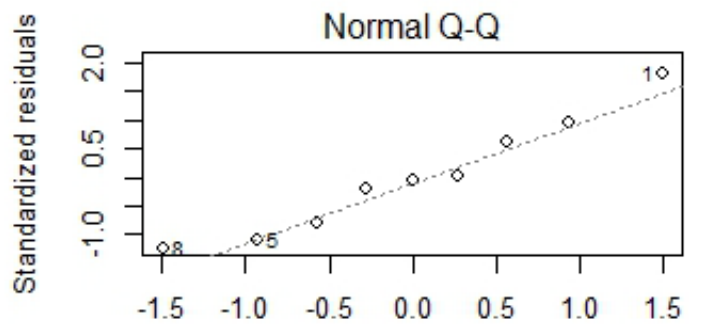

Theoretical Quantiles

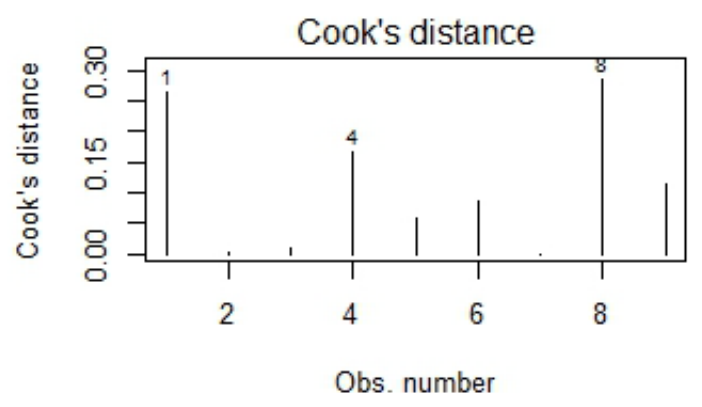

Figure 4-22. MLR diagnostic plots for the model Paleozoic Bedrock and Organic Deposits for the wetland (GWMP2015) end-member.
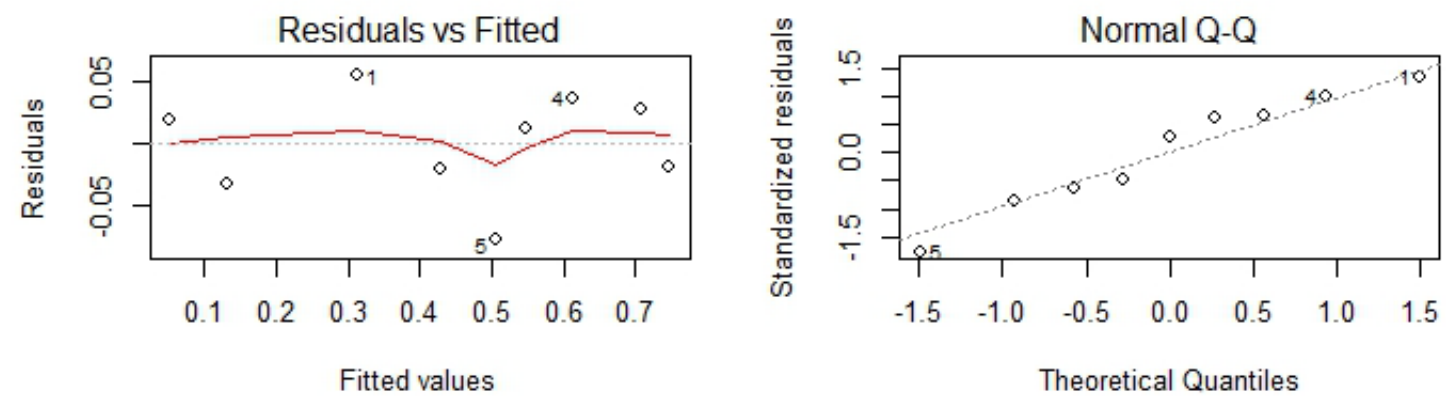

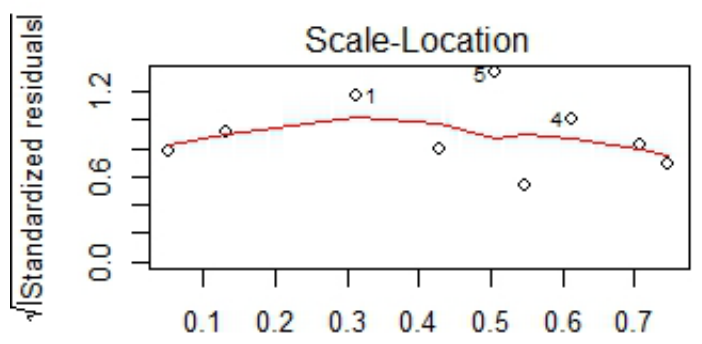

Fitted values

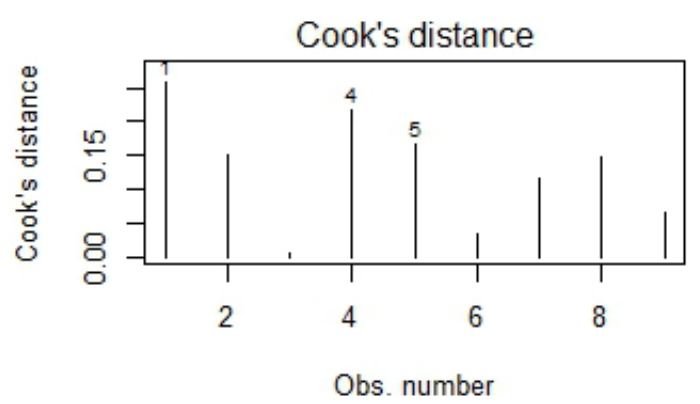

Figure 4-23. MLR diagnostic plots for the model March Formation and Forest for the wetland (GWMP2015) end-member. 


\subsection{DISCUSSION}

The purpose of this study was to determine important areas of baseflow generation in the Jock River watershed and to better understand the dynamic behaviour of baseflow due to spatial heterogeneity and temporal variability. The applicability of EMMA to determine potential sources contributing to baseflow across the Jock River watershed was investigated. EMMA and environmental tracer studies have been applied at the catchment scale, to gain a better understanding of flow dynamics at scales useful for water resource management (Soulsby et al., 2004; James and Roulet, 2006; Wagener et al., 2010; McGrane et al., 2014). The main aim of this project was to determine variation in groundwater and surface water interactions across the Jock River watershed using varying scales of analysis. The influence of landscape composition on the spatial variation of average end-member proportions was investigated through linear analysis of watershed characteristics extracted from various GIS data layers. Hydrometric measurements collected in 2015 and the results from previous studies are also used to enhance and validate findings and provide a holistic conceptual model of baseflow dynamics across the Jock River watershed.

The discussion section which follows will outline the major conceptual understandings of groundwater and surface water interactions gained from the combined results (EMMA, hydrometric and watershed characteristics analysis). The discussion will focus on the spatial and temporal variations in end-member contributions across the watershed. The second section of the Discussion will address what aspects of the groundwater flow system the identified end-members represent. This section will also address limitations and potential directions for0 further investigation. The final section 
will provide an evaluation of the Jock River mixing model, discussing model limitations, model success and model uncertainty in relation to other studies. This section will also discuss the projection of upstream sites into the final model at varying scales of analysis. Future methods of analysis and research will be suggested based on the findings from this project.

\subsection{Conceptual Model of Baseflow Generation in the Jock River watershed}

Baseflow is often conceptualized as simply representing groundwater discharge. The end-members identified from the EMMA model illustrate that while baseflow represents groundwater discharge, there are multiple sources of groundwater discharge contributing to baseflow across the Jock River watershed. Tóth (1963) first described multiple scales of groundwater flow systems: regional, intermediate and local. The relative dominance of these flow systems was believed to related to the topography of the region; with local groundwater flow systems dominating in areas with pronounced topographic relief and regional groundwater flow systems dominating in flatter regions (Tóth, 1963; Freeze and Cherry, 1979; Sophocleous, 2002). However, as these flow systems are imposed upon one another, surface water bodies may receive groundwater flow from multiple sources, as highlighted in Winter et al., (2003). Studies conducted using similar geochemical and isotopic techniques have also highlighted spatial and temporal variability in contributions to streamflow from different shallow and deep groundwater flow systems (Rodgers et al., 2004; Tetzlaff and Soulsby, 2008a). Rodgers et al., (2004) found that contributions from shallow groundwater flow systems at the edge of the braided floodplain were significant to stream flow, while deeper groundwater was 
identified to be significant closer to the main channel. Results from the Jock River EMMA model indicate that baseflow in the Jock River watershed is maintained by three end-members which represent different aspects of the groundwater flow system. Results also indicate that contributions from the groundwater flow systems demonstrate spatial and temporal variability across the Jock River watershed.

Temporal variations in end-member contributions across the catchment scale during the 2015 growing season were identified for the following sites: Flowing Creek, Hobbs Drain, the Jock River at Eagleson Road and the Jock River at Prince of Wales. Under wet antecedent moisture conditions, runoff generated from wetlands in the upper reaches of the catchment are the dominant source of baseflow at these sites. Hydrometric baseflow survey results confirm those from EMMA; on July $6^{\text {th }} 2015$, increased flow contributions from wetland dominated sub-catchments were observed in the Jock watershed. McGlynn (2004) combined tracer techniques using ${ }^{18} \mathrm{O}$ and silica with hydrometric measurements of water levels and discharge rates to determine runoff contributions from different parts of the landscape at the Maimai research catchment in New Zealand. A strong correlation between the riparian zone groundwater levels and the runoff from the headwaters was found, while water tables in the valley bottom were uncorrelated to runoff (McGlynn, 2004). McGlynn (2004) also found that during increased antecedent moisture conditions or large scale events, the valley bottom contributed to event runoff directly. Results from McGlynn (2004) indicate that different landscape components contribute to flow under different antecedent moisture conditions. Results from the Jock River mixing model demonstrate a change in end-member contributions during dry antecedent moisture conditions. During the low flow period, 
baseflow at the sites mentioned above, originates primarily from deeper groundwater sources. Contributions to baseflow from the basal gravel/esker end-member increase greatly during the low flow period at Flowing Creek, the Jock River at Eagleson Road and the Jock River at Prince of Wales. Contributions from the deep regional limestone aquifer to baseflow at Hobbs Drain also increase during the low flow period. Results indicate a dynamic relationship between the sources contributing to baseflow under different antecedent moisture conditions at sites in the Jock watershed.

Sub-catchments in the upper portion of the Jock watershed (Kings Creek, Nichols Creek and the Jock River at Franktown Road), demonstrate less temporal variation in end-member contributions throughout the 2015 growing season. EMMA results indicate that the wetland end-member contributes the most significantly to baseflow in the upper watershed. Smaller, more variable contributions from the basal gravel/esker end-member were also observed at these sites. Velderman (1993) describes the basal gravel till aquifer under the clay aquitard outcropping in the western portion of the watershed. Isotopic results from Velderman (1993) demonstrated flow reversals from the confined basal gravel till aquifer and the marsh lands due to a drastic lowering of the water table in the summer. It is therefore likely that this aquifer discharges to wetlands in the upper reaches, which may explain why it is observed in upstream sites. The upper watershed had smaller temporal variations in baseflow sources throughout the 2015 growing season compared to sites in the lower watershed which contain less natural features such as forests and wetlands.

Spatial variations in the main sources of baseflow generation occur across the Jock River watershed. As discussed above baseflow in the upper reaches of the Jock 
watershed are mainly sourced from the surrounding wetlands. Baseflow at streams in the lower reaches of Jock watershed demonstrate different controlling end-members. The results from the projection of the main tributaries into the Jock River mixing model indicates that baseflow at Monahan Drain is primarily sourced from the basal gravel/esker end-member. Surficial geologic mapping of the area indicates that Monahan Drain is located overtop of a buried esker, providing further justification for the dominance of this end-member at this site. Results from the projected tributaries into the Jock River mixing model indicated that baseflow at Flowing Creek originates from deeper groundwater sources (basal gravel/esker and the deep regional limestone aquifer).

These results highlight that different groundwater sources are important for baseflow generation across the Jock River watershed. Furthermore, EMMA demonstrates that there are significant temporal variations in the sources contributing to baseflow at several sites within the watershed. Tetzlaff and Soulsby (2008a) applied geochemical and hydrometric analysis to determine sources of baseflow generation in the Dee River, Scotland. Tetzlaff and Soulsby (2008a) indicated that varying sources were contributing to baseflow generation across the catchment. Contributions from groundwater sources in montane headwaters of the Dee River, were found to be significant to maintaining baseflow downstream during the low flow period (Tetzlaff and Soulsby, 2008a). Tetzlaff and Soulsby (2008a) argued that these findings challenge the assumption of hydrologic stability during the low flow period and highlight the dynamic behaviour of hydrological and biogeochemical processes at low flows. Spatial and temporal variability in the sources contributing to baseflow has important implications for traditional baseflow analysis techniques. Simple baseflow separation methods rely on the assumption that 
groundwater dynamics across the contributing area are captured at the downstream site where baseflow separation is performed. However, as the sources contributing to baseflow in the Jock are both spatially and temporally variable, this assumption is violated due to a scale effect. Processes occurring during baseflow conditions are much more complex and spatially distributed than commonly assumed in larger river systems (Tetzlaff and Soulsby, 2008a). Model results demonstrate that EMMA can be applied to gain a better understanding of areas important for baseflow generation. This is important from a water resource management perspective as these sources are responsible for maintaining streamflow and providing valuable ecosystem services. Areas of baseflow generation are also vulnerable to environmental and anthropogenic effects. Therefore, the results from this thesis can help guide source water conservation and protection efforts. In particular, these results highlight the crucial role which the wetlands in the upper portion of the watershed play in regulating baseflow throughout the Jock River watershed.

\subsection{What do the End-Members Represent?}

Determining the number and identity of end-members contributing to streamflow was a main objective of this study. Two methods of analysis for determining the number of end-members were evaluated: residual plots and the rule of one. Residual analysis of the predicted concentrations is believed to be more statistically rigorous than the heuristic rule of one (Hooper, 2003). Residual analysis requires a large number of samples collected under a variety of hydrologic conditions for the underlying structure, or lack there-of, to become visually apparent. Therefore, due to the small number of samples collected during the 2015 growing season, residual analysis was not used to determine the number of end-members for the Jock watershed. The number of end-members selected 
was based on the rule of one, which states each eigenvector must explain a proportion greater than or equal to one divided by the number of tracers variance for it to be retained (Christophersen and Hooper, 1992; Hooper, 2003; James and Roulet, 2006). A rigorous assessment of the model results for both a one and two-dimensional mixing model were used to provide further justification in the number of end-members selected. A limitation of this study is the number of tracers used in the EMMA model. The number of endmembers which can be determined in this study is limited to three. Future studies which increase the number of parameters sampled may reveal other important end-members in the system. The end-members in the final two-dimensional mixing model for the Jock River were: GW_DW_1, W156-2 and GWMP2015. The following section describes what aspects of the groundwater flow system these end-members represent.

\subsubsection{GW_DW_1: Deep Groundwater from the Regional Limestone Aquifer}

Deciding on a groundwater end-member species was difficult as spatial heterogeneity was apparent amongst the groundwater end-members, despite the fact most wells were completed in the same or similar formations. The Oxford Formation and the Gull River Formation are both limestone/dolostone formations. Therefore, the geochemical differences observed between the wells indicate that variations in bedrock composition and overlying surficial geology produces differences in the groundwater geochemistry across scale. The selection of the groundwater end-member in the Jock River mixing model was based on criteria derived from Hooper (2001), James and Roulet (2006) and Barthold et al., (2011). The final end-members selected needed to completely constrain the stream water mixing space and have a low percent difference. End-members with lower percent differences were chosen over other end-members which also 
constrained the stream water mixing space. The decision between selecting GW_DW_1 and GW_DW_2 was based on selecting the end-member which completely constrained the mixing space. Both wells represent deep groundwater from carbonate bedrock, which is part of the regional groundwater flow system. The percent differences were the lowest for both sites in comparison to all other deep groundwater end-members, indicating that either one would have produced good predicted solute concentrations.

The position of the GW_DW_1 the end-member in the stream water U-space (figure 4-7), indicates that the mixing model may underestimate the proportion of groundwater contributions at sites across the Jock watershed. Projection of the main tributary samples into their own individual mixing spaces resulted in changes in the deep groundwater end-member identified at Flowing Creek, Kings Creek and Leamy Creek. These sites were better characterized by more localized, deep groundwater end-members, indicating that spatial heterogeneity may influence the accuracy of calculated endmember proportions across the Jock watershed. James and Roulet (2006) state that spatial variation in stream water chemistry may be a function of spatial variation in soil and bedrock composition, which will affect the geochemical signature of the groundwater end-member.

\subsubsection{W156-2: Basal Gravel or Esker?}

The geochemistry for W156-2 and its deeper well W156-3 were found to be unique when compared to other wells sampled. W156-2 has a lower alkalinity concentration and higher $\mathrm{SpC}$ and $\mathrm{SiO}_{2}$ concentration than GWMP2015. The $\mathrm{SiO}_{2}$ concentration of W156-2 is the second highest and closest to GW_DW_1 amongst all end-members sampled. These results show that well W156-2 has high $\mathrm{SiO}_{2}$ weathering 
but low carbonate weathering. As stated in section 3.3.2.2, carbonate weathering, does not achieve calcite saturation under confined conditions. The well record at this site indicates the presence of clay, which has been described by Velderman (1993) as an aquitard in this region. As W156-2 is drilled to the interface of the Oxford Formation and the gravel/boulder layer, it should have a higher alkalinity concentration in line with that of other groundwater wells in the area. If this well is confined by the clay aquitard this could explain the lower alkalinity observed at this site for W156-2 and W156-3. An alternate possibility is that this well is accessing the fans of the esker which cuts across the upper portion of the watershed. The extremely porous media in this formation could transmit water more rapidly than that in fracture flow reducing the residence time and therefore reducing the amount of carbonate weathering. As previously stated in section 3.3.2.1, $\mathrm{SiO}_{2}$ weathers more slowly than carbonate materials and would therefore require a long residence time to explain the relatively high $\mathrm{SiO}_{2}$ concentration observed. The increased $\mathrm{SiO}_{2}$ concentration opposes the theory that reduced carbonate weathering is the result of increased transmissivity. Thus, increased $\mathrm{SiO}_{2}$ may be the result of water infiltrating from the clay aquitard. The increased residence time in the aquitard would increase weathering time and may explain the increased concentration of $\mathrm{SiO}_{2}$. Further geochemical sampling is required to confirm these findings and distinguish between the basal gravel aquifer and the esker. Direct sampling of the esker end-member and more dense sampling of wells completed at the basal gravel aquifer within the confined area are required.

The wells W156-2/3 are in close proximity to the Jock River. Hydrometric analysis between wells W156-2/3, the Jock River WSC Moodie gauge and the Jock River 
at Eagleson Road water level was conducted to evaluate the hydrologic connection between the river and the aquifers. Cross correlation analysis demonstrated a direct connection between the river and both aquifers. Velderman (1993) states that wells completed in this region are artesian indicating that groundwater is discharging to the river. It is most likely that groundwater from the basal gravel till aquifer and the limestone aquifer are discharging to the Jock River in this section. Groundwater discharge of this end-member is important to low flow generation in the lower portion of the Jock watershed. Velderman (1993) demonstrated that groundwater levels in this aquifer have been impacted by the extraction of groundwater resources. Moreover, increased urbanization in the Village of Richmond may impact low flow generation in the summer period, if domestic and industrial water usage increases. EMMA results provide insight into areas which need to be protected and conserved by water resource managers.

\subsubsection{GWMP2015: Wetland}

The wetland end-member GWMP2015 is believed to represent a diluted wetland end-member species. The site GWMP2015 is a forested wetland in which the main overburden material is primarily organic deposits (peat and muck). As samples were collected during high antecedent moisture conditions in autumn this end-member is believed to represent a geochemically diluted sample. The wetlands themselves represent a mixture of groundwater discharge and lagged precipitation inputs. The boxplot (figure 4-3) and the end-members projected in U-Space (figure 4-7) illustrated the spatial variation between wetland sites: Hobbs Drain forested wetland (HBP), Highway 15 headwater swamp (HWY15SW) as well as temporal variation in the Goodwood Marsh forested wetland (GWMP2015 and GWMP2016). Selection between the wetland end- 
members was decided based on the end-member that completely constrained the stream water mixing space and had the lowest percent difference amongst end-members sampled. The GWMP2015 end-member met both criteria. Contributions from this endmember are significant along the Jock River and in the headwaters, illustrating the importance of wetlands at regulating streamflow. These areas form important storage areas for precipitation under high antecedent moisture conditions and maintain streamflow important for ecological activity under low flow conditions. Ahmed (2017) investigated the importance of wetlands in the Black Creek sub-catchment, Ontario, Canada using MIKE 11/NAM software. Results from the long term continuous simulation of the Black Creek basin with wetland coverage and without wetland coverage demonstrated a decrease in overland flow by $21 \%$ and an increase in baseflow by $15 \%$ due to wetland presence (Ahmed, 2017). Model results of flood forecasting analysis also revealed that the presence of wetlands significantly reduced flood impacts in the Black Creek basin (Ahmed, 2017). Results from the EMMA indicate significant contributions from the wetland end-member at sites across the Jock watershed. Removal or drainage of wetland areas would therefore have a significant impact on baseflow dynamics in the Jock River watershed.

\subsection{Methodological Outcomes: Applying EMMA with Limited Resources}

The application of EMMA in this study is unique due to the limitations imposed on the number of variables analyzed and the number of samples collected. The application of EMMA under these circumstances is unconventional, however model results indicate good predictive ability for solute concentrations. EMMA theory is based 
on using an over-determined system of equations to solve for end-member proportions. However, it is mathematically possible to use a smaller number of tracers (R. Hooper, personal communication, 2017). Model results of the Jock River mixing models predicted versus observed concentrations demonstrates good model predictive ability; $\mathrm{R}^{2}$ of 0.81 for $\mathrm{SiO}_{2}$ and $\mathrm{SpC}$ and 1 for alkalinity with slopes equal to 1. Burns et al., (2001) applied EMMA to determine end-member contributions from outcrop runoff, hillslope runoff and the riparian area to streamflow in a 10 ha sub-catchment of Panola Mountain Research Watershed during two storm events. Linear analysis of the relationship between observed and predicted concentrations of the solutes gave an $\mathrm{R}^{2}$ between 0.95 and 0.99 and slopes of 0.86 to 1.03 , which indicates that the EMMA model is a strong, unbiased predictor of the stream solute concentration (Burns et al., 2001). James and Roulet (2006) investigated groundwater and surface water interactions across the Mont-Saint-Hilaire catchment through the projection of upstream sites into the outlet mixing space. The RRMSE for sites projected into their own mixing space were low (2-15\%) (James and Roulet, 2006). The RRMSE for sites along Jock river is between $0-0.3 \%$. The lower RRMSE observed for the Jock River sites is most likely due to the inclusion of fewer variables in the EMMA. In most applications of EMMA, often at least five cation, anion and other integrated water quality variables (i.e., $\mathrm{SpC}$ and alkalinity) are included in the model. The eigenvectors in these models often represent more than one tracer, thereby integrating more variability into the model. Results from the Jock River PCA, reveals that the first eigenvector represents two tracers $\left(\mathrm{SpC}\right.$ and $\left.\mathrm{SiO}_{2}\right)$, while the second eigenvector represents one tracer (alkalinity). The RRMSE of the predicted concentrations for SpC and $\mathrm{SiO}_{2}$ is higher than the RRMSE of alkalinity. The representation of fewer tracers in 
the eigenvectors, may explain why results have a lower RRMSE when compared to other studies. EMMA model results indicate that the model provides accurate predictions of solute concentrations. The greatest source of uncertainty/error lies in the tracer concentration uncertainty and the proper selection of end-members.

\subsubsection{Integration of Spatial Variation into the Jock River Mixing Model}

The Jock River mixing model differs from other published EMMA mixing models as it integrates spatial variability in end-member contributions across space. The Jock River mixing model represents an integrated mixing space from the headwaters to the outlet. The integration of multiple sample points into one mixing space potentially increases the representation of spatial heterogeneity across the landscape. The large RRMSE and relative bias of projected upstream sites observed by James and Roulet (2006) is believed to be related to the changing of the mixing ratios of ions upstream of the reference point. Results from the projection of the main tributaries into the Jock River mixing model demonstrate lower RRMSE and relative bias than those observed in James and Roulet (2006) and Hooper (2003). The RRMSE for alkalinity projected into the Jock River mixing space was lower than the RRMSE when projected into its own mixing space. The RRMSE and relative bias were highest for $\mathrm{SiO}_{2}$. The coefficient of determination $\left(\mathrm{R}^{2}\right)$ was also very low for $\mathrm{SiO}_{2}$, indicating that the mixing ratio of $\mathrm{SiO}_{2}$ either does not adhere to assumptions of physical mixing or that it is not mixing in the same ratio as the Jock River. James and Roulet (2006) found that alkalinity and conductivity had smaller and more consistent projected RRMSE and relative bias across space. James and Roulet (2006) suggested that these solutes would be most appropriate to use in a single linear mixing model across scale for the Mont Saint-Hilaire catchment. 
The low RRMSE and relative bias for the tracer's alkalinity and $\mathrm{SpC}$ seem to indicate similar findings. Evaluation of model quality parameters for sites projected into the Jock River mixing model and projected into their own mixing space demonstrates improvements in the predictive ability of end-member contributions across scale using a spatially integrated EMMA model.

\subsubsection{The Influence of Spatial and Temporal Heterogeneity in End-members}

A single linear mixing model can be applied to enhance our understanding of baseflow dynamics in the Jock River watershed. However, caution must be taken when interpreting the contributions of end-members across scale, as spatial and temporal heterogeneity in end-member composition may influence calculated proportions. The largest source of uncertainty in the projected main tributary sites is the end-members identified. Results demonstrated that when sites were projected into their own mixing space the number and identity of the end-members changed. At wetland dominated subcatchments (Hobbs Drain, Kings Creek and Nichols Creek) comparison of the endmember proportions between the at-site projected proportions and the Jock River mixing model projected proportions remained consistent, but reflected spatial or temporal variations in the wetland and deep regional limestone aquifer. At groundwater dominated sites (Flowing Creek and Leamy Creek) the identity of the end-members changed drastically indicating that a single linear mixing model cannot be applied to all the main tributary sites.

The projection of sites into their own mixing space also led to a reduced number of identifiable end-members. In most cases, only two end-members could be identified, with the exception of Kings Creek and Nichols Creek. The reduction in the number of 
end-members identified is partially attributable to missing end-members which were not sampled during the study period. Agricultural runoff, which was not sampled as a possible end member and may contribute significantly to flow at Leamy Creek and Flowing Creek. The only site in which no end-members could be defined based on at-site projections was Monahan Drain. In the Jock River mixing model, this site is dominated by the end-member W156-2, which may represent the basal gravel aquifer between the Oxford Formation and the clay aquitard or the esker, as discussed in section 5.2.2. The end-member contributions identified in the Jock River model fit with our conceptual understanding of baseflow generation at this site. However, when projected into its own mixing space this end-member is not identified as a constraining end-member. Spatial heterogeneity in this end-member may have affected our ability to constrain the mixing space at this site. Direct sampling of the esker end-member may aid in confirming results from the Jock River mixing model at Monahan Drain.

The use of a single linear mixing model across scale is not applicable at the finer spatial resolution of the headwater sites. Model results demonstrate significant relative bias and structure in the residual plots indicating that the mixing ratios of end-members may differ or the solutes are not mixing conservatively. Spatial and temporal heterogeneity in the end-members at smaller order streams is most likely also a significant factor. Results from the projection of the main tributary sites into the Jock River mixing model illustrated that end-members changed to reflect spatial and temporal variability in the groundwater and wetland end-member. Spatial variability is heightened at a finer resolution, as the geochemistry of each site might be influenced by slight variations in the geochemistry of end-members. The headwater sites could potentially be 
projected into the mixing space of their upstream contributing areas but this would require increased sampling of surface water and end-members at the main tributary sites.

Projections into the Jock River mixing model were found to be scale-dependent. Spatial and temporal heterogeneity in the end-members, limits the scale at which projection into the upstream mixing model can be performed. Analysis of end-members spatial and temporal variability at projected sites is necessary to confirm projections into a single linear mixing model, as the assumption of end-member invariability in time and space is violated at the catchment scale. Future EMMA studies in this region will need to sample additional variables in order to identify end-members in lower portion of the watershed. However, results from the projection of the main tributary sites into the Jock River mixing model, was successful in highlighting the variability in groundwater flow systems contributing to baseflow generation across the Jock watershed. Baseflow in flat topographic areas, such as the Jock River watershed, are thought to be maintained primarily by regional groundwater flow systems. EMMA results demonstrate that baseflow generation is more complex than originally assumed, as baseflow is maintained by multiple groundwater flow systems throughout the watershed. Furthermore, groundwater flow systems in the Jock watershed are dynamic, and interactive with one another. These results highlight the superimposition of groundwater flow systems first described by Tóth (1963) and demonstrate that groundwater and surface water interactions are complex even in topographically flat regions. 


\subsection{Conclusion}

Sources of baseflow generation across the Jock watershed have been shown to be both spatially and temporally variable. Results show that the sources of baseflow generation are temporally variable in the lower reaches of the Jock River due to changing antecedent moisture conditions. Conversely, sources of baseflow generation in the upper portion of the watershed demonstrate temporal invariability, due to the regulating affect of the wetlands. Results from this project challenge assumptions of static hydrologic behaviour under low flow conditions and sources of baseflow generation in flat topographic regions. This project demonstrates that multiple groundwater flow systems contribute and have contrasting roles in baseflow generation across the Jock river watershed. Results from EMMA demonstrate that the basal gravel/esker aquifer is an important component of low flow generation in the lower watershed. The sensitivity of the basal gravel/esker aquifer to extraction was illustrated by Velderman (1993); therefore, over extraction could impact low flow generation in the Jock River. EMMA results also demonstrated that the wetlands are crucial to mitigating both high and low flow conditions within the Jock River watershed. The drainage or removal of these wetlands could have significant impacts on baseflow generation throughout the watershed. These findings corroborate results from other studies highlighting the hydrological importance of wetlands in the landscape (Ahmed, 2017). EMMA results highlight areas of importance for conservation and protection by water resource managers. Increasing urban and agricultural pressures and climate change may significantly impact hydrologic conditions in the Jock watershed. These results highlight 
that management and conservation of wetland areas and deep groundwater resources is crucial to maintaining ecohydrological health across the Jock River watershed.

The applicability of EMMA with a limited number of variables and samples was shown to be successful for the Jock River sites. Results from the EMMA were supported and enhanced by results from hydrometric and geospatial analysis of watershed characteristics. The projection of the main tributary sites into the Jock River mixing model demonstrated better model fit for wetland dominated sub-catchments. Increased sampling of other potential end-members and inclusion of more variables is needed to constrain the mixing spaces of the groundwater dominated tributaries in the lower portion of the watershed. Projection of the headwater sites into the Jock River mixing model demonstrated scalability issues due to spatial heterogeneity in end-members. Increased sampling of the main tributary sites and end-members contributing to stream water at these sites could allow for projection of headwater features into the main tributary sites. The main objective of this project was achieved, as application of EMMA in the Jock River watershed improved on current and past hydrologic and hydrogeologic understandings of catchment processes. 
Appendix A 
Isotopic analysis was performed on all water samples as it was initially thought that the isotopic ratios of water samples could be used as a tracer in the EMMA model. However, after further review of the literature and discussions with academic peers, it was determined that as the isotopic ratio of water represents a time source component rather than a geographic source component and was therefore left out of the EMMA model. An analysis of the isotopic ratios of different surface water sites and end-members was performed to enhance and verify EMMA results. It was not included in the body of thesis as it not longer fit with the flow of the thesis but still provided valuable additional information about groundwater and surface water interactions in the Jock River watershed. In the following sections there is a short review of the literature, a description of the laboratory and data analysis methods as well as a summary of the results.

\section{A-1.0 Isotope Hydrology}

\section{A-1.1 Stable Isotopes of Oxygen and Hydrogen}

Stable environmental isotopes are naturally occurring within the environment, making them ideal tracers for natural systems. The most commonly used isotopes in hydrologic applications are ${ }^{18} \mathrm{O}$ and ${ }^{2} \mathrm{H}$, also known as deuterium (D). These are ideal tracers of the hydrologic cycle as they are intrinsic to the water molecule itself. The slight increase in the atomic mass of the isotopes affects the rate at which they react leading to variations in their abundance in different reservoirs (Clarke, 2015). Stable isotope concentrations are measured as a ratio of the rare isotope to the abundant isotope and expressed as the difference in this ratio between the sample and a known reference, see equation 17 (Clarke, 2015). The normalized difference between the sample and the reference is multiplied by 1000 to express the measurement in permil (\%o) units, see 
equation 18 (Clarke, 2015). The reference used is Vienna Standard Mean Ocean Water (VSMOW).

$$
\begin{array}{ll}
\delta^{18} O_{\text {sample }}=\frac{\left({ }^{18} O /{ }^{16} O\right)_{\text {sample }}-\left({ }^{18} O /{ }^{16} O\right)_{\text {reference }}}{\left({ }^{18} O /{ }^{16} O\right)_{\text {reference }}} & \text { Equation } 17 \\
\delta^{18} O_{\text {sample }}=\left(\frac{\left({ }^{18} O /{ }^{16} O\right)_{\text {sample }}}{\left({ }^{18} O /{ }^{16} O\right)_{\text {reference }}}-1\right) \cdot 1000 \% \text { VSMOW } & \text { Equation } 18
\end{array}
$$

\section{A-1.2 Fractionation in the Hydrologic Cycle}

The slight variations in the atomic mass of isotopic elements, means that while they still behave the same chemically, they will react at slightly different rates physically and in geochemical reactions (Clarke, 2015). Differences in mass affect bond strength which partitions heavy and light isotopes into different reservoirs (Clarke, 2015). Heavier atoms form stronger bonds, which are more resistive to fractionation. Isotope fractionation is a thermodynamic process and as such it is greatly influenced by temperature. At lower temperatures, the rate of fractionation increases (Clarke, 2015). The degree of fractionation of $\mathrm{D}$ is much greater than ${ }^{18} \mathrm{O}$, as $\mathrm{D}$ is twice the mass of $\mathrm{H}$, while ${ }^{18} \mathrm{O}$ is only $12.5 \%$ heavier than ${ }^{16} \mathrm{O}$ (Clarke, 2015). The distribution of isotopes in the hydrologic cycle is controlled by the interplay between fractionation and distillation (Clarke, 2015).

\section{A-1.3 Rayleigh Distillation}

Rayleigh distillation is the exponential function which describes the progressive partitioning of heavy isotopes into the water reservoir as evaporation continues, see equation 19 (Clarke and Fritz, 1997). In equation 19, $R_{f}$ represents the isotope ratio of the reactant reservoir after some reaction to the residual fraction $(f)$ of the initial isotope ratio 
$\left(R_{o}\right)$ occurs. The exponent $\alpha$ is the equilibrium fractionation factor during evaporation. This equation describes the progressive enrichment of ${ }^{18} \mathrm{O}$ or $\mathrm{D}$ in liquid water as evaporation occurs (Clarke and Fritz, 1997). During the condensation of water vapor in an air mass, as a result of adiabatic cooling, equilibrium fractionation preferentially partitions the heavier isotopes ${ }^{18} \mathrm{O} / \mathrm{D}$ into the rain/snow (Clarke and Fritz, 1997). As the air mass moves along its trajectory, the process of rainout preferentially sheds the heavier isotope from the vapour (Clarke and Fritz, 1997). The vapour in the air mass becomes progressively more depleted in the heavy isotopes as it passes. As rainout is driven by a decrease in temperature, there exists a correlation between temperature and the isotope content of precipitation (Clarke, 2015).

$$
R_{f}=R_{o} f^{(\alpha-1)}
$$

Equation 19

\section{A-1.4 Isotopic Signature of Groundwater}

The use of stable isotopes to evaluate groundwater recharge areas is a common application in hydrogeology. Variations in the spatial and temporal patterns of groundwater and precipitation isotopic signatures allow for the determination of groundwater recharge areas and flow paths. The dispersion and attenuation of water in recharge environments through soil pores and fractures influences the isotopic translation of precipitation into groundwater (Clarke, 2015). Mixing of groundwater/soil water of different ages in the subsurface dampens the event-scale to seasonal-scale variability of isotopes in precipitation (Clarke, 2015). Consequently, the weighted mean annual value of $\delta^{18} \mathrm{O}$ and $\mathrm{D}$ in precipitation is often similar with the isotopic signature of groundwater (Clarke, 2015). In temperate regions where snowmelt and autumn precipitation contribute significantly to groundwater recharge, the weighted mean annual isotopic signature of 
precipitation is often slightly enriched over the local groundwater (Clarke, 2015).

Differences in shallow versus deep flow systems is also observable in the variability of $\delta{ }^{18} \mathrm{O}$ values. In phreatic aquifers, groundwater isotopic signatures near the water table can vary $1-2 \%$ in $\delta{ }^{18} \mathrm{O}$ values due to fast infiltration to the water table through macropores (Clarke, 2015). Where as, groundwater with little to no variability is often indicative of deeper regional flow systems (Clarke, 2015). 


\section{A-1.5 Isotope Hydrograph Separation}

Isotope hydrograph separation (IHS) investigates the temporal dynamics of groundwater contributions to surface water at a specific site. IHS is a measurable objective technique based on the components of the water itself, rather than relying on the pressure response in the channel (Klaus and McDonnell, 2013). Storm hydrograph IHS is considered a time source analysis, in which the hydrograph is a two component mixing model (McGuire and Mcdonnell, 2008). A major underlying assumption is that isotopic species of groundwater (old water/pre-event water) and precipitation (new water/event water) are distinct and can be separated based on a mass balance equation, see equations 20-22. In which, $Q_{T}$ is streamflow, $Q_{P}$ is contributions from pre-event water, $Q_{E}$ is contributions from event water, $C_{T}, C_{P}, C_{E}$ are the $\delta^{18} \mathrm{O}$ values of streamflow, pre-event and event water and $f_{P}$ is the fraction of pre-event water in the stream.

$$
\begin{gathered}
Q_{T}=Q_{P}+Q_{E} \\
C_{T} Q_{T}=C_{P} Q_{P}+C_{E} Q_{E} \\
f_{P}=\frac{C_{T}-C_{E}}{C_{P}-C_{E}}
\end{gathered}
$$

The use of stable isotopes in hydrograph separation sparked a paradigm shift in our conceptualization of catchment runoff dynamics. It was determined that precipitation contributions to streamflow during storm events is often minimal and the event hydrograph is dominated by the pre-event component in most humid environments 
(Klaus and McDonnell, 2013). Despite this insight into catchment runoff dynamics twocomponent hydrograph separation is limited in scope to pre-event and event portions. IHS relies on numerous assumptions regarding the invariability of the pre-event/event components throughout space and time, an assumption which is often violated. A major assumption of IHS is that contributions from soil water must be negligible or similar to that of groundwater (Klaus and McDonnell, 2013). Early IHS demonstrated that this assumption is violated as soil water can both contribute significantly to stormflow and can have a unique isotopic signature (Klaus and McDonnell, 2013). The addition of the third end-member, relates to the geographic sources of other end-members such as soil water, snow, rain and riparian water (Klaus and McDonnell, 2013). To determine proportions in a three component mixing model requires the addition of another tracer or the measurement of a flow component in order to solve the mass balance equation (Klaus and McDonnell, 2013).

\section{A-2.0 Isotopic Analysis Methods}

\section{A-2.1 Laboratory Analysis}

Isotopic ratios of $\delta^{18} \mathrm{O}, \delta^{2} \mathrm{H}$ act as conservation tracers as their chemical

composition is not altered through reactions with other elements. The ratio's of $\delta^{18} \mathrm{O}, \delta^{2} \mathrm{H}$ are partitioned in the environment based on hydrologic processes which result in the fractionation, distillation and translation of water throughout the system. The partitioning of unique isotopic signatures for water species throughout the hydrologic cycle has been used as in numerous studies to assess hydrologic flow paths such as groundwater surface water interactions (Walker et al., 2003; Praamsma et al., 2009; McGrane et al., 2014; Mountain et al., 2015). All water samples (precipitation, groundwater and surface water) 
were analyzed for isotopic ratios of $\delta^{18} \mathrm{O}, \delta^{2} \mathrm{H}$ at the Water and Ice Research Laboratory (WIRL) at Carleton University. Isotopic samples were analyzed using the Los Gatos Research (LGR) Triple - Liquid Water Isotope Analyzer (T-LWIA), which uses Off-Axis Integrated Cavity Output Spectroscopy (OA-ICOS) to measure the optical absorption of $\delta^{17} \mathrm{O}, \delta^{18} \mathrm{O}, \delta^{2} \mathrm{H}$ (Los Gatos Research, 2015). T-LWIA uses direct injection of liquid water samples, and allows for many samples to be analyzed with minimal sample preparation. Samples were prepared by pipetting $1 \mathrm{ml}$ of the sample into $2 \mathrm{ml}$ glass vials. New pipette tips and sample vials were used for each sample to prevent cross contamination. Samples were analyzed in batches of 50 or less depending on the number of samples available. Five standards and deionized water were also analyzed during each batch. Sample runs included two preparation injections and four injections per sample which were then average to provide the final reading. Injection sample volumes are approximately $1 \mu \mathrm{L}$ per injection, however the actual injection volume is a source of uncertainty in the final reading and is assessed using post-processing software. A typical sample run included analysis of the deionized water sample 6 times before any samples were analyzed to provide a baseline reading. A standard was analyzed after every 3 samples. The T-LWIA has a precision of $\pm 0.15 \%$, and all results are evaluated for uncertainty and precision using the post processing software.

T-LWIA post processing software was used to prepare the final output files and ensure measurements were within acceptable uncertainty limits. The largest source of uncertainty is the injected volume. Injection volume is filtered based on 3 criteria the absolute injected volume $(a v o l)$, injected volume fluctuation $(f v o l)$ and injected volume standard deviation (svol). Samples were rejected if they: did not fall within an avol of 
$2.5 \times 10^{16} \mathrm{~N} / \mathrm{cm}^{3}$ and $5.5 \times 10^{16} \mathrm{~N} / \mathrm{cm}^{3}$, the $f v o l$ was outside $\pm 5.0 \%$ of the 72 point running average or the $s v o l$ was outside \pm 3 standard deviations. Another source of uncertainty is the temperature variation (tvar) as the sample needs to be completely evaporated before data acquisition (Los Gatos Research, 2015). Samples were rejected if the tvar was $1.0^{\circ} \mathrm{C}$ outside the accepted temperature range. Outliers and precision of all isotopic species are also analyzed using the post processing software. Outlier warnings were generated for $\delta^{17} \mathrm{O}, \delta^{18} \mathrm{O}, \delta^{2} \mathrm{H}$ when values were outside \pm 3 standard deviations. Precision warnings were generated for $\delta^{2} \mathrm{H}$ when values were outside \pm 1 standard deviation. Higher precision is expected for $\delta^{18} \mathrm{O}$ and $\delta^{17} \mathrm{O}$, precision warnings were set to generate when values were outside \pm 0.5 standard deviation and \pm 0.3 standard deviation respectively. Data which was rejected or was flagged with precision warnings was re-run at a later date, if data was rejected a second time it was omitted only four data points were omitted from all collected water samples $($ total $=457)$ analyzed.

\section{A-2.0 Isotopic Data Analysis}

\section{A-2.1 Local Meteoric Water Line (LMWL)}

The global meteoric water line (GWML) is used to describe the strong linear correlation between ${ }^{18} \mathrm{O}$ and $\mathrm{D}$ in meteoric waters with a slope of 8 and a deuterium intercept of 10, see equation 23 (Clarke, 2015). The GMWL has a slope of 8, due to the increased fractionation of $\mathrm{D}$, which is 8 times greater than for ${ }^{18} \mathrm{O}$ (Clarke, 2015). The deuterium intercept demonstrates that the $\delta^{18} \mathrm{O}-\delta \mathrm{D}$ line does not pass through at $0 \%$ and $0 \%$, but rather at $+10 \%$ (Clarke, 2015). This phenomenon is called deuterium excess and can be used to trace water to its origin. Deuterium excess is the result of kinetic nonequilibrium evaporation of the primary vapour mass, which increases with lower 
humidity (Clarke, 2015). The GMWL is the average of many local/regional meteoric water lines which differ slightly from the GMWL due to variability in climate and geography (Clarke, 2015).

$$
\delta D=8 \delta^{18} O+10 \%
$$

Equation 2

As air masses move along their trajectory there will be additions of water vapor to the air mass from evaporation of surface water bodies and transpiration from vegetation, as well as mixing with other air masses in the troposphere (Clarke, 2015). Differences in the origin of the original vapor, mixing with other vapor sources and rainout along its trajectory means that any given region will have its own characteristic MWL, called the local meteoric water line (LMWL) (Clarke, 2015). The LMWL is also affected by evaporation in the air column after condensation (Clarke, 2015). If rain is falling through a dry air column, partial evaporation will impart a kinetic fractionation and selectively enrich the rain (Clarke, 2015). The lower the humidity, the greater the amount of partial evaporation. This phenomenon, is called the amount effect and may lower the slope of the LMWL. This is particularly problematic when the LMWL is used to assess groundwater and surface water data, as allowing smaller precipitation events which may have experienced evaporative enrichment to have equal influence on the slope of the LMWL, produces an effect that is not proportionate to the hydrologic significance introduced (Hughes and Crawford, 2012). To mitigate this effect, smaller rain fall events which do not contribute to groundwater recharge can be omitted from the LMWL (Clarke, 2015). Perhaps a more rigorous method which can be used to address this problem, is to use a precipitation amount weighted least squares regression (Hughes and Crawford, 2012). The LMWL slope and intercept can be calculated from event-based measurements of 
$\delta^{18} \mathrm{O}, \delta \mathrm{D}$, and precipitation (p), see equations 24 and 25 (Hughes and Crawford, 2012;

Clarke, 2015).

$$
\begin{gathered}
\text { slope, } m=\frac{\sum_{i=1}^{n} p_{i}{ }^{18} O_{i} D_{i}-\frac{\sum_{i=1}^{n} p_{i}{ }^{18} o_{i} \cdot \sum_{i=1}^{n} p_{i} D_{i}}{\sum_{i=1}^{n} p_{i}}}{\sum_{i=1}^{n} p_{i}{ }^{18} O_{i}{ }^{2}-\frac{\left(\sum_{i=1}^{n} p_{i}{ }^{18} O_{i}\right)^{2}}{\sum_{i=1}^{n} p_{i}}} \\
\text { intercept }=\frac{\sum_{i=1}^{n} p_{i} D_{i}-m \sum_{i=1}^{n} p_{i}{ }^{18} O_{i}}{\sum_{i=1}^{n} p_{i}}
\end{gathered}
$$

Equation 3

Equation 4

A long term LWML was generated for the Ottawa area using data obtained through the Global Networks of Isotopes in Precipitation (GNIP) for Ottawa, Ontario. The GNIP dataset spans from 1972-2012 and contains the mean monthly values for $\delta$ D and $\delta^{18} \mathrm{O}$. A long term LMWL was generated through simple linear regression. A seasonal LMWL was also created using snowmelt and precipitation samples collected from the Jock in 2015. The seasonal LMWL was generated following the precipitation amount weighted least squares regression method proposed by Hughes and Crawford, (2012). The $\delta \mathrm{D}$ and $\delta^{18} \mathrm{O}$ values were weighted by the precipitation amount measured at the Ottawa CDA Environment Canada weather station. The Ottawa CDA weather station was chosen over other weather stations as it was located closer to the rain water collection site.

\section{A-2.2 Spatial and Temporal Variations}

Spatial and temporal variations amongst the Jock River, the main tributary sites, headwater sites, groundwater wells and wetland piezometers was investigated graphically. Analysis of spatial and temporal variations in isotopic ratios of stream water and potential end-members was conducted through the construction of bi-variate plots of 
$\delta \mathrm{D} \%$ versus $\delta^{18} \mathrm{O} \%$ and time series plots of $\delta^{18} \mathrm{O} \%$ over the course of the 2015 growing season. Stream water samples from the headwaters were plotted and viewed based on their respective distributions and locations relative to the LMWL and groundwater/wetland end-members. Stream water samples from the Jock River and its main tributaries were also plotted and viewed similarly. Plots were generated to determine if a two end-member isotopic mixing model could be used to explain streamflow at two different spatial and temporal scales in the Jock River watershed. Temporal variation throughout the growing season was analyzed for the Jock River and its main tributaries based on time series analysis of $\delta^{18} 0 \%$ values.

\section{A-2.3 Isoscapes}

Isoscapes are interpolated contour maps of isotopic ratios. Isoscapes provide a useful tool for visualizing spatial variations in isotopic ratios related to processes such as interactions between groundwater and surface water systems (Brooks et al., 2012; Mountain et al., 2015). Isoscapes were generated to analyze spatial variation in the isotopic ratios of groundwater and stream water across the Jock River watershed. An isoscape of surface water $\delta^{18} 0 \%$ was generated from the spring and summer headwater samples to view large scale spatial variability in surface water isotopic ratios and identify potential sources of groundwater recharge and discharge. All isoscapes were generated in ArcMap version 10.3.1 (ESRI, 2015) using the inverse distance weighted method (IDW). This method assumes that features close to one another are more alike than those further away. IDW weights the values in closer proximity more heavily to interpolate the values of unknown cells. In generating the isoscapes default parameters were used in which the output cell size was $130 \mathrm{~m}$, the power was 2 and the search radius was variable with a 
minimum number of 12 . The final output provides a finer scale visual representation in the distribution of $\delta^{18} 0 \%$ values throughout the watershed than that of the main tributary sites.

\section{A-3.0 Isotope Results}

\section{A-3.1 LMWL}

Several LMWLs were generated from the GNIP data, as the Jock 2015 seasonal LMWL had a significantly different deuterium intercept from the long term (1972-2012) LMWL. The GNIP data was subset into two sets of years to determine if more current data produced a LMWL more similar to that observed in 2015. All the LMWLs generated for the Ottawa area demonstrate a slope which is slightly lower than the GWML. The lower slope observed is common for continental regions with non-ideal rainout trajectories (Clarke, 2015). A lower slope may also indicate that the vapour has been slightly enriched in $\delta^{18} \mathrm{O}$ due to partial evaporation in dry air columns (Clarke, 2015). Examining the LMWLs generated from the GNIP long term data and the subsets of more current time periods, there is an apparent trend which demonstrates an increasing slope and deuterium intercept as the number of years included is reduced and more current time periods are examined. The 2006-2012 subset has the greatest slope, which is almost equal to the GMWL slope of 8 . The 2006-2012 subset also has a deuterium intercept of $10.12 \%$, which is slightly higher than the GMWL. The deuterium intercept of the GMWL is $10 \%$ because most global freshwaters are formed under about $85 \%$ humidity (Clarke, 2015). The relationship observed between humidity and the deuterium intercept is due to kinetic evaporation. The higher the humidity under primary formation the lower the deuterium intercept and vice versa (Clarke, 2015). The implications of these 
observations in relation to climate over a long-time scale are difficult to assess. However, the data subsets from 2000 onward appear to be more similar to the seasonal LWML created using the 2015 data from the Jock watershed. The slope of the 2000-2012 data subset is most like the Jock 2015 slope, 7.76 and 7.71 respectively. The deuterium intercept from the 2006-2012 data subset is most like the Jock 2015 deuterium intercept $10.12 \%$ and $10.41 \%$, respectively. Examining the LMWLs graphically in figure A-0-1 there is little visible difference apparent between all four lines. Examining the LMWLs closer, figure A-0-2 illustrates that there is a difference between them. Graphically the LMWL's for 1972-2012 and 2000-2012 overlap each other the most and are almost indistinguishable. The Jock 2015 LMWL and the 2006-2012 data are most distinct from one another. The average difference between the two lines is approximately $0.5 \%$ for $\delta^{18} \mathrm{O}$, although this is a small difference the of range $\delta^{18} \mathrm{O}$ between the most depleted (snow) and enriched (rain) is approximately $17 \%$, based on values of $-20 \%$ to $-3 \%{ }^{18} \mathrm{O}$. This equates to a $3 \%$ difference between these two LMWL, which appears more visually significant than it is numerically. Therefore, as the differences between the LMWLs are relatively minor the Jock and GNIP 1972-2012 LMWLs were both used in subsequent analysis. 


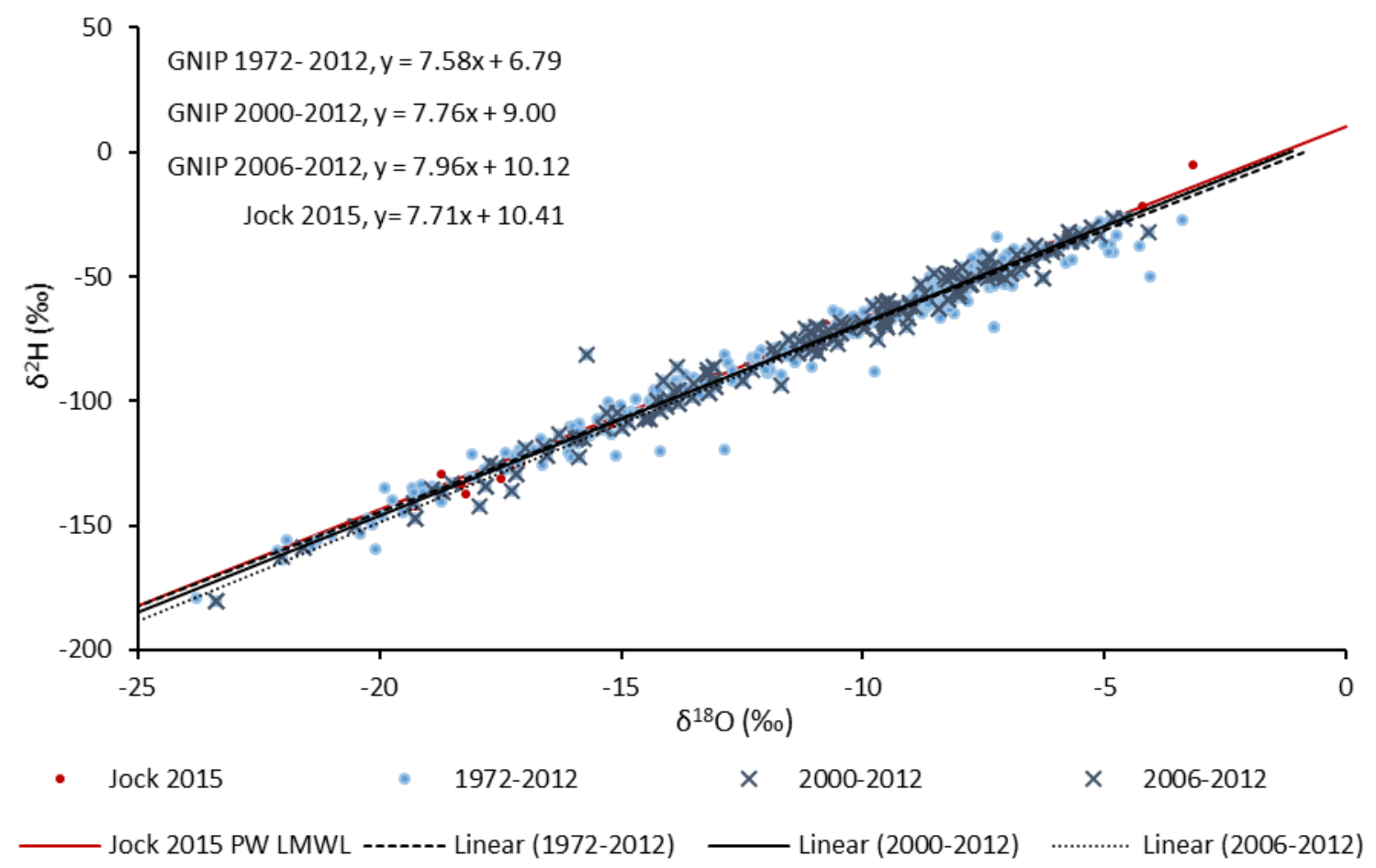

Figure A-0-1. Local meteoric water lines (LMWLs) for the Ottawa area. Multiple lines have been plotted to show changes in the slopes and intercepts calculated from the long term (1972-2012) GNIP data for Ottawa, subsets of the Ottawa GNIP data from recent years (2000-2012 \& 2006-2012) and data collected from the Jock in 2015. 


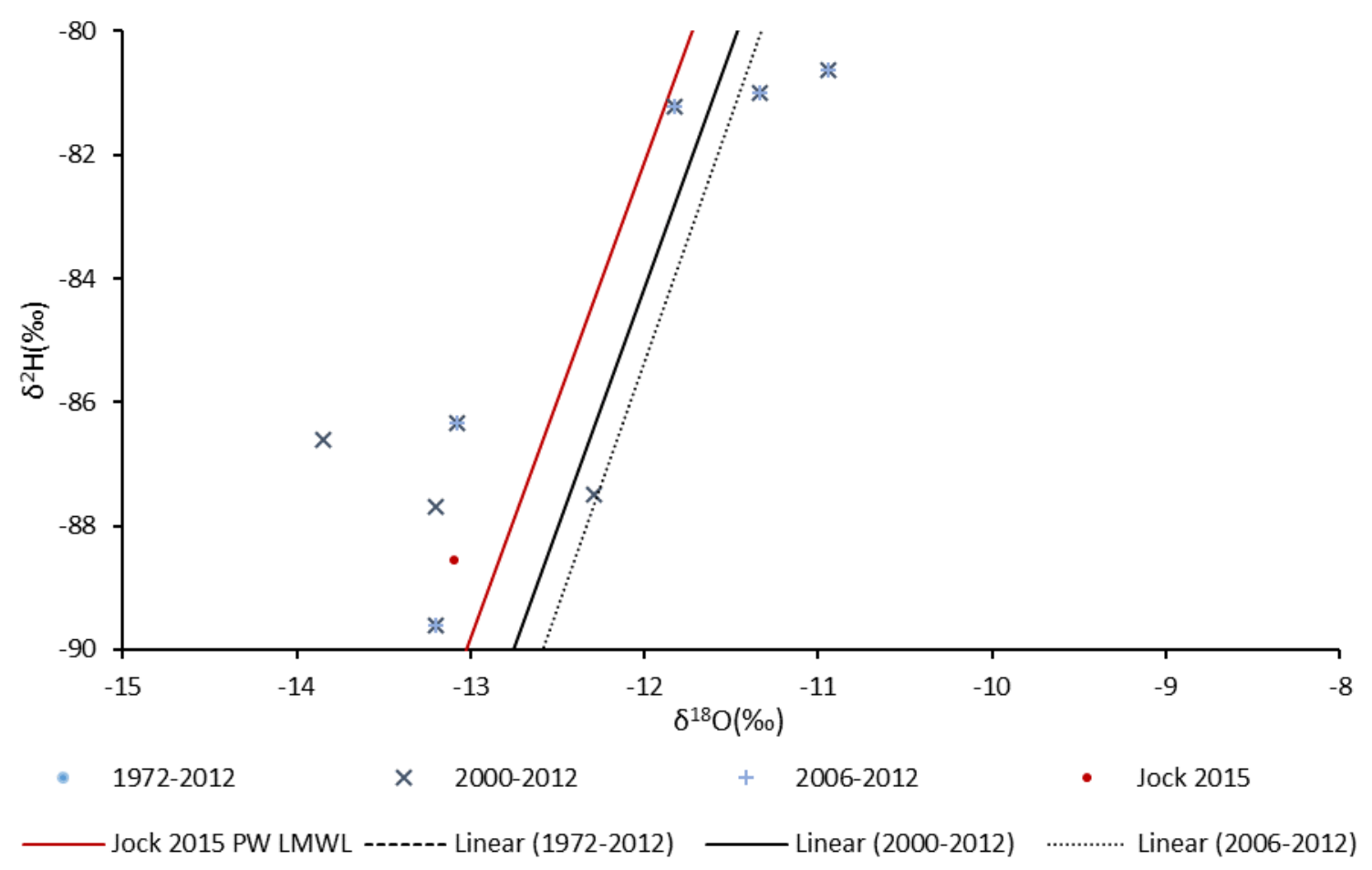

Figure A-0-2. LMWL's plotted with a limited range for $\delta^{2} H$ and $\delta^{18} O$ to illustrate differences between LMWL's.

\section{A-3.2 Spatial and Temporal Variation of Isotopic Ratios}

\section{A-3.2.1 End-members: Groundwater and Wetlands}

Figure A-0-3 demonstrates the spatial variation amongst the deep groundwater wells and shallow groundwater wetland sites. The weighted mean annual precipitation (WMAP) has also been plotted, as it is typically considered to represent the isotopic signature of groundwater (Clarke, 2015). The WMAP value is enriched compared to the deep groundwater wells as is common for temperate regions, in which more depleted precipitation (snowmelt) and autumn precipitation contribute most significantly to groundwater recharge. The deep groundwater end-members demonstrate 3 distinct groupings. The first group, wells GW_DW_1, W085, W084 and W175-3 are more enriched and plot closer to the WMAP. The second group GW_DW_2, W156-3 and 
W175-2 are more depleted and plot further from the WMAP. The third group, isn't a group but a single point; W156-2, this well is depleted like the wells in the second group, but it is unique as it is offset from the LMWL, due to enrichment of $\delta^{18} \mathrm{O}$. This site is potentially offset from the LWML due to molecular diffusion. Well W156-2 is completed in the basal gravel aquifer at the interface of the Oxford Formation and is overlain by thick clay deposits which are believed to act as an aquitard (Velderman, 1993). Fractionation through molecular diffusion through the clay aquitard at this site may explain its offset from the LMWL. Groundwater transport in aquitards is dominated by molecular diffusion in the porewaters (Clarke, 2015). Molecular diffusion can cause fractionation of isotopes based on the molecular velocity of the heavy isotope relative to the light isotope (Clarke, 2015). The wells GW_DW_2 and W156-3 are also overlain by this aquitard but are not offset from the LMWL, presumably because these wells are accessing water from the deeper regional bedrock aquifer. The position of W175-2 along the LMWL is more difficult to interpret. The well W175 is a multi-level well in which, W175-2 is the shallow well completed $\sim 25$ mBGS (below ground surface) and W175-3 is the deeper well completed $\sim 35$ mBGS. The well record here describes only a thin soil cover and shows that both wells are drilled into the Gull River Formation. Well W084 is also drilled into the Gull River Formation and is completed at $\sim 25 \mathrm{mBGS}$, similar to W175-2. However, figure 4-15 indicates that W175-3 and W084 have almost the exact same isotopic ratio, while W175-2 is more similar to the isotopically depleted wells GW_DW_2 and W156-3. The causality of this distinction at this site is difficult to determine. The position and difference amongst the PGMN groundwater wells are all 
based on a single sample point, therefore more in-depth analysis of the implications and true differences would require increased sampling of these sites.

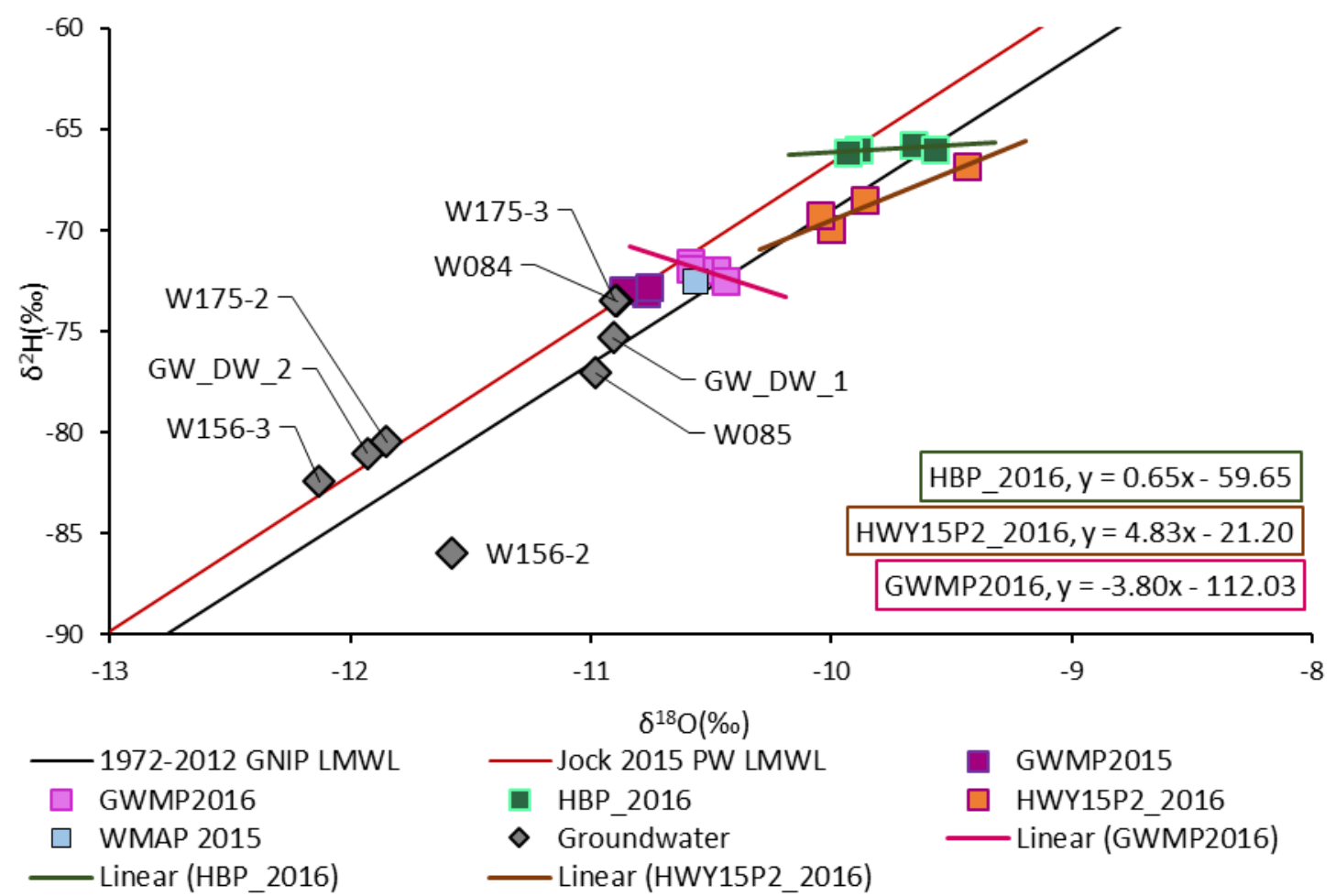

Figure A-0-3. Isotopic variation of end-member's: groundwater (GWMP2015, GWMP2016), and wetlands (HBP_2016 and HWY15P2_2016) along the LMWL. The mean isotopic ratios have been plotted for $G W \ldots W_{-} 1$ and $G W \ldots W \_2$; the remaining PGMN wells are all single measuring points. All measuring points have been plotted for wetland sites to demonstrate their temporal variations, which were higher than observed variations groundwater isotopic ratios. Weighted mean annual precipitation (WMAP) for 2015 has been plotted as it typically represents the isotopic signature of groundwater.

Shallow groundwater from the wetlands was more enriched than the deep groundwater wells. The exception being GWMP2015, as it was the most depleted and has a similar isotopic ratio to wells W175-3 and W084. The similarity between this site and the wells could be attributed to the time period when the sample was collected. GWMP2015 was collected in late autumn, due to issues addressed in section 3.2.3.2, therefore water may be isotopically similar to recharge waters for W175-3 and W084. GWMP2016 is slightly more enriched than GWMP2015, samples from 2016 plot above 
the WMAP. GWMP2016 samples were collected in the summer of 2016, their enrichment may reflect contributions from isotopically enriched summer rainfall.

Wetlands HBP_2016 and HWY15P2_2016 are significantly more enriched and plot further above the WMAP. The increased enrichment at these wetland sites demonstrates that source waters for these sites may be isotopically lighter, i.e., rain rather than snowmelt. The headwater swamp site HWY15P2_2016 clearly demonstrates a deviation from the LMWL due to evaporative enrichment. Evaporation produces a positive linear trend for both $\delta \mathrm{D}$ and $\delta^{18} \mathrm{O}$, but with preferential enrichment of $\delta^{18} \mathrm{O}$ (Clarke, 2015). The slope of the local evaporation line (LEL) at HWY15P2_2016 is 4.83 which is common for LELs as they typically have slopes between 4 and 7 (Clarke, 2015). Wetlands HBP_2016 and GWMP2016 do not deviate due to evaporation. The slope of the line for GWMP2016 is atypical of evaporation as it demonstrates a negative trend and slightly a smaller slope. The slope of the line for HBP_2016 is positive but is much smaller (0.64) than the typical LEL. The observed deviation from the LMWL, is most likely not due to evaporation. The variability observed is typical of phreatic aquifers close to the water table, which often demonstrate a variance of $1-2 \%$ for $\delta^{18} \mathrm{O}$ (Clarke, 2015). The variance in $\delta^{18} \mathrm{O}$ observed at these sites in June and July of 2016 is small, 0.004 $(\mathrm{n}=5)$ and $0.03(\mathrm{n}=4)$ for GWMP2016 and HBP2016 respectively.

The isotopic variation observed matches with the site characteristics. HWY15P2_2016 is located at the edge of a large swamp with large swathes of open surface water where evaporative enrichment would be significant. GWMP2016 and HBP_2016 are both forested wetlands with organic soils, therefore evaporative enrichment would not be significant at these sites. As the water is stored beneath the 
ground surface evaporation would be less influential than transpiration at these sites. GWMP2015-2016 are much more similar to groundwater isotopic ratios than HBP_2016 indicating that GWMP2015-2016 is potentially more groundwater dominated, while HBP_2016 is potentially more precipitation dominated. The hydrodynamics of these sites help to confirm this theory as the piezometer at GWMP2015-2016 was never dry and consistently supplied a good sample volume. Conversely, the piezometer at HBP_2016 was often dry and produced a lower sample volume. Unfortunately, no hydraulic head measurements were conducted at these sites to confirm this theory. The piezometer at HBP_2016 was also moved several times to find an area with sufficient soil depth to supply more sample volume but was consistently lower than other sites. The stream running through this wetland, Hobbs Drain (HBFT), also demonstrated a significant decline in outflow as the growing season progressed. Figure A-0-4 demonstrates the decline in water level at the outlet of the Hobbs Drain wetland and the Jock River headwater swamp along Highway 15 . The water level at Hobbs Drain was approximately $20 \mathrm{~cm}$ higher than that at the Jock River headwater swamp at the beginning of the growing season. As the growing season progressed a steady decline in the water level at Hobbs drain is observed. During the low flow period the water level at Hobbs Drain is lower than that observed at the Jock River headwater swamp. The water level at the Jock River headwater swamp also demonstrates a gradual and steady decline in water level during the course of the growing season, however it appears to plateau at approximately $40 \mathrm{~cm}$ even during the low flow period. It is less responsive in magnitude to precipitation events than the outlet at Hobbs Drain which increases greatly in response to precipitation events. The consistency in the water level at the Jock River headwater swamp outlet 
indicates that this site may be groundwater fed while the variability and responsiveness of the Hobbs Drain outlet indicates that this site may be precipitation dominated.

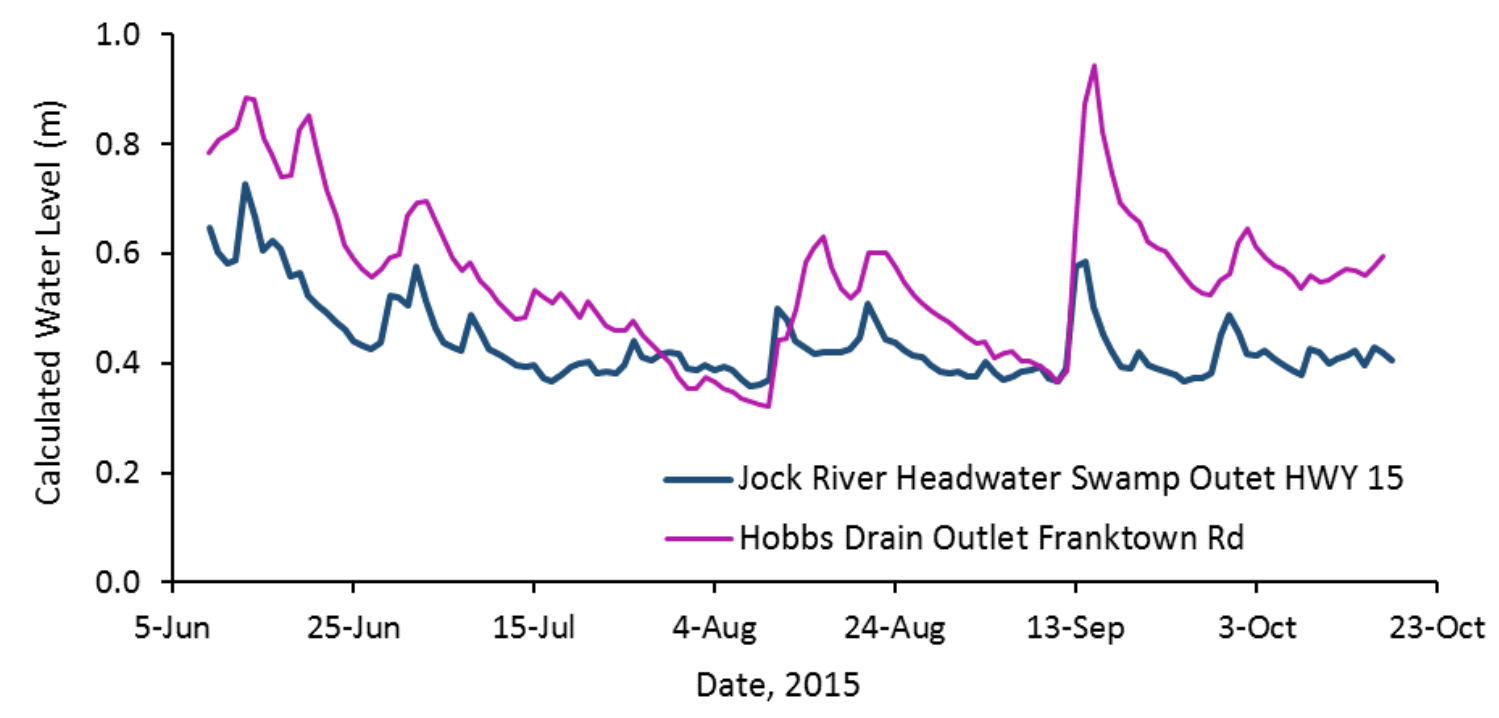

Figure A-0-4. Calculated water level at Hobbs Drain outlet and Jock headwater swamp along Highway 15. The water level was calibrated based on manual water level measurements at these sites and corrected HOBO logger pressure transducer data.

\section{A-3.2.2 Stream Water: Headwaters, Jock River, Main Tributaries}

The isotopic ratios of headwater sites sampled in the spring and summer of 2015 provide a coarse temporal analysis of differences between early spring surface water compositions and late summer surface water compositions. The spring headwater samples are all significantly more depleted than the summer samples. The most depleted samples are primarily composed of snowmelt. During this sample period, the timing of sample collection is important as many samples may have been collected during or after most snow melt had occurred, discussed in more detail in section 4.1.4. Figure A-0-5 demonstrates that most of the spring headwater samples have isotopic ratios similar to the deep groundwater end-members. This similarity indicates that the dominant source of streamflow during spring snow melt is from the exfiltration of groundwater to surface 
water systems due to large inputs of snow melt into the system. During the spring melt period the watershed is well defined by two end-members: groundwater and snowmelt.

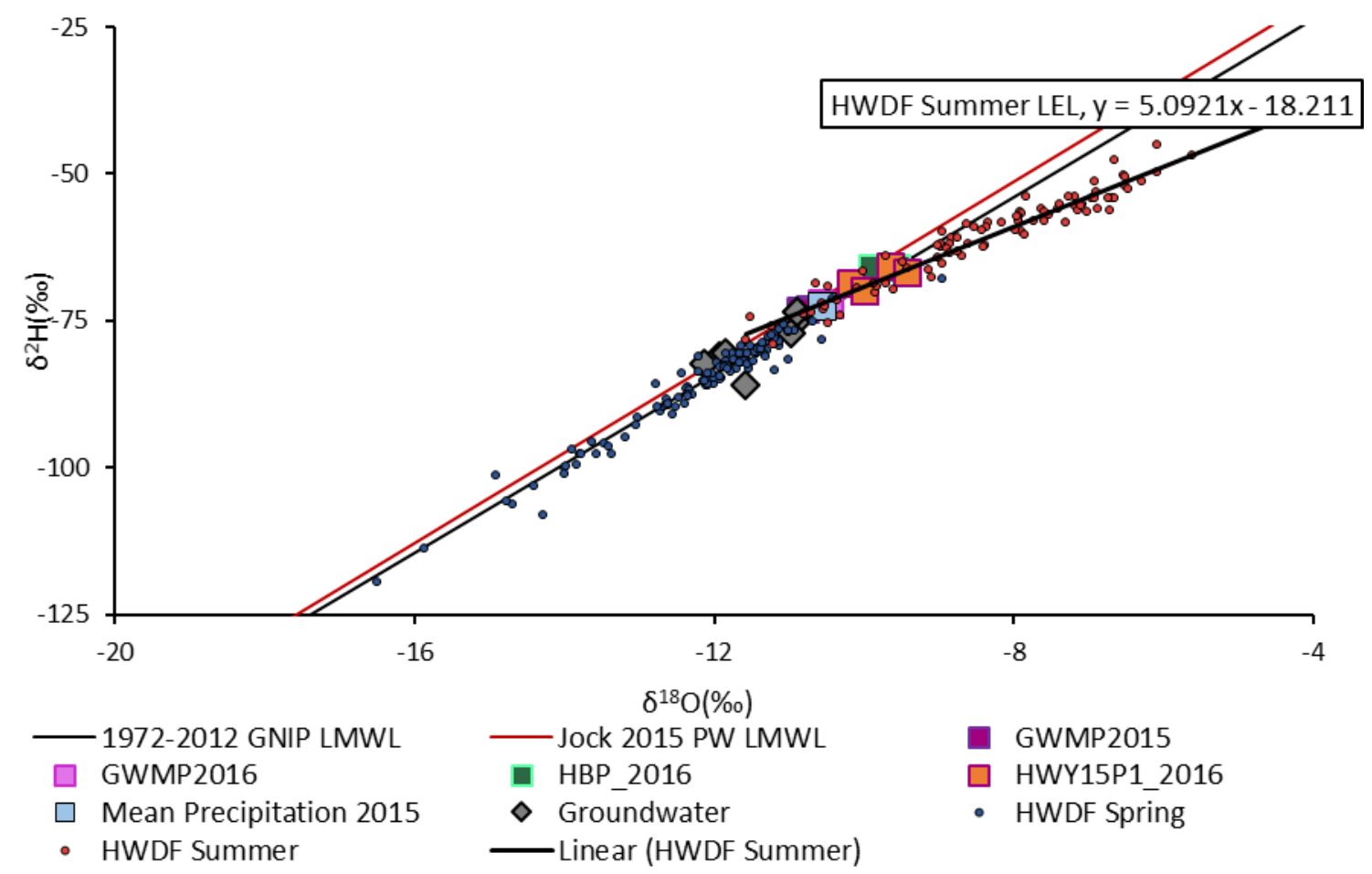

Figure A-0-5. The isotopic ratios from headwater sites across the Jock River watershed collected in the spring (HWDF Spring) and summer (HWDF Summer) of 2015. The GNIP long term LMWL, the Jock seasonal LMWL and groundwater/wetland end-members have been plotted to demonstrate relative positions along the LMWL's.

The summer headwater sites in figure $A-0-5$ are enriched in $\delta \mathrm{D}$ and $\delta^{18} \mathrm{O}$ due to evaporative fractionation. The LEL for headwater sites has a positive linear slope of 5.09. Some of the summer headwater sites demonstrate values similar to groundwater and wetland end-members. The majority of the summer headwater samples are isotopically enriched compared to the end-members. Therefore, determining the source waters at these sites is not possible as the tracers $\delta \mathrm{D}$ and $\delta^{18} \mathrm{O}$ no longer behave conservatively. Consequently, a two end-member mixing model cannot be used to determine the source waters for summer headwater samples. The main tributary samples collected over the course of the growing season are similarly affected by evaporative fractionation. Figure 
$A-0-6$ illustrates isotopic variation of $\delta \mathrm{D}$ and $\delta^{18} \mathrm{O}$ at the Jock River and its main tributaries over the 2015 growing season. The time series presented in figure $\mathrm{A}-0-7$ shows the increase in enrichment of $\delta^{18} \mathrm{O}$ during the warmest and driest months of July and August when evaporative demands are highest. All sites have depleted $\delta^{18} \mathrm{O}$ values for the sample date September $17^{\text {th }}$, which was collected 3 days after a large rain event, 46.2 $\mathrm{mm}$ over the course of 3 days. All sites demonstrate an increase in $\delta^{18} \mathrm{O}$ values in the following measurement on September $24^{\text {th }}$, which was taken 5 days after the large rainfall event before another rainfall event had occurred. This phenomenon demonstrates the input of groundwater to streamflow as a result of saturation in the subsurface due to increased precipitation input and the enrichment of the surface water as the input of groundwater declines. 


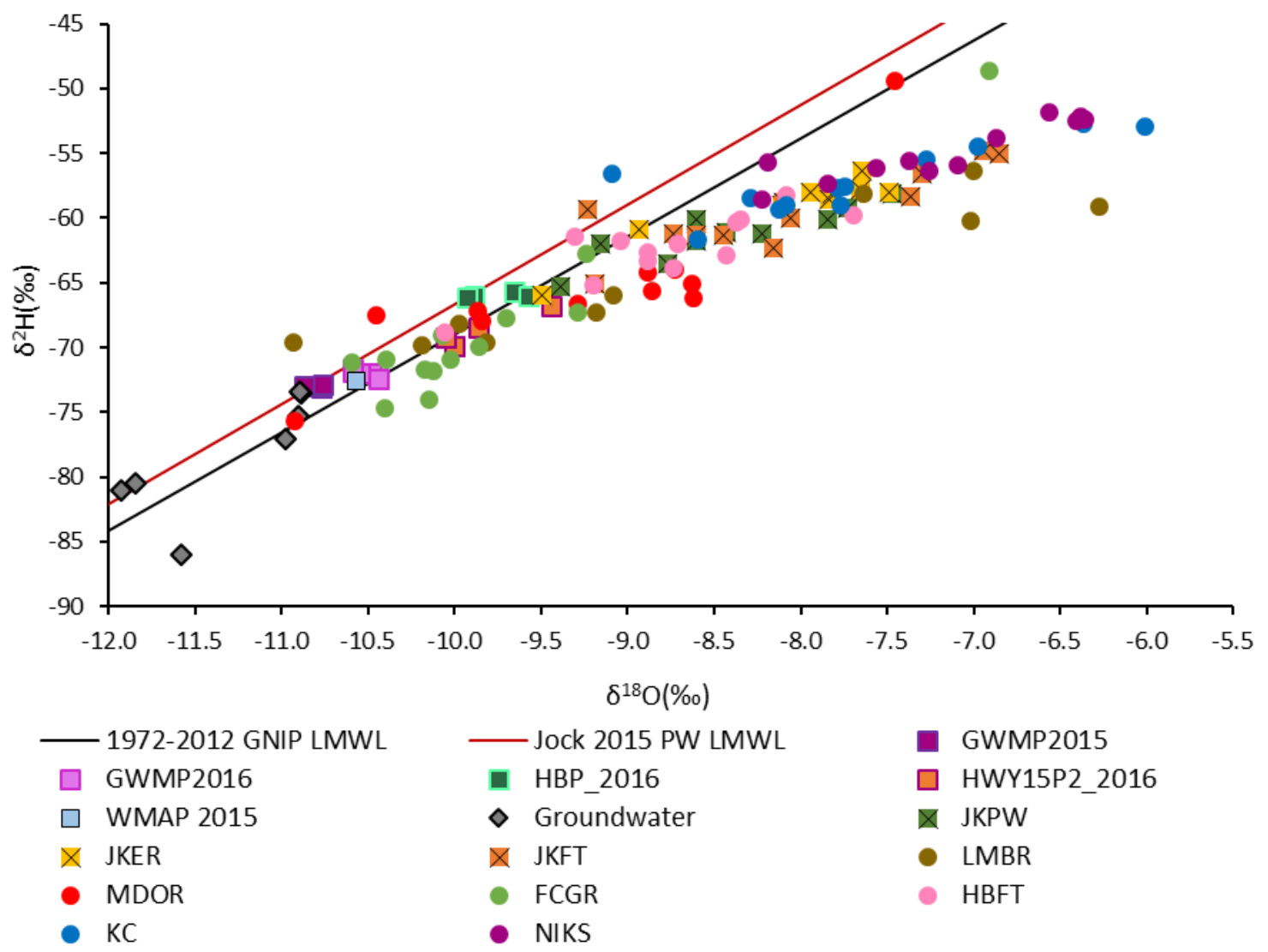

Figure A-0-6. Isotopic ratios of the Jock River outlet (JKPW), mid-point (JKER) and headwaters (JKFT) and its main tributaries: Leamy Creek (LMBR), Monahan Drain (MDOR), Flowing Creek (FCGR), Hobbs Drain (HBFT), Kings Creek (KC) and Nichols Creek (NIKS) plotted along the long term and seasonal LMWL's. Weighted mean annual precipitation (WMAP), groundwater and wetland (GWMP2015 GWMP2016, HBP_2016 and HWY15P2_2016) end-members have also been plotted. 


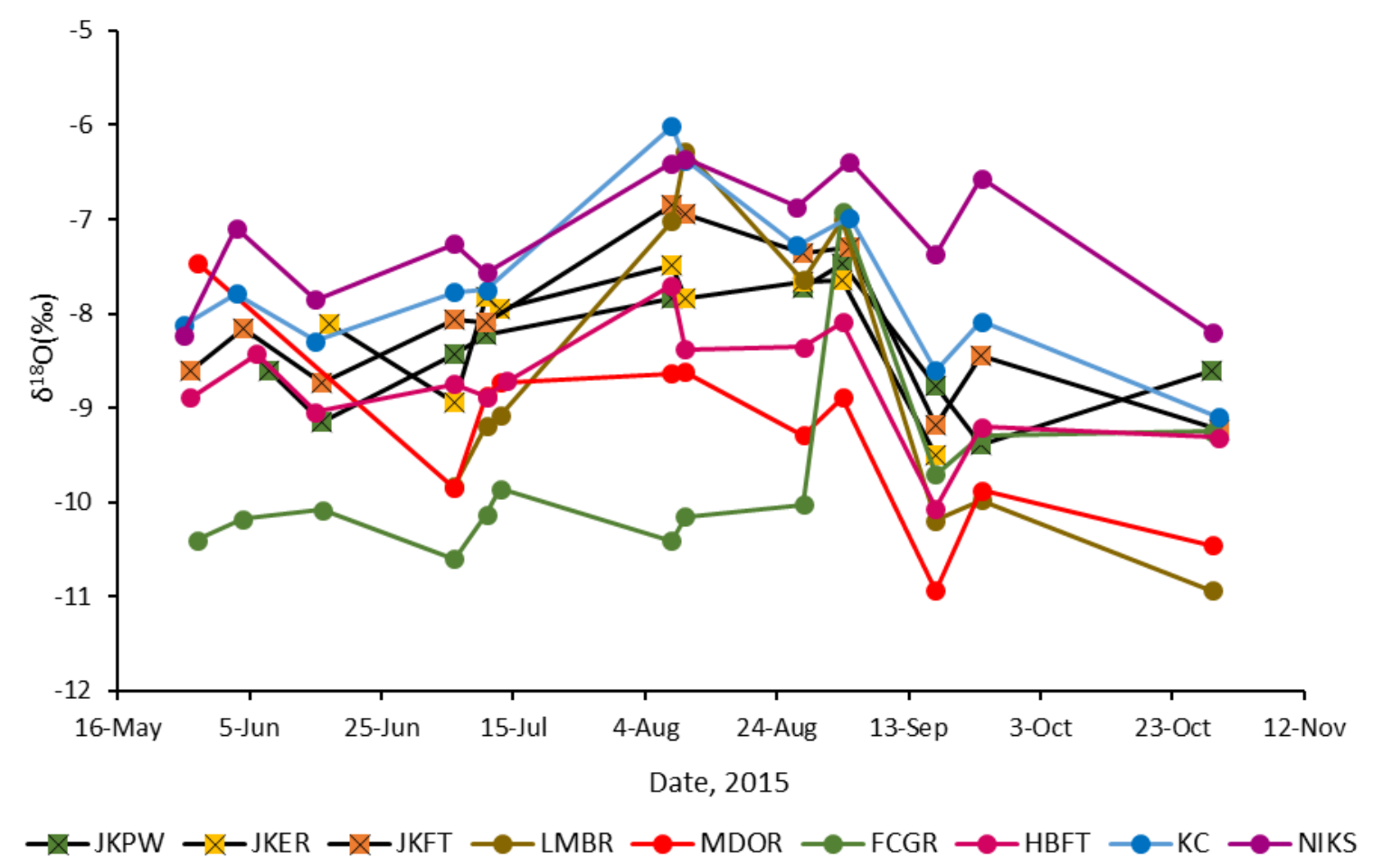

Figure A-0-7. Time series of $\delta^{18} \mathrm{O} \%$ content along the Jock River and main tributary sites during the 2015 growing season.

Spatial variations between the Jock River and its main tributaries is visible in both figure A-0-6 and figure A-0-7. The main tributary site Flowing Creek (FCGR) has the most depleted isotopic signature for $\delta \mathrm{D}$ and $\delta^{18} \mathrm{O}$. The $\delta^{18} \mathrm{O}$ values at this site fluctuate between approximately $-10.5 \%$ and $-9.2 \%$, apart from one outlier $\left(\delta^{18} \mathrm{O},-6.91 \%\right.$ ). The more depleted isotopic ratio at this site could indicate increased groundwater contributions. The tributaries Monahan Drain (MDOR) and Leamy Creek (LMBR) also have samples demonstrating more depleted isotopic ratios but have a wide range of values, $3.45 \%$ and $4.66 \%$ for $\delta^{18} \mathrm{O}$ respectively. The tributaries Kings Creek and Nichols Creek have the most enriched isotopic ratios of all the sites. These tributaries drain catchments in which a large proportion of their area is comprised of forests and wetlands. Although forested wetland end-members demonstrated little evaporative enrichment the 
riparian zones of these streams which flow through the forested wetlands are large and swampy allowing for evaporative enrichment to occur. The sample sites along the Jock River (JKPW, JKER and JKFT) and at Hobbs Drain (HBFT) compose the middle area of the graphs. The $\delta^{18} \mathrm{O}$ values for the Jock River at Franktown road (JKFT) are most similar to Kings Creek. Their similarity is expected as they have similar dominant land cover types: forests and wetlands. The Jock River at Eagleson road (JKER) is the most variable, back water was observed at this site potentially resulting from anthropogenic usage. The Jock River at Prince of Wales road (JKPW) is often the most depleted of the Jock River sites. The depletion at this site could be the result of groundwater input from more groundwater dominated tributaries near the outlet. Hobbs Drain is similar to the Jock at Prince of Wales but often slightly more depleted. As discussed in the previous section (4.2.2.1) the Hobbs Drain piezometer is potentially precipitation dominated, therefore the depleted isotopic signature observed may be the result of depleted precipitation contributions and not groundwater. The overall trend observed across the watershed demonstrates enriched samples in the upper watershed with sites becoming progressively more depleted towards the outlet potentially due to increased groundwater inputs.

\section{A-3.2.3 Isoscapes}

Spring headwater drainage feature samples were interpolated to create an isoscape of surface water $\delta^{18} \mathrm{O}$ before the beginning of the growing season. The points represent the location of sample collection and have been colour coded to reflect the date of sample collection. Sample dates span a 10-day window in the beginning of April. The center of the watershed demonstrates the most depleted isotopic signatures. The average $\delta^{18} \mathrm{O} \%$ 
for snowmelt collected in 2015 was $-18.31 \%$, while groundwater hovers around $-10 \%$ o and $-12 \%$. Samples in the center of the watershed were collected earlier in the melt period, which could explain the more depleted (-13\% to $-15 \%$ ) signature observed in this area. The topography of this area would also facilitate increased snow melt contributions at these locations. Figure A-0-9 illustrates the spring HWDF isoscape projected onto the surface of the $5 \mathrm{~m}$ integer DEM with a vertical exaggeration of 50 . This area demonstrates an break in slope in which snow melt would preferentially accumulate and flow downslope. If there is an increase in snow melt water in this area, it could have significant implications for groundwater recharge dynamics. The surficial geology of this area is primarily sand and coarse texture glacial till (diamicton), which would allow for more rapid infiltration and recharge to occur. Furthermore, this area was identified in Velderman (1993) as a deep groundwater recharge area, see Appendix C. Velderman (1993) also identified the upper and lower portions of the watershed as bedrock groundwater discharge areas, see Appendix C. In figure A-0-8, the upper and lower portions have more enriched $\delta^{18} \mathrm{O}$ values with isotopic signatures more similar to those of groundwater samples collected in the summer. The input of massive snowmelt contributions would result in the exfiltration of groundwater across the landscape. The patterns observed in the spring surface water isoscape match very closely with the groundwater recharge and discharge areas previously identified. 


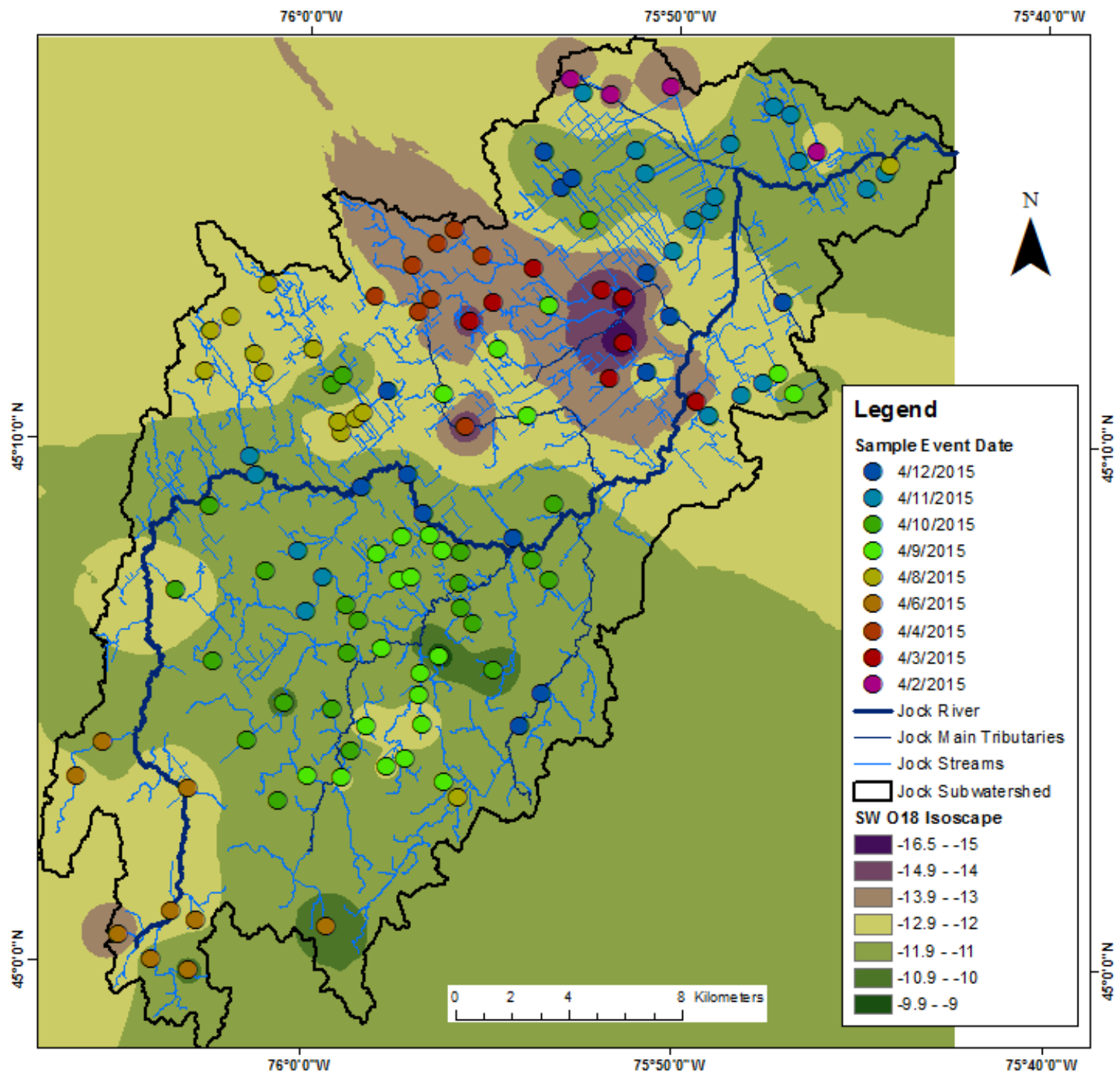

Figure A-0-8. Isoscape of $\delta^{18} \mathrm{O} \%$ from spring headwater samples during 2015. Sample collection dates have been identified. 


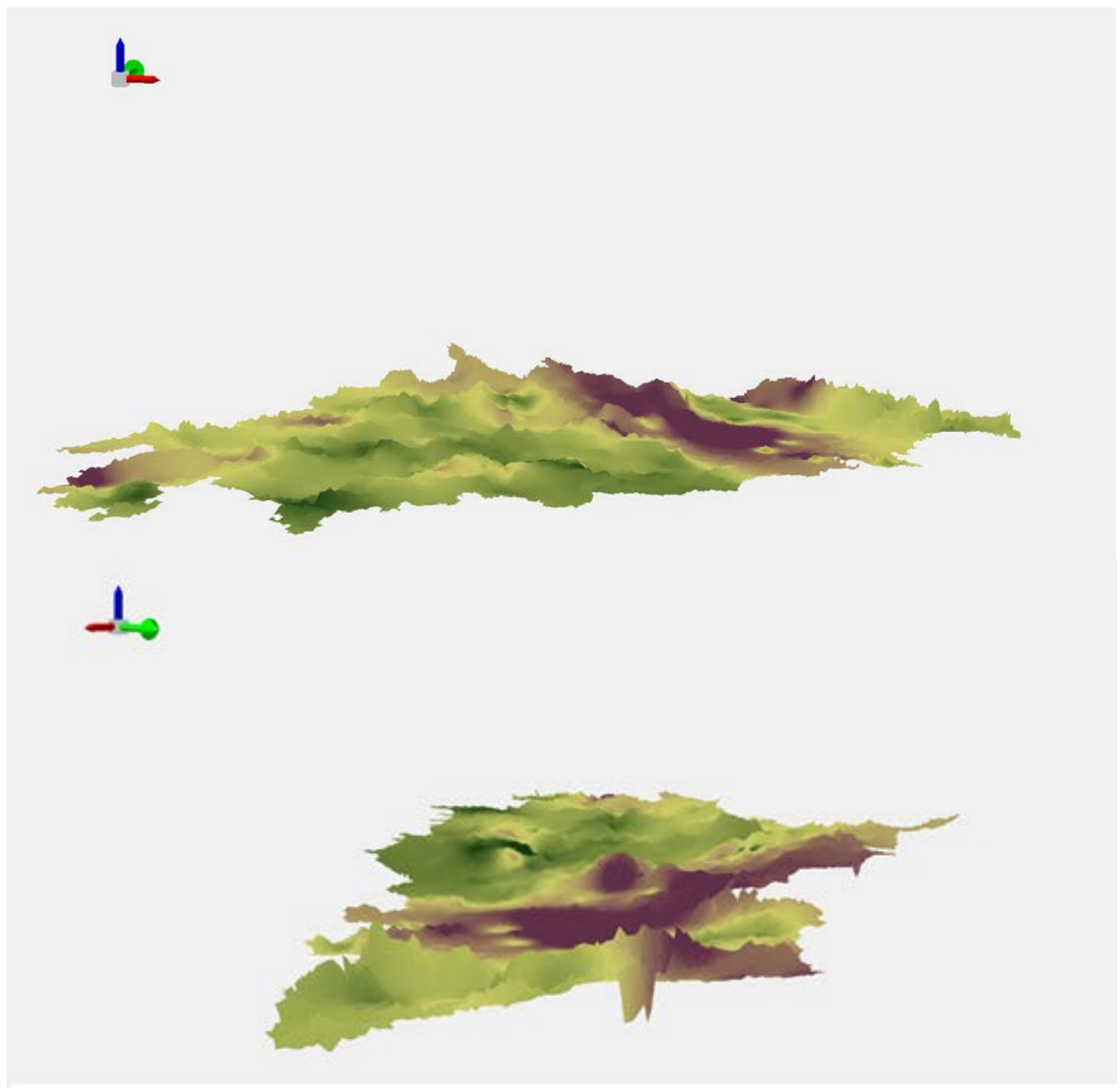

Figure A-0-9. These two scenes demonstrate the spring headwater isoscape which has been projected onto the $5 \mathrm{~m}$ integer DEM surface in ArcScene 10.3.1 with a vertical exaggeration of 50. The direction of the green arrow indicates North (y), the direction of the red arrow indicates East $(x)$ and the blue arrow indicates the vertical direction $(z)$. 


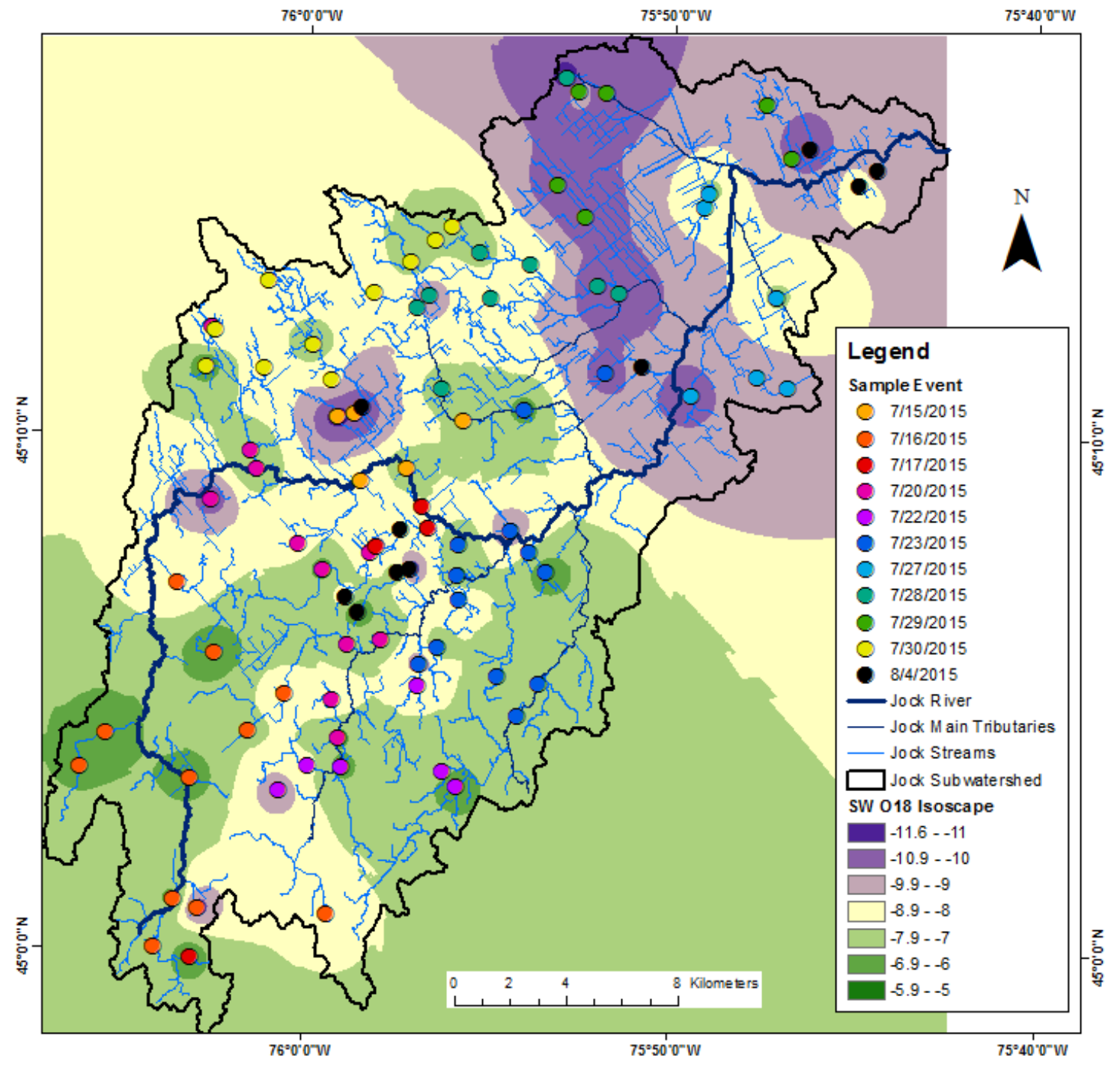

Figure A-0-10. Isoscape of $\delta^{18} \mathrm{O} \%$ from summer headwater samples during 2015. Sample collection dates have been identified.

The summer surface water isoscape (figure A-0-10), illustrates more complicated dynamics across the watershed. Samples were collected in late July at the beginning of the low flow period from July $15^{\text {th }}$ to $30^{\text {th }}$ with an additional sample day August $8^{\text {th }}$. During this time, there were two small precipitation events with $13 \mathrm{~mm}$ on July $17^{\text {th }}$ and $5.6 \mathrm{~mm}$ on July $25^{\text {th }}$. Between August $2^{\text {nd }}$ and August $4^{\text {th }}$ there were consecutive rain events, although small in volume $(3-5 \mathrm{~mm})$ the August $4^{\text {th }}$ samples could be affected by precipitation inputs. The lower portion of the watershed demonstrates the most depleted 
surface water indicating that this is a potentially significant groundwater discharge area. The depletion in surface water seems to coincide with the beginning of the clay plains. Artesian wells in and around the Village of Richmond, further indicate that groundwater discharge is significant in this region. The basal gravel aquifer described by Velderman (1993) is believed to also be contributing significantly to flow in this area. The surface water isoscape generated seems to validate that groundwater contributions are significant in this region, and are most likely from basal gravel aquifer described by Velderman. In the most northern portion of the watershed where the esker and buried esker are present, figure A-0-10 demonstrates more isotopically depleted surface water. Further indicating that the esker and the basal gravel aquifer comprise significant groundwater discharge features in the area, but are difficult to discern based on current available data.

Discrete depleted surface water samples are also present in the upper portion of the watershed indicating possible groundwater discharge areas. Figure A-0-11 illustrates the overlying surficial geology of the region. Discrete groundwater discharge areas in the upper portion of the watershed appear to correspond with areas of coarse texture deposits. Mountain et al., (2015) also found that groundwater discharge areas in isoscapes corresponded with coarse texture glacial deposits. The upper portion of the watershed also has the most enriched surface water. The increased presence of wetlands in this area may explain the enrichment of the surface water samples, as increased surface water area would result in increased evaporative fractionation. 


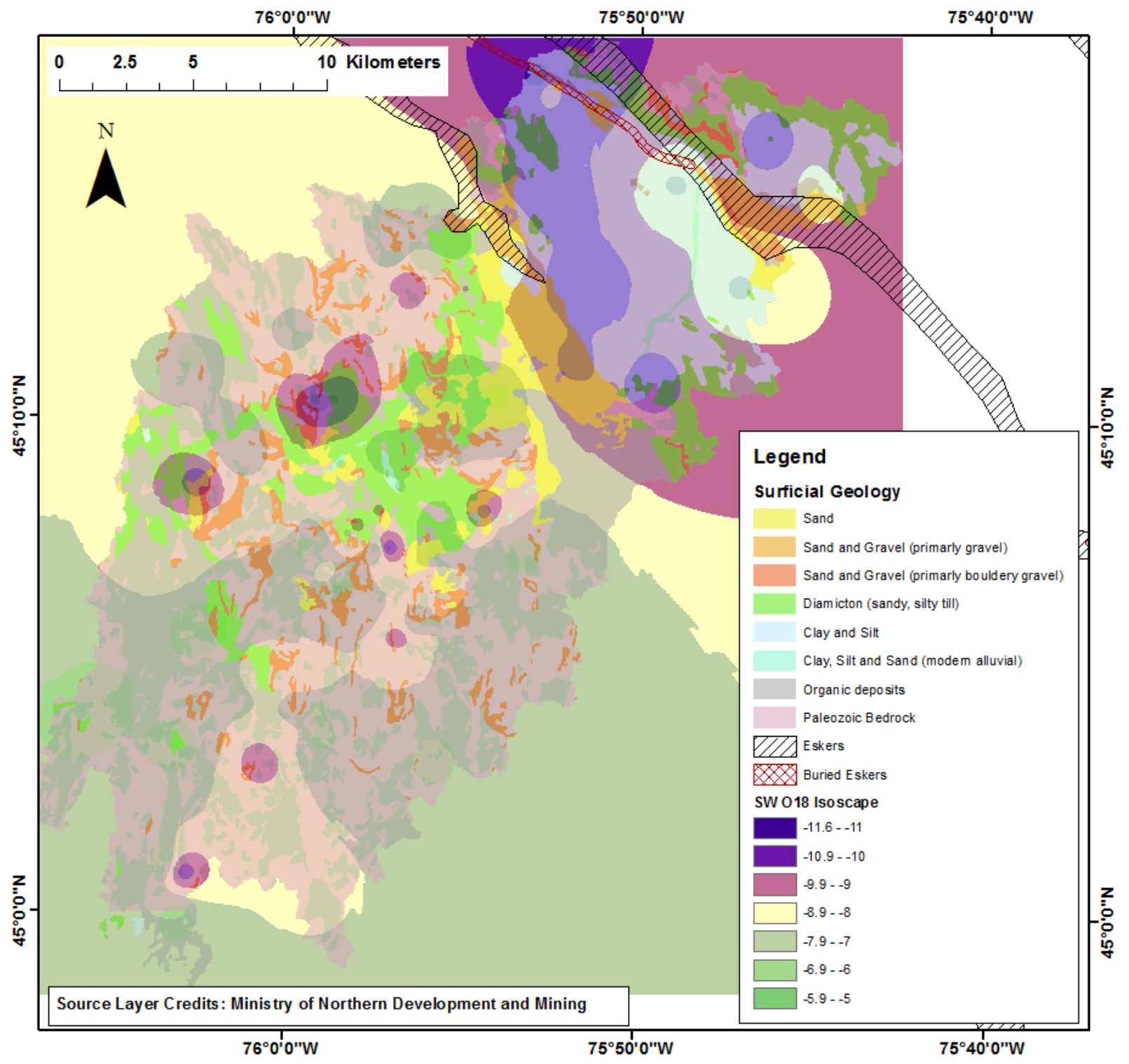

Figure A-0-11. Surface water $\delta^{18} O \%$ isoscape with surficial geology overlay.

Surficial geology data source: Ontario Geological Survey. (2010). Surficial Geology of Southern Ontario [GIS data set]. Retrieved from http://www.geologyontario.mndm.gov.on.ca 
Appendix B 
Table B-0-1.Geochemical/ isotopic sample collection days.

\begin{tabular}{|c|c|c|c|c|}
\hline Date & Sites & Baseflow & $\begin{array}{c}\text { Days Since } \\
\text { Last Rain } \\
\text { Event } \\
\end{array}$ & $\begin{array}{c}\text { Last Precipitation } \\
\text { Event }(\mathbf{m m})\end{array}$ \\
\hline 26-May-15 & $\mathrm{KC}, \mathrm{NC}$ & $\mathrm{N}$ & 1 & 23.8 \\
\hline 27-May-15 & $\mathrm{HD}, \mathrm{JKFT}$ & $\mathrm{N}$ & 2 & 23.8 \\
\hline 28-May-15 & $\mathrm{FC}, \mathrm{MD}$ & $\mathrm{N}$ & 3 & 23.8 \\
\hline 3-Jun-15 & $\mathrm{KC}, \mathrm{NC}$ & $\mathbf{Y}$ & 4 & 17 \\
\hline 4-Jun-15 & FC, JKFT & $\mathbf{Y}$ & 5 & 17 \\
\hline 6-Jun-15 & HD & $\mathbf{Y}$ & 7 & 17 \\
\hline 8-Jun-15 & JKPW & $\mathrm{N}$ & 0 & 16 \\
\hline 15-Jun-15 & $\mathrm{HD}, \mathrm{KC}, \mathrm{NC}$ & $\mathrm{N}$ & 2 & 16.6 \\
\hline 16-Jun-15 & $\begin{array}{l}\text { JKPW, JKFT, } \\
\text { FCGR }\end{array}$ & $\mathrm{N}$ & 0 & 16.6 \\
\hline 17-Jun-15 & JKER & $\mathrm{N}$ & 1 & 16.6 \\
\hline 6-Jul-15 & All & $\mathbf{Y}$ & 5 & 11.2 \\
\hline 11-Jul-15 & All & $\mathbf{Y}$ & 4 & 9.2 \\
\hline 13-Jul-15 & $\begin{array}{c}\text { JKER, JKFT, LC, } \\
\text { MD }\end{array}$ & $\mathbf{Y}$ & 6 & 9.2 \\
\hline 14-Jul-15 & HD & $\mathbf{Y}$ & 7 & 9.2 \\
\hline 8-Aug-15 & All & $\mathbf{Y}$ & 3 & 10.8 (over 4 days) \\
\hline 10-Aug-15 & All & $\mathbf{Y}$ & 5 & 10.8 (over 4 days) \\
\hline 27-Aug-15 & FC, HB, KC & $\mathbf{Y}$ & 7 & 16.4 \\
\hline 28-Aug-15 & $\begin{array}{c}\text { JKPW, JKFT, } \\
\text { JKER, LC, MD, } \\
\text { NC }\end{array}$ & $\mathbf{Y}$ & 8 & 16.4 \\
\hline 3-Sep-15 & $\begin{array}{c}\text { JKPW, JKER, } \\
\text { LC, MD, FC, HD }\end{array}$ & $\mathbf{Y}$ & 15 & 16.4 \\
\hline 4-Sep-15 & JKFT, KC, NC & $\mathbf{Y}$ & 16 & 16.4 \\
\hline 17-Sep-15 & All & $\mathbf{Y}$ & 3 & 46.2 (over 3 days) \\
\hline 24-Sep-15 & All & $\mathbf{Y}$ & 5 & 8.6 \\
\hline 29-Oct-15 & $\begin{array}{c}\text { JKPW, JKER, LC, } \\
\text { MD, FC }\end{array}$ & $\mathrm{N}$ & 0 & 33 (over 2 days) \\
\hline 30-Oct-15 & JKFT, HB, KC, NC & $\mathrm{N}$ & 1 & 33 \\
\hline
\end{tabular}



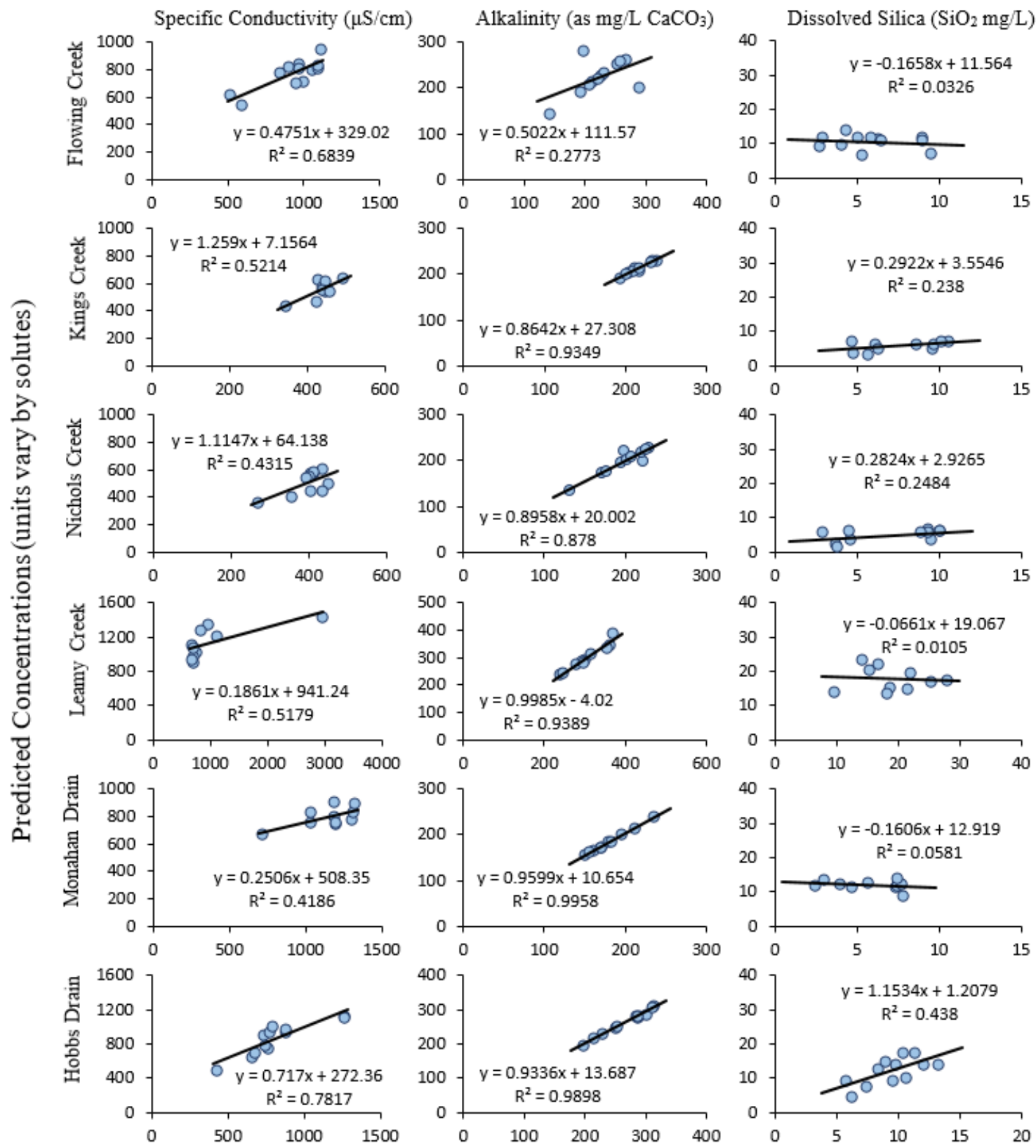

Measured Concentrations (units vary by solutes)

Figure B-0-1. Bi-variate plots indicating linear relationships between measured concentrations and predicted concentrations of the main tributary sites projected into the Jock River mixing space. 


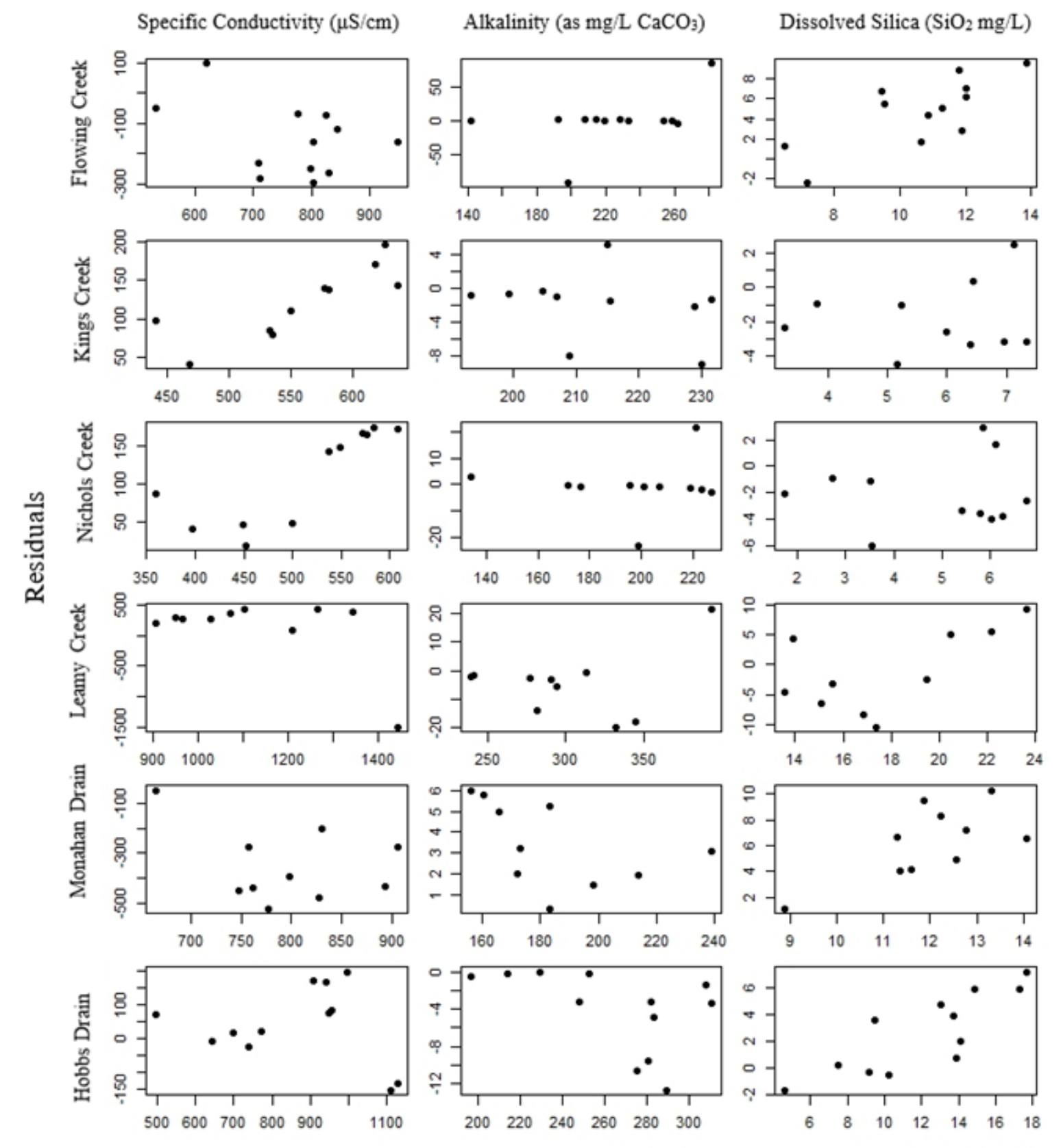

Fitted Concentrations (units vary by solutes)

Figure B-0-2. Residuals for main tributary sites projected into the Jock River mixing space. 


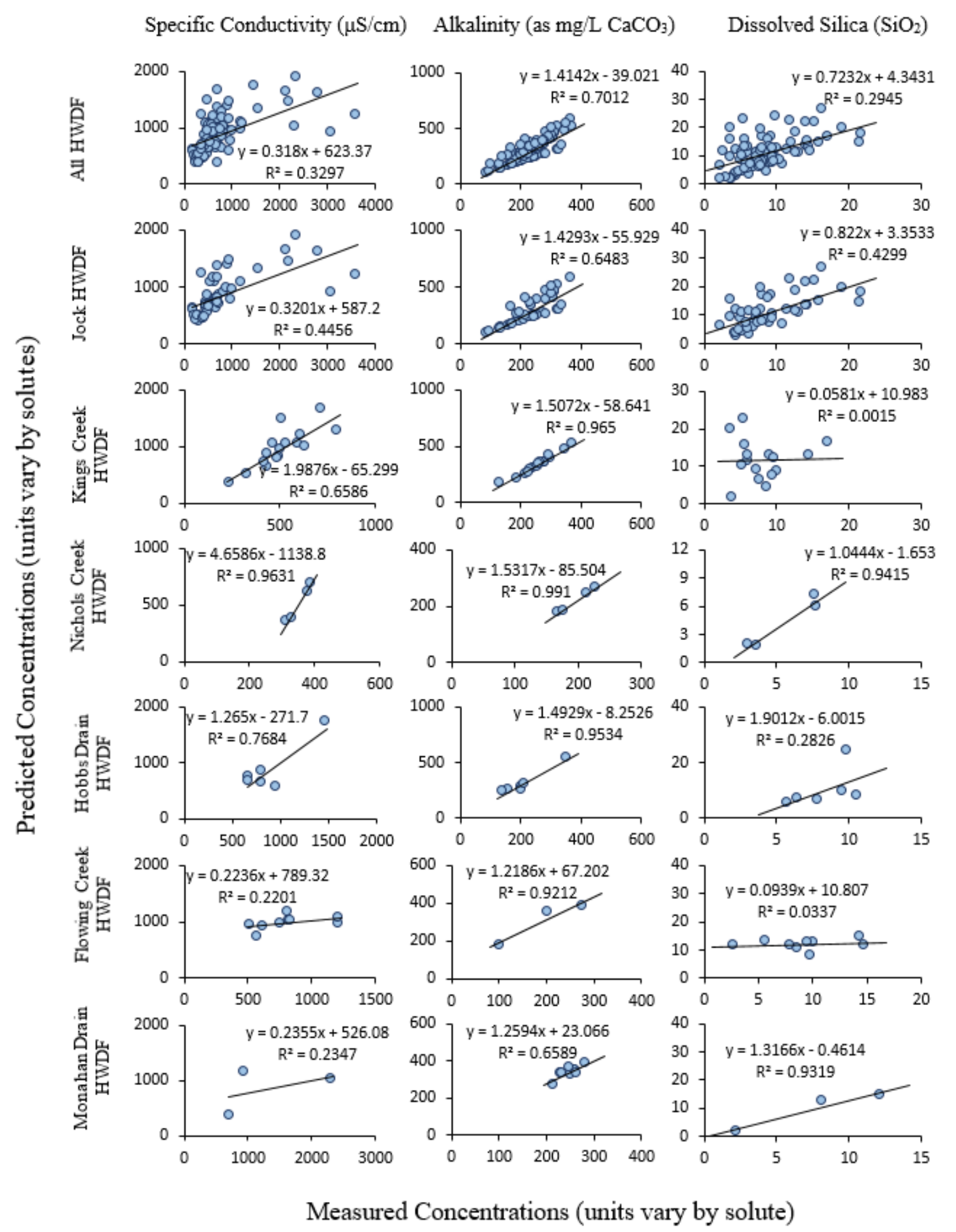

Figure B-0-3. Bi-variate plots indicating linear relationships between measured concentrations and predicted concentrations of the headwater sites projected into the Jock River mixing space. 


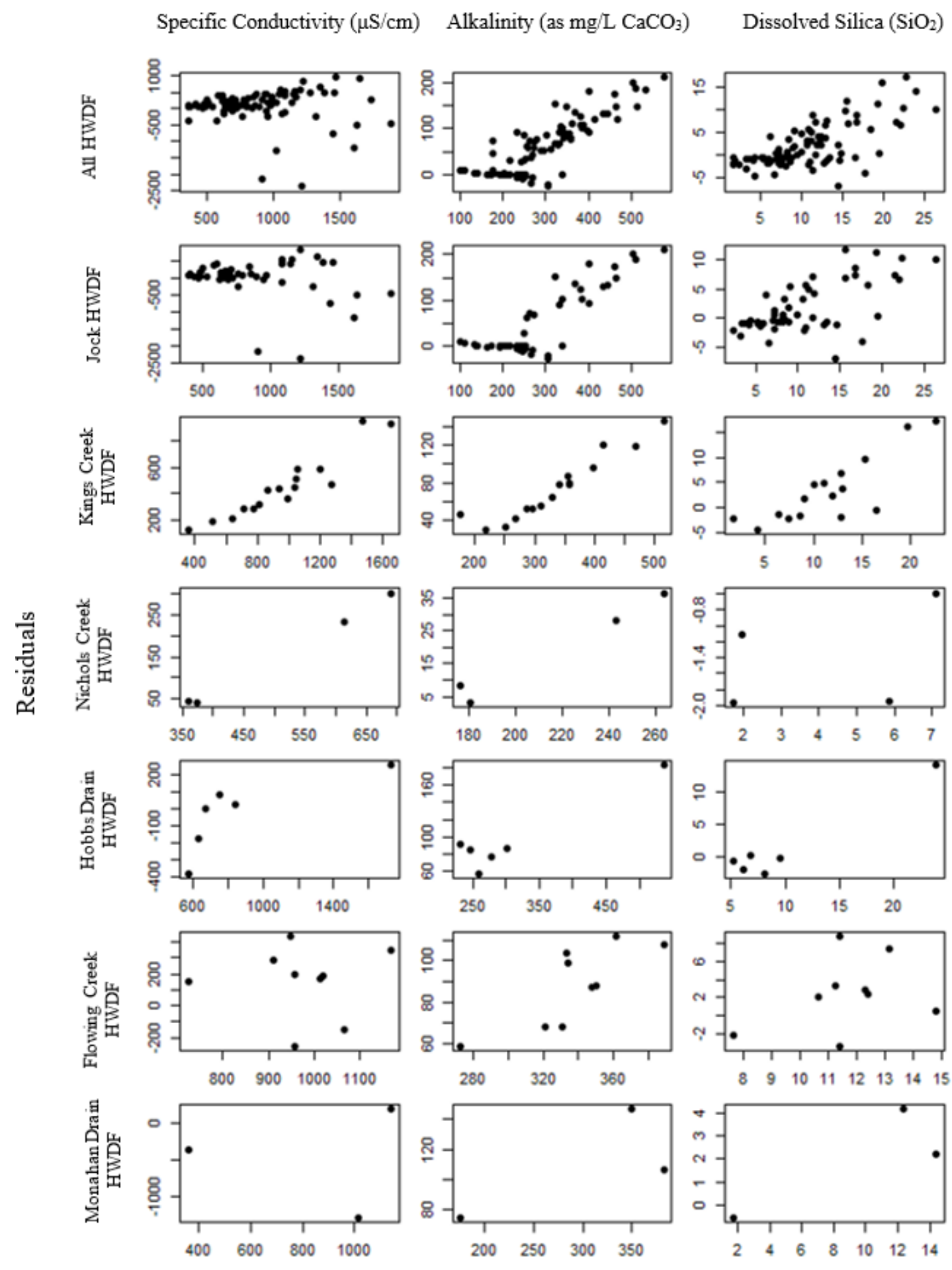

Fitted Concentrations (units vary by solute)

Figure B-0-4. Residuals for main tributary sites projected into the Jock River mixing space. 

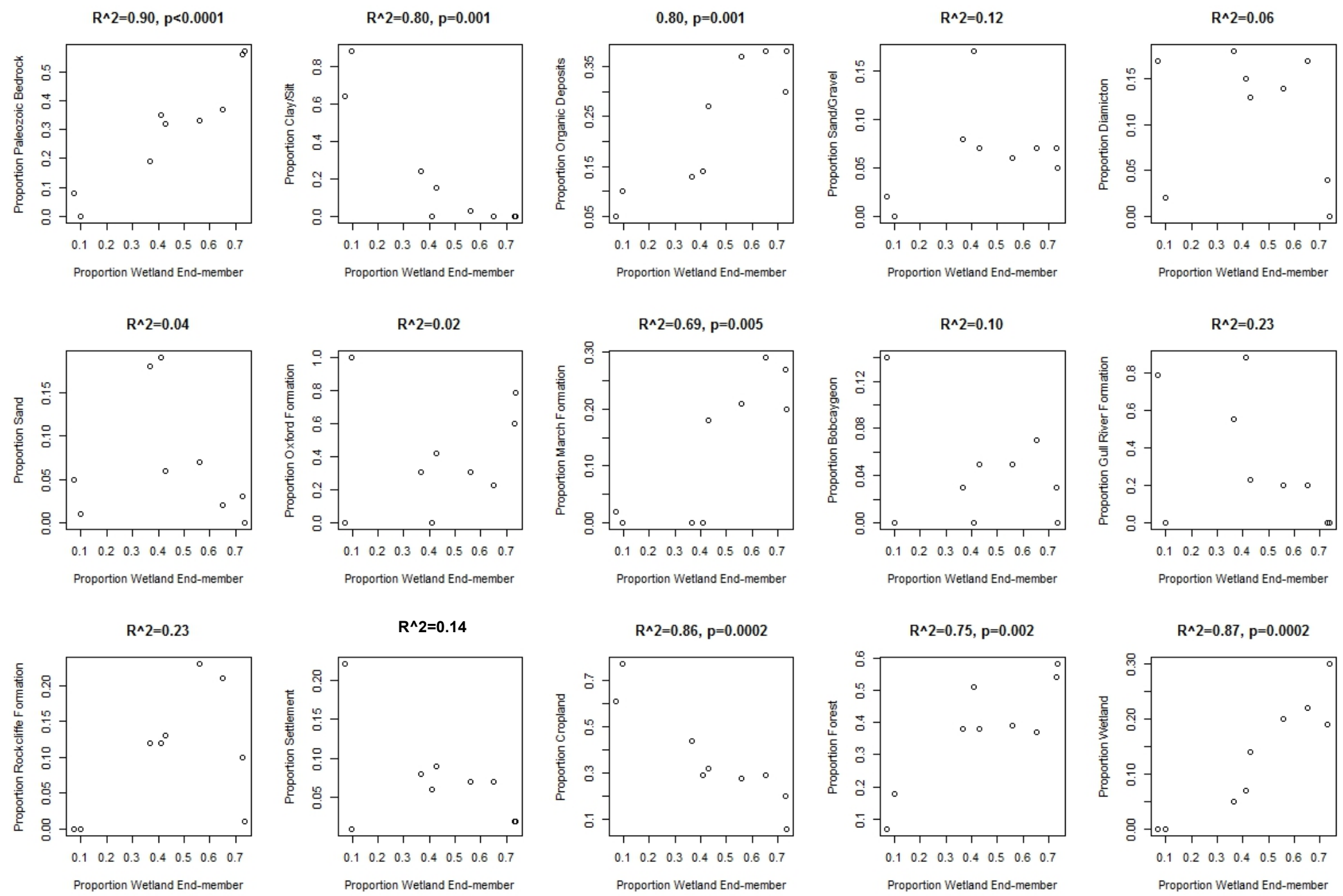

Figure B-0-5. Bi-variate plots indicating linear relationships between the average proportion of the wetland end-member and the proportion of land use and land cover classes. 


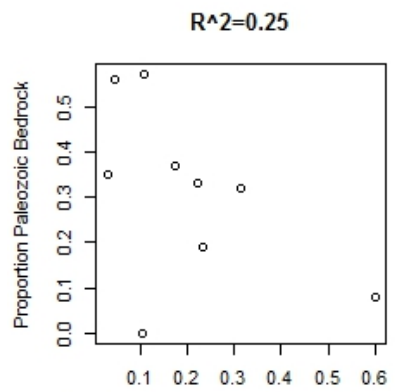

Proportion Basal GraveVEsker End-member

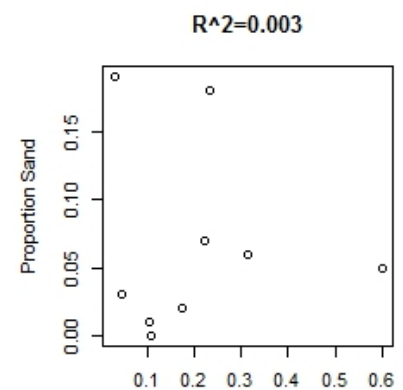

Proportion Basal GraveVEsker End-member

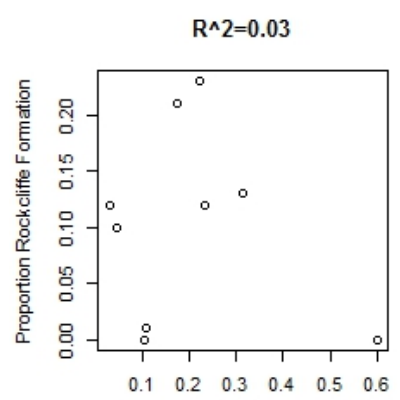

Proportion Basal GraveVEsker End-member

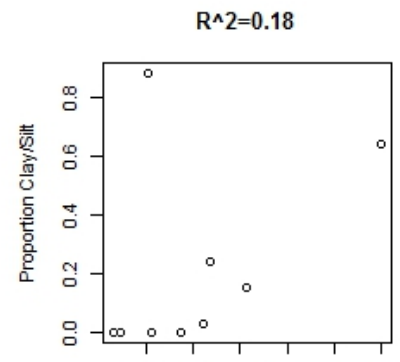

$\begin{array}{llllll}0.1 & 0.2 & 0.3 & 0.4 & 0.5 & 0.6\end{array}$

Proportion Basal GraveVEsker End-member

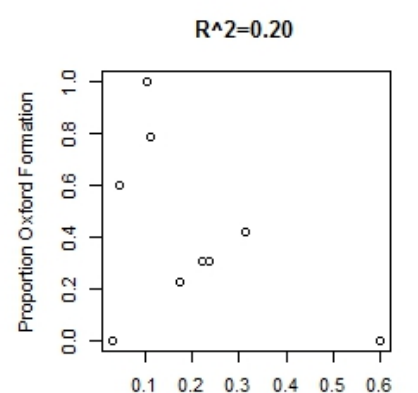

Proportion Basal GraveVEsker End-member

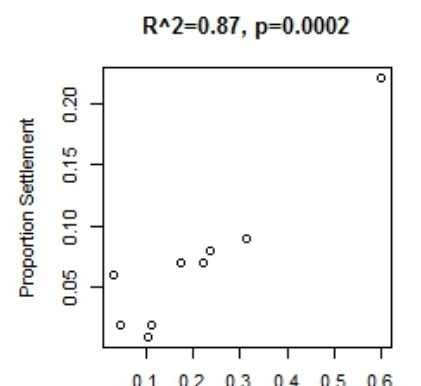

Proportion Basal GraveVEsker End-member
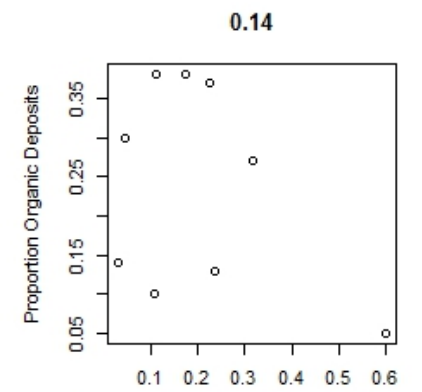

Proportion Basal GraveVEsker End-member

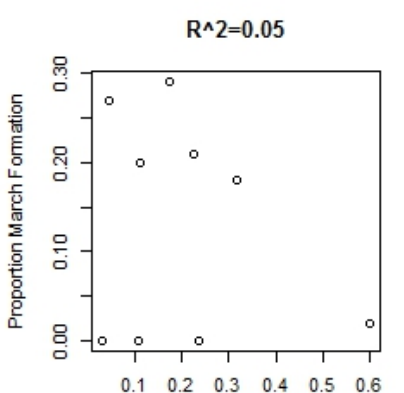

Proportion Basal GraveVEsker End-member

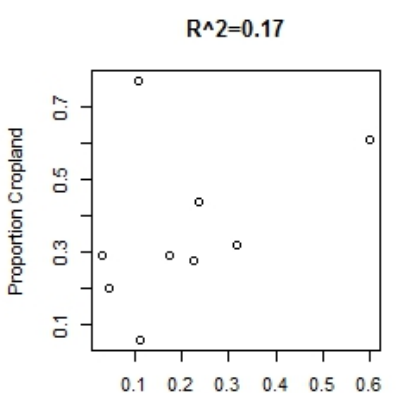

Proportion Basal GraveVEsker End-member

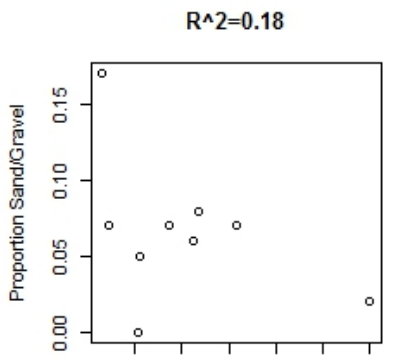

$\begin{array}{llllll}0.1 & 0.2 & 0.3 & 0.4 & 0.5 & 0.6\end{array}$

Proportion Basal GraveVEsker End-member

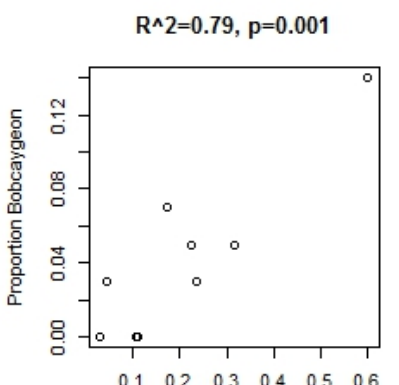

Proportion Basal GraveVEsker End-member

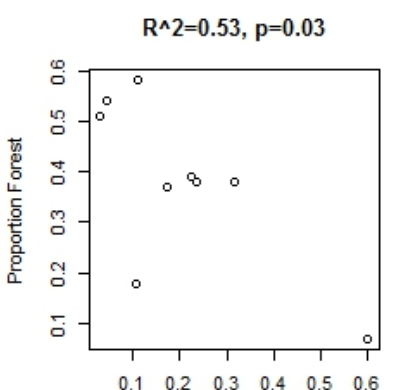

Proportion Basal GraveVEsker End-member

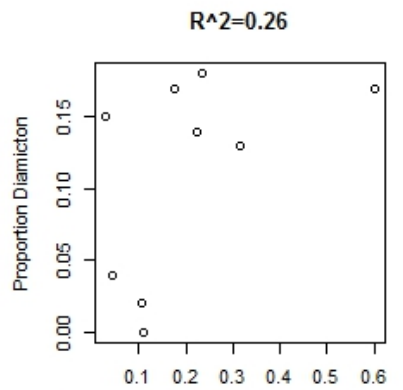

Proportion Basal GraveVEsker End-member

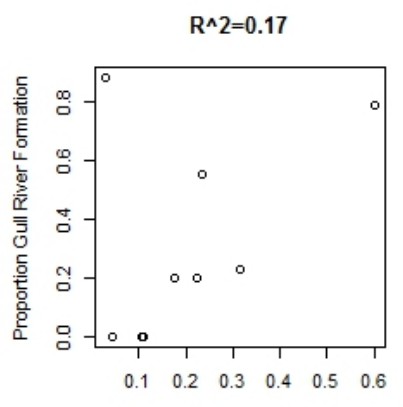

Proportion Basal GraveVEsker End-member

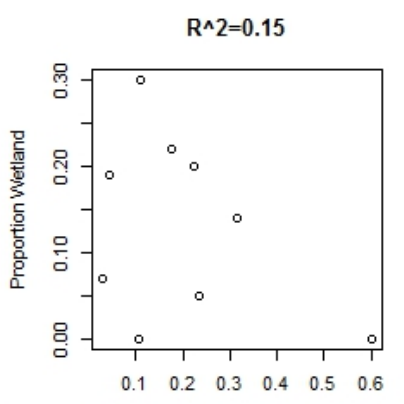

Proportion Basal GraveVEsker End-member

Figure B-0-6. Bi-variate plots indicating linear relationships between the average proportion of the basal gravel/esker endmember and the proportion of land use and land cover classes. 

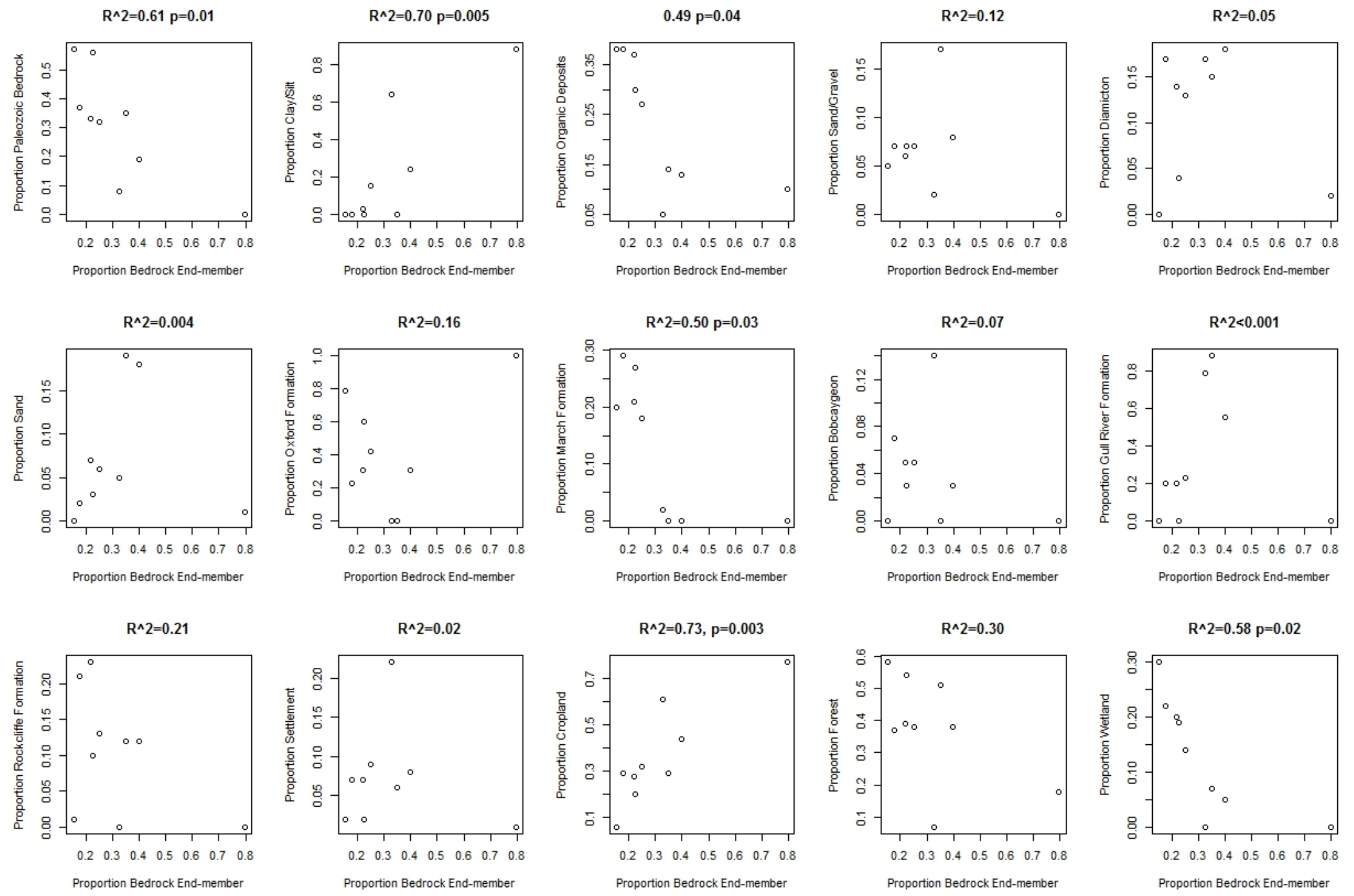

Figure B-0-7. Bi-variate plots indicating linear relationships between the average proportion of the bedrock end-member and the proportion of land use and land cover classes. 
Table B-0-2. Results of multiple linear regression (MLR) models assessing the relationships between average end-member proportions and land use/cover proportions.

\begin{tabular}{|c|c|c|c|}
\hline MLR Models & $\mathrm{R}^{2}$ & p-value & Significant Variables \\
\hline \multicolumn{4}{|c|}{ Wetland (GMWMP2015) } \\
\hline Paleozoic.Bedrock+Clay_Silt & 0.9145 & 0.0006 & Paleozoic Bedrock 0.02 \\
\hline Paleozoic.Bedrock*Clay_Silt & 0.9274 & 0.002 & Paleozoic Bedrock 0.07 \\
\hline Paleozoic.Bedrock+Clay_Silt+Organic.Deposits & 0.9675 & 0.0003 & Paleozoic Bedrock $=0.04$ and Organic Deposits $=0.04$ \\
\hline Paleozoic.Bedrock+Organic.Deposits & 0.9626 & $<0.00001$ & Paleozoic Bedrock $=0.002$ and Organic Deposits $=0.02$ \\
\hline Paleozoic.Bedrock*Organic.Deposits & 0.9653 & 0.0004 & Paleozoic Bedrock $=0.03$ and Organic Deposits $=0.07$ \\
\hline Paleozoic.Bedrock+Organic.Deposits+March.Formation & 0.9628 & 0.0005 & Paleozoic Bedrock $=0.005$ \\
\hline Paleozoic.Bedrock+Organic.Deposits*March.Formation & 0.9678 & 0.003 & Paleozoic Bedrock $=0.01$ \\
\hline Paleozoic.Bedrock+Organic.Deposits + Cropland & 0.9627 & 0.0005 & Paleozoic Bedrock $=0.10$ and Organic Deposits $=0.04$ \\
\hline Paleozoic.Bedrock+Organic.Deposits+Forest & 0.9708 & 0.0002 & Organic Deposits $=0.02$ \\
\hline Paleozoic.Bedrock+Organic.Deposits + Wetland & 0.966 & 0.0004 & Paleozoic Bedrock $=0.01$ \\
\hline Cropland + Forest + Wetland & 0.9458 & 0.001 & Wetland $=0.05$ \\
\hline Cropland $*$ Forest $*$ Wetland & 0.9848 & 0.2483 & none \\
\hline Forest + Wetland & 0.9455 & 0.0001 & Forest $=0.03$, Wetland $=0.004$ \\
\hline Forest*Wetland & 0.956 & 0.0008 & Forest $=0.03$, Wetland $=0.03$ \\
\hline Cropland + Wetland & 0.9204 & 0.0005 & Wetland $=0.08$ \\
\hline Cropland+Forest & 0.8706 & 0.002 & Cropland $=0.06$ \\
\hline March.Formation+Cropland & 0.9353 & 0.0003 & March Formation $=0.04$, Cropland $=0.003$ \\
\hline March.Formation+Cropland+Forest & 0.9764 & 0.0002 & March Formation $=0.005$, Forest $=0.03$ \\
\hline March.Formation+Forest & 0.9732 & $<0.00001$ & March Formation $=0.0004$, Forest $=0.0002$ \\
\hline March.Formation*Forest & 0.9732 & 0.0002 & Forest $=0.002$ \\
\hline March.Formation+Forest+Paleozoic.Bedrock & 0.9738 & 0.0002 & March Formation $=0.01$, Forest $=0.05$ \\
\hline March.Formation+Forest+Organic.Deposits & 0.9754 & 0.0001 & March Formation $=0.07$, Forest $=0.002$ \\
\hline
\end{tabular}




\begin{tabular}{|c|c|c|c|}
\hline MLR Models & $\mathrm{R}^{2}$ & $\mathrm{p}$-value & Significant Variables \\
\hline March.Formation+Wetland & 0.8727 & 0.002 & Wetland $=0.03$ \\
\hline Paleozoic.Bedrock+Wetland & 0.9446 & 0.0001 & Paleozoic Bedrock $=0.03$, Wetland $=0.07$ \\
\hline Paleozoic.Bedrock+Forest & 0.9021 & 0.0009 & Paleozoic Bedrock $=0.02$ \\
\hline Paleozoic.Bedrock+Cropland & 0.9037 & 0.0008 & none \\
\hline Paleozoic.Bedrock+March.Formation & 0.938 & 0.0002 & Paleozoic Bedrock $=0.003$ \\
\hline Organic.Deposits+March.Formation & 0.8043 & 0.008 & none \\
\hline Organic.Deposits+Cropland & 0.9319 & 0.0003 & Organic Deposits $=0.05$, Cropland $=0.02$ \\
\hline Organic.Deposits+Wetland & 0.8706 & 0.002 & none \\
\hline Organic.Deposits+Forest & 0.9498 & 0.0001 & Organic Deposits $=0.003$, Forest $=0.006$ \\
\hline Organic.Deposits+Clay_Silt & 0.9152 & 0.0006 & Organic Deposits $=0.03$, Clay $/$ Silt $=0.03$ \\
\hline Clay_Silt+Forest & 0.8319 & 0.005 & none \\
\hline Clay_Silt+Wetland & 0.9399 & 0.0002 & Clay/Silt $=0.03$, Wetland $=0.008$ \\
\hline Clay_Silt+Cropland & 0.8656 & 0.002 & none \\
\hline Clay_Silt+March.Formation & 0.9057 & 0.0008 & Clay $/$ Silt $=0.01$, March Formation $=0.04$ \\
\hline Clay_Silt+March.Formation+Wetland & 0.945 & 0.001 & Clay/Silt $=0.05$ \\
\hline \multicolumn{4}{|c|}{ Basal Gravel/Esker (W156-2) } \\
\hline Bobcaygeon.Formation + Settlement & 0.8821 & 0.002 & Settlement $=0.08$ \\
\hline Bobcaygeon.Formation+Forest & 0.8365 & 0.004 & Bobcaygeon Formation $=0.02$ \\
\hline Settlement+Forest & 0.8981 & 0.001 & Settlement $=0.004$ \\
\hline Bobcaygeon.Formation + Settlement + Forest & 0.9051 & 0.005 & none \\
\hline \multicolumn{4}{|c|}{ Bedrock (GW_DW_1) } \\
\hline Paleozoic.Bedrock+Clay_Silt & 0.7066 & 0.03 & none \\
\hline Paleozoic.Bedrock+Organic.Deposits & 0.6273 & 0.05 & none \\
\hline Paleozoic.Bedrock+March.Formation & 0.6435 & 0.05 & none \\
\hline
\end{tabular}




\begin{tabular}{lccc}
\hline MLR Models & $\mathrm{R}^{2}$ & $\mathrm{p}$-value & Significant Variables \\
\hline Paleozoic.Bedrock+Cropland & 0.755 & 0.01 & none \\
Paleozoic.Bedrock+Wetland & 0.6309 & 0.05 & none \\
Clay_Silt+Organic.Deposits & 0.7114 & 0.02 & Clay/Silt $=0.07$ \\
Clay_Silt+March.Formation & 0.7462 & 0.02 & Clay $/$ Silt $=0.05$ \\
Clay_Silt+Cropland & 0.7364 & 0.02 & none \\
Clay_Silt+Wetland & 0.7287 & 0.02 & none \\
Organic.Deposits+March.Formation & 0.514 & 0.1 & none \\
Organic.Deposits+Cropland & 0.7283 & 0.02 & Cropland $=0.06$ \\
Organic.Deposits+Wetland & 0.5895 & 0.07 & none \\
March.Formation+Cropland & 0.755 & 0.01 & Cropland $=0.05$ \\
March.Formation+Wetland & 0.5847 & 0.07 & none \\
Cropland+Wetland & 0.7271 & 0.02 & none \\
\hline
\end{tabular}


Table B-0-3. Hydrometric measurements collected during baseflow synoptic surveys and the calculated proportions, sites were normalized based on area, equations provided below.

\begin{tabular}{|c|c|c|c|c|c|c|c|c|}
\hline Site & Date & $\begin{array}{l}\text { Discharge } \\
\text { Measured in } \\
\text { the Field } \\
\left(\mathrm{m}^{3} / \mathrm{s}\right)\end{array}$ & $\begin{array}{c}\text { Normalized } \\
\text { catchment } \\
\text { Discharge } \\
\text { (mm/year) }\end{array}$ & $\begin{array}{c}\text { Proportion } \\
\text { of } \\
\text { Discharge } \\
\text { to Total } \\
\text { Outflow } \\
(\%)\end{array}$ & $\begin{array}{c}\text { Net } \\
\text { Catchment } \\
\text { Discharge } \\
\left(\mathrm{m}^{3} / \mathrm{s}\right)\end{array}$ & $\begin{array}{c}\text { Proportion of } \\
\text { Net } \\
\text { Catchment } \\
\text { Discharge to } \\
\text { Total } \\
\text { Discharge } \\
(\%)\end{array}$ & $\begin{array}{l}\text { Normalized } \\
\text { Net } \\
\text { Catchment } \\
\text { Discharge } \\
\text { (mm/year) }\end{array}$ & $\begin{array}{c}\text { Relative } \\
\text { Proportion of } \\
\text { Normalized } \\
\text { Net } \\
\text { Catchment } \\
\text { Discharge } \\
(\%)\end{array}$ \\
\hline JKPW & 6-Jul-15 & 1.68 & 94.45 & $100.0 \%$ & 0.21 & $12.3 \%$ & 204.00 & $32.9 \%$ \\
\hline Moodie & 6-Jul-15 & 1.47 & 88.30 & $87.7 \%$ & 0.65 & $38.9 \%$ & 127.77 & $20.6 \%$ \\
\hline JKER & 6-Jul-15 & 1.19 & 87.49 & $71.1 \%$ & 0.38 & $22.4 \%$ & 179.33 & $22.4 \%$ \\
\hline JKFT & 6-Jul-15 & 0.54 & 102.20 & $32.3 \%$ & 0.54 & $32.3 \%$ & 102.20 & $16.5 \%$ \\
\hline FGCR & 6-Jul-15 & 0.06 & 36.43 & $3.4 \%$ & 0.06 & $3.4 \%$ & 36.43 & $5.9 \%$ \\
\hline HBFT & 6-Jul-15 & 0.02 & 26.98 & $1.4 \%$ & 0.02 & $1.4 \%$ & 26.98 & $4.4 \%$ \\
\hline NIKS & 6-Jul-15 & 0.10 & 85.85 & $5.8 \%$ & 0.10 & $5.8 \%$ & 85.85 & $13.8 \%$ \\
\hline $\mathrm{KC}$ & 6-Jul-15 & 0.10 & 36.66 & $5.9 \%$ & 0.10 & $5.9 \%$ & 36.66 & $5.9 \%$ \\
\hline JKPW & 11-Jul-15 & 1.34 & 75.75 & $100.0 \%$ & 0.18 & $13.3 \%$ & 175.32 & $34.5 \%$ \\
\hline Moodie & 11-Jul-15 & 1.16 & 69.68 & $86.7 \%$ & 0.50 & $37.5 \%$ & 98.21 & $19.3 \%$ \\
\hline JKER & 11-Jul-15 & 0.53 & 38.86 & $39.6 \%$ & -0.13 & $-9.6 \%$ & -61.54 & $-13.8 \%$ \\
\hline JKFT & 11-Jul-15 & 0.35 & 65.39 & $25.9 \%$ & 0.35 & $25.9 \%$ & 65.39 & $12.9 \%$ \\
\hline FGCR & 11-Jul-15 & 0.05 & 29.93 & $3.5 \%$ & 0.05 & $3.5 \%$ & 29.93 & $5.9 \%$ \\
\hline HBFT & 11-Jul-15 & 0.01 & 7.48 & $0.5 \%$ & 0.01 & $0.5 \%$ & 7.48 & $1.5 \%$ \\
\hline NIKS & 11-Jul-15 & 0.07 & 62.37 & $5.3 \%$ & 0.07 & $5.3 \%$ & 62.37 & $12.3 \%$ \\
\hline $\mathrm{KC}$ & 11-Jul-15 & 0.19 & 69.82 & $14.1 \%$ & 0.19 & $14.1 \%$ & 69.82 & $13.7 \%$ \\
\hline JKPW & 8-Aug-15 & 0.41 & 23.39 & $100.0 \%$ & 0.14 & $33.9 \%$ & 138.07 & $61.6 \%$ \\
\hline Moodie & 8-Aug-15 & 0.27 & 16.40 & $66.1 \%$ & 0.14 & $34.6 \%$ & 27.99 & $12.5 \%$ \\
\hline JKER & 8-Aug-15 & 0.12 & 8.64 & $28.5 \%$ & -0.01 & $-3.0 \%$ & -5.88 & $-2.7 \%$ \\
\hline JKFT & 8-Aug-15 & 0.05 & 8.74 & $11.2 \%$ & 0.05 & $11.2 \%$ & 8.74 & $3.9 \%$ \\
\hline FGCR & 8-Aug-15 & 0.03 & 16.60 & $6.2 \%$ & 0.03 & $6.2 \%$ & 16.60 & $7.4 \%$ \\
\hline HBFT & 8-Aug-15 & 0.00 & 0.82 & $0.2 \%$ & 0.00 & $0.2 \%$ & 0.82 & $0.4 \%$ \\
\hline
\end{tabular}




\begin{tabular}{|c|c|c|c|c|c|c|c|c|}
\hline Site & Date & $\begin{array}{l}\text { Discharge } \\
\text { Measured in } \\
\text { the Field } \\
\left(\mathrm{m}^{3} / \mathrm{s}\right)\end{array}$ & $\begin{array}{l}\text { Normalized } \\
\text { catchment } \\
\text { Discharge } \\
\text { (mm/year) }\end{array}$ & $\begin{array}{c}\text { Proportion } \\
\text { of } \\
\text { Discharge } \\
\text { to Total } \\
\text { Outflow } \\
(\%)\end{array}$ & $\begin{array}{c}\text { Net } \\
\text { Catchment } \\
\text { Discharge } \\
\left(\mathrm{m}^{3} / \mathrm{s}\right)\end{array}$ & $\begin{array}{c}\text { Proportion of } \\
\text { Net } \\
\text { Catchment } \\
\text { Discharge to } \\
\text { Total } \\
\text { Discharge } \\
(\%)\end{array}$ & $\begin{array}{c}\text { Normalized } \\
\text { Net } \\
\text { Catchment } \\
\text { Discharge } \\
\text { (mm/year) }\end{array}$ & $\begin{array}{c}\text { Relative } \\
\text { Proportion of } \\
\text { Normalized } \\
\text { Net } \\
\text { Catchment } \\
\text { Discharge } \\
(\%)\end{array}$ \\
\hline NIKS & 8-Aug-15 & 0.02 & 18.22 & $5.0 \%$ & 0.02 & $5.0 \%$ & 18.22 & $8.1 \%$ \\
\hline $\mathrm{KC}$ & 8-Aug-15 & 0.04 & 13.54 & $8.8 \%$ & 0.04 & $8.8 \%$ & 13.54 & $6.0 \%$ \\
\hline JKPW & 10-Aug-15 & 0.35 & 20.01 & $100.0 \%$ & 0.10 & $29.3 \%$ & 102.00 & $57.7 \%$ \\
\hline Moodie & 10-Aug-15 & 0.25 & 15.02 & $70.7 \%$ & 0.14 & $39.1 \%$ & 27.09 & $15.3 \%$ \\
\hline JKER & 10-Aug-15 & 0.22 & 16.23 & $62.6 \%$ & 0.11 & $31.0 \%$ & 52.37 & $22.8 \%$ \\
\hline JKFT & 10-Aug-15 & 0.04 & 7.97 & $11.9 \%$ & 0.04 & $11.9 \%$ & 7.97 & $4.5 \%$ \\
\hline FGCR & 10-Aug-15 & 0.02 & 15.96 & $7.0 \%$ & 0.02 & $7.0 \%$ & 15.96 & $9.0 \%$ \\
\hline NIKS & 10-Aug-15 & 0.01 & 11.83 & $3.8 \%$ & 0.01 & $3.8 \%$ & 11.83 & $6.7 \%$ \\
\hline $\mathrm{KC}$ & 10-Aug-15 & 0.03 & 11.35 & $8.7 \%$ & 0.03 & $8.7 \%$ & 11.35 & $6.4 \%$ \\
\hline JKPW & 24-Sep-15 & 1.38 & 78.04 & 1.00 & 0.40 & 0.29 & 398.44 & 0.57 \\
\hline Moodie & 24-Sep-15 & 0.97 & 58.51 & 0.71 & 0.40 & 0.29 & 78.64 & 0.11 \\
\hline JKER & 24-Sep-15 & 1.04 & 76.18 & 0.75 & 0.47 & 0.34 & 222.78 & 0.24 \\
\hline JKFT & 24-Sep-15 & 0.31 & 58.56 & 0.22 & 0.31 & 0.22 & 58.56 & 0.08 \\
\hline FGCR & 24-Sep-15 & 0.07 & 45.18 & 0.05 & 0.07 & 0.05 & 45.18 & 0.06 \\
\hline HBFT & 24-Sep-15 & 0.04 & 44.03 & 0.03 & 0.04 & 0.03 & 44.03 & 0.06 \\
\hline NIKS & 24-Sep-15 & 0.04 & 31.45 & 0.03 & 0.04 & 0.03 & 31.45 & 0.04 \\
\hline $\mathrm{KC}$ & 24-Sep-15 & 0.12 & 44.00 & 0.09 & 0.12 & 0.09 & 44.00 & 0.06 \\
\hline
\end{tabular}


Equations for Table B-0-3:

Normalized catchment discharge (mm/year): (flow $\left.\left(\mathrm{m}^{3} / \mathrm{s}\right) \times 1000 \times 24 \mathrm{~h} \times 3600 \mathrm{~s}\right) /$ area $\left(\mathrm{m}^{2}\right)$

Proportion of discharge to total outflow (\%): (site flow $\left(\mathrm{m}^{3} / \mathrm{s}\right) /$ total outlet flow JKPW $\left(\mathrm{m}^{3} / \mathrm{s}\right)$ ) x 100\%

Net catchment discharge $\left(\mathrm{m}^{3} / \mathrm{s}\right)$ : site upstream $\left(\mathrm{m}^{3} / \mathrm{s}\right)$ - site $(\mathrm{s})$ downstream $\left(\mathrm{m}^{3} / \mathrm{s}\right)$

Proportion of net catchment discharge to total discharge (\%):

(net catchment discharge $\left(\mathrm{m}^{3} / \mathrm{s}\right) /$ total outlet discharge JKPW $\left.\left(\mathrm{m}^{3} / \mathrm{s}\right)\right) \times 100 \%$

Normalized net catchment discharge (mm/year): (net catchment discharge $\left.\left(\mathrm{m}^{3} / \mathrm{s}\right) \times 1000 \times 24 \mathrm{~h} \times 3600 \mathrm{~s}\right) / \operatorname{area}\left(\mathrm{m}^{2}\right)$ )

Relative proportion of normalized net catchment discharge $(\%)$ :

(normalized net catchment discharge (mm/year)/ (all normalized net catchment discharge (mm/year) summed)) x 100\% 


\begin{tabular}{|c|c|c|c|c|c|c|c|}
\hline Site & Date & $\begin{array}{c}\text { Proportion } \\
\text { Wetland End- } \\
\text { Member } \\
\text { (GWMP2015) } \\
(\%)\end{array}$ & $\begin{array}{l}\text { Proportion Basal } \\
\text { Gravel/ Esker } \\
\text { End-Member } \\
(\mathrm{W} 156-2)(\%)\end{array}$ & $\begin{array}{c}\text { Proportion } \\
\text { Groundwater } \\
\text { End-Member } \\
(\text { GW_DW_1) } \\
(\%)\end{array}$ & $\begin{array}{l}\text { Wetland End- } \\
\text { Member } \\
\text { Discharge } \\
\left(\mathrm{m}^{3} / \mathrm{s}\right)\end{array}$ & $\begin{array}{c}\text { Basal Gravel/ } \\
\text { Esker End- } \\
\text { Member } \\
\text { Discharge } \\
\left(\mathrm{m}^{3} / \mathrm{s}\right)\end{array}$ & $\begin{array}{c}\text { Groundwater } \\
\text { End-Member } \\
\text { Discharge } \\
\left(\mathrm{m}^{3} / \mathrm{s}\right)\end{array}$ \\
\hline JKPW & 6-Jul-15 & $61 \%$ & $19 \%$ & $19 \%$ & 0.13 & 0.04 & 0.04 \\
\hline Moodie & 6-Jul-15 & & & & & & \\
\hline JKER & 6-Jul-15 & $76 \%$ & $7 \%$ & $17 \%$ & 0.28 & 0.03 & 0.07 \\
\hline JKFT & 6-Jul-15 & $73 \%$ & $20 \%$ & $8 \%$ & 0.39 & 0.11 & 0.04 \\
\hline FGCR & 6-Jul-15 & $42 \%$ & $25 \%$ & $34 \%$ & 0.02 & 0.01 & 0.02 \\
\hline HBFT & 6-Jul-15 & $65 \%$ & & $35 \%$ & 0.01 & 0.00 & 0.01 \\
\hline NIKS & 6-Jul-15 & $84 \%$ & $5 \%$ & $11 \%$ & 0.08 & 0.00 & 0.01 \\
\hline $\mathrm{KC}$ & 6-Jul-15 & $86 \%$ & $0 \%$ & $14 \%$ & 0.08 & 0.00 & 0.01 \\
\hline JKPW & 11-Jul-15 & $58 \%$ & $18 \%$ & $24 \%$ & 0.10 & 0.03 & 0.04 \\
\hline Moodie & 11-Jul-15 & & & & & & \\
\hline JKER & 11-Jul-15 & $66 \%$ & $21 \%$ & $13 \%$ & -0.09 & -0.03 & -0.02 \\
\hline JKFT & 11-Jul-15 & $73 \%$ & $17 \%$ & $9 \%$ & 0.25 & 0.06 & 0.03 \\
\hline FGCR & 11-Jul-15 & $34 \%$ & $0 \%$ & $66 \%$ & 0.02 & 0.00 & 0.03 \\
\hline HBFT & 11-Jul-15 & $58 \%$ & & $42 \%$ & 0.00 & 0.00 & 0.00 \\
\hline NIKS & 11-Jul-15 & $73 \%$ & $1 \%$ & $26 \%$ & 0.05 & 0.00 & 0.02 \\
\hline $\mathrm{KC}$ & 11-Jul-15 & $79 \%$ & $0 \%$ & $21 \%$ & 0.15 & 0.00 & 0.04 \\
\hline JKPW & 8-Aug-15 & $18 \%$ & $49 \%$ & $33 \%$ & 0.03 & 0.07 & 0.05 \\
\hline Moodie & 8-Aug-15 & & & & & & \\
\hline JKER & 8-Aug-15 & $31 \%$ & $41 \%$ & $28 \%$ & 0.00 & -0.01 & 0.00 \\
\hline JKFT & 8-Aug-15 & $63 \%$ & $25 \%$ & $13 \%$ & 0.03 & 0.01 & 0.01 \\
\hline FGCR & 8-Aug-15 & $15 \%$ & $49 \%$ & $36 \%$ & 0.00 & 0.01 & 0.01 \\
\hline HBFT & 8-Aug-15 & $35 \%$ & & $65 \%$ & 0.00 & 0.00 & 0.00 \\
\hline NIKS & 8-Aug-15 & $86 \%$ & $3 \%$ & $12 \%$ & 0.02 & 0.00 & 0.00 \\
\hline $\mathrm{KC}$ & 8-Aug-15 & $65 \%$ & $11 \%$ & $23 \%$ & 0.02 & 0.00 & 0.01 \\
\hline JKPW & 10-Aug-15 & $20 \%$ & $48 \%$ & $32 \%$ & 0.02 & 0.05 & 0.03 \\
\hline
\end{tabular}




\begin{tabular}{|c|c|c|c|c|c|c|c|}
\hline Site & Date & $\begin{array}{c}\text { Proportion } \\
\text { Wetland End- } \\
\text { Member } \\
\text { (GWMP2015) } \\
(\%)\end{array}$ & $\begin{array}{c}\text { Proportion Basal } \\
\text { Gravel/ Esker } \\
\text { End-Member } \\
(\mathrm{W} 156-2)(\%)\end{array}$ & $\begin{array}{c}\text { Proportion } \\
\text { Groundwater } \\
\text { End-Member } \\
(\text { GW_DW_1) } \\
(\%)\end{array}$ & $\begin{array}{l}\text { Wetland End- } \\
\text { Member } \\
\text { Discharge } \\
\left(\mathrm{m}^{3} / \mathrm{s}\right)\end{array}$ & $\begin{array}{l}\text { Basal Gravel/ } \\
\text { Esker End- } \\
\text { Member } \\
\text { Discharge } \\
\left(\mathrm{m}^{3} / \mathrm{s}\right)\end{array}$ & $\begin{array}{c}\text { Groundwater } \\
\text { End-Member } \\
\text { Discharge } \\
\left(\mathrm{m}^{3} / \mathrm{s}\right)\end{array}$ \\
\hline Moodie & 10-Aug-15 & & & & & & \\
\hline JKER & 10-Aug-15 & $27 \%$ & $44 \%$ & $29 \%$ & 0.03 & 0.05 & 0.03 \\
\hline JKFT & 10-Aug-15 & $61 \%$ & $25 \%$ & $14 \%$ & 0.03 & 0.01 & 0.01 \\
\hline FGCR & 10-Aug-15 & $10 \%$ & $55 \%$ & $35 \%$ & 0.00 & 0.01 & 0.01 \\
\hline HBFT & 10-Aug-15 & $33 \%$ & & $67 \%$ & 0.00 & 0.00 & 0.00 \\
\hline NIKS & 10-Aug-15 & $71 \%$ & $0 \%$ & $29 \%$ & 0.01 & 0.00 & 0.00 \\
\hline $\mathrm{KC}$ & 10-Aug-15 & $65 \%$ & $13 \%$ & $23 \%$ & 0.02 & 0.00 & 0.01 \\
\hline JKPW & 24-Sep-15 & 0.40 & 0.34 & 0.26 & 0.16 & 0.14 & 0.11 \\
\hline Moodie & 24-Sep-15 & & & & & & \\
\hline JKER & 24-Sep-15 & 0.64 & 0.12 & 0.25 & 0.30 & 0.05 & 0.11 \\
\hline JKFT & 24-Sep-15 & 0.73 & 0.07 & 0.20 & 0.23 & 0.02 & 0.06 \\
\hline FGCR & 24-Sep-15 & 0.495 & 0.000 & 0.505 & 0.03 & 0.00 & 0.04 \\
\hline HBFT & 24-Sep-15 & 0.64 & & 0.36 & 0.02 & 0.00 & 0.01 \\
\hline NIKS & 24-Sep-15 & 0.731 & 0.073 & 0.196 & 0.03 & 0.00 & 0.01 \\
\hline $\mathrm{KC}$ & 24-Sep-15 & 0.785 & 0.000 & 0.215 & 0.00 & 0.00 & 0.00 \\
\hline
\end{tabular}


Appendix C 


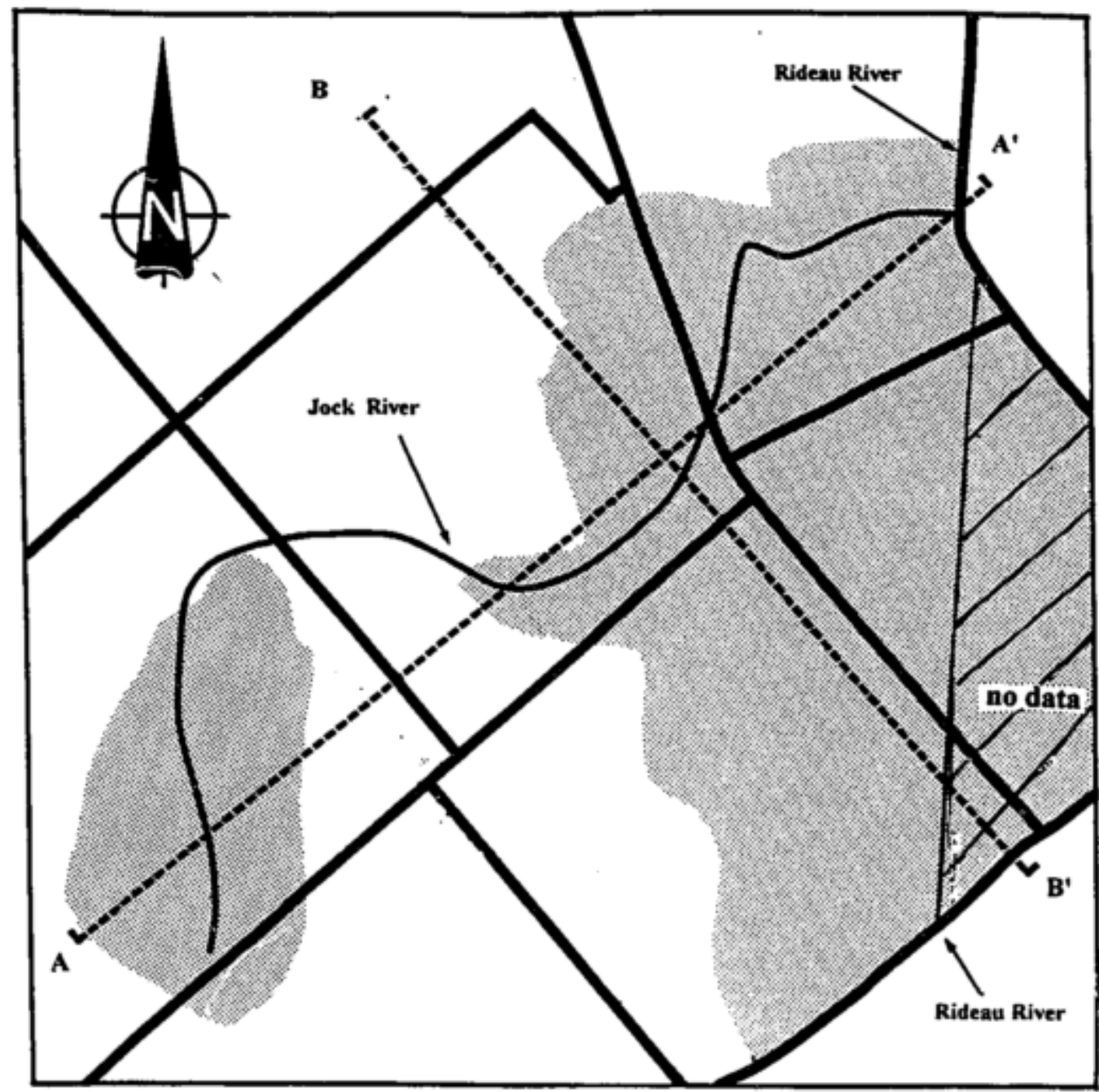

Figure 15 - Bedrock Groundwater Discharge Area

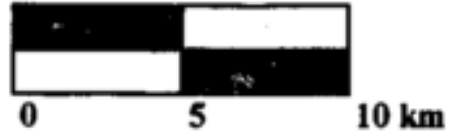

Discharge Area

56

Figure C-0-1. Bedrock groundwater discharge area delineated for the Jock River watershed from Velderman (1993). 


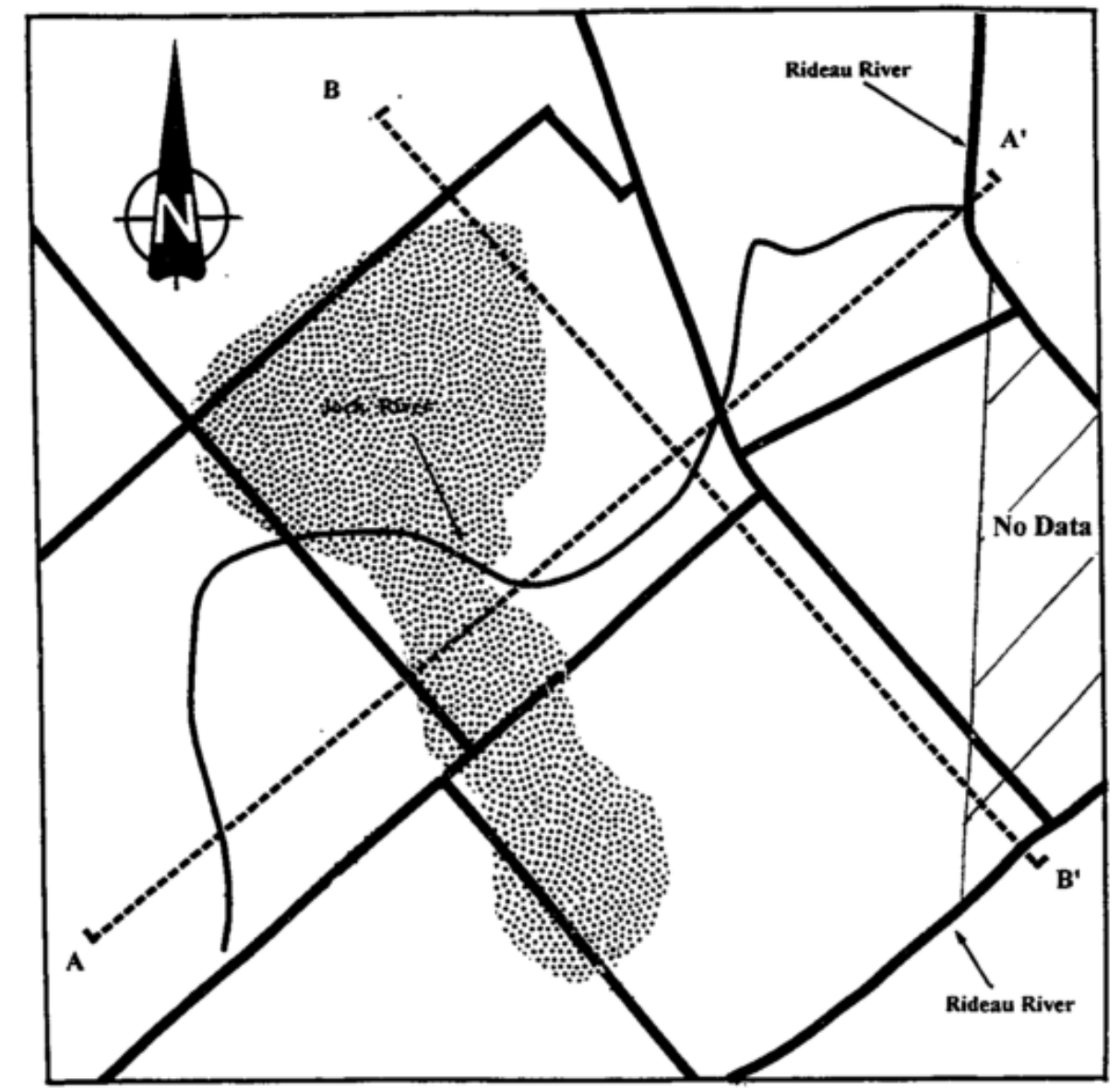

Figure 16 - Deep Bedrock Groundwater Recharge Area
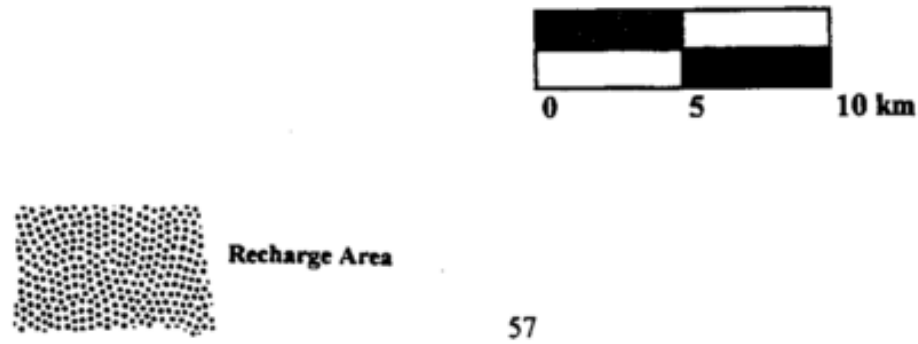

Figure C-0-2. Bedrock groundwater recharge area delineated for the Jock River watershed from Velderman (1993). 


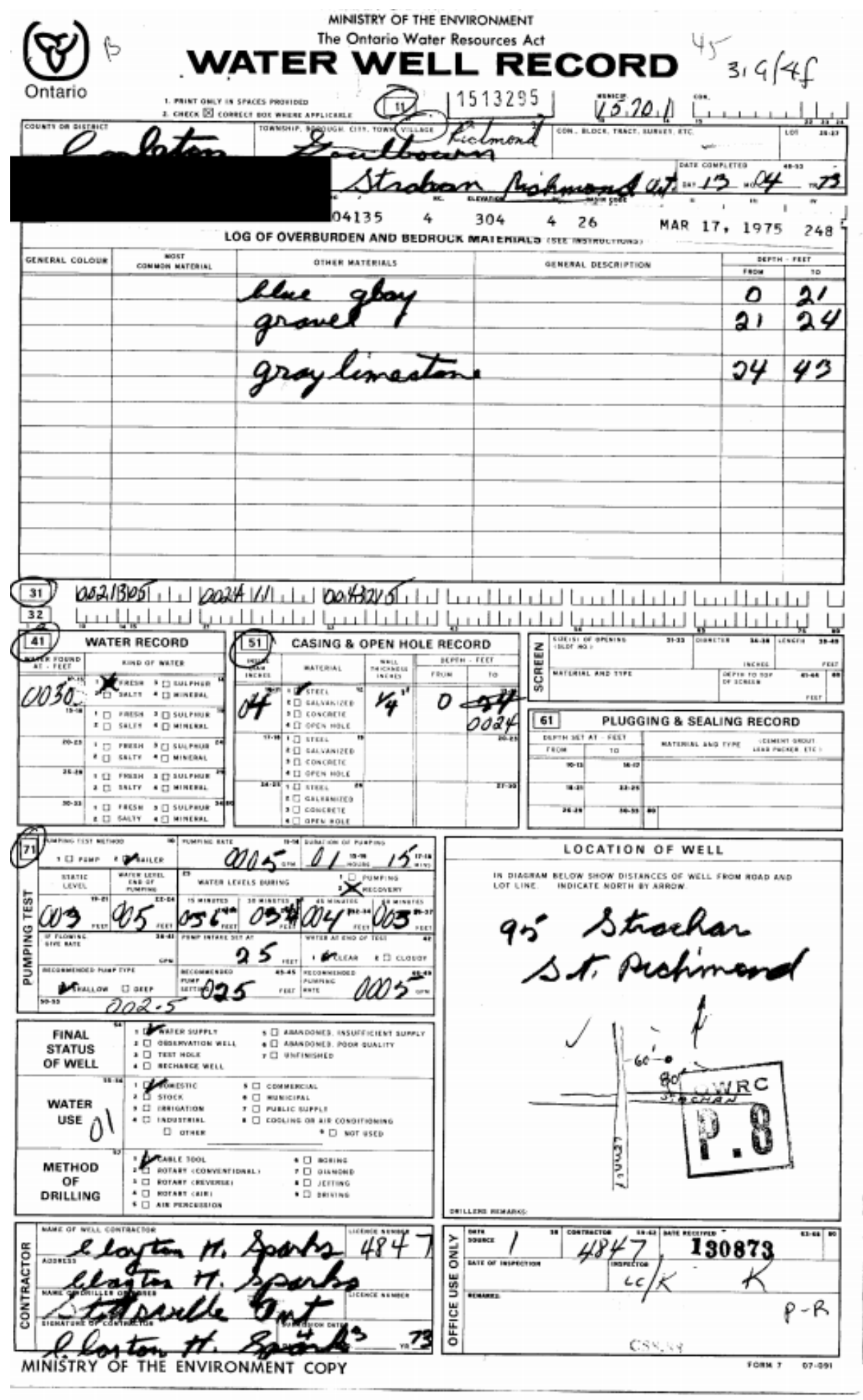

Figure C-0-3. Water well record for neighbouring well to $G W_{-} D W_{-} 2$. 


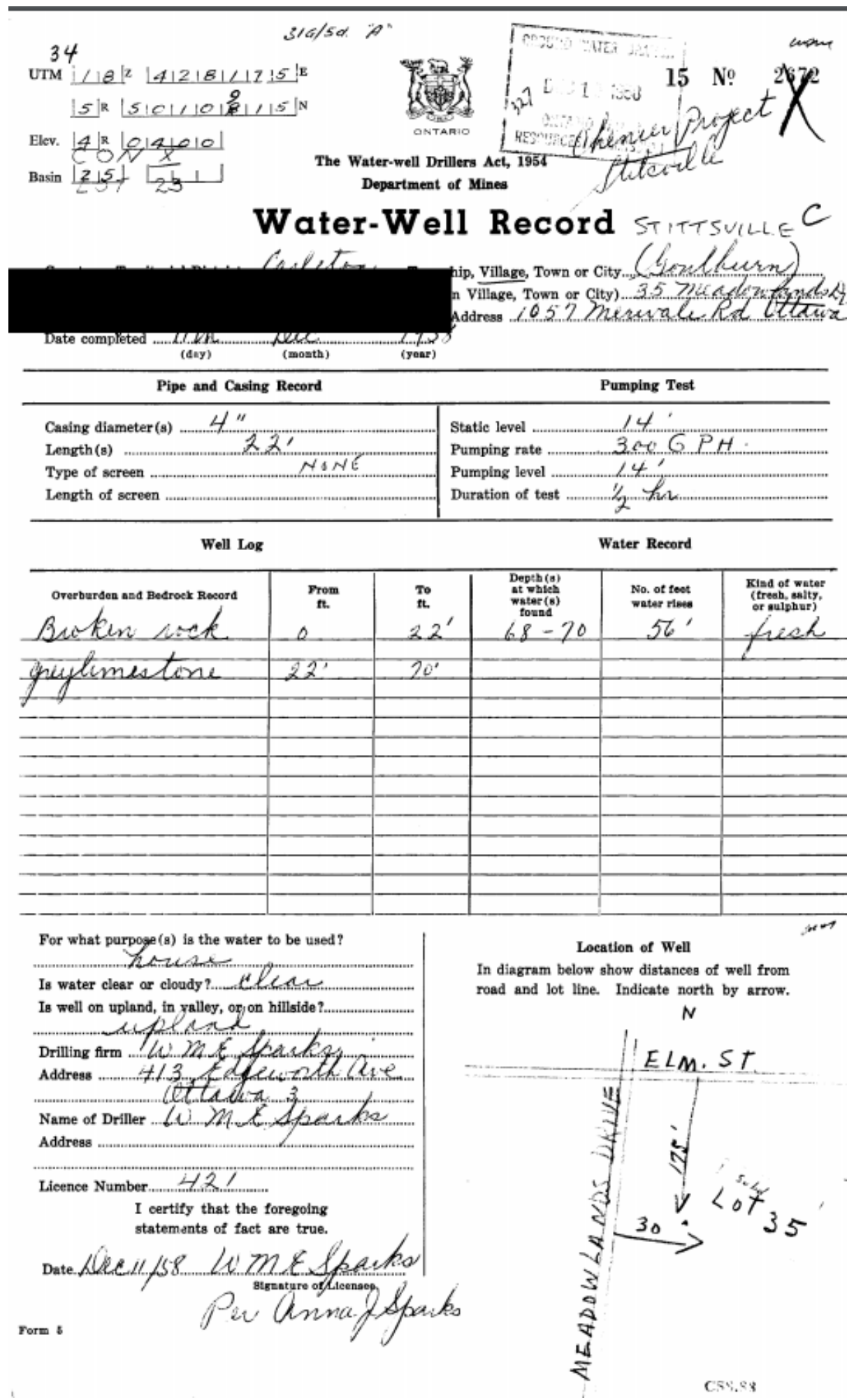

Well Figure C-0-4. Water well record for neighbouring well to $G W_{-} D W_{-} 1$. 


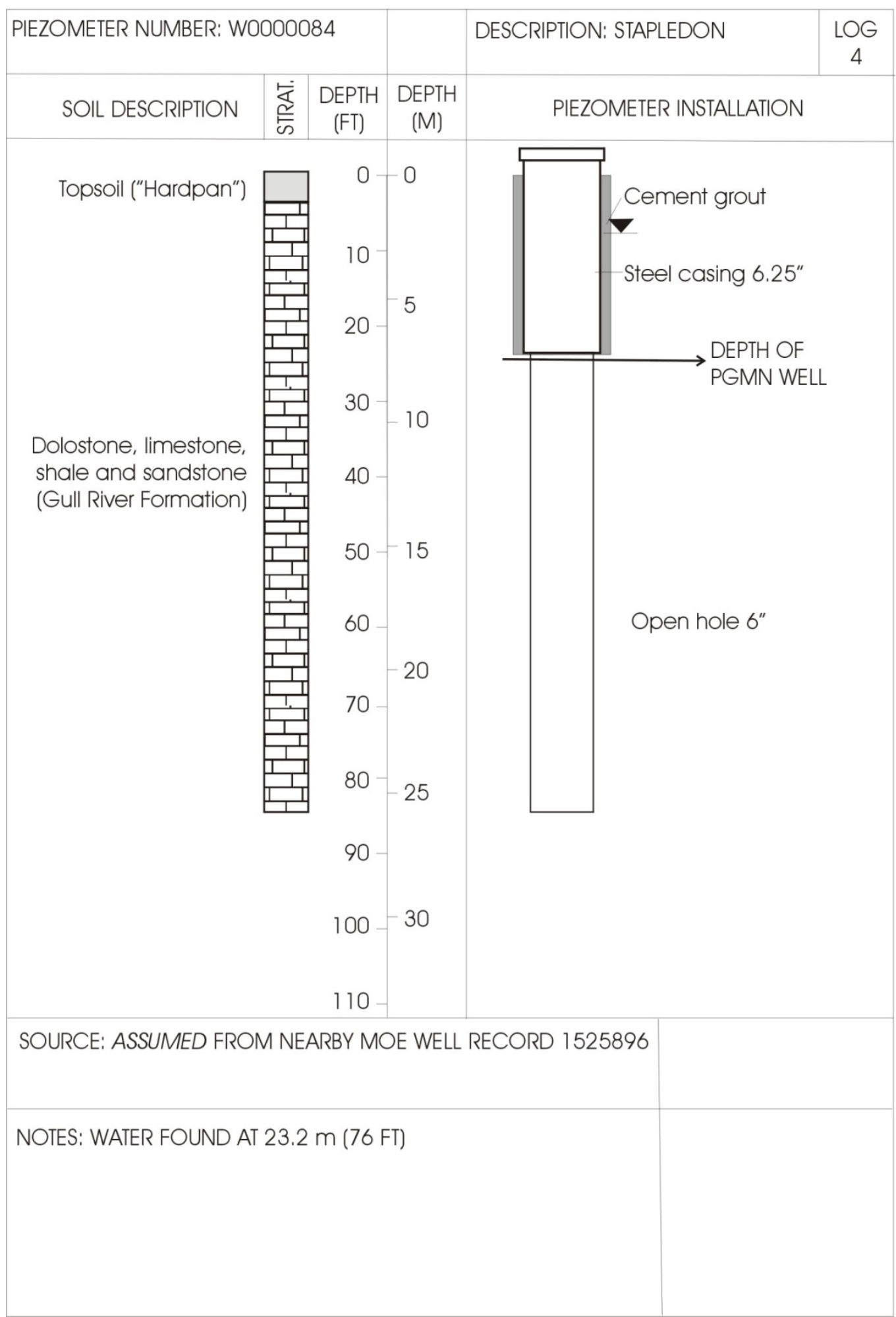

Figure C-0-5. Well log for PGMN water well W084. 


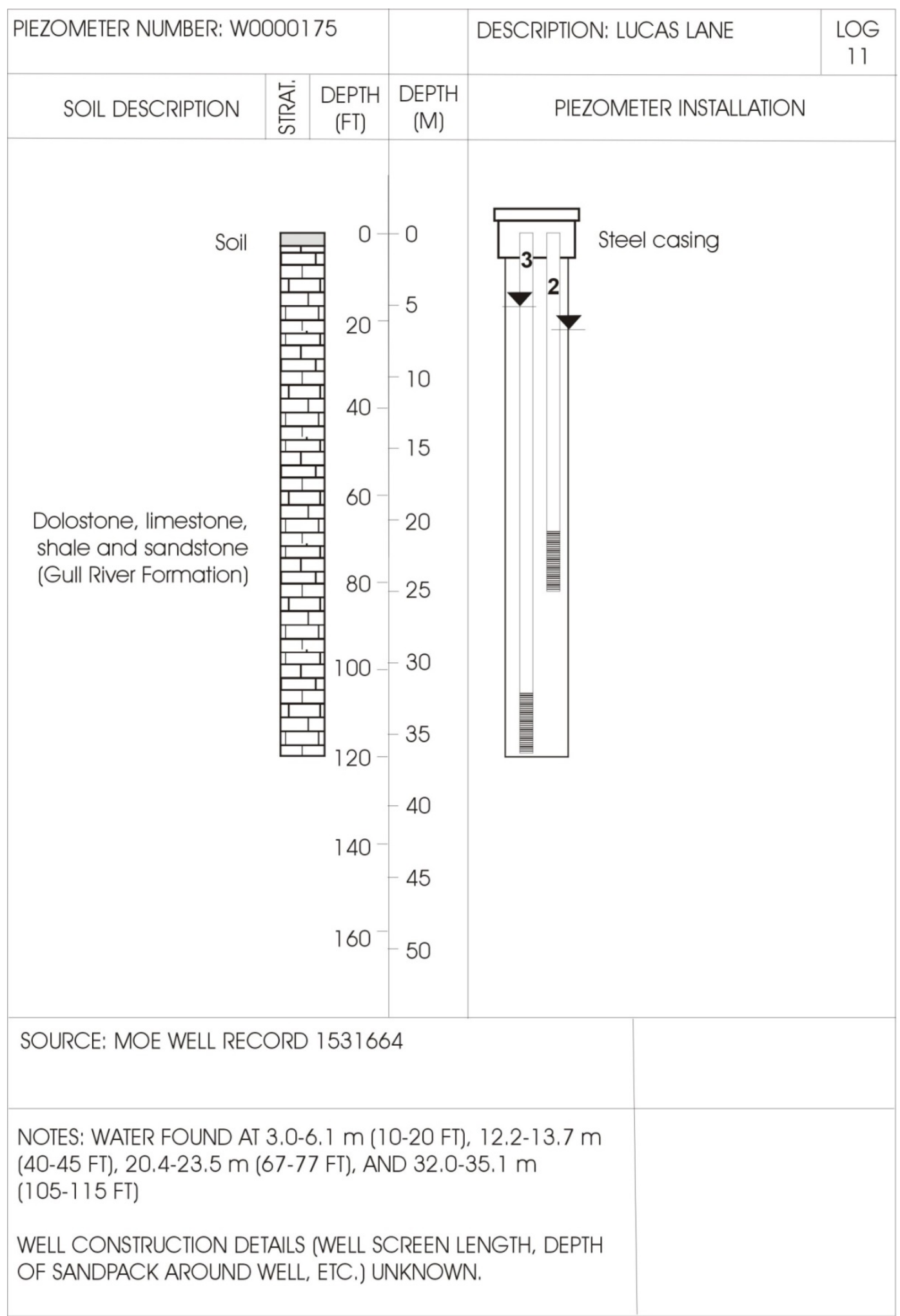

Figure C-0-6. Well log for PGMN water well W175-2/3. 


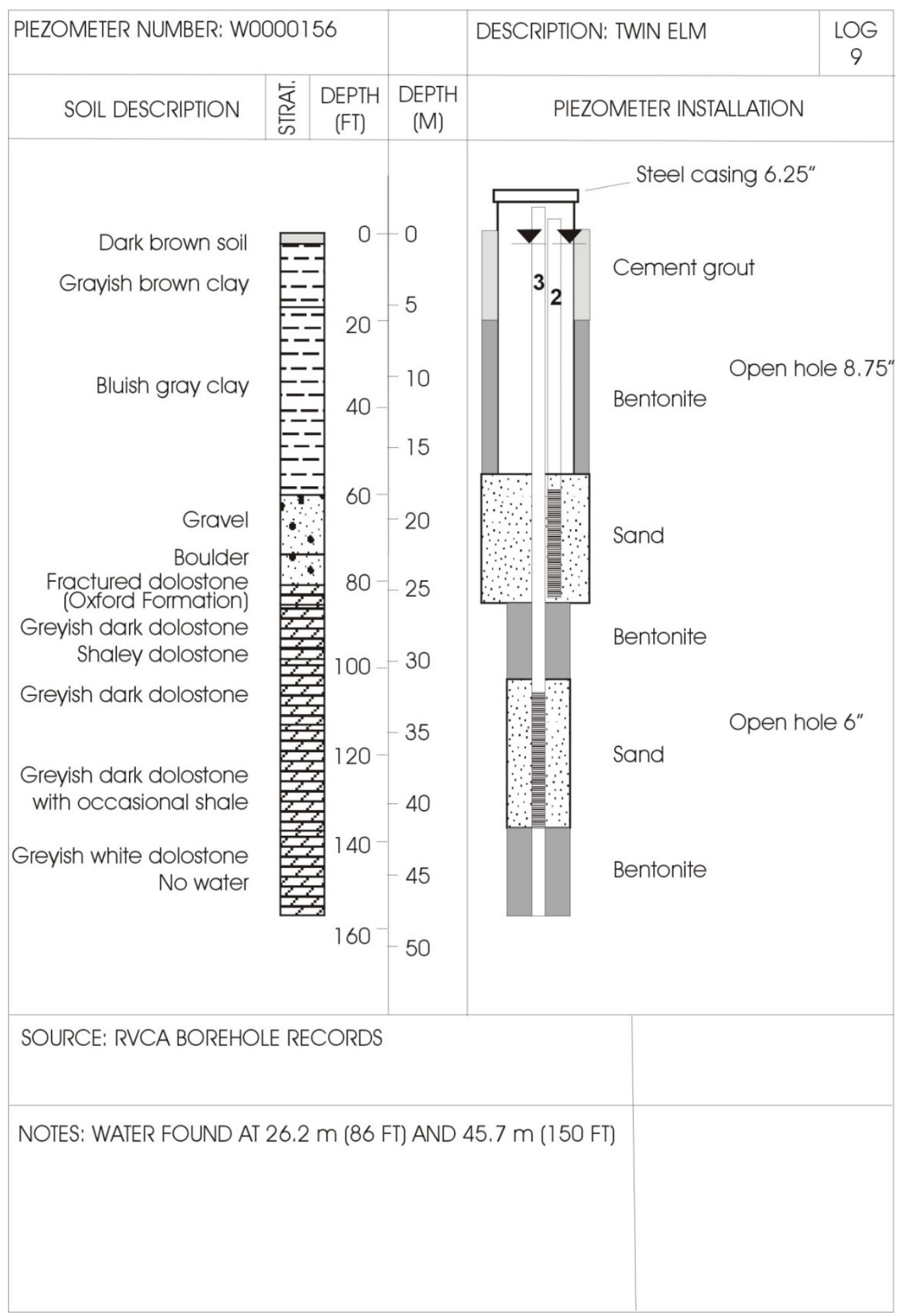

Figure C-0-7. Well log for PGMN water well W156-2/3. 


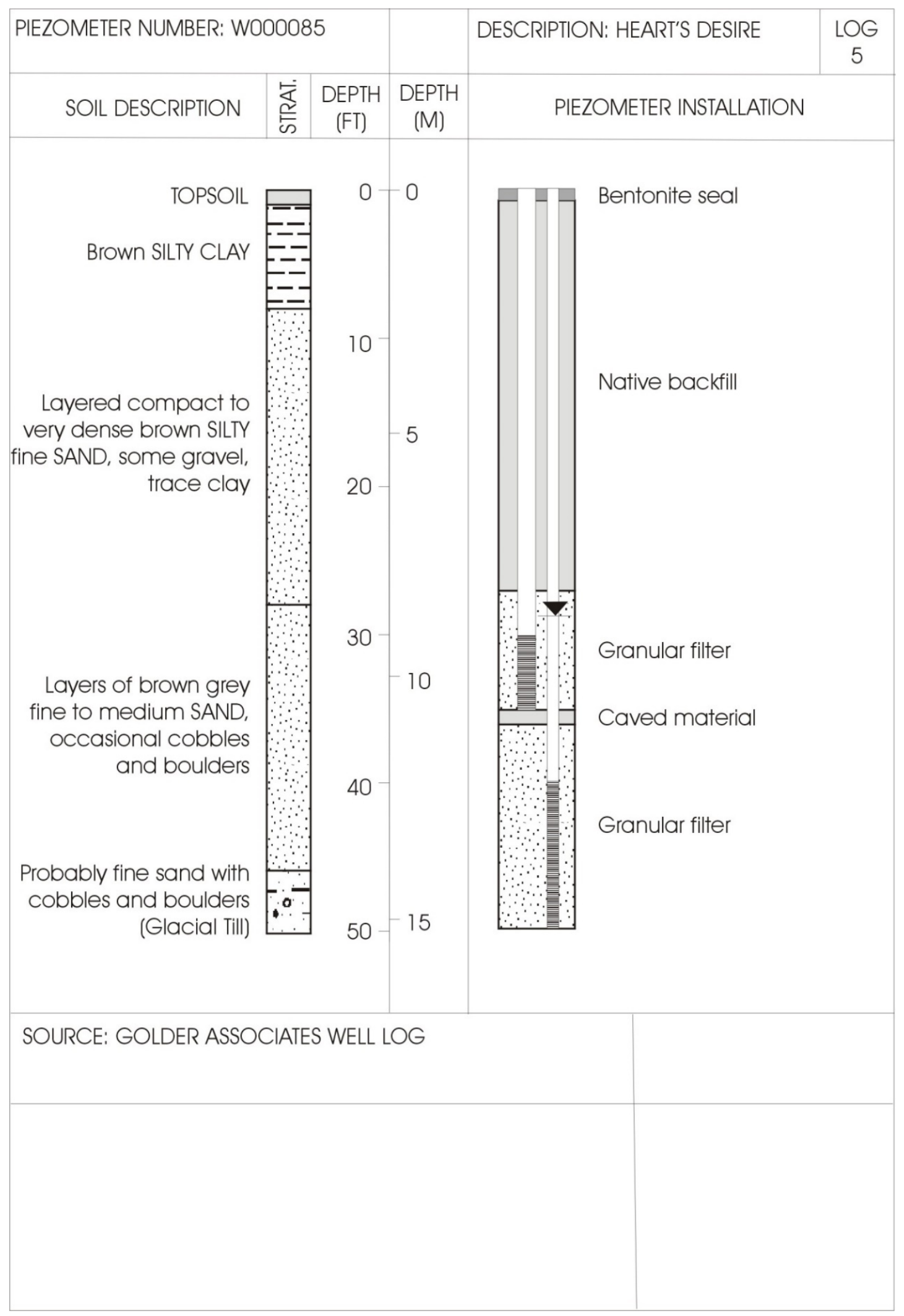

Figure C-0-8. Well log for PGMN water well W085. 
Appendix D 
Table D-0-1. Stage and discharge measurements for the Jock River at Prince of Wales Road.

\begin{tabular}{|c|c|c|c|c|c|c|c|}
\hline Date & $\begin{array}{c}\text { Stage } \\
\mathbf{H ~ ( m ) ~}\end{array}$ & $\begin{array}{c}\text { Stage } \\
\mathbf{H} \\
\mathbf{( c m )}\end{array}$ & $\begin{array}{c}\text { Discharge } \\
\mathbf{Q}(\mathbf{l} / \mathbf{s})\end{array}$ & $\begin{array}{c}\text { Discharge } \\
\text { Uncertainty } \\
\text { (ISO) \% }\end{array}$ & H-HO & $\begin{array}{c}\text { Log } \\
\text { (H-HO) }\end{array}$ & $\begin{array}{c}\text { LOG } \\
\text { (Q) }\end{array}$ \\
\hline July 2nd 2015 & 0.496 & 49.6 & 3218.6 & 3.4 & 49.6 & 1.7 & 3.5 \\
\hline July 11th 2015 & 0.395 & 39.5 & 1337.9 & 3.6 & 39.5 & 1.6 & 3.1 \\
\hline July 24th 2015 & 0.336 & 33.6 & 1007.4 & 3.2 & 33.6 & 1.5 & 3.0 \\
\hline August 8th 2015 & 0.253 & 25.3 & 413.1 & 3.9 & 25.3 & 1.4 & 2.6 \\
\hline August 10th 2015 & 0.276 & 27.6 & 353.5 & 3.7 & 27.6 & 1.4 & 2.5 \\
\hline August 27th 2015 & 0.407 & 40.7 & 965.4 & 3.3 & 40.7 & 1.6 & 3.0 \\
\hline $\begin{array}{c}\text { September 3rd } \\
\text { 2015 }\end{array}$ & 0.339 & 33.9 & 719.8 & 3.1 & 33.9 & 1.5 & 2.9 \\
\hline $\begin{array}{c}\text { September 17th } \\
\text { 2015 }\end{array}$ & 0.539 & 53.9 & 2960.8 & 3.0 & 53.9 & 1.7 & 3.5 \\
\hline $\begin{array}{c}\text { September 24th } \\
\text { 2015 }\end{array}$ & 0.418 & 41.8 & 1378.3 & 3.0 & 41.8 & 1.6 & 3.1 \\
\hline October 29th 2015 & 0.637 & 63.7 & 5383.8 & 3.6 & 63.7 & 1.8 & 3.7 \\
\hline
\end{tabular}

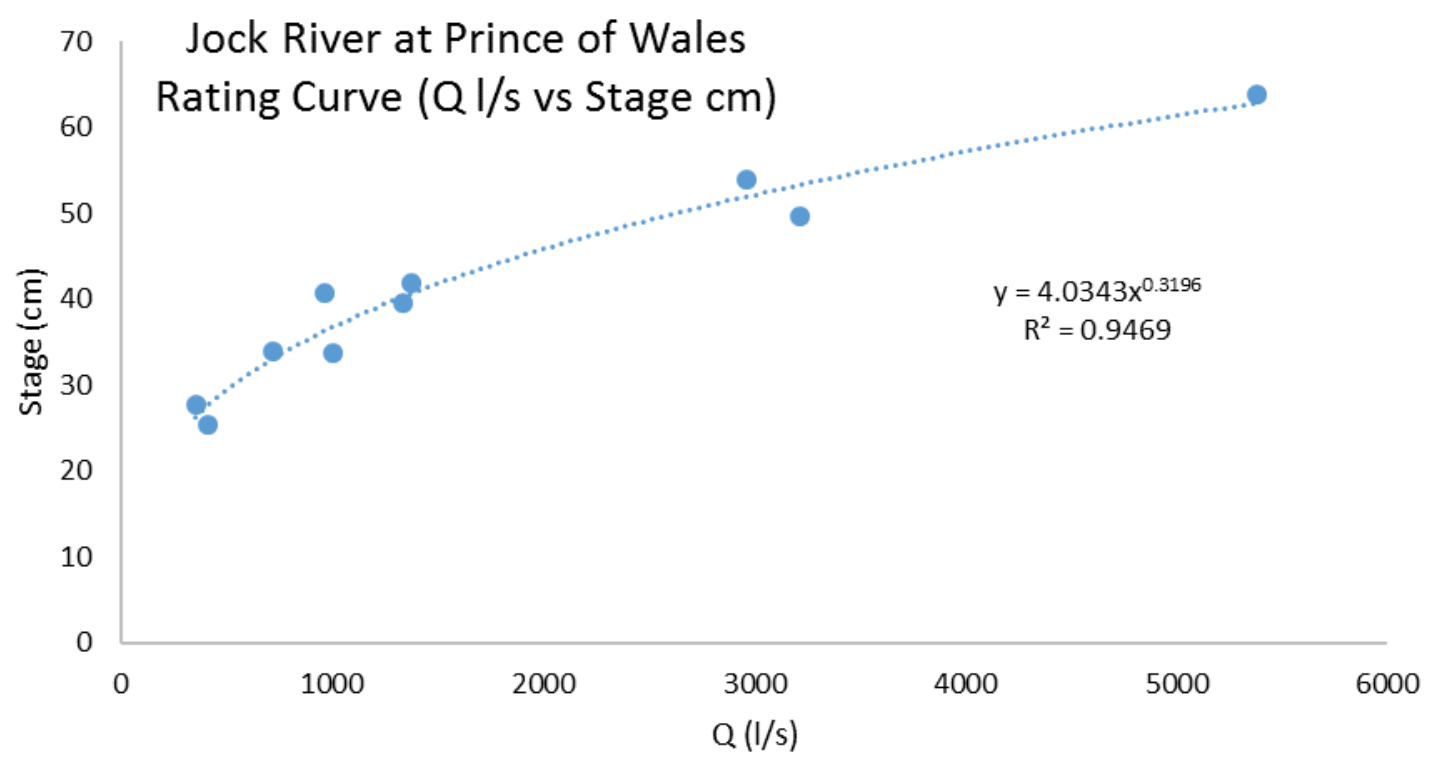

Figure D-0-1. Stage discharge rating curve for the Jock River at Prince of Wales Road. 
Table D-0-2. Stage and discharge measurements for the Jock River at Eagleson Road.

\begin{tabular}{|c|c|c|c|c|c|c|c|}
\hline Date & $\begin{array}{c}\text { Stage } \\
\mathbf{H} \\
\mathbf{( m )}\end{array}$ & $\begin{array}{c}\text { Stage } \\
\mathbf{H}(\mathbf{c m})\end{array}$ & $\begin{array}{c}\text { Discharge } \\
\mathbf{Q}(\mathbf{l} / \mathbf{s})\end{array}$ & $\begin{array}{c}\text { Discharge } \\
\text { Uncertainty } \\
\text { (ISO) \% }\end{array}$ & H-HO & $\begin{array}{c}\text { Log } \\
\mathbf{( H - H O )}\end{array}$ & $\begin{array}{c}\text { LOG } \\
(\mathbf{Q})\end{array}$ \\
\hline June 17th 2015 & 0.965 & 96.5 & 5716.2 & 2.8 & 96.5 & 2.0 & 3.8 \\
\hline July 3rd 2015 & 0.771 & 77.1 & 2337.1 & 3.3 & 77.1 & 1.9 & 3.4 \\
\hline July 11th 2015 & 0.614 & 61.4 & 529.8 & 4.2 & 61.4 & 1.8 & 2.7 \\
\hline July 13 2015 & 0.555 & 55.5 & 532.4 & NA & 55.5 & 1.7 & 2.7 \\
\hline August 8th 2015 & 0.317 & 31.7 & 117.8 & 3.4 & 31.7 & 1.5 & 2.1 \\
\hline August 10th 2015 & 0.312 & 31.2 & 221.3 & 3.1 & 31.2 & 1.5 & 2.3 \\
\hline August 28th 2015 & 0.531 & 53.1 & 190.9 & 5.2 & 53.1 & 1.7 & 2.3 \\
\hline $\begin{array}{c}\text { September 3rd } \\
\text { 2015 }\end{array}$ & 0.451 & 45.1 & 378.8 & 3.0 & 45.1 & 1.7 & 2.6 \\
\hline $\begin{array}{c}\text { September 30th } \\
\text { 2015 }\end{array}$ & 0.661 & 66.1 & 1005.3 & 3.2 & 66.1 & 1.8 & 3.0 \\
\hline
\end{tabular}

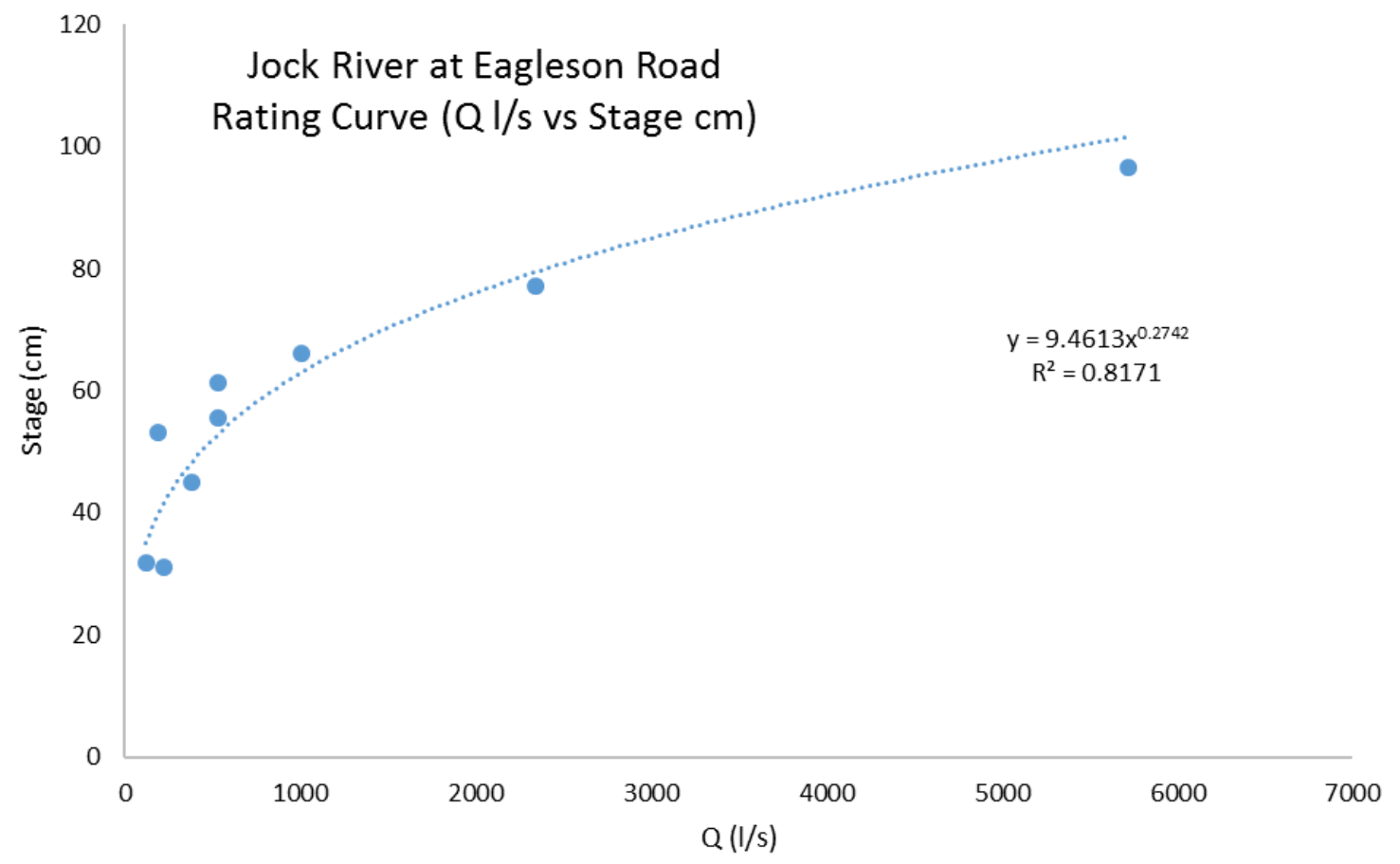

Figure D-0-2. Stage discharge rating curve for the Jock River at Eagleson Road. 
Table D-0-3. Stage and discharge measurements for the Jock River at Franktown Road

\begin{tabular}{|c|c|c|c|c|c|c|c|}
\hline Date & $\begin{array}{c}\text { Stage } \\
\text { H (m) }\end{array}$ & $\begin{array}{c}\text { Stage } \\
\mathbf{H} \\
\mathbf{( c m )}\end{array}$ & $\begin{array}{c}\text { Discharge } \\
\mathbf{Q}(\mathbf{l} / \mathbf{s})\end{array}$ & $\begin{array}{c}\text { Discharge } \\
\text { Uncertainty } \\
\text { (ISO) } \%\end{array}$ & H-HO & $\begin{array}{c}\text { Log } \\
\text { (H-HO) }\end{array}$ & $\begin{array}{c}\text { LOG } \\
\text { (Q) }\end{array}$ \\
\hline July 2nd 2015 & 0.540 & 54.0 & 1375.8 & 3.3 & 54.0 & 1.7 & 3.1 \\
\hline July 6th 2015 & 0.396 & 39.6 & 541.2 & 3.2 & 39.6 & 1.6 & 2.7 \\
\hline July 11th 2015 & 0.436 & 43.6 & 346.3 & 3.3 & 43.6 & 1.6 & 2.5 \\
\hline July 25th 2015 & 0.380 & 38.0 & 127.9 & 3.1 & 38.0 & 1.6 & 2.1 \\
\hline August 8th 2015 & 0.340 & 34.0 & 46.3 & 3.3 & 34.0 & 1.5 & 1.7 \\
\hline August 10th 2015 & 0.334 & 33.4 & 42.2 & 3.1 & 33.4 & 1.5 & 1.6 \\
\hline August 28th 2015 & 0.433 & 43.3 & 311.5 & 2.9 & 43.3 & 1.6 & 2.5 \\
\hline $\begin{array}{c}\text { September 4th } \\
\text { 2015 }\end{array}$ & 0.377 & 37.7 & 116.9 & 3.0 & 37.7 & 1.6 & 2.1 \\
\hline $\begin{array}{c}\text { September 17th } \\
\text { 2015 }\end{array}$ & 0.484 & 48.4 & 544.2 & 2.8 & 48.4 & 1.7 & 2.7 \\
\hline $\begin{array}{c}\text { September 24th } \\
\text { 2015 }\end{array}$ & 0.431 & 43.1 & 310.1 & 3.0 & 43.1 & 1.6 & 2.5 \\
\hline October 30th 2015 & 0.703 & 70.3 & 3095.2 & 3.3 & 70.3 & 1.8 & 3.5 \\
\hline
\end{tabular}

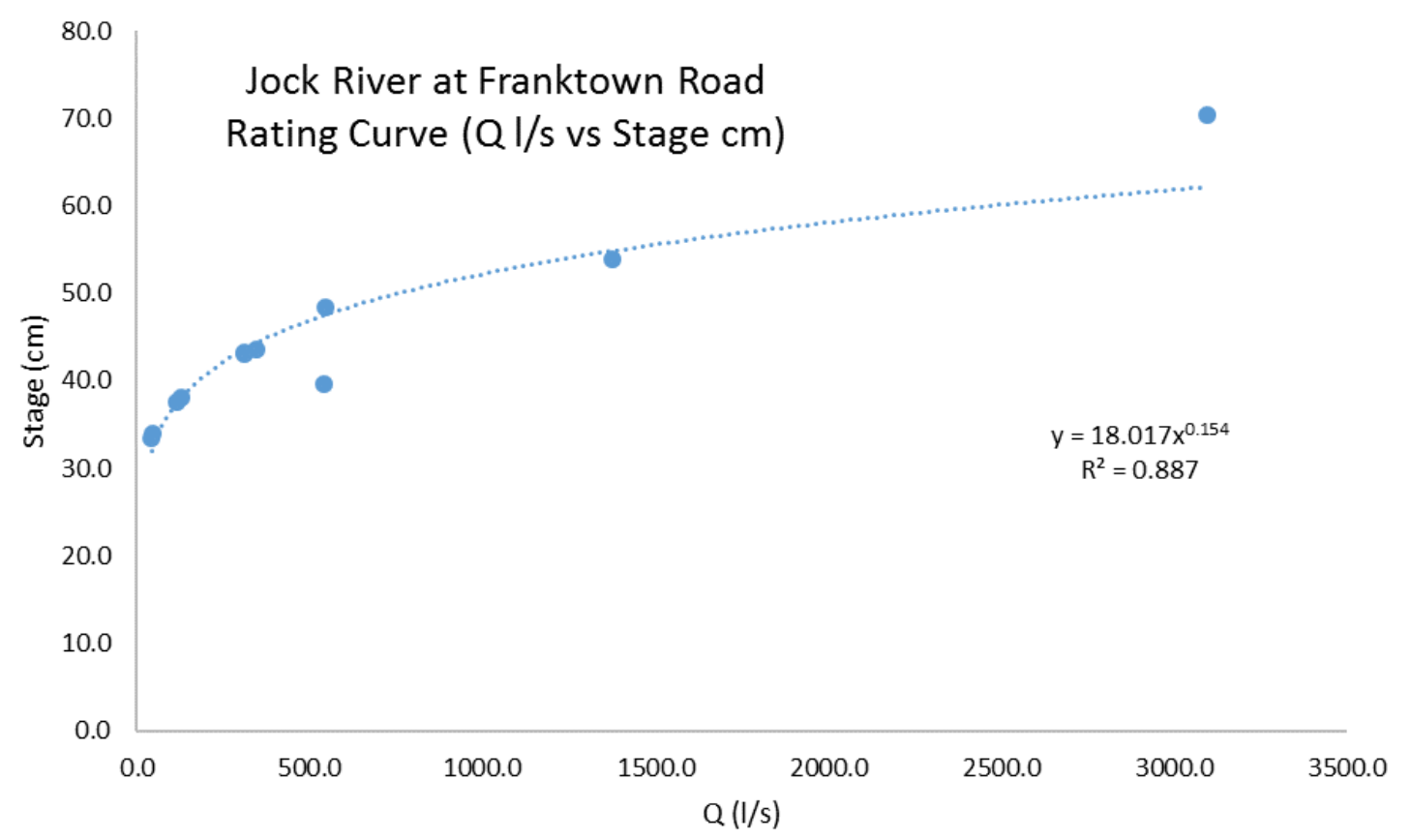

Figure D-0-3. Stage discharge rating curve for the Jock River at Franktown Road. 
Table D-0-4. Stage and discharge measurements for Flowing Creek.

\begin{tabular}{|c|c|c|c|c|c|c|c|}
\hline Date & $\begin{array}{c}\text { Stage } \\
\mathbf{H} \\
\mathbf{( m )}\end{array}$ & $\begin{array}{c}\text { Stage } \\
\mathbf{H}(\mathbf{c m})\end{array}$ & $\begin{array}{c}\text { Discharge } \\
\mathbf{Q}(\mathbf{l} / \mathbf{s})\end{array}$ & $\begin{array}{c}\text { Discharge } \\
\text { Uncertainty } \\
\text { (ISO) } \%\end{array}$ & H-HO & $\begin{array}{c}\text { Log } \\
\text { (H-HO) }\end{array}$ & $\begin{array}{c}\text { LOG } \\
\text { (Q) }\end{array}$ \\
\hline June 30th 2015 & 0.568 & 56.8 & 112.4 & 4.1 & 56.8 & 1.8 & 2.1 \\
\hline July 6th 2015 & 0.507 & 50.7 & 56.6 & 4.2 & 50.7 & 1.7 & 1.8 \\
\hline July 11th 2015 & 0.494 & 49.4 & 46.5 & 6.3 & 49.4 & 1.7 & 1.7 \\
\hline July 13th 2015 & 0.498 & 49.8 & 46.9 & 3.6 & 49.8 & 1.7 & 1.7 \\
\hline July 24th 2015 & 0.474 & 47.4 & 30.4 & 6.5 & 47.4 & 1.7 & 1.5 \\
\hline August 8th 2015 & 0.474 & 47.4 & 25.8 & 4.3 & 47.4 & 1.7 & 1.4 \\
\hline August 10th 2015 & 0.479 & 47.9 & 24.8 & 4.3 & 47.9 & 1.7 & 1.4 \\
\hline August 27th 2015 & 0.515 & 51.5 & 47.6 & 3.5 & 51.5 & 1.7 & 1.7 \\
\hline $\begin{array}{c}\text { September 3rd } \\
\text { 2015 }\end{array}$ & 0.457 & 45.7 & 40.4 & 4.6 & 45.7 & 1.7 & 1.6 \\
\hline $\begin{array}{c}\text { September 17th } \\
\text { 2015 }\end{array}$ & 0.550 & 55.0 & 190.0 & 3.1 & 55.0 & 1.7 & 2.3 \\
\hline $\begin{array}{c}\text { September 24th } \\
\text { 2015 }\end{array}$ & 0.491 & 49.1 & 70.2 & 3.5 & 49.1 & 1.7 & 1.8 \\
\hline October 29th 2015 & 0.823 & 82.3 & 1668.5 & 2.5 & 82.3 & 1.9 & 3.2 \\
\hline
\end{tabular}

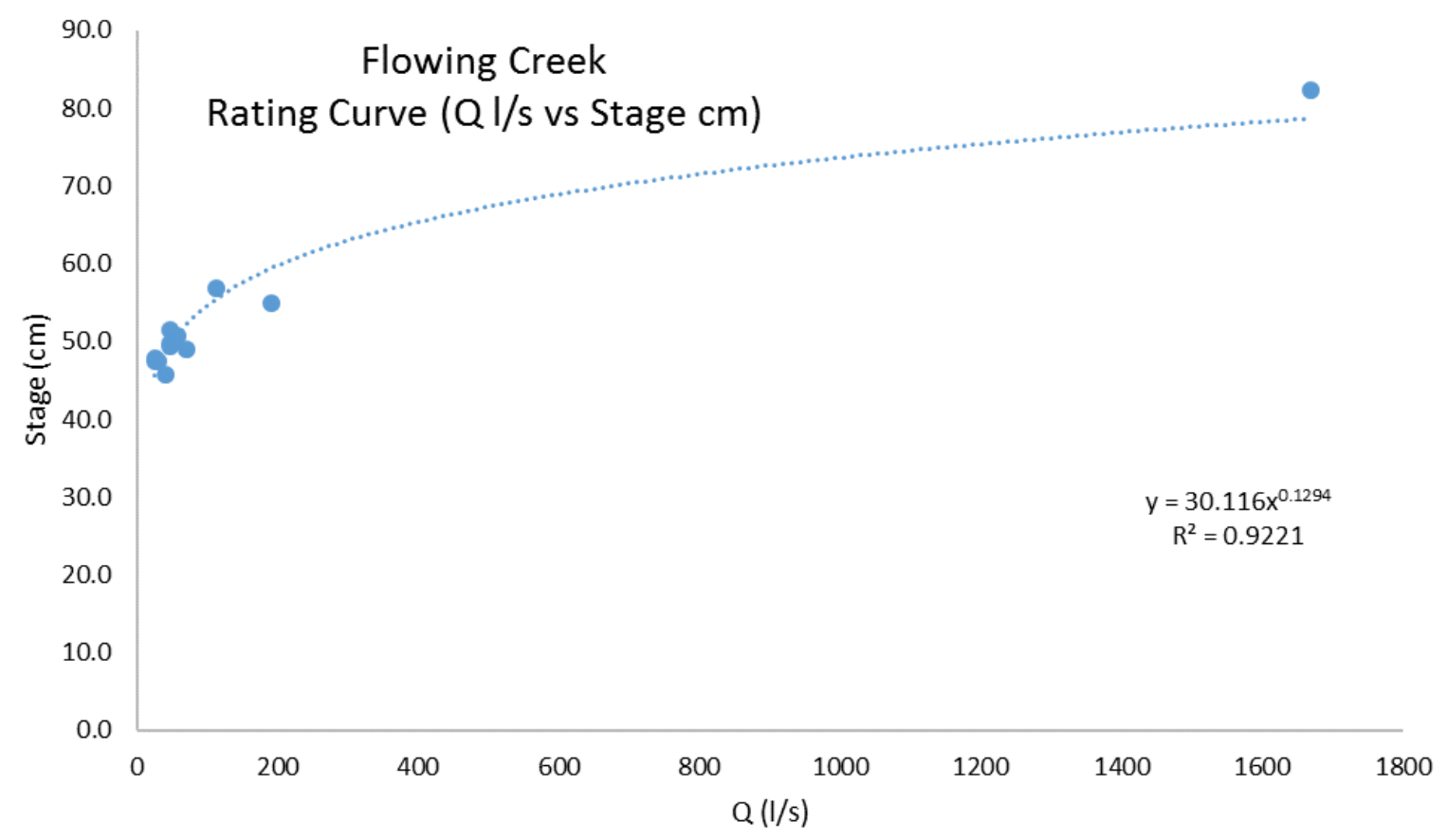

Figure D-0-4. Stage discharge rating curve for Flowing Creek. 
Table D-0-5. Stage and discharge measurements for Hobbs Drain.

\begin{tabular}{|c|c|c|c|c|c|c|c|}
\hline Date & $\begin{array}{c}\text { Stage } \\
\mathbf{H} \\
\mathbf{( m )}\end{array}$ & $\begin{array}{c}\text { Stage } \\
\mathbf{H} \\
\mathbf{( c m )}\end{array}$ & $\begin{array}{c}\text { Discharge } \\
\mathbf{Q}(\mathbf{l} / \mathbf{s})\end{array}$ & $\begin{array}{c}\text { Discharge } \\
\text { Uncertainty } \\
\text { (ISO) } \%\end{array}$ & H-HO & $\begin{array}{c}\text { Log } \\
\text { (H-HO) }\end{array}$ & $\begin{array}{c}\text { LOG } \\
(\mathbf{Q})\end{array}$ \\
\hline June 30th 2015 & 0.598 & 59.8 & 26.0 & 3.4 & 59.8 & 1.8 & 1.4 \\
\hline July 6th 2015 & 0.591 & 59.1 & 23.1 & 3.2 & 59.1 & 1.8 & 1.4 \\
\hline July 11th 2015 & 0.504 & 50.4 & 6.4 & 6.1 & 50.4 & 1.7 & 0.8 \\
\hline July 14th 2015 & 0.471 & 47.1 & 3.0 & 3.6 & 47.1 & 1.7 & 0.5 \\
\hline July 24th 2015 & 0.461 & 46.1 & 3.3 & 3.5 & 46.1 & 1.7 & 0.5 \\
\hline August 8th 2015 & 0.332 & 33.2 & 0.7 & 5.6 & 33.2 & 1.5 & -0.2 \\
\hline August 10th 2015 & 0.317 & 31.7 & 0.6 & 5.6 & 31.7 & 1.5 & -0.2 \\
\hline August 27th 2015 & 0.509 & 50.9 & 11.8 & 3.3 & 50.9 & 1.7 & 1.1 \\
\hline $\begin{array}{c}\text { September 3rd } \\
\text { 2015 }\end{array}$ & 0.436 & 43.6 & 2.5 & 5.8 & 43.6 & 1.6 & 0.4 \\
\hline $\begin{array}{c}\text { September 17th } \\
\text { 2015 }\end{array}$ & 0.742 & 74.2 & 152.9 & 2.8 & 74.2 & 1.9 & 2.2 \\
\hline $\begin{array}{c}\text { September 24th } \\
\text { 2015 }\end{array}$ & 0.582 & 58.2 & 37.7 & 2.9 & 58.2 & 1.8 & 1.6 \\
\hline October 30th 2015 & 0.994 & 99.4 & 417.6 & 3.4 & 99.4 & 2.0 & 2.6 \\
\hline
\end{tabular}

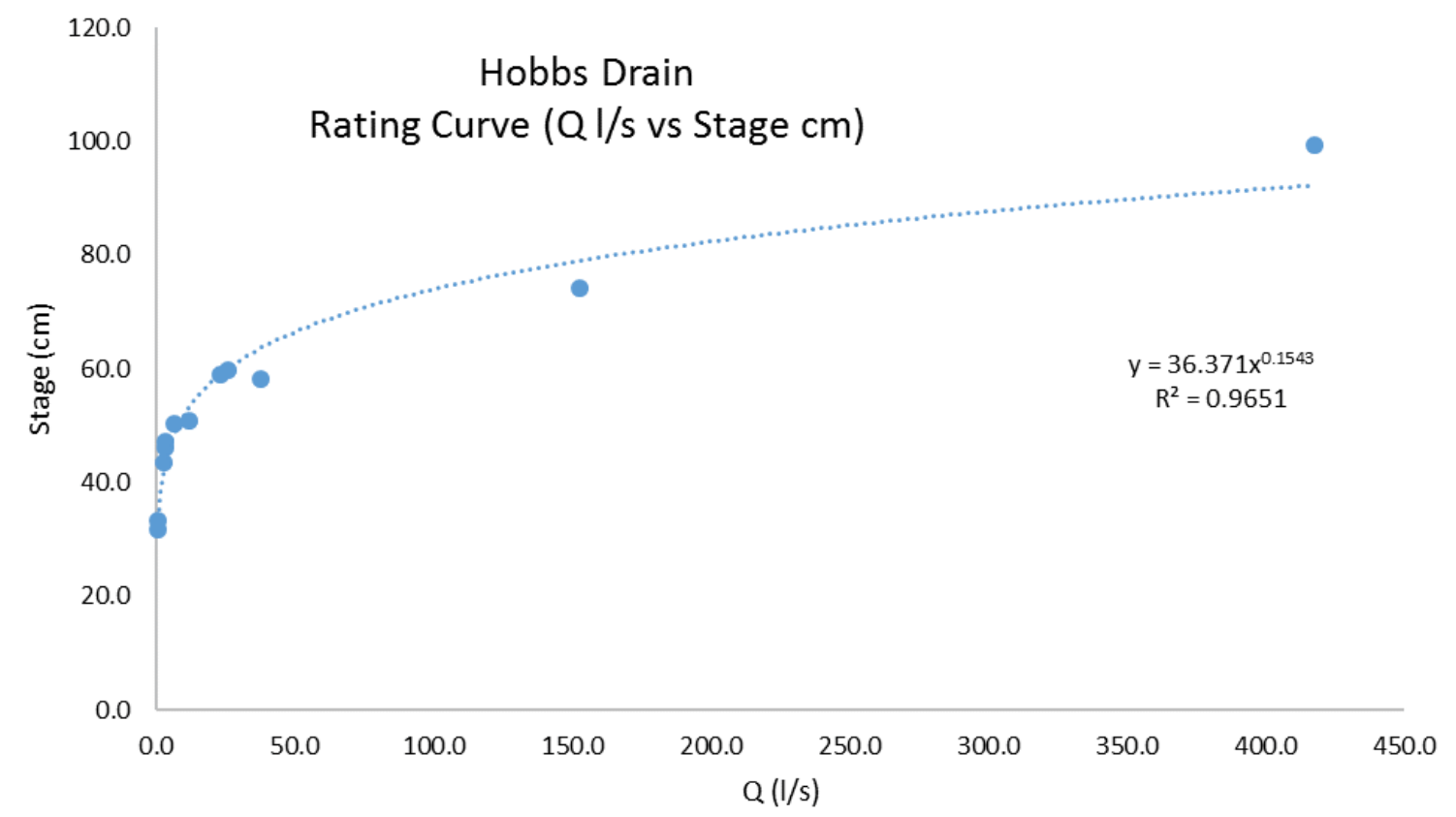

Figure D-0-5. Stage discharge rating curve for Hobbs Drain. 
Table D-0-6. Stage and discharge measurements for Nichols Creek

\begin{tabular}{|c|c|c|c|c|c|c|c|}
\hline Date & $\begin{array}{c}\text { Stage } \\
\mathbf{H} \\
(\mathbf{m})\end{array}$ & $\begin{array}{c}\text { Stage } \\
\mathbf{H} \\
\mathbf{( c m )}\end{array}$ & $\begin{array}{c}\text { Discharge } \\
\mathbf{Q}(\mathbf{l} / \mathbf{s})\end{array}$ & $\begin{array}{c}\text { Discharge } \\
\text { Uncertainty } \\
\text { (ISO) \% }\end{array}$ & H-HO & $\begin{array}{c}\text { Log } \\
\text { (H-HO) }\end{array}$ & $\begin{array}{c}\text { LOG } \\
\text { (Q) }\end{array}$ \\
\hline June 30th 2015 & 0.314 & 31.4 & 162.2 & 3.2 & 31.4 & 1.5 & 2.2 \\
\hline July 6th 2015 & 0.267 & 26.7 & 98.0 & 3.0 & 26.7 & 1.4 & 2.0 \\
\hline July 11th 2015 & 0.252 & 25.2 & 71.2 & 3.2 & 25.2 & 1.4 & 1.9 \\
\hline July 25th 2015 & 0.198 & 19.8 & 28.7 & 3.1 & 19.8 & 1.3 & 1.5 \\
\hline August 8th 2015 & 0.191 & 19.1 & 20.8 & 2.9 & 19.1 & 1.3 & 1.3 \\
\hline August 10th 2015 & 0.178 & 17.8 & 13.5 & 3.0 & 17.8 & 1.3 & 1.1 \\
\hline $\begin{array}{c}\text { September 4th } \\
\text { 2015 }\end{array}$ & 0.182 & 18.2 & 11.8 & 2.9 & 18.2 & 1.3 & 1.1 \\
\hline $\begin{array}{c}\text { September 17th } \\
\text { 2015 }\end{array}$ & 0.232 & 23.2 & 37.7 & 3.4 & 23.2 & 1.4 & 1.6 \\
\hline $\begin{array}{c}\text { October 30th } \\
\text { 2015 }\end{array}$ & 0.878 & 87.8 & 574.2 & 3.4 & 87.8 & 1.9 & 2.8 \\
\hline
\end{tabular}

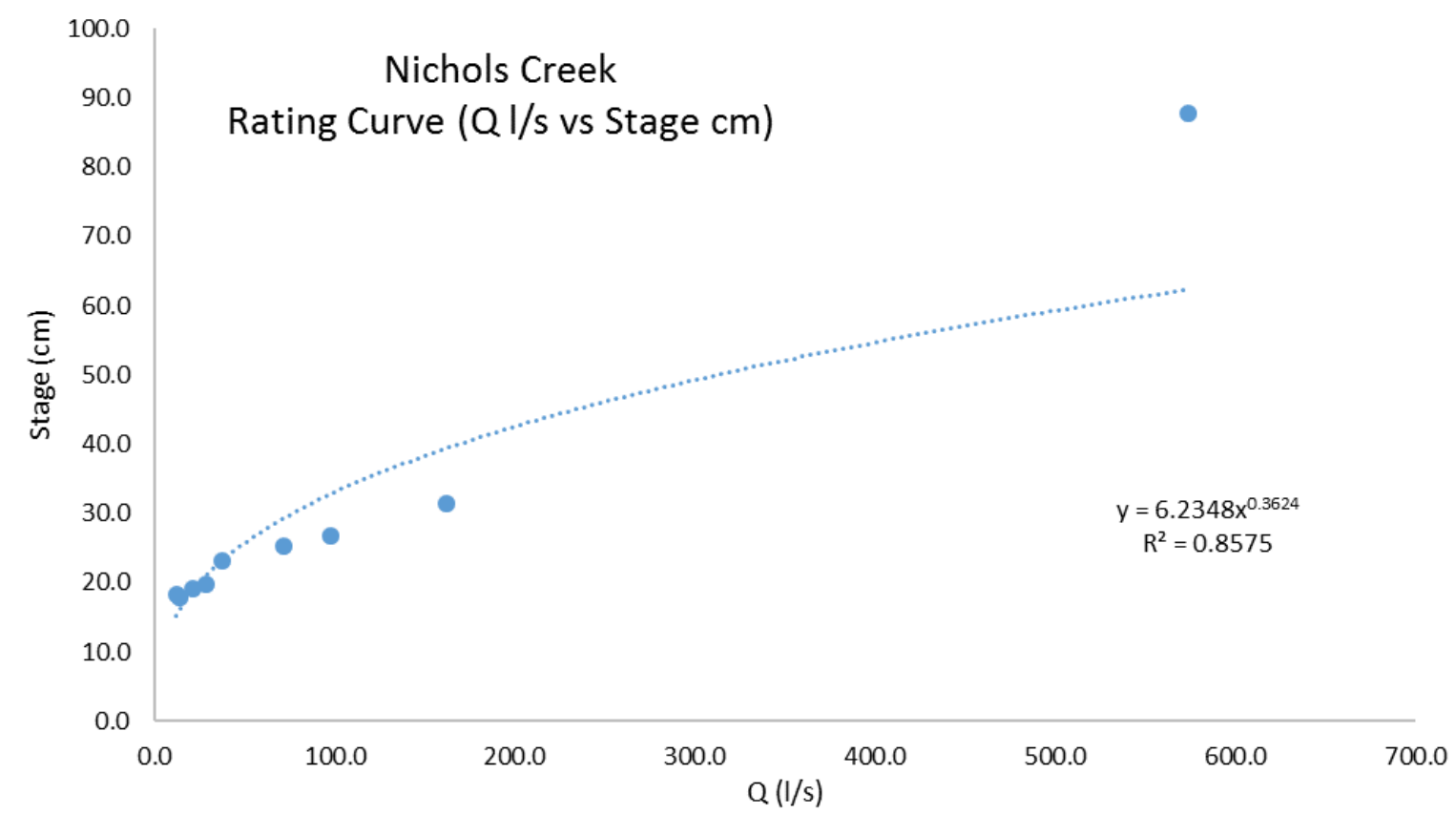

Figure D-0-6. Stage discharge rating curve for Nichols Creek. 
Table D-0-7. Statistics for 2015 stream water geochemistry.

\begin{tabular}{|c|c|c|c|c|c|c|c|c|c|c|c|c|c|c|c|c|c|}
\hline \multirow{2}{*}{$\begin{array}{c}\text { Main } \\
\text { Tributary } \\
\text { Sample Site }\end{array}$} & \multirow[b]{2}{*}{$\mathrm{n}$} & \multicolumn{4}{|c|}{$\mathrm{SpC}(\mu \mathrm{S} / \mathrm{cm})$} & \multicolumn{4}{|c|}{$\delta \mathrm{O}^{18 \% 0}$} & \multicolumn{4}{|c|}{ Alkalinity as $\left(\mathrm{mg} / \mathrm{l} \mathrm{CaCO}_{3}\right)$} & \multicolumn{4}{|c|}{$\mathrm{SiO} 2(\mathrm{mg} / \mathrm{l})$} \\
\hline & & $\begin{array}{c}\text { Mean } \\
\bar{x}\end{array}$ & $\begin{array}{l}\mathrm{SD} \\
(\sigma)\end{array}$ & SE & $\begin{array}{c}\mathrm{COV} \\
(\%)\end{array}$ & $\begin{array}{c}\text { Mean } \\
\bar{x}\end{array}$ & $\begin{array}{l}\mathrm{SD} \\
(\sigma)\end{array}$ & $\mathrm{SE}$ & $\begin{array}{c}\mathrm{COV} \\
(\%)\end{array}$ & $\begin{array}{c}\text { Mean } \\
\bar{x}\end{array}$ & $\begin{array}{l}\mathrm{SD} \\
(\sigma)\end{array}$ & $\mathrm{SE}$ & $\begin{array}{c}\mathrm{COV} \\
(\%)\end{array}$ & $\begin{array}{c}\text { Mean } \\
\bar{x}\end{array}$ & $\begin{array}{l}\text { SD } \\
(\sigma)\end{array}$ & SE & $\begin{array}{c}\mathrm{COV} \\
(\%)\end{array}$ \\
\hline $\begin{array}{c}\text { Jock River at } \\
\text { Prince of } \\
\text { Wales Road }\end{array}$ & 10 & 682.3 & 83.9 & 26.5 & 12.3 & -8.4 & 0.6 & 0.2 & 7.3 & 195.4 & 10.2 & 3.2 & 5.2 & 7.3 & 2.1 & 0.7 & 29.5 \\
\hline $\begin{array}{l}\text { Leamy } \\
\text { Creek }\end{array}$ & 10 & 1005.0 & 696.5 & 220.2 & 69.3 & -8.7 & 1.6 & 0.5 & 18.4 & 305.5 & 45.9 & 14.5 & 15.0 & 18.9 & 5.4 & 1.7 & 28.5 \\
\hline $\begin{array}{l}\text { Monahan } \\
\text { Drain }\end{array}$ & 10 & 1148.9 & 184.4 & 58.3 & 16.1 & -9.2 & 1.0 & 0.3 & 10.6 & 183.3 & 26.5 & 8.4 & 14.4 & 5.5 & 2.1 & 0.7 & 38.8 \\
\hline $\begin{array}{c}\text { Jock River at } \\
\text { Eagleson } \\
\text { Road }\end{array}$ & 11 & 562.3 & 93.8 & 28.3 & 16.7 & -8.2 & 0.7 & 0.2 & 8.5 & 198.5 & 6.9 & 2.1 & 3.5 & 7.8 & 2.7 & 0.8 & 34.4 \\
\hline $\begin{array}{c}\text { Flowing } \\
\text { Creek }\end{array}$ & 12 & 921.8 & 190.7 & 55.1 & 20.7 & -9.8 & 0.9 & 0.3 & 9.7 & 227.4 & 39.8 & 11.5 & 17.5 & 5.9 & 2.2 & 0.6 & 37.4 \\
\hline Hobbs Drain & 12 & 821.6 & 237.6 & 68.6 & 28.9 & -8.8 & 0.6 & 0.2 & 6.8 & 267.5 & 37.1 & 10.7 & 13.9 & 9.1 & 2.5 & 0.7 & 27.9 \\
\hline $\begin{array}{c}\text { Jock River at } \\
\text { Franktown } \\
\text { Road }\end{array}$ & 11 & 551.9 & 63.0 & 19.0 & 11.4 & -8.1 & 0.8 & 0.2 & 10.1 & 194.8 & 11.5 & 3.5 & 5.9 & 5.4 & 1.9 & 0.6 & 36.3 \\
\hline Kings Creek & 11 & 542.5 & 353.5 & 106.6 & 65.2 & -7.7 & 0.9 & 0.3 & 11.6 & 219.6 & 20.1 & 6.1 & 9.2 & 6.9 & 2.6 & 0.8 & 37.5 \\
\hline $\begin{array}{c}\text { Nichols } \\
\text { Creek }\end{array}$ & 11 & 397.8 & 48.5 & 14.6 & 12.2 & -7.2 & 0.7 & 0.2 & 9.5 & 197.4 & 28.1 & 8.5 & 14.2 & 6.7 & 3.2 & 1.0 & 47.9 \\
\hline
\end{tabular}


Table D-0-8. Statistics for 2015-2016 end-member geochemistry.

\begin{tabular}{cccccccccc}
\hline End Members & \multicolumn{3}{c}{$\mathrm{SpC}(\mu \mathrm{S} / \mathrm{cm})$} & \multicolumn{3}{c}{ Alkalinity as $\left(\mathrm{mg} / 1 \mathrm{CaCO}_{3}\right)$} & \multicolumn{3}{c}{$\mathrm{SiO} 2(\mathrm{mg} / \mathrm{l})$} \\
\hline Code & $\begin{array}{c}\text { Mean } \\
\bar{x}\end{array}$ & $\mathrm{SD}(\sigma)$ & $\mathrm{SE}$ & $\begin{array}{c}\text { Mean } \\
\bar{x}\end{array}$ & $\mathrm{SD}(\sigma)$ & $\mathrm{SE}$ & $\begin{array}{c}\text { Mean } \\
\text { SD }(\sigma)\end{array}$ & $\mathrm{SE}$ \\
\hline GW_DW_1 & 1260.0 & 98.6 & 56.9 & 332.0 & 15.4 & 8.9 & 20.5 & 0.8 & 0.4 \\
GW_DW_2 & 726.5 & 55.9 & 39.5 & 258.0 & 18.4 & 13.0 & 10.0 & 0.6 & 0.4 \\
W156-3 & 398.6 & 29.0 & 2.9 & 164.0 & 7.6 & 11.0 & 8.8 & 1.1 & 0.4 \\
W156-2 & 248.0 & 126.9 & 5.4 & 107.0 & 18.6 & 36.6 & 17.0 & 3.7 & 1.1 \\
W084 & 1017.0 & 126.5 & 5.3 & 290.0 & 11.9 & 56.6 & 11.2 & 0.8 & 0.4 \\
W085 & 1495.0 & 133.4 & 13.3 & 393.0 & 35.1 & 50.4 & 15.1 & 1.4 & 0.5 \\
W175-2 & 1106.0 & 163.8 & 12.2 & 308.0 & 29.9 & 66.9 & 10.7 & 1.2 & 0.5 \\
W175-3 & 1293.0 & 305.4 & 13.8 & 372.0 & 33.8 & 124.7 & 10.8 & 0.7 & 0.3 \\
GWMP2015 & 279.5 & 67.2 & 47.5 & 184.0 & 12.9 & 7.4 & 2.4 & 0.4 & 0.2 \\
GWMP2016 & 421.0 & 31.5 & 15.8 & 326.0 & 8.0 & 4.0 & 9.1 & 1.7 & 0.8 \\
HWY15SW & 319.0 & 15.1 & 8.7 & 138.0 & 1.5 & 0.9 & 6.0 & 1.0 & 0.6 \\
Rain & 30.9 & 34.4 & 11.5 & 9.7 & 10.1 & 1.9 & 0.2 & 0.1 & 0.1 \\
Snow melt & 60.5 & 45.5 & 16.1 & 14.8 & 6.3 & 4.1 & 0.1 & 0.2 & 0.0 \\
\hline
\end{tabular}


Table D-0-9. Percent Differences Between Observed and Predicted Solute Concentrations from EMMA for the Jock River Mixing Sites.

\begin{tabular}{|c|c|c|c|}
\hline & $\mathrm{SpC} \%$ & Alkalinity \% & $\mathrm{SiO} 2 \%$ \\
\hline & 0.60 & 0.01 & 1.21 \\
\hline & 10.82 & 0.20 & 26.66 \\
\hline & 4.05 & 0.08 & 8.36 \\
\hline & 1.37 & 0.02 & 3.46 \\
\hline & 7.30 & 0.15 & 15.62 \\
\hline & 4.67 & 0.08 & 11.51 \\
\hline & 8.45 & 0.15 & 22.83 \\
\hline & 6.48 & 0.18 & 10.59 \\
\hline & 11.36 & 0.29 & 19.72 \\
\hline & 4.23 & 0.08 & 9.65 \\
\hline & 11.47 & 0.21 & 28.60 \\
\hline & 4.92 & 0.09 & 11.62 \\
\hline & 10.38 & 0.22 & 21.08 \\
\hline & 10.48 & 0.19 & 27.89 \\
\hline & 5.63 & 0.16 & 9.29 \\
\hline & 11.29 & 0.30 & 19.20 \\
\hline & 1.55 & 0.03 & 3.43 \\
\hline & 5.70 & 0.15 & 9.92 \\
\hline & 11.66 & 0.27 & 21.86 \\
\hline & 1.36 & 0.03 & 2.67 \\
\hline & 0.42 & 0.01 & 0.75 \\
\hline & 6.84 & 0.17 & 11.89 \\
\hline & 4.79 & 0.09 & 11.11 \\
\hline & 3.22 & 0.08 & 5.81 \\
\hline & 8.72 & 0.20 & 16.25 \\
\hline & 0.93 & 0.02 & 1.73 \\
\hline & 2.72 & 0.07 & 4.95 \\
\hline & 3.50 & 0.07 & 7.36 \\
\hline & 7.82 & 0.14 & 18.46 \\
\hline & 0.93 & 0.02 & 2.16 \\
\hline & 11.83 & 0.21 & 29.84 \\
\hline & 8.56 & 0.16 & 20.06 \\
\hline Average & 6.06 & 0.13 & 12.98 \\
\hline Maximum & 11.83 & 0.30 & 29.84 \\
\hline Minimum & 0.42 & 0.01 & 0.75 \\
\hline
\end{tabular}




\section{References}

Ahmed, F., 2017, Influence of Wetlands on Black-Creek Hydraulics: v. 22, no. 1, p. 112, doi:10.1061/(ASCE)HE.1943-5584.0001401.

Anderson, M. P., and X. Cheng, 1993, Long- and short-term transience in a groundwater/lake system in Wisconsin, USA: Journal of Hydrology, v. 145, no. 1-2, p. 1-18, doi:10.1016/0022-1694(93)90217-W.

Armstrong, D., and J. E. P. Dodge, 2007, Paleozoic Geology of Southern Ontario.

ASTM International, 2010, Standard Test Method for Silica in Water: West Conshohocken, 1-5 p., doi:10.1520/D0859-10.1.

Baker, M. E., M. J. Wiley, M. L. Carlson, and P. W. Seelbach, 2003, A GIS Model of Subsurface Water Potential for Aquatic Resource Inventory, Assessment, and Environmental Management: Environmental Management, v. 32, no. 6, p. 706-719, doi:10.1007/s00267-003-0018-1.

Barthold, F. K., C. Tyralla, K. Schneider, K. B. Vaché, H.-G. Frede, and L. Breuer, 2011, How many tracers do we need for end member mixing analysis (EMMA)? A sensitivity analysis: Water Resources Research, v. 47, no. 8, p. n/a-n/a, doi:10.1029/2011WR010604.

Brooks, J. R., P. J. Wignigton, D. L. Phillips, R. Comeleo, and R. Coulombe, 2012, Willamette River Basin surface water isoscape ( $18 \mathrm{O}$ and d $2 \mathrm{H}$ ): temporal changes of source water within the river: Ecosphere, v. 3, no. 5.

Burns, D. a., J. J. McDonnell, R. P. Hooper, N. E. Peters, J. E. Freer, C. Kendall, and K. Beven, 2001, Quantifying contributions to storm runoff through end-member mixing analysis and hydrologic measurements at the Panola Mountain Research Watershed 
(Georgia, USA): Hydrological Processes, v. 15, no. 10, p. 1903-1924, doi:10.1002/hyp.246.

Capell, R., D. Tetzlaff, a. J. Hartley, and C. Soulsby, 2012, Linking metrics of hydrological function and transit times to landscape controls in a heterogeneous mesoscale catchment: Hydrological Processes, v. 26, no. May 2011, p. 405-420, doi:10.1002/hyp.8139.

Cey, E. E., D. L. Rudolph, G. W. Parkin, and R. Aravena, 1998, Quantifying groundwater discharge to a small perennial stream in southern Ontario, Canada: Journal of Hydrology, v. 210, no. 1-4, p. 21-37, doi:10.1016/S0022-1694(98)001723.

Christophersen, N., and R. Hooper, 1992, Multivariate analysis of stream water chemical data: The use of principal components analysis for the end -member mixing problem: Water Resources Research, v. 28, no. 1, p. 99-107.

Christophersen, N., C. Neal, R. P. Hooper, R. D. Vogt, and S. Andersen, 1990, Modelling streamwater chemistry as a mixture of soilwater end-members--A step towards second-generation acidification models: p. 307-320, doi:10.1016/00221694(90)90130-P.

Clarke, I., 2015, Groundwater Geochemistry and Isotopes: Boca Raton, CRC Press.

Clarke, I., and P. Fritz, 1997, Environmental Isotopes in Hydrogeology: Boca Raton, CRC Press.

Derry, Michner, Booth, Wahl, and Ontario Geological Survey, 1989, Limestone Industries of Ontario, Volume 1 - Geology, Properties and Economics: Toronto, 1$174 \mathrm{p}$. 
Eckhardt, K., 2008, A comparison of baseflow indices, which were calculated with seven different baseflow separation methods: Journal of Hydrology, v. 352, no. 1-2, p. 168-173, doi:10.1016/j.jhydrol.2008.01.005.

Freeze, A., and J. Cherry, 1979, Groundwater: New Jersey, Prentice Hall.

Gibson, J. J., B. M. Fekete, and G. J. Bowen, 2010, Stable Isotopes in Large Scale Hydrological Applications, in Isoscapes: Understanding Movement, Pattern, and Process on Earth Through Isotope Mapping: p. 389-405, doi:10.1007/978-90-481$3354-3$.

Hach Company, 2015, Alkalinity, Digital Titrator (4000 mg/L): Hach Company, p. 1-6. Hach Company, 2013a, Method 8185 Silica, High Range (0-75.0 mg/L) For water and seawater: Hach Company, p. 551-554.

Hach Company, 2013b, Method 8186 Silica, Low Range (0 to $1.60 \mathrm{mg} / \mathrm{L}$ ) For water and seawater: Hach Company, p. 4-7.

Hinton, M. J., 2005, Methodology for measuring the spatial distribution of low streamflow within watersheds.

Hooper, R. P., 2001, Applying the scientific method to small catchment studies: a review of the Panola Mountain experience: Hydrological Processes, v. 15, no. 10, p. 20392050, doi:10.1002/hyp.255.

Hooper, R. P., 2003, Diagnostic tools for mixing models of stream water chemistry: Water Resources Research, v. 39, no. 3, p. n/a-n/a, doi:10.1029/2002WR001528. Hooper, R. P., B. T. Aulenbach, D. A. Burns, J. J. McDonnell, J. E. Freer, C. Kendall, and K. Beven, 1998, Riparian control of stream-water chemistry: implications for hydrochemical basin models: p. 451-458. 
Hooper, R. P., N. Christophersen, and N. E. Peters, 1990, Modelling streamwater chemistry as a mixture of soilwater end-members- an application to the Panola Mountain Catchment, Georgia, U.S.A.: Journal of Hydrology, v. 116, p. 321-343.

Hooper, R. P., and C. a. Shoemaker, 1986, A Comparison of Chemical and Isotopic Hydrograph Separation: Water Resources Research, v. 22, no. 10, p. 1444, doi:10.1029/WR022i010p01444.

Hughes, C. E., and J. Crawford, 2012, A new precipitation weighted method for determining the meteoric water line for hydrological applications demonstrated using Australian and global GNIP data: Journal of Hydrology, v. 464-465, no. August 2016, p. 344-351, doi:10.1016/j.jhydrol.2012.07.029.

James, A. L., and N. T. Roulet, 2006, Investigating the applicability of end-member mixing analysis (EMMA) across scale: A study of eight small, nested catchments in a temperate forested watershed: Water Resources Research, v. 42, p. 1-17, doi:10.1029/2005WR004419.

Kendall, C., M. B. Young, and S. R. Silva, 2010, Applications of Stable Isotopes for Regional to National-Scale Water Quality and Environmental Monitoring Programs, in Isoscapes: Understanding Movement, Pattern, and Process on Earth Through Isotope Mapping: p. 89-109, doi:10.1007/978-90-481-3354-3.

Klaus, J., and J. J. McDonnell, 2013, Hydrograph separation using stable isotopes: Review and evaluation: Journal of Hydrology, v. 505, p. 47-64, doi:10.1016/j.jhydrol.2013.09.006.

Laudon, H., V. Sjöblom, I. Buffam, J. Seibert, and M. Mörth, 2007, The role of catchment scale and landscape characteristics for runoff generation of boreal 
streams: Journal of Hydrology, v. 344, no. 3-4, p. 198-209, doi:10.1016/j.jhydrol.2007.07.010.

Lee, D. R., J. A. Cherry, and J. F. Pickens, 1980, Groundwater Transport of a Salt Tracer Through a Sandy Lakebed: Limnology and Oceanography, v. 25, no. 1, p. 45-61.

Loh, W.-Y., 2011, Classification and regression trees: Wiley Interdisciplinary Reviews: Data Mining and Knowledge Discovery, v. 1, no. 1, p. 14-23, doi:10.1002/widm.8. Los Gatos Research, 2015, Simple, precise and accurate measurements of 17 O, 18 O and $2 \mathrm{H}$ for Hydrology, Climatology, Life Sciences and other water applications Los Gatos Research ( LGR ): Mountain View, California, ABB, p. 1-8.

McGlynn, B. L., 2004, Scale effects on headwater catchment runoff timing, flow sources, and groundwater-streamflow relations: Water Resources Research, v. 40, no. 7, p. 1-14, doi:10.1029/2003WR002494.

McGrane, S. J., D. Tetzlaff, and C. Soulsby, 2014, Influence of lowland aquifers and anthropogenic impacts on the isotope hydrology of contrasting mesoscale catchments: Hydrological Processes, v. 28, no. November 2012, p. 793-808, doi:10.1002/hyp.9610.

McGuire, K. J., and J. Mcdonnell, 2008, Stable Isotope Tracers in Watershed Hydrology, in Stable Isotopes in Ecology and Environmental Science: Second Edition: Blackwell Publishing Ltd, p. 334-374.

van Meerveld, H. J., J. Seibert, and N. E. Peters, 2015, Hillslope-riparian-stream connectivity and flow directions at the Panola Mountain Research Watershed: Hydrological Processes, v. 29, no. 16, p. 3556-3574, doi:10.1002/hyp.10508. Mountain, N., A. L. James, and K. Chutko, 2015, Groundwater and surface water 
influences on streamflow in a mesoscale Precambrian Shield catchment:

Hydrological Processes, v. 29, no. 18, p. 3941-3953, doi:10.1002/hyp.10590.

Neal, C., 2001, Alkalinity measurements within natural waters: Towards a standardised approach: Science of the Total Environment, v. 265, no. 1-3, p. 99-113, doi:10.1016/S0048-9697(00)00652-5.

Praamsma, T., K. Novakowski, K. Kyser, and K. Hall, 2009, Using stable isotopes and hydraulic head data to investigate groundwater recharge and discharge in a fractured rock aquifer: Journal of Hydrology, v. 366, no. 1-4, p. 35-45, doi:10.1016/j.jhydrol.2008.12.011.

Rice, K. C., and G. M. Hornberger, 1998, Comparison of hydrochemical tracers to estimate source contributions to peak flow in a small, forested, headwater catchment: Water Resources Research, v. 34, no. 7, p. 1755-1766, doi:10.1029/98WR00917.

Rodgers, P., C. Soulsby, J. Petry, I. Malcolm, C. Gibbins, and S. Dunn, 2004, Groundwater-surface-water interactions in a braided river: A tracer-based assessment: Hydrological Processes, v. 18, no. 7, p. 1315-1332, doi:10.1002/hyp.1404.

Smart, R. P., C. Soulsby, M. S. Cresser, a J. Wadec, J. Townend, M. F. Billett, and S. Langand, 2001, Riparian zone influence on stream water chemistry atdifferent spatial scales: a GIS-based modellingapproach, an example for the Dee, NE Scotland: The Science of the Total Environment, v. 280, p. 173-193, doi:10.1016/S0048-9697(01)00824-5.

Sophocleous, M., 2002, Interactions between groundwater and surface water: The state of 
the science: Hydrogeology Journal, v. 10, no. 1, p. 52-67, doi:10.1007/s10040-001$0170-8$.

Sørensen, R., and J. Seibert, 2007, Effects of DEM resolution on the calculation of topographical indices: TWI and its components: Journal of Hydrology, v. 347, p. 79-89, doi:10.1016/j.jhydrol.2007.09.001.

Soulsby, C., P. J. Rodgers, J. Petry, D. M. Hannah, I. a. Malcolm, and S. M. Dunn, 2004, Using tracers to upscale flow path understanding in mesoscale mountainous catchments: Two examples from Scotland: Journal of Hydrology, v. 291, p. 174196, doi:10.1016/j.jhydrol.2003.12.042.

Soulsby, C., D. Tetzlaff, N. van den Bedem, I. a. Malcolm, P. J. Bacon, and a. F. Youngson, 2007, Inferring groundwater influences on surface water in montane catchments from hydrochemical surveys of springs and streamwaters: Journal of Hydrology, v. 333, no. 2-4, p. 199-213, doi:10.1016/j.jhydrol.2006.08.016.

Soulsby, C., D. Tetzlaff, P. Rodgers, S. Dunn, and S. Waldron, 2006, Runoff processes, stream water residence times and controlling landscape characteristics in a mesoscale catchment: An initial evaluation: Journal of Hydrology, v. 325, no. 1-4, p. 197-221, doi:10.1016/j.jhydrol.2005.10.024.

Tallaksen, L., 1995, A review of baseflow recession analysis: Journal of Hydrology, v. 165, p. 349-270.

Tetzlaff, D., and C. Soulsby, 2008a, Sources of baseflow in larger catchments - Using tracers to develop a holistic understanding of runoff generation: Journal of Hydrology, v. 359, no. 3-4, p. 287-302, doi:10.1016/j.jhydrol.2008.07.008.

Tetzlaff, D., and C. Soulsby, 2008b, Sources of baseflow in larger catchments - Using 
tracers to develop a holistic understanding of runoff generation: Journal of Hydrology, v. 359, no. 3-4, p. 287-302, doi:10.1016/j.jhydrol.2008.07.008.

Tetzlaff, D., C. Soulsby, S. Waldron, I. A. Malcolm, P. J. Bacon, S. M. Dunn, A. Lilly, and A. F. Youngson, 2007, Conceptualization of runoff processes using a geographical information system and tracers in a nested mesoscale catchment: Hydrological Processes, v. 21, no. October 2006, p. 1289-1307, doi:10.1002/hyp. Tetzlaff, D., S. Waldron, M. J. Brewer, and C. Soulsby, 2007, Assessing nested hydrological and hydrochemical behaviour of a mesoscale catchment using continuous tracer data: Journal of Hydrology, v. 336, no. 3-4, p. 430-443, doi:10.1016/j.jhydrol.2007.01.020.

Tóth, J., 1963, A theoretical analysis of groundwater flow in small drainage basins: Journal of Geophysical Research, v. 68, no. 16, p. 4795-4812, doi:10.1029/JZ068i016p04795.

U.S. Geological Survey, 2012, 6.6 Alkalinity: 1-36 p.

Uhlenbrook, S., and S. Hoeg, 2003, Quantifying uncertainties in tracer-based hydrograph separations: A case study for two-, three- and five-component hydrograph separations in a mountainous catchment: Hydrological Processes, v. 17, no. 2, p. 431-453, doi:10.1002/hyp.1134.

Velderman, B.-J., 1993, Groundwater Recharge and Contamination: Sensitivity Analysis for Carbonate Aquifers in South- Eastern Ontario - The Jock River Basin Study: University of Ottawa, 1-206 p.

Wagener, T., M. Sivapalan, P. A. Troch, B. L. McGlynn, C. J. Harman, H. V. Gupta, P. Kumar, P. S. C. Rao, N. B. Basu, and J. S. Wilson, 2010, The future of hydrology: 
An evolving science for a changing world: Water Resources Research, v. 46, no. 5, p. 1-10, doi:10.1029/2009WR008906.

Walker, J. F., R. J. Hunt, T. D. Bullen, D. P. Krabbenhoft, and C. Kendall, 2003, Variability of Isotope and Major Ion Chemistry in the Allequash Basin, Wisconsin: GroundWater, v. 41, no. 7, p. 883-894, doi:10.1111/j.1745-6584.2003.tb02431.x. Winter, T. C., 1984, Geohydrologic Setting of Mirror Lake, West Thornton, New Hampshire: Colorado, 1-61 p.

Winter, T. C., 1995, Recent advances in understanding the interaction of groundwater and surface water: Reviews of Geophysics, v. 33, no. July, p. 985-994, doi:10.1029/95RG00115.

Winter, T. C., 1999, Relation of streams , lakes , and wetlands to groundwater flow systems: Hydrogeology Journal, v. 7, p. 28-45.

Winter, T. C., D. O. Rosenberry, and J. . W. LaBaugh, 2003, Where does the ground water in small catchment come from? Ground Water, v. 41, no. 7, p. 989-1000, doi:10.1111/j.1745-6584.2003.tb02440.x. 